\title{
ELIJAH: Electronic Linkage for Inflammatory bowel disease to deliver Joint Access to Health-reports
}

\author{
Dodds, Phedra L.
}

How to cite:

Dodds, Phedra L. (2018) ELIJAH: Electronic Linkage for Inflammatory bowel disease to deliver Joint Access to Health-reports. Doctoral thesis, Swansea University.

http://cronfa.swan.ac.uk/Record/cronfa50579

Use policy:

This item is brought to you by Swansea University. Any person downloading material is agreeing to abide by the terms of the repository licence: copies of full text items may be used or reproduced in any format or medium, without prior permission for personal research or study, educational or non-commercial purposes only. The copyright for any work remains with the original author unless otherwise specified. The full-text must not be sold in any format or medium without the formal permission of the copyright holder. Permission for multiple reproductions should be obtained from the original author.

Authors are personally responsible for adhering to copyright and publisher restrictions when uploading content to the repository.

Please link to the metadata record in the Swansea University repository, Cronfa (link given in the citation reference above.)

http://www.swansea.ac.uk/library/researchsupport/ris-support/ 
ELIJAH: Electronic Linkage for Inflammatory bowel disease to deliver Joint Access to Health-reports

Phedra Lara Dodds BSc Hons

Submitted to Swansea University in fulfilment of the requirements for the Degree of Doctor of Philosophy

Swansea University 


\section{$\underline{\text { Abstract }}$}

Aims

The aim of my research was to evaluate a novel way to empower patients with inflammatory bowel disease by giving them access to personalised information about their condition and management. I also reviewed the literature relating to personal health records and have reflected on my experience of conducting research from my perspective as a nurse practitioner.

\section{Methods}

We took a pragmatic mixed methods approach to the study. We convened a local focus group and employed a summative analysis technique to explore the topic.

Based on the outcomes of the focus group we developed an intervention (ELIJAH) that extended the local IBD electronic health record to enable the creation of individualised IBD health reports that were educationally enriched. We tested this intervention in a pragmatic randomised controlled feasibility study with 61 patients from one District General Hospital in South Wales.

From the learning and recommended modifications of the feasibility study we drew up a protocol for a fully powered phase III trial of the intervention.

\section{Results}

The focus group showed that patients wanted more access to their IBD health records and individualised education about their disease.

The randomised controlled feasibility study of the ELIJAH intervention showed that the intervention met the clinical and feasibility criteria, and the intervention with modifications could be progressed for a fully powered phase III trial.

\section{Conclusion}

The ELIJAH intervention is wanted by patients and is feasible to produce and test. 


\section{Table of contents}

\begin{tabular}{|c|c|}
\hline & Page \\
\hline Abstract & 2 \\
\hline Declarations and statements & 3 \\
\hline Acknowledgements & 6 \\
\hline List of figures and tables & 7 \\
\hline List of abbreviations & 9 \\
\hline Chapter one: Introduction & 11 \\
\hline $\begin{array}{l}\text { 1.1 Background } \\
\text { 1.2 Aims and objectives }\end{array}$ & $\begin{array}{l}12 \\
19\end{array}$ \\
\hline Chapter two: The focus group & 21 \\
\hline $\begin{array}{l}\text { 2.1 Background and objectives } \\
\text { 2.2 Methods } \\
\text { 2.3 Results } \\
\text { 2.4 Discussion } \\
\text { 2.5 Conclusion }\end{array}$ & $\begin{array}{l}22 \\
25 \\
32 \\
40 \\
42\end{array}$ \\
\hline $\begin{array}{l}\text { Chapter three: The intervention } \\
\text { Electronic Linkage for Inflammatory bowel disease to } \\
\text { deliver Joint Access to Health reports (ELIJAH) }\end{array}$ & 43 \\
\hline $\begin{array}{l}\text { 3.1 Background } \\
\text { 3.2 Methods } \\
\text { 3.3 Findings } \\
\text { 3.4 Discussion } \\
\text { 3.5 Conclusion }\end{array}$ & $\begin{array}{l}45 \\
48 \\
54 \\
56 \\
58\end{array}$ \\
\hline $\begin{array}{l}\text { Chapter four: A pragmatic randomised controlled } \\
\text { feasibility trial of the intervention }\end{array}$ & 59 \\
\hline $\begin{array}{l}\text { 4.1 Background and objectives } \\
\text { 4.2 Methods } \\
\text { 4.3 Results } \\
\text { 4.4 Discussion } \\
\text { 4.5 Conclusion } \\
\end{array}$ & $\begin{array}{l}60 \\
64 \\
81 \\
109 \\
119\end{array}$ \\
\hline $\begin{array}{l}\text { Chapter five: A reflection on my research as a nurse } \\
\text { practitioner }\end{array}$ & 121 \\
\hline $\begin{array}{l}\text { 5.1 Background } \\
5.2 \text { Reflection } \\
5.3 \text { Conclusion }\end{array}$ & $\begin{array}{l}122 \\
124 \\
131\end{array}$ \\
\hline Chapter six: Systematic literature review & 132 \\
\hline 6.1 Background & 132 \\
\hline
\end{tabular}




\begin{tabular}{|l|l|}
\hline 6.2 Methods & 134 \\
6.3 Results & 140 \\
6.4 Discussion & 173 \\
6.5 Conclusion & 186 \\
\hline Chapter seven: Future research protocol design and & 187 \\
conclusion & \\
& \\
7.1 Introduction & 187 \\
7.2 Background & 188 \\
7.3 Methods / design & 201 \\
7.4 Discussion & 210 \\
7.5 Conclusion & 211 \\
\hline Appendices & \\
1 COREQ checklist & 213 \\
2 TIDier checklist & 215 \\
3 ELIJH participant information sheet & 217 \\
4 ELIJAH consent form & 222 \\
5 Example of My History & 223 \\
6 Example of My Plan & 226 \\
7 Example of My Update & 228 \\
8 ELIJH Data Abstraction Form DAF & 231 \\
9 ELIJAH Adverse Events form & 237 \\
10 Inflammatory bowel disease Service Satisfaction Questionnaire & 240 \\
(ISSQ) & 287 \\
11 Welsh Index of Multiple Deprivation (WIMD) & 283 \\
12 Letter of confirmation of full ethical approval & 283 \\
13 Combined CONSORT reporting outline with appropriate & 251 \\
extensions for the ELIJAH RCT feasibility trial \\
14 List of treatments and investigations, frequency and likely linked \\
to IBD & 260 \\
15 Primary and secondary care appointments and frequency & \\
16 List of medications & 261 \\
17 Time taken to produce the ELIJAH intervention & 262 \\
18 List of ELIJAH adverse events & 269 \\
19 List of ISSQ patient free text comments & 274 \\
20 ELIJAH budget \\
21 PRISMA checklist & 280 \\
22 Search strategy and findings & \\
23 Quality scoring of the articles & 283 \\
\hline References & 28 \\
\hline
\end{tabular}




\section{Acknowledgements}

I wish to extend my heartfelt thanks to my friends, family, professional and academic colleagues and my patients who have each helped, supported, encouraged and inspired me throughout my ELIJAH journey.

ELIJAH has given me much more than lessons in research. Through my learning I have had opportunities to study, pioneer practice, learn from some great clinical and academic researchers, be part of a formative research team and explore and develop potential within my service. While trying out new ideas and developing new pathways to better my patients' care I have been continually challenged to do better and have found huge excitement throughout the process.

Each one of my friends has brought laughter to times of difficulty whilst I have been studying, and I would like thank to Bethan and Neil Hawkes, Fleur Buchanan, Lucy Williams and Nicola Griffiths for their true friendship. My family have shown patience and understanding when ELIJAH has taken precedence over everything, and Peter Neville has shown me understanding, love and friendship in abundance which has enabled me to grow and develop.

I wish to thank Dr Rahman for his calm and thoughtful training, and the wider endoscopy team who facilitated this study. Carol Shillabeer has enabled me to have the space to complete the thesis, and Cheryl Davies has been a true friend and good colleague.

I was very fortunate during ELIJAH to be part of a very experienced research team who worked with an impressive can-do attitude. I am indebted to Professor Russell, Professor Cohen, Professor Rolfe, and Professor Rapport for their generosity in sharing their knowledge and experience with me. In developing the intervention I received invaluable technical help from Jayne Morgan and Hayley Dickinson. The feasibility study was funded by The Health Foundation through their Shine programme.

I wish to extend special thanks to my very learned supervisors; Professor Hutchings and Professor Williams, I feel extremely fortunate to have had their unfailing support, sage advice, expert vision and their belief in me and the project. They have been central to the completion of this study.

I would like to thank my patients for providing the motivation for the study. It was a huge privilege to serve and know them and their families, and immensely inspiring to work with them.

This work is dedicated to my two funny, thoughtful, adventurous and inspiring children; Erin and Ewan Dodds, who I am sure thought ELIJAH was a member of our extended family at times, and have never know their mum not study, but nevertheless have shown understanding, maturity and patience beyond their years. 


\section{$\underline{\text { List of tables and illustrations }}$}

\begin{tabular}{|c|c|}
\hline & Page \\
\hline ANP service activity $2002-2010$ & 16 \\
\hline Summary of ELIJAH timeline: focus group & 26 \\
\hline $\begin{array}{l}\text { ELIJAH colon diagram for self management plan; distal ulcerative } \\
\text { colitis }\end{array}$ & 49 \\
\hline ELIJAH research project timeline & 54 \\
\hline Example of paper-based hospital notes & 61 \\
\hline MRC Complex Intervention Analysis & 63 \\
\hline $\begin{array}{l}\text { Location of participating GP practices, demonstrating the location } \\
\text { of Neath Port Talbot area in Wales, and the location of ELIJAH } \\
\text { participating GP surgeries within Neath Port Talbot }\end{array}$ & 65 \\
\hline $\begin{array}{l}\text { ELIJAH flowchart which illustrates the number of patients } \\
\text { identified and included in the study }\end{array}$ & 71 \\
\hline $\begin{array}{l}\text { ELIJAH progression criteria highlighting the ELIJAH feasibility } \\
\text { criteria }\end{array}$ & 79 \\
\hline ELIJAH study chronology & 82 \\
\hline $\begin{array}{l}\text { ELIJAH CONSORT diagram, adapted from Eldridge et al (2016) } \\
\text { CONSORT } 2010\end{array}$ & 83 \\
\hline ELIJAH participant demographics & 84 \\
\hline ELIJAH participants by GP practice & 85 \\
\hline ELIJAH participants by choice of contact method & 85 \\
\hline Results of ELIJAH feasibility outcomes & 86 \\
\hline Timings of ELIJAH production & 88 \\
\hline Primary care appointments & 89 \\
\hline Secondary care appointments & 90 \\
\hline Treatments and investigations & 91 \\
\hline Medications & 92 \\
\hline ELIJAH adverse events & 93 \\
\hline ELIJAH serious adverse events & 94 \\
\hline ELIJAH unexpected adverse events & 95 \\
\hline ISSQ reminders and non-responders & 96 \\
\hline ISSQ introductory answers & 97 \\
\hline ISSQ introductory answers: missing data & 98 \\
\hline ISSQ answers & 99 \\
\hline ISSQ missing data across ELIJAH trimesters & 100 \\
\hline Patient free text comments & 102 \\
\hline ISSQ summary statistics & 103 \\
\hline EQ5D missing data & 104 \\
\hline EQ5D missing data across ELIJAH trimesters & 105 \\
\hline EQ5D summary statistics & 105 \\
\hline ELIJAH timeliness & 106 \\
\hline $\begin{array}{l}\text { Summary ELIJAH results; clinical outcomes, missing data and } \\
\text { attainment of progression criteria }\end{array}$ & 107 \\
\hline Systematic literature review inclusion and exclusion criteria & 134 \\
\hline Key word combinations & 136 \\
\hline Quality of studies & 138 \\
\hline
\end{tabular}




\begin{tabular}{|l|l|}
\hline PRISMA 2009 flow diagram & 140 \\
\hline Summary of articles included in literature review & 142 \\
\hline Population & 148 \\
\hline Location of articles / authors & 151 \\
\hline Study design & 155 \\
\hline Number of participants / articles & 161 \\
\hline Quality score & 162 \\
\hline Thematic identification & 165 \\
\hline Randomised cluster-wedge study design overview & 194 \\
\hline Proposed components of the intervention & 197 \\
\hline Summary of the proposed trial & 200 \\
\hline
\end{tabular}




\section{$\underline{\text { List of abbreviations }}$}

\begin{tabular}{|c|c|}
\hline Abbreviation & Definition \\
\hline ABMUHB & Abertawe Bro-Morgannwg University Health Board \\
\hline $\mathrm{AE}$ & Adverse Event \\
\hline ANP & Advanced Nurse Practitioner \\
\hline BSG & British Society of Gastroenterology \\
\hline COREQ & Consolidated criteria for REporting Qualitative studies \\
\hline DAF & Data Abstraction Form \\
\hline EHR & Electronic Health Record \\
\hline ELIJAH & $\begin{array}{l}\text { Electronic Linkage for Inflammatory bowel disease to deliver } \\
\text { Joint Access to Health-reports }\end{array}$ \\
\hline EPR & Electronic patient record \\
\hline EQ5D & EuroQol Five Dimensions questionnaire \\
\hline GCP & Good Clinical Practice \\
\hline GeneCIS & Generic Clinical Information System \\
\hline GESQ & Gastro-intestinal Endoscopy Satisfaction Questionnaire \\
\hline GP & General Practitioner \\
\hline IBD & Inflammatory Bowel Disease \\
\hline IRAS & Integrated Research Application System \\
\hline ISSQ & Inflammatory bowel disease Service Satisfaction Questionnaire \\
\hline IT & Information Technology \\
\hline MRC & Medical Research Council \\
\hline $\mathrm{n}$ & number \\
\hline NACC & National Association of Crohn's and Colitis \\
\hline NHS & National Health Service \\
\hline NIHR & National Institute for Health Research \\
\hline Nmiss & Number missing \\
\hline NPTH & Neath Port Talbot Hospital \\
\hline PAS & Patient Administration System \\
\hline PCASSO & Patient-Centred Access to Secure Systems \\
\hline PIMS & Patient Information Management System \\
\hline PSSRU & Personal Social Services Research Unit \\
\hline
\end{tabular}




\begin{tabular}{|l|l|}
\hline QALY & Quality-Adjusted Life Year \\
RCT & Randomised Controlled Trial \\
REC & Research Ethics Committee \\
R\&D & Research and Development \\
SAE & Serious Adverse Event \\
SOP & Standard Operating Procedure \\
SUSAR & Suspected Unexpected Serious Adverse Reaction \\
TiDieR & Template for Intervention Description and Replication \\
UK & United Kingdom \\
WIMD & Welsh Index of Multiple Deprivation \\
WWORTH & West Wales Organisation for Rigorous Trials in Health \\
\hline
\end{tabular}




\section{Chapter one: Introduction}

Chronic disease is a major cause of health problems in the U.K. Finding ways to best serve chronically ill patients is amongst the most important challenges facing the health care system. Self-management programmes and open access to specialist services at times of need can offer new models of care, but heavily rely on well educated patients who are able to take responsibility for their care and have effective communication with health care providers.

In Gastroenterology, Inflammatory Bowel Disease (IBD) is an example of a chronic disease of unpredictable pattern that heavily uses primary and secondary care resources, and may be better managed by empowering patients to take increased responsibility for their own care (Hall 2007). For patients to be more able to selfmanage, they need to have increased individualised information and education about their condition, their individual care pathway including agreed plans for care, and easy and effective ways to communicate with the multi-disciplinary team. 


\subsection{Background}

\section{Inflammatory bowel disease}

Inflammatory Bowel Disease (IBD) encompasses many chronic, unpredictable, relapsing disorders that originate within the bowel or gastro-intestinal tract. The two most common forms: Ulcerative Colitis and Crohn's disease often require powerful medical treatments: steroid, immunosuppressive or more powerful biologic therapy and / or major surgery (Travis et al 2008) in order to treat the often debilitating and distressing symptoms and establish maintenance. The treatments also can cause additional symptoms and complications (Carter et al 2004). As with many chronic diseases there is no known cure (Stange et al 2008), and patients can experience an exacerbation of their symptoms which could include defecation of up to 20 times a day with diarrhoea, mucus, pus and blood, nutritional depletion and weight loss, anaemia, abdominal pain, vomiting and emergency situations such as bowel narrowing, blocking and stasis (stricturing and obstructing), septicaemia (from toxic megacolon) without reason or warning. IBD is a major cause of morbidity (British Society of Gastroenterology 2005), but has no raised mortality rate (Williams et al 2006), for men and women equally and affects an age range of early teens to old age.

\section{Overview of UK patient management of inflammatory bowel disease}

There are about 150,000 cases of IBD within the United Kingdom (Mowat et al 2011), mostly cared for within the National Health Service (NHS) in secondary care settings (Robinson et al 2001). There are approximately 8,500 new diagnoses made each year (British Society of Gastroenterology 2005). Care of IBD has traditionally mostly been based in secondary care with little involvement from the primary sector principally because of the unpredictable nature of the disease, potential complications, powerful treatments and subsequent medication monitoring regimes. Both newly diagnosed, and patients with a long history of IBD, may make frequent demands on health services from both their secondary care provider (Williams et al 2007) and GPs as patients often require close communication with long-term specialist follow-up and seek significant involvement with their careproviders to make important decisions regarding their care. 
Within secondary care, patients regularly access services offered to investigate or follow up their care according to their presenting symptoms, and up to half of patients experience a flare of their IBD symptoms annually (Mowat et al 2011). Secondary care providers usually offer scheduled care in gastroenterology or surgical outpatient clinic, some offer joint clinic between these two specialities, as well as endoscopy and inpatient care, and emergency care as needed. Patients with non-acute disease are often provided routine follow-up appointments of typically three month to annual frequency to assess their disease, alongside open access opportunities via a telephone helpline. However, this arrangement for an unpredictable disease process often misses the opportunity to provide rapid appropriate specialist intervention at time of need, or misuses resources by assessing a well patient. Increasingly services have recognised these issues and have provided open access services such as telephone helplines and email, alongside scheduled care, that have provided remote access to clinical advice, information and triage to specialist care at time of need (Rogers et al 2004). These open access services are usually staffed by IBD Clinical Nurse Specialists working with the multidisciplinary IBD team.

A patient's- IBD clinical team is usually multi-disciplinary consisting of Gastroenterologists (who usually lead care), Gastro-Intestinal Surgeons, Endoscopists, Clinical Nurse Specialists or Nurse Practitioners in IBD, Radiologists, Dieticians and Nutritionists, Pharmacists, Histo-pathologist, and ward staff amongst others (Williams et al 2006). The tertiary sector of care is very active in supporting patients with IBD, and in the U.K. the charity Crohn's and Colitis UK provides advice, support and helplines alongside research grants and professional and patient led forums.

IBD care, due to its unpredictability, is costly to provide because of the intense demands upon healthcare resources. The IBD Standards 2009, reported that the cost of IBD care to the NHS per annum is approximately $£ 720$ million of which half some $£ 360$ million is directed toward the small proportion of IBD in-patient based care. They recommended that responsive outpatient care with the resulting effective assessment and management of symptoms at time of need and efficient maintenance of remission could prove cost effective and for the patient clinically optimal. 


\section{Our service}

Since our records began in 1990 till 2015 when I left the service, we had looked after 860 patients with IBD in the Gastroenterology and Endoscopy Department of Neath Port Talbot Hospital, a small District General Hospital within the Health Board organisation of services in South Wales.

I joined the Gastroenterology team in 2002, and was appointed as an Advanced Nurse Practitioner in Gastroenterology and Endoscopy. My appointment was made as a direct result of a research study, carried out within the Neath Port Talbot area that looked at the opportunities open access follow up could have for IBD patients (Williams et al 2000). The randomised trial concluded that open access follow-up of patients with IBD reduced demand on overall health resources due to lower outpatient clinic and investigative contacts. The study found that patients and GPs both preferred open access i.e. patients receiving secondary care clinic appointments and investigations during time of symptoms rather than in a prescriptive pre-determined way, but both groups reported issues with the system. Patients reported "difficulty in obtaining an urgent appointment" (Williams et al 2000 p.544), so negating the premise of open access, and 64\% of participating GP's "favoured a gastrointestinal nurse practitioner as a point of contact" (Williams et al 2000 p.546) based within the secondary care setting and allied to a medical gastroenterology team, rather than primary care contact.

The additional benefit of educating patients to manage their own care was reported in a similar study at around the same time as the Williams study in 2000. Robinson et al 2001 demonstrated reduced hospital and GP visits if patients were given education of how to deal with increased symptoms, however they noted that wide-spread implementation of the scheme would require "radical reorganisation of most outpatient clinics ... available at short notice" (P976).

These two studies, Williams et al, and Robinson et al helped fundamentally shape my role in 2002. I was tasked primarily to help provide scheduled follow up and investigations for IBD patients, postal review follow up for stable patients, and establish a telephone helpline that patients could contact at time of need. Each of these activities was underpinned by an electronic patient record (GeneCIS), that 
provided immediate access to relevant demographic, and clinical coded and free-text details (Williams 1999).

These innovations lead to a stabilisation of rising demand initially, improved the variety of access for patients and extended use of the electronic patient record. However, outpatient workload rose steadily from 2005, and the telephone helpline in particular constituted a significant portion of the clinical activity of my role. The department of gastroenterology had also expanded during the late 2000's, and provided increasing numbers of diagnostic, therapeutic, and rapid access services for more chronic and complex inflammatory bowel disease patients who required longterm and sometimes life-long follow up. Our experience was not unique, and was a reflection of the UK-wide IBD service provision (BSG 2006).

\section{The issue}

By 2010 we had approximately 600 IBD patients actively under our care, and the innovations implemented to try to divert pressure upon clinics such as the telephone helpline service had not helped quell demand for outpatient services. My service had seen growth since 2002 (see figure 1. ANP service activity 2002-2010). The rising demand from 2002 to 2010 threatened to outstrip the capacity of the service to provide responsive IBD patient centred services, especially at time of patient need. 
Figure 1. ANP service activity 2002-2010

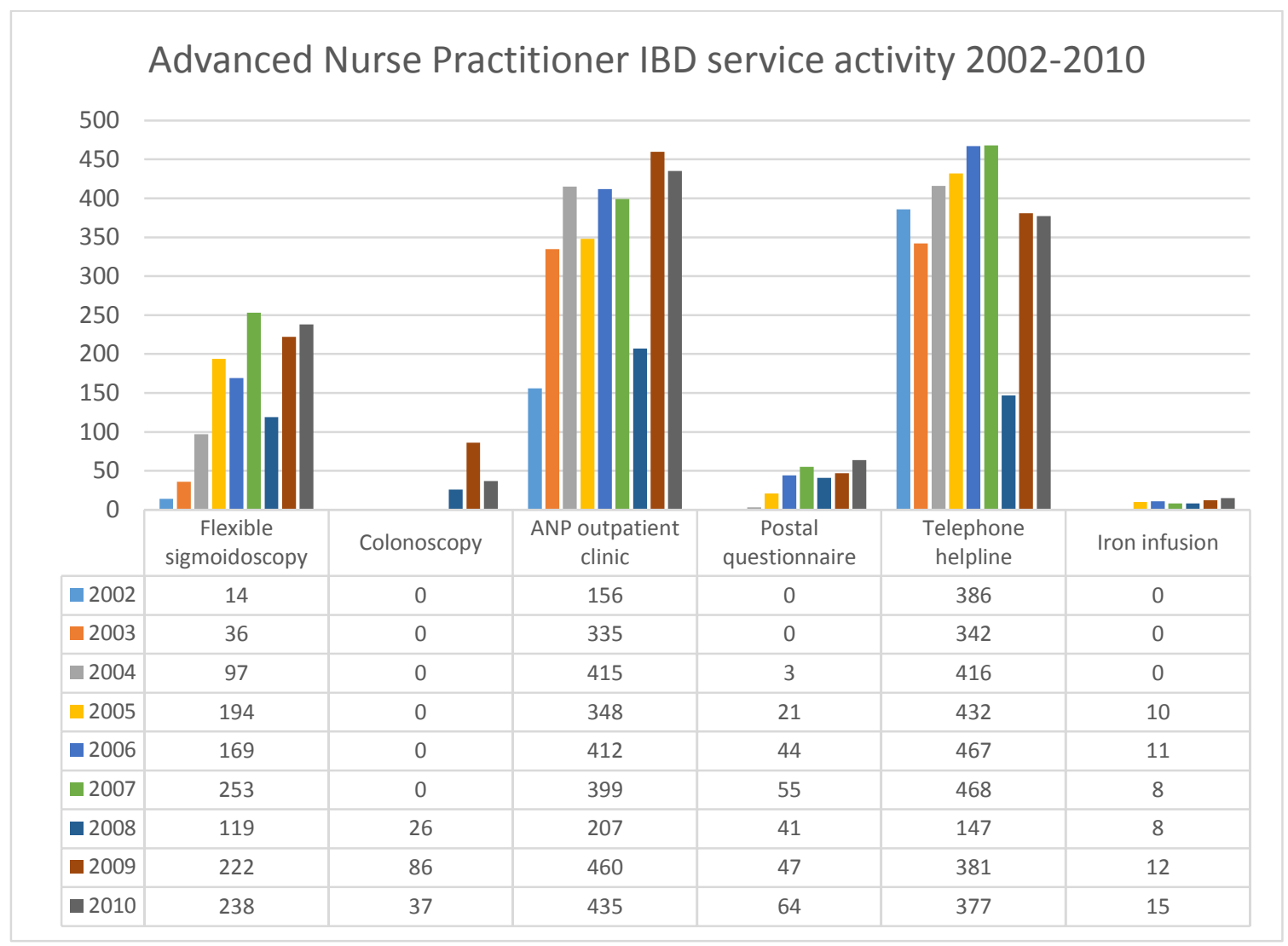

Note: data from 2008 is taken from six months of activity only due to maternity leave.

Our clinical team met in late 2009 to discuss the rising pressures on the IBD service. We considered how best we could meet the rising patient demand for services, while maintaining a vision of care delivery that provided safe, costeffective, and flexible services to meet each individual patient need. We did not want to compromise on the quality of care afforded to our IBD patients and felt it important to maintain patient empowerment and open access to services especially at time of exacerbation of symptoms when rapid access to specialist care is essential.

In previous times of increased demand we had expanded the clinical team by recruiting additional doctors or specialist nurses, enlarged the involvement of primary care and implemented innovations such as open access to services.

Our first option of increasing the clinical team was not feasible as in 2010 the UK and healthcare was in an age of recession and austerity (Department of Health 2010). There was an appreciated lack of opportunity to bid for additional funds. We 
were advised we had to look at ways of providing expansion of clinical services within our budget and any innovation was required to be cost-neutral.

Enlarging the involvement of primary care in the management of IBD patients was not popular with primary care as shown in the Williams et al study (2001), and there did not exist the specialist knowledge in primary care of IBD to facilitate this.

\section{Our approach to the issue}

We considered improving our clinical processes and discussed whether we could further innovate our existing open access patient provision. From data gathered from the telephone helpline and anecdotally in outpatient clinic we understood that patients wanted more information about their IBD and about their own disease process and pathway. One way patients tried to achieve this was by gathering information from a wide variety of resources outside their main care providers including patient forums, charities, the internet and support from other patients. We understood that collectively available patients' information about IBD was largely generic, mass produced and wide-ranging in terms of quality and reliability. Much of it was, therefore not applicable to the idiosyncratic individual patient disease pathway.

We hypothesised that if we could provide patients with their own IBD information they may be empowered to better self care as they could hold clinically accurate information, understand their medical history more fully, and implement care-plans at time of need to treat mild to moderate symptoms quickly and effectively without attending outpatient clinic or contacting the telephone helpline. We considered whether patients should simply have access to their whole IBD record as it was held in secondary care. However, we realised that the records were sometimes complex, disordered, incomplete, and the medical terminology used in correspondence and reports held in the patient records i.e. clinic letters, endoscopy reports or discharge notification, could be confusing or cause misunderstanding for patients. We also debated whether patients should have direct access to their information held in GeneCIS, but found this approach to be too technically challenging and costly. 
Our use of the EPR in endoscopy told us that we could produce summary reports by completing a multi-levelled questionnaire. The endoscopy report was routinely given to patients and consisted of a short précis of the examination that had taken place, we recognised that an IBD patient report would need to be more detailed, but the endoscopy report concept could be transferrable. We keenly understood that we would need to electronically attach portions of educationally explanatory information to the clinical facts relayed to ensure patient understanding of the clinical terminology and provide clear information regarding patients' individual care pathways and inform patients how to access care when needed.

We envisaged improved patient empowerment and self management through this method of sharing the clinical information held within our EPR and providing the information in the form of a personalised and educationally enriched IBD report. We wanted to provide this new patient service in conjunction with traditional outpatient clinics and open access services to provide a realistic complementary approach to traditional follow up services. We postulated that via this approach we could reduce the load on clinics, and free up clinical time to allow patients who did need to be seen quickly have rapid access to outpatient appointments.

In 2010 we found little evidence of the cost or effectiveness of our proposed approach. There were some studies, mainly from primary care, of the experience of primary care teams enabling patient access to medical records (Bhavnani et al 2010, Cimino et al 2000, Fisher 2009, McKinstry 2006), but few from secondary care and none looked at these type of innovations with IBD patients. 


\subsection{Aims and objectives}

As a result of our deliberations we proposed to pragmatically extend the capabilities of our electronic patient record system (GeneCIS) to produce individualised, educationally enhanced IBD reports, and added email to our existing repertoire of methods of contact for GPs and patients. We researched these innovations within a funded mixed methods trial utilising qualitative and quantitative research techniques.

Our stated aims were:

- $\quad$ To understand what patients want from access to their information and from an IBD report.

- $\quad$ To understand the pertinent factors when providing patients access to their health records.

- To develop an intervention to produce individualised, educationally enriched IBD patient information.

- $\quad$ To determine the feasibility of undertaking a trial of the intervention.

Our objectives were:

- $\quad$ To undertake a focus group to determine whether patients want access to their personalised health reports, and, if so how these should look and the content.

- To use the results of the focus group to inform the development of the intervention

- $\quad$ To create a facility within our existing EPR to produce individualised and educationally enriched IBD reports, and make these available to patients and GPs.

- $\quad$ To use the IBD reports to facilitate greater understanding of a patient's IBD history and care plan, and enable patients to take greater responsibility for their healthcare through better communication between patients and clinicians

- $\quad$ To evaluate whether the approach was feasible to test in a fully powered randomised controlled trial. 
- $\quad$ To undertake a literature review to identify the most appropriate way of providing patients with access to their own medical health records, and to identify gaps in the research literature.

Within this thesis I will describe how we met our stated aims and objectives.

In chapter two, I will discuss the findings of a patient focus group held to explore the views of IBD patients' regarding access to their healthcare information, and to elicit patient views on the development of an intervention to deliver patients their IBD information. How this valuable patient insight was used to develop the intervention is described within chapter three. The pragmatic randomised controlled feasibility trial to determine feasibility of testing the intervention is examined in chapter four. In chapter five I relay a reflection of my experiences whilst conducting the trial and in chapter six a systematic literature review of the pertinent evidence used to develop the trial in 2010, and developments to the present day are presented. The systematic literature review is placed within chapter six as it reflects on the findings of the focus group and feasibility trial and informs a protocol for further study. The final chapter draws on all of the examination of the development and testing of the intervention and sets out a protocol for a fully powered randomised controlled trial of a modified ELIJAH intervention. 


\section{Chapter two: The Focus group}

In the introduction, I discussed how we had noted an increase in the number of patients with IBD attending outpatient clinics and seeking advice from the telephone helpline. We recognised that traditional methods of increasing the capacity of the IBD outpatient service were not feasible and so we considered further developing our EPR: GeneCIS, to develop individualised and educationally enriched IBD reports.

We thought that these reports could be shared between patients, their GPs and secondary care, and that the reports could be used to by patients to enable them to better self manage their symptoms. We hypothesised that having these structured, detailed and individualised IBD reports could empower patients to better self-care through a raised understanding of their disease process, and by patients' initiating an agreed plan of action in the event of increased symptoms. But we recognised that this potential innovation was the vision of the clinical team. We needed input from patients to ensure the IBD reports were what patients wanted based on their previous experiences of access to their IBD information.

In this chapter I will relay how we convened a local IBD focus group, and employed a summative analysis technique to gather and explore patients' views of their previous IBD education, care planning, communication, and their opinions of our proposed intervention.

The methods used in this explanation of the focus group follow the COREQ (COnsolidated criteria for REporting Qualitative studies checklist and guide (Tong et al 2007), appendix 1 . 


\subsection{Background and objectives}

In 2010 there was little published evidence on patients' views of access to their IBD information and how this access could affect patients' health outcomes.

Cimino et al $(2001,2002)$ reported that when patients in the U.S. were given access to their medical records they reported better knowledge and understanding of their condition and had an improved relationship with their clinicians. However, the study was small and had few participants: thirteen. Of these thirteen patients many had used the system infrequently, and only five patients remained in the study until completion of the trial. The research was of limited quality because of the low number of participants and high number of trial drop-outs.

McKinstry et al (2006), in a seminal paper, looked at the clinical effects on known hypertensive patients of an individualised care plan. This high quality, large, randomised study of over 200 U.K. patients found no statistically significant effect of the intervention on blood pressure readings, and this quantitative trial did not include patients' views of the intervention. Fisher et al (2009) did explore primary care patients' views of access to their records and again found this had the potential to improve the $\mathrm{Dr}$ - patient relationship. Three themes emerged from their findings of how patients used the additional information offered to them through access to their records; "participation in care, quality of care and self-care strategies" ( $p$ 77). There was some evidence that if patients used the system frequently then over time this could have a positive effect on their health outcomes, but this was not proved by the results presented.

There were few U.K. based papers showing evidence of patients' views, opinions or outcomes of having greater access to their health information. Honeyman et al 2005, conducted interviews with over 100 primary care patients questioning whether they wanted more access to their health records and what potential benefit they believed they may gain if they were given access. They reported that the participants did want to see their information and, in a reflection of the Cimino et al (2001, 2002) findings, thought this would enhance the patient/ clinician dynamic. The patients acknowledged that there could be errors in the records but were enthusiastic to have the opportunity to correct these and up-date the record to include current issues or problems. However, the Honeyman et al research explored the 
potential of enhanced access to the record without giving the patients the opportunity to try a system designed to achieve improved access, nor gave examples of what the access could look like.

There were a limited number of literature reviews looking at patient views of access to their health information. Ross et al 2003 reported that patients liked having access to their health information and benefits included better communication with their clinicians. Ferreira et al 2007, concurred with the findings of Ross et al, and they concluded there were few drawbacks or risks of enabling patients to view or hold their information. However, the assessment of quality of the articles appraised within the literature reviews revealed that many of the studies examined were of low quality and none demonstrated an improvement in clinical outcomes (Ko et al 2010).

There was a paucity of evidence looking at what IBD patients wanted from access to their records. None of the papers, in 2010, included IBD patients in their participant cohorts but there were calls from professional and patient representative IBD groups, at this time, for patients to be given greater access to their health information. Politi et al (2008), in a pan-European and Israeli study, provided a questionnaire to nearly 1000 patients, asking how they best they liked receiving information about general IBD issues. The study did not ask whether or how patients received their own individualised information. The majority of patients (over twothirds) reported they preferred information via their countries IBD information channels and in paper form. However, the study concluded that patients should have more access to information in the way that they individually prefer and electronic means of communicating the information should be increased.

We concluded from a review of the above literature that the evidence base for our intervention development was mostly of poor quality and there was little usable data that we could apply to the development of our intervention. We decided to conduct an IBD focus group to enable us to gather useful and insightful data that could plug the gaps in the evidence base.

\section{Aims}

Our aims were to:

- To understand what patients want from access to their information and from an IBD report. 


\section{Objectives}

- To undertake a focus group to determine whether patients want access to their personalised health reports, and, if so how these should look and the content.

- $\quad$ To use the results of the focus group to inform the development of the intervention

- To ascertain whether patients think that the IBD information they have received is adequate, appropriate and can be utilised effectively especially at time of need.

- $\quad$ To determine how patients communicate with health professionals and discover where improvements can be made.

- $\quad$ To identify whether an intervention output that would deliver individualised and educationally enriched patient reports is wanted by patients.

- $\quad$ To gather opinions and views to inform the construction and content of the intervention.

We decided to carry out a focus group to collect the data, rather than harvest patients views via alternative means such as questionnaires or structured interviews, because we wanted to quickly and conveniently gather the information as our trial period in total was limited to one year only. We also believed that a focus group could allow us to pick on richer data through the interaction of participants and the interplay between them and the use of open questions (Kitzinger 1995). We wanted to allow the focus group participants to explore the broad themes and were interested if themes arose that we had not envisaged.

Focus group methodology has been used extensively within healthcare research to explore patients' views and understanding of health and we wanted to exploit the potential advantages of this methodology; effective and efficient data collection, easy identification of themes, easy-going environment to create productive discussion and empowerment of patients to give their views in a collective of similar patients (Robinson 1999).

Within this chapter I will describe how we held a focus group that comprised of IBD patients, and how we met our stated aims and objectives. 


\subsection{Methods}

We designed this study to amass IBD patient views of their IBD information and education that they had received since their diagnosis, care planning and how they communicate with their healthcare providers. We also gathered opinions on the design and content of an intervention to deliver individualised IBD information.

\section{Research team}

I conducted the focus group, and invited patients to take part in the focus group. Some of the ten patients who attended the focus group had been under my care and had attended the IBD clinic or endoscopy sessions that I carried out as part of my role as an Advanced Nurse Practitioner. The trial manager and a lecturer from Swansea University were also present at the focus group to take notes and help in the organisation of the group if required. Each of the research team present at the focus group introduced themselves to the participants at the start of the focus group.

\section{Participants}

Participants from Neath Port Talbot Hospital, ABMUHB were invited to participate in the focus group. We recruited the patients in March 2010 and the focus group was held in May 2010 (see figure 2. Summary of ELIJAH timeline: focus group). 
Figure 2. Summary of ELIJAH timeline: focus group

Summary of timeline

\begin{tabular}{|c|c|c|}
\hline TASK & ACTION & FINISH \\
\hline \multirow[t]{4}{*}{ ETHICS.R\&D } & APPLICATION & 24.12.09 \\
\hline & INTERVIEW & 22.01 .10 \\
\hline & PT LEAFLET \& CONSENT & 05.02 .10 \\
\hline & NHS R\&D & 05.02 .10 \\
\hline \multirow{8}{*}{ SHINE FUNDING } & APPLICATION & 02.11 .09 \\
\hline & INTERVIEW & 09.12 .09 \\
\hline & MEET SPRINGFIELD CONSULTANCY & 08.01 .10 \\
\hline & HEALTH CHECK & 04.02 .10 \\
\hline & CONTRACT & 03.02 .10 \\
\hline & APPOINT PROJECT MANAGER 0.4 & 01.02 .10 \\
\hline & CONFERENCE AWARD & 25.02 .10 \\
\hline & DASHBOARD & 01.02 .11 \\
\hline \multirow{6}{*}{ OUTCOMES } & PT SATISFACTION QUESTIONNAIRE & 26.03.10 \\
\hline & TESTING Q & 12.03 .10 \\
\hline & ADVERSE EVENTS & 15.04 .10 \\
\hline & COST & 09.02 .10 \\
\hline & TIMELINESS & 19.03.10 \\
\hline & EQUITY & 19.03.10 \\
\hline \multirow[t]{2}{*}{ INTERVENTION } & AGREE SPECIFICS \& CUSTOMISE & 25.06 .10 \\
\hline & REVISE INTERVENTION \& PILOT & 07.07.10 \\
\hline \multirow[t]{4}{*}{ RECRUITMENT } & IBD PT LIST GENECIS & 17.12.09 \\
\hline & IBD PT LIST BY GP & 20.12.09 \\
\hline & GP RECRUITMENT & 12.02.10 \\
\hline & GP INFORMATION LETTER & 06.02 .10 \\
\hline \multirow[t]{6}{*}{ FOCUS GROUP } & ADVICE RE FOCUS GROUP QUESTIONS & $\underline{10.02 .10}$ \\
\hline & PATIENT RECRUITMENT & $\underline{10.03 .10}$ \\
\hline & HOLD FOCUS GROUP & $\underline{26.05 .10}$ \\
\hline & FULL TRANSCRIPTION & $\underline{10.11 .10}$ \\
\hline & ANALYSES & $\underline{13.02 .11}$ \\
\hline & REPORT & $\underline{12.04 .11}$ \\
\hline \multirow[t]{3}{*}{ PATIENT EDUCATION } & SOURCE EDUCATION PACKAGES & 28.02 .10 \\
\hline & NACC VISIT TO NPTH & 29.01.10 \\
\hline & REVIEW EDUCATIONAL PACKAGES & 12.03 .10 \\
\hline PATIENT RECRUITMENT & SEND LETTERS & 02.06 .10 \\
\hline PATIENT RANDOMISATION & & 30.06 .10 \\
\hline TRIAL START & & 01.12 .10 \\
\hline EXTRACT GP NOTES & & 22.02 .11 \\
\hline FINAL FOLLOW UP & & 31.03 .11 \\
\hline FULL ANALYSIS \& REPORT & & $\begin{array}{l}31.08 .11 \\
31.08 .11\end{array}$ \\
\hline
\end{tabular}

PUBLICATIONS

We identified patients with a secure diagnosis of IBD by searching within the GeneCIS EPR for coded IBD terms and verified these by cross-checking the information with endoscopic and histological evidence of IBD found in the electronic and paper hospital records. We checked whether patients were currently 
under the care of the gastroenterology team at Neath Port Talbot by identifying the date of the last admission to clinic or endoscopy and noted the patients' registered GP practice.

The eligibility criteria for inclusion for patients were:

- Confirmed diagnosis of IBD

- Recent review (within 18 months) of IBD care at Neath Port Talbot Hospital

Patient ineligible for inclusion included those who did not meet the inclusion criteria in terms of diagnosis and IBD care, and those who could not understand the study.

We stratified the patients by GP practice and created a database of patients listed alphabetically by GP, and under each GP listed the patients numerically according to their hospital number. We randomly invited every tenth patient in the list to take part in the focus group on $10^{\text {th }}$ March 2010 (see figure 1). This method of randomisation was undertaken to reduce the potential bias of the focus group, and to ensure equal representation from the wide geographical areas of the patients.

A total of number of 23 patients were invited from 35 GP practices. Patients were sent a letter and a consent form outlining the purpose of the focus group and detailing that ethical approval for the focus group had been obtained. Patients were asked to consider the invitation and inform us of their choice to attend or not.

One patient did not respond to the invitation call and the GP informed us that the patient was immobile and so would not be able to attend. In total nine patients of the 23 patients invited could not attend the meeting or did not want to. Reasons for not attending varied and included being busy on the evening of the focus group, not wanting be a participant, having hospital appointments that day already and side effects from treatment that could affect the wellness of the patient to attend. One patient stated their IBD was so unpredictable that they did not think they could participate for the two hours required as they had frequent requirement to use the toilet. Of the 14 patients who replied that they would attend the focus group, ten attended the evening meeting.

The participants consisted of seven female and three male participants. The ages of the participants ranged from 23 to 71 years of age, and there was an equal 
split of IBD with five patients having a diagnosis of ulcerative colitis and five with Crohn's disease.

\section{Setting}

We held the focus group in a conference room in the Post Graduate Centre of Neath Port Talbot Hospital on the $26^{\text {th }}$ March 2010 from five till seven PM with a 20 minute break for refreshments provided by the research team. We chose to hold the focus group in the hospital as we thought this would make travel easy for patients as they had had appointments within the building previously, and there were good parking and public transport links available. We reimbursed the patients $£ 50.00$ each to cover their travel costs.

Before the focus group started the trial manager who was attending the focus group, answered any participant questions about the focus group and obtained written informed consent from each participant.

At the start of the focus group we welcomed the group, and I introduced the other two researchers in attendance. The total number of people therefore in attendance was 13 - ten participants and three researchers. We reassured the participants that confidentiality of their inclusion in the focus group would be maintained and that any quotes used from them would be anonymised. We also implored the group to not discuss the focus group with anyone to maintain the privacy of the group members.

We asked that participants write their names on a card and place it in front of them and when speaking we asked that patients state their name to ensure that their comments could be differentiated from each other on the recording. We gave the participants the opportunity to ask any questions prior to the focus group starting and also informed them that the researchers would be available immediately after the focus group had finished to speak with if needed. We re-iterated that full ethical and research and development approval had been sought and secured.

\section{Ethics}

As we were conducting a focus group with IBD patient participation we were required to obtain full ethical and local NHS Health Board research and development approval. We applied and received this prior to the invitation of participants to the focus group. The IRAS application was submitted in December 2009 and we were 
notified that we had been granted full ethical approval on $5^{\text {th }}$ March 2010 (see appendix 12).

The focus group conduct and study monitoring was overseen regularly by the trial manager and by monthly meetings of the research management team.

\section{Data collection}

I prepared questions for the focus group in three main topics: IBD information and education, care planning and communication with health professionals. I informed the participants that we would not be covering subject areas specifically about their condition or their current symptoms, but would rather be listening to them talk about their views on the ways they had sought IBD information and used this to self care and impart and transmit information with their IBD care provider.

The prepared questions were:

- Education and information:

1. What information about your condition have you had and has it met your needs or expectations?

2. What information would help you to manage your problems?

3. How do you perceive your individual needs?

- Care planning:

1. What would you find most beneficial to know? What would be most useful to be contained in any information?

2. Which areas do you think you need most help and support in, and are there things we have left out in your care information?

- Communication:

1. How would you want to contact us when you need help and why?

2. How helpful is it to come and see a Dr or nurse or could seeing or holding your own IBD information give you answers to your queries?

3. How comfortable would you be looking at the clinical IBD letters we send from outpatients to your GP? 
Following the refreshment break we reconvened and we asked the participants to consider critiquing a prototype demonstration of our designed intervention. We asked the participants to:

- Consider whether the title was more appropriate as "Your history" or "My history".

- Think about whether they would use the kind of IBD report we proposed.

- Identify if they felt it could be helpful in them knowing more about their disease and care.

- Judge whether it could save patients time.

- Contemplate whether it could alleviate concerns.

We used audio recording of the focus group to capture the data and the lecturer researcher made field notes during the discussions. The one hour and forty minutes of recordings were transcribed shortly after the focus group.

\section{Summative analysis}

The focus group was held to provide us with patient views of their IBD information, care planning and communication with healthcare providers, and for us to gather opinions on our potential intervention ELIJAH.

We employed a summative analysis methodology (Rapport 2010) to sort and explore the data. We chose this methodology to exploit the very good multiprofessional research team working we had already established within the ELIJAH team. We were drawn to the methodology by the opportunity for

“an egalitarian approach: (where) everyone's view matters; (and) all members are included"

$$
\text { Rapport } 2010 \text { (p272) }
$$

and the potential to identify the more nuanced themes and topics discussed by the participants.

We wanted to ensure that we had analysis of the focus group text from the many different points of view of members of the research team, and we aspired to work through the summative analysis method and achieve a consensus of the key components of the focus group feedback. 
We consulted with Professor Rapport, author of the summative analysis technique and drew on her experience and knowledge while following the basis of the summative analysis methodology.

We first gave each of the six research team members the full transcript of the focus group and asked each of them to write a short and concise paragraph of each of the focus group question topics i.e.: education and information, care planning, communication and the prototype intervention. We asked that the group reflected within their paragraphs their understanding of the core elements of the transcript. I then gathered these short reports together and reviewed them, and identified similarities, differences and unexpected instances between the reports.

We then met as a team to discuss our summary reports and to debate pertinent points. During the afternoon session we also reviewed the items I had identified in the collation of the individual reports. After debate and discussion of the overall themes and topics of the text and identification of supporting evidence for our consensus, we agreed the results of the focus group. 


\subsection{Results}

Ten, randomly selected people with a confirmed diagnosis of IBD and under the care of the gastroenterology team at Neath Port Talbot Hospital attended the focus group. Three researchers attended alongside the participants.

The focus group met to discuss the information provided for patients with IBD, and how patients' use this information to self-manage and communicate with health professionals, particularly at time of increased symptoms. The adequacy and provision of information and accessibility was discussed, and a potential intervention to deliver individualised educationally enriched IBD information was critiqued by the participants following their review of a mock-up of the intervention.

Patients' ability to gather useful information dominated the first part of the focus group conversation. Patients' were keen to describe the lack in the consistency in information provision:

"Information ... should be uniform right through the NHS, every place should have exactly the same information wherever you go"

(participant number 019).

Many patients reported they had not been given any IBD information by their healthcare providers, and consequently had sought and acquired information themselves that suited their individual needs. Some had gained information via buying books or searched the internet. There was consensus that the information received from the major U.K. IBD charity - National Association of Crohn's and Colitis was very applicable and reliable and some patients relied largely on the IBD telephone helpline for general and specific information.

Patients reported that some of the information gathered from the sources outside the healthcare setting could "frighten you" (participant number 023) and that some felt the information could be overwhelming in amount and content. But the group acknowledged that insightful IBD information could help support patients in understanding and self-managing their disease, however the wide variety and sources of information that they could access could be confusing or frustrating.

The focus group reported that information from GPs or GPs surgeries varied in quality and availability and some agreed that they would bypass this facility and be "better off coming straight direct to the hospital" (participant 021) for any advice 
or help. Members of the group felt that GPs should be able to have access to more information about IBD and then impart this to patients more readily, but they understood that GPs breadth of expertise meant that this may not always be achievable; "they do need to have a little bit of information particularly if they know they have got a patient on their books" (participant number 021). The GPs lack of knowledge about IBD left patients feeling unable to comprehend their care and they felt unable to access help from the GP to help them understand their disease process, investigations or treatment options.

When participants were asked about the kind of information they would like to help them manage their condition better, they replied that they wanted to know how they could help limit the chances of increased symptoms "things you could do to prevent things changing" (participant number 005). They wanted to know if IBD was hereditary, and "triggers" (participant number 023) that could exacerbate symptoms were discussed at length.

Patients wanted to know what may arise in their disease process and wanted to be clear on what may happen to them; "it is worrying when you don't know what it is" (participant number 023). This lack of knowledge was identified as a cause of worry and concern for patients and imagining of a wide variety of scenarios.

Participant number 021 wanted to be able to "get in touch immediately when your symptoms are arising", and stated that there had been conflicting advice received from different departments that meant that knowing what to do if symptoms arose was confusing. They continued to state that the information and knowledge they could hold if informed, could reduce their reliance on secondary care contacts and reduce the time they spent on trying to access help. The participants described sometimes as if they were a bother to their healthcare providers if they did make contact: “you're afraid of making a fuss" (participant number 022).

Patients described using personal experience of their disease and personal wisdom as important in providing a sense of autonomy over their disease process.

There was broad agreement from the participants that any advice or information should be clear, concise and should avoid abbreviations, complex sentences and in particular jargon. Participants reported they had asked for further explanation especially when clinicians had discussions with other clinician: "I don't 
understand can you repeat that. Can you put it in layman's terms please?" (participant number 019). This participant further stated:

"There is a lot of jargon unless you hear them speaking about it all the time ... you do get used to what they say, it's just now and again they throw in a word and you think what on earth!"

The participants thought that newly diagnosed patients could need more information than those who had their diagnosis for a long time.

Patients discussed the items they thought could be most beneficial to know. They reported that more guidance on diet, medications and who and how to contact a specialist at time of need was needed.

When questioned more closely on how participants would want to have contact with their clinicians most considered varied options that relied more upon information technology than more traditional methods of contact through outpatient clinics. Ringing and speaking to a clinician was considered important especially for reassurance, but also text and particularly e-health methods such as email.

Participants considered how they accessed other services in their lives and thought that these methods could be applied to their health needs; "the world is on-line. It would be good to send a question and get a reply" (participant number 015). There was an appreciation of the security requirements of using I.T. methods of contact "I would want to make sure that it is secure as well" (participant number 021).

Participants concentrated on defining the things that could improve their well-being: a speedy response to queries, the ability of health care providers to support them when they were stressed or anxious and they wanted systems that included both their primary and secondary care health providers working in collaboration with access to all of their IBD information. Participant number 021 suggested a new way of health professionals working that could quicken processes and enable speedier access to treatment. They suggested that at time of need patients could email secondary care, have a quick response with a treatment plan and this reply could be forwarded to the GP by email and a prescription for medication dispensed immediately. Other participants supported this idea and endorsed a more joined up care system between primary and secondary care, and they were emphatic that they should be fully included in their care team "it would be a three way thing" 
(participant number 019), "between yourselves, us and ... (the) GP” (participant number 023).

The focus group participants discussed the possibility of seeing and retaining their medical records, so that they could know more about their care and feel more in control of their IBD through greater understanding of their disease. Some participants thought they would like to hold their own medical records because they saw that organisation and care of their medical records by secondary care was sometimes lacking;

"I would be able to sort my own notes out properly ... and be able to control them and take them wherever I went and know what was happening" (participant number 019).

Participants reported how they had experience of their notes being unread by the health professional they saw, and how they were asked to repeat information they had already given, some had notes lost by hospital and had been seen in clinic without their full notes. Other participants thought there might be issues with them holding their own medical records. One thought they may lose them, others worried about the security of them at home and some wanted the information electronically rather than the physical file as they thought this could be easier to keep safe. One participant worried that if a patient had not been explicit with their partner or family about their illness, then their privacy could be compromised, one worried that the information could be stolen.

Overall, having better access to their IBD health information was seen as a positive move forward as it could improve patients' ability to keep abreast of their illness, tracing its patterns and ensuring better preparedness for future flares.

When asked how they would use the information if they held their own IBD information, participants reported a range of ways they would actively use the data. Some would update the notes and use it as a diary of their symptoms, some would use it as an aide memoire during appointments to remember pertinent dates in their disease such as diagnosis or surgeries.

"If you have a flare up ... you can look back through and see what happened to make you improve instead of calling someone else and you could try and improve your condition yourself and control it more" 
Many participants agreed with this form of self-management and gave examples of how they already self-cared during flares, they reported that they largely drew upon previous experience to manage symptoms.

One participant stated they did not think that patients should be enabled to "change your notes" (participant number 021), and they drew on their own experience of working in a confidential environment to support their assertion.

During the second section of the focus group we asked the participants to spend ten minutes reviewing a prototype of our idea for an intervention that could deliver access to individualised educationally enhanced IBD reports.

The prototype was developed by reviewing two IBD patient self-care management plans, one sourced from a NHS Trust (Luton and Dunstable Hospital 2010), and one from NACC. Both examples were brief, paper based and generic. Within each patient management plan there was space provided for clinicians to manually write and relay information to patients. Advice was given regarding the recognition of a flare in symptoms and how and who to contact regarding this. No individualised patient education was given within the leaflets. We used and adapted the broad patient information topics included in both leaflets i.e.: diagnosis, current medication and how to recognise a flare, and expanded upon it to create a more complete patient history and care plan.

Both examples were formatted on an A4 sized, hand-written leaflet. We produced a more detailed proto-type product using publisher software. The prototype looked similar to a newsletter of individualised patient information with attached educationally enriched paragraphs. We called the three prototypes "Your History", "Your Plan" and "Your Follow-up" and included baseline specifications such as patient demographics, details of the care team, previous medical history, medication, investigations, how to access help when needed, what to do in the event of a flare and any recent changes to planned care. We provided a set of the completed prototypes with details of an invented patient history.

Participants fed back that they wanted the name of the reports to be changed from "Your History" to "My History" to increase a sense of ownership over the reports; "My, because if its "your" it is someone telling you what to do" (participant number 023). 
The group very much welcomed the inclusion of sections of education alongside their information and reasoned that this improved the clarity and ability to understand the clinical terms contained. The participants stressed that jargon and abbreviations should not be used. They endorsed the inclusion of epidemiological information about IBD, such as incidence, because this was felt too be reassuring that there were many others with the same condition.

Patients required detailed personal information that was easy to understand, without jargon but providing reliable, practical information of how they can help themselves and when and where to seek expert advice.

\section{The research group report}

Six members of the research group were given the full transcript of the focus group and asked to write a short synopsis of the major themes they elicited from their reading of the text. Each of the six researchers completed the task and I reviewed them to identify similarities, differences and anomalies between them.

There was broad agreement regarding the major emerging themes of the focus group. We heard there was a lack of uniformity in the provision and quality of information across primary and secondary care, patients' ability to self care developed over time and patients wanted more information about their care and a more collaborative team working approach with their primary and secondary care clinicians working with patients to provide care.

All of the research group picked up on themes of the use of jargon by health professionals and patients dislike of jargon as they felt it could lead to confusion and misunderstanding of information. The ways that patients sourced IBD information varied and different hospitals provided different information. The information received from an IBD charity was found to be most useful, whilst some information gleaned from television or the internet was found to be inconsistent and could cause anxiety.

Patients wanted to know more about diet, triggers for flares and treatments. Some patients were happy to self-care and others required more guidance and intensive help from their IBD care providers. Self-medication at time of flare was initiated by some patients, but others felt unsure about how to do this, and were not confident without clear guidance and the permission to do this. Patients' experiences 
of their disease process were idiosyncratic and differed greatly between the participants. All members of the research group felt that patients wanted appropriate, timely and effective care at time of need.

The research team keenly picked up that patients wanted closer working between their primary and secondary providers and patients wanted to be more included within decision making and communication. All the researchers felt the participants voiced that they wanted more information about their care and some would like to hold their medical records.

There were dissimilarities between the researchers reading of the focus group transcription. Some researchers felt that participants stressed the importance of secondary led IBD care and stated that the search for IBD information had taken a lot of time. Some researchers picked up that patients mostly wanted tailor-made dietary advice, and whilst some participants would want IBD reports electronically, some wanted paper copies.

The researchers were asked if there were any aspects of the focus group discussion that was unexpected. The researchers concurred that there was surprise at how many of the participants used their own experiences and wisdom rather than prescribed plans to cope with episodes of increased symptoms. The revelation that some participants may not want to hold their records because they had not divulged their health information to their family, was also unanticipated. The way that participants had described the loneliness and helplessness of coping with their symptoms was acutely noted by the researchers.

The researchers felt there was broad endorsement of the idea for the ELIJAH intervention, but there were important modifications and requirements that would have to be considered and included. These were: naming the products "My" instead of "Your" to increase patient ownership of the product and content, the exclusion of jargon and abbreviations from the text. Clear individualised information supported by explanatory text, presented in a uncluttered way and delivered via electronic or paper means according to patient preferences.

We met as a research team and discussed the focus group transcription, our summary reflections of the transcription and my analysis of researchers' texts. We 
spent an afternoon debating the differences picked up by each researcher and democratically reached consensus on the main outcomes:

- That patients want more IBD information and this should be individualised and include their IBD disease history.

- Patients want to better self care under guidance.

- The information should be jargon and abbreviation free.

- There should be educational supplement to each section of information.

- The same information should be shared with the patient, and primary and secondary care providers.

- Patients need a variety of methods of contact especially at time of need, including email. 


\subsection{Discussion}

We gained a rich yield of patient feedback from the focus group about how patients gather information about IBD, how they use this to self-care, and how they communicate with their primary and secondary care providers. We also gained approval for a modified development of an intervention that could enable patients to have individualised IBD reports supported by interwoven educational paragraphs.

\section{Strengths and weaknesses}

The patient engagement has been very rewarding, with good recruitment and participation in the focus group which clarified patients views and opinions of their requirements of IBD information. Recruitment and consent of the participants worked well, as did the randomisation of the participants. The focus group included a range of ages and IBD disease types, but male participants were unrepresented on the focus group and the sample was drawn from one secondary care settings.

I conducted the focus group, and some of the participants were patients under my care, this may have skewed their openness in sharing their views and opinions of the information they had received.

The research group individually worked thoroughly to analyse the transcription of the focus group and progressed through the summative analysis phases well. The research team together maintained a democratic focus and all the researchers were encouraged to contribute to discussions. There were differences in the researchers reading of the transcription and in their subsequent reporting. Perhaps this was because the group was multi-professional and there was a high degree of diversity between the members. However, these differentiations were viewed by the group as a positive, particularly in discussions of dissimilarities in the text, and were used to explore nuances and gain deeper understanding of the text.

The use of summative analysis methodology to explore the findings of the focus group proved to be very useful as it ensured that many disparate views of the text were heard, and consensus of the richer meaning of the text was gained through open, honest and focused discussion. Had we had only one or two researchers analysing the text we could have missed the opportunity to elicit some of the more surprising or subtly aspects of the participant feedback. The debate of the text 
between the researchers allowed different meanings of the text to be explored, defended, challenged and collectively defined.

A limitation of using the summative analysis methodology was that we did not carry out a formal thematic analysis of the transcription. As a result of this, we could have missed the opportunity to identify underlying emerging themes. It is possible the use of an alternative methodology could have yielded more useful insight from the data set to inform the development of the intervention. We may have, as a research group, negated to appreciate some of the more subtle ideas or assumptions revealed by the transcript.

As with all qualitative research methodology the results of this focus group cannot be generalised to whole populations. 


\subsection{Conclusion}

As a result of the focus group we understood that we needed to extend the scope of our electronic health record system to enable the production of individualised and personalised IBD reports, and add email to our existing repertoire of methods of contact. We needed to share these IBD reports with patients and GPs in order to enhance our communication methods and ensure parity of information and understanding of the content of the reports. 


\section{Chapter three: The intervention:}

\section{Electronic Linkage for Inflammatory bowel disease to deliver Joint Access to Health reports (ELIJAH)}

So far, I have conveyed how we noted a rising demand for outpatient IBD services that outstripped our capacity and, how we were unable to gain additional funding to expand the number of clinical personnel to accommodate this upsurge in referrals. As a result of these two interdependent factors we were led to consider innovative ways to provide patients with opportunities to better self-manage whilst maintaining the balance of the financial cost of the service and preserving the patient safety profile. We decided to extend the functionality of our existing electronic patient record (EPR) GeneCIS, and use it to provide more detailed information to patients and their GPs. We hypothesised that we could produce individualised and educationally enriched IBD patient reports that could be used by patients and their GPs and these would better guide care, and empower patients to self-manage within agreed IBD care pathways.

In the previous chapter (Chapter two: the focus group), I reported the findings of our IBD patient focus group. The patients were asked questions about their views on their hospital based records, whether they had sufficient IBD information and how they gained help from their IBD care providers when needed. The valuable feedback relayed how patients felt frustrated having to repeat their IBD history, medication or care plan at appointments in primary and secondary care. They reported how they felt an individualised summary of their past medical history and future care plans would be useful, particularly if this was held by themselves, their GP and secondary care provider. Some voiced concern over the poor presentation of their notes and incomplete or disordered clinical information. They were supportive of the development of an intervention that would provide individualised IBD information supported by educational supplementation that could circumnavigate patients' reliance upon generic patient information that often did not have relevance to their disease process.

In this chapter, I will describe how we developed the ELIJAH intervention by pragmatically extending the functionality of our EPR. 
The methods used in this explanation of the intervention follow the TIDieR (Template for Intervention Description and Replication) 2014 checklist and guide (Hoffman et al 2014) (see appendix 2). 


\subsection{Background}

Why

Patients' access to their health information and records has been a longstanding policy priority supported by professional bodies (Royal College of Physicians 2017), government legislators (Ross 2003, Cruikshank et al 2012) and IBD patients (Politi et al 2008, Winkleman et al 2005) and other patient groups (Honeyman et al 2005).

There is evidence to suggest that better access to health information can improve patients' knowledge (Cimino et al 2002) and understanding of their health condition (Cimino et al 2001, Ferreira et al 2007), and that this can lead to better self-management of care and enhance the patient/ clinician relationship (Bhavnani et al 2010, Fisher et al 2009). Cimino et al (2000) acknowledge these patient benefits, and found that the safety profile of traditionally run clinical services do not deteriorate by increasing patient access to their health information.

In 2010, at the time of building the intervention, we found there to be a paucity of high quality literature describing how EHR systems could be built to enable patients to gain greater access their health information (Ross et al 2003). We found only two papers that could influence our development process. Masys et al (2002) described how their team had created a security system to protect on-line communication between patients and their physicians. They tested the system in detail to identify and potential security breaches. They found that PCASSO (PatientCentered Access to Secure Systems $O$ nline p. 181) met each security challenge without infringement of the security processes, but overall the system was had low ratings for usability by physicians because of the complex log-in process. Patients, however, liked the system and found it easy to use. Di Marco et al, four years later in 2006, explained how a developmental system intended to deliver tailored educational information to pre-surgical patients could supplement the traditional outpatient appointment and verbal explanation of surgery and giving of a generic patient leaflet. The article concentrates on the development of "National Language Generation" to support the production of the output of the system, but there was no evidence that the system was implemented or tested. 
When we were undertaking the feasibility trial, pre 2010, we found a limited number of published rigorous trials testing an intervention to deliver increased patient information using an EHR, and of those identified very few showed statistically significant results or positive impact of the intervention. In 2001 Williams et al assessed the effectiveness of producing a patient held record for cancer patients. The randomised controlled trial found "no significant impact on the quality of life for patients or NHS resource use" (p. 159), but some younger patients, and those with multi-professional input did find the intervention advantageous. In 2006, another U.K. based research team published the randomised control trial results of a patient-held guideline for hypertension. McKinstry et al in a large study, again found "no clinically significant perceived benefit" (p. 842). Garcia-Lizana (2007), in a systematic review, concurred with the two trial findings of Williams et al (2001) and McKinstry et al (2006) and did not find evidence of a link between the use of advanced IT communication interventions and an improvement in clinical outcomes. We were unable to locate evidence of a trial that included IBD patients, and neither intervention provided patients with the individualisation of the record and the supplemental education component that we proposed developing from our EHR.

Since 1990 our department of Gastroenterology within Neath Port Talbot Hospital was supported clinically and administratively by an electronic system: GeneCIS (Generic Clinical Information System). At the time of building the intervention, the vast repository housed 20 years of information and data in structured coded form (Clinical Terms Version 3) and free text, and detailed all patient contacts with the department. Each patient endoscopy reports, outpatient letters to GPs, telephone calls to the IBD helpline and free text were stored and organised to create a longitudinal record about each patient. The patient record was used by all staff within the department for administrative and clinical functions. Outputs included the generation of endoscopy reports by the completion of clinical questionnaires and the production of formatted letters to GPs. Audit and research functions including analysis of activity were facilitated by the clinical and clerical coding of information. Within my routine clinical function I used the electronic patient record to support all my clinical, research and educational activity. 
As GeneCIS had been designed to facilitate customisation to specific contexts we discussed a pragmatic use of the existing software and extension of the programme concept applications. We considered whether we could allow direct patient access, through the NHS firewall, to enable patients to view their longitudinal record. But, after consultation with NHS IT security we found this to be a complex, costly and timely adjustment to facilitate within our constraints and one that did not meet the focus group patient feedback requirement of a summary of patient history or care plans for more directed self-management. 


\subsection{Methods}

\section{What}

Drawing on our experience of using GeneCIS we were supported by Jayne Morgan (Information scientist, and original developer of GeneCIS, based at Swansea University) and Hayley Dickinson (GeneCIS technical manager) who customised the system to meet the functionality needed to produce individualised educationally enriched IBD reports from clinical questionnaires. During this developmental period the customisation of GeneCIS to support the data collation and production of personalised reports was undertaken, piloted and refined.

The prototype, that was developed and discussed by patients in the focus group (detailed in chapter two), was produced using Publisher software. The final intervention products to be used in the feasibility trial, were planned to be produced using a different software programme; GeneCIS. We utilised GeneCIS' existing facility to transfer clinical questionnaire data into a WORD document and utilised this facility for the production of the intervention. Therefore, we anticipated and understood there would be significant differences between the prototype and the finalised intervention product in terms of appearance, but we aimed to maintain the broad content themes and included the modifications identified by the focus group.

The hierarchical questionnaires we designed had questions and corresponding answers for each section of information which we wished to relay, e.g. for IBD diagnosis the high-level answers were Ulcerative Colitis, Crohn's disease, Indeterminate Colitis and Microscopic Colitis. The answer to any question had multi-levels of potentially different answers written in so that we could carefully and precisely detail the clinical information e.g. if a person were diagnosed with Ulcerative Colitis, the next level of questioning sought information on the extent of the known disease (see appendix 5 example of ELIJAH report).

The speedy production of individualised IBD reports was aided by access to the existing clinical data that were held in paper and electronic form in secondary care. However, much of the data needed were already held within GeneCIS in the existing patient electronic healthcare record. We did not include an IBD disease symptom index calculated score within the intervention as we did not find evidence of routine use of such a tool within the patients' notes in either primary or secondary 
care. Supplementary evidence about other health conditions and interventions were obtained from the hospital medical paper based notes. Investigation results were obtained from the electronic results system (INDIGO), and the hospital patient administration system (PIMS) provided information about appointments and admissions. The information was inputted by a clinician, and used to populate the questionnaires. Patient educational components were also included in this structure.

Each answer in the questionnaire was linked to a specific paragraph or picture of educational content, this was automatically included in the output of the report e.g. for a patient diagnosed with distal ulcerative colitis a picture describing the extent of the disease was attached (see figure 3. ELIJAH colon diagram for self management plan; distal ulcerative colitis).

Figure 3. ELIJAH colon diagram for self management plan; distal ulcerative colitis.

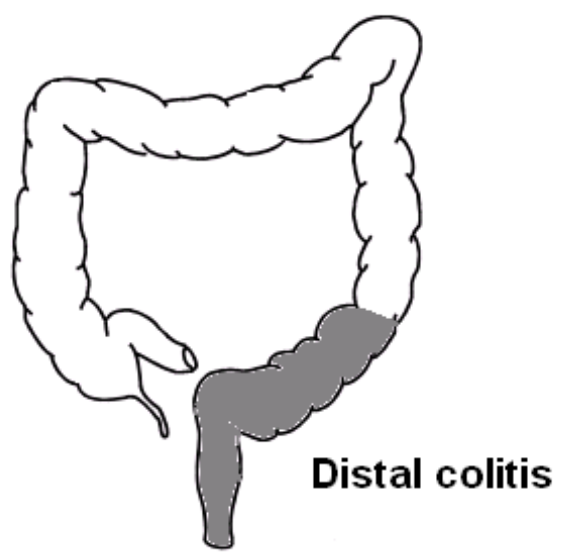

We involved the National Association for Colitis and Crohn's (NACC now known as Crohn's Colitis UK), the charity supportive of people with IBD, to enable the educational element of the intervention to be obtained from existing, evidence based and peer reviewed information. We validated the educational content and we involved the President of NACC at that time; Richard Driscoll and gained permission to use and dissect the patient information as required. We analysed NACC's generic patient information for useable content, directly took sections that were applicable and applied them to the ELIJAH levels and descriptors. We were careful to use unambiguous phraseology in the reports and adhered to the Plain English (www.plainenglish.co.uk) directives. 
A user friendly and comprehensive structure for the reports was devised. The ELIJAH report was to be in three parts, and formed a "My folder" of information for the patient, secondary care and GP.

- The first section called "My History" gave information and education about the patients' diagnosis, previous investigations and surgery, medication, diet, co-morbidities and social history. This enabled patients and clinicians to gain a greater understanding of the past IBD medical history.

- The second section: "My plan" informed patients and GP's of how to make contact with secondary care services to gain advice when needed and how to initiate treatment modifications. The information contained within "My plan" detailed current medication, planned changes to treatment, investigations to be carried out, planned surgery, medication monitoring, and general health guidance, follow up arrangements and referrals and a communication plan and feedback opportunity.

- The final element of "My folder": "My update" was a documentation of any contact with the gastroenterology department either by clinic appointment, telephone call or email. It detailed the symptoms, medication, investigation results and the GP correspondence.

Intervention patients choose to receive this information via email or in paper form. As part of the intervention, facilities to provide feedback and update secondary care about any clinical changes was available to patients and GPs via a secure NHS email Elijah.gastro@ wales.nhs.uk. This provided the patients and the GP practices participating in ELIJAH use of email to answer queries and receive advice or triage.

Each report was saved automatically in GeneCIS as an ELIJAH report in the patient longitudinal record.

Who

Our multi-disciplinary research team included my participation as an Advanced Nurse Practitioner and researcher, and a Consultant Gastroenterologist, Computer Scientist, local GP, Trial Manager, Health Economist, Research Methodologist and Nurse Academic. 
I undertook the collation of the patient data, input into the questionnaires, production of the reports and dissemination of the elements of "My Folder" to the intervention patients, GPs and secondary care clinicians. I was a band 8A Advanced Nurse Practitioner (ANP) with experience as an IBD Specialist Nurse and had cocreated the GeneCIS ELIJAH extension. No specific education or training was therefore given for these tasks. I had experience of reading and deciphering the hospital paper and electronic notes and navigating the other patient information systems.

We did not provide additional training in secondary care to members of the multi-disciplinary team involved in the care of the intervention patients i.e. Consultant Gastroenterologists and Colorectal surgeons, Registrars, Junior Doctors, Specialist Nurses, Ward and outpatient Nurses, Dieticians and Pharmacists as the information provided was a summary and explanation of care, and was a new format, rather than additional information. The inclusion of educational information alongside the clinical information was thought sufficient to inform secondary care clinicians if they were unfamiliar with the IBD terminology.

In primary care, patient GPs had agreed to be part of the trial implementing the intervention, and so they had information on the structure and format of the reports. GP interest and support for the project was crucial. We involved a GP within our research team to ensure GP's and their practice views were taken into account when designing the intervention. The information we gleaned about systems of working in primary care was used to ensure that the ELIJAH intervention dovetailed with their existing processes rather than added bureaucracy or duplication. Other members of the primary care team e.g. District and Practice Nurses, Health care support workers and Pharmacists may have come into contact with the reports, but this was less likely than the patient GP, and we presumed that the educational content would suffice to render the reports understandable.

\section{How}

The customised ELIJAH report outputs; "My Folder" were shared with the patient and their GP, either electronically or in paper form.

Intervention patients decided to receive the reports by post or via email or both, and GP's received the intervention by post. I sent all of the correspondence in 
paper form with an accompanying letter or in electronic form attached to a formatted email.

The ELIJAH reports were stored within GeneCIS under each individual patient record automatically and were available to be viewed by clinicians accessing GeneCIS. A print out of the reports was also filed into the hospital paper record.

\section{Where}

Participants for the trial were recruited from one Gastroenterology Department located within Neath Port Talbot Hospital, a District General Hospital operating within the Local Health Board scenario of NHS Wales. All patients had a confirmed diagnosis of inflammatory bowel disease and were under the specialised out-patient secondary care of two local Gastroenterologists. The patients were also registered to the practice of six local GPs who had agreed to participation in the trial.

\section{When \& how much}

The intervention was delivered four times over a six month intervention period. The first intervention episode was at the trial commencement, and then bimonthly.

The first time the intervention was delivered "My History" and "My Update" was sent to patients and GPs. At the subsequent intervention periods these elements of "My Folder" were re-sent, and were updated if changes had occurred that influenced the information they contained during the two months since the last intervention was delivered. If the patient had a secondary care appointment e.g. outpatient clinic, endoscopy, blood results, then "My Update" was sent additionally to give information and results of the test or appointment. If no changes had occurred during the two month gap between sending the intervention, the intervention was still sent.

\section{Tailoring}

The intervention was tailored and personalised for each patient according to their medical history and care plan. The ELIJAH IBD reports contained individualised information retrieved and collated from the patients' paper and electronic notes. Therefore, no two interventions were identical, but each 
intervention followed the same structure and format as the same questionnaires were answered to formulate the intervention.

Patients chose to receive the intervention in paper or electronic form according to their preference.

\section{Modifications}

The intervention was modified following the original ethics application. Initially we requested permission to enable patients to view their IBD record within GeneCIS by direct access through the NHS firewall and security. When we explored this further we found that the time needed to develop the technology to enable this, and the financial costs required proved impracticable. We had been awarded a research grant for the trial, but the strict stipulations stated we had only one year to complete the study and only $£ 75,000$ as the budget and we recognised that we could not carry out the planned intervention within the time period or budget. We therefore applied for an amendment to our application to reflect a more pragmatic and achievable intervention. We were successful in our application to produce "My Folder" as the intervention.

Initially we enrolled four GP surgeries to yield 61 participants with a 2:1 ratio in favour of the intervention. Due to a less than anticipated recruitment rate we extended the number of GP practices to six. This action delivered the required number of participants.

The intervention was piloted before implementation in July and August 2010 and revised in light of the patient feedback gathered. The intervention was deemed usable, efficient and effective and the few minor layout and content adjustments were made. 


\subsection{Findings}

\section{How well}

The ELIJAH intervention; "My Folder", and the three sections contained within the folder: "My history", "My Plan" and "My update" were designed and created as planned (see figure 4. ELIJAH research project timeline). Elements crucial to the development of the intervention i.e. the agreement of the clinical and IT specifics of the intervention, customisation, piloting and sourcing of the linked education component are highlighted in figure 4.

\section{Figure 4. ELIJAH research project timeline.}

Summary of timeline

\begin{tabular}{|c|c|c|}
\hline TASK & ACTION & FINISH \\
\hline \multirow[t]{4}{*}{ ETHICS.R\&D } & APPLICATION & 24.12 .09 \\
\hline & INTERVIEW & 22.01 .10 \\
\hline & PT LEAFLET \& CONSENT & 05.02 .10 \\
\hline & NHS R\&D & 05.02 .10 \\
\hline \multirow[t]{8}{*}{ SHINE FUNDING } & APPLICATION & 02.11 .09 \\
\hline & INTERVIEW & 09.12 .09 \\
\hline & MEET SPRINGFIELD CONSULTANCY & 08.01 .10 \\
\hline & HEALTH CHECK & 04.02 .10 \\
\hline & CONTRACT & 03.02 .10 \\
\hline & APPOINT PROJECT MANAGER 0.4 & 01.02 .10 \\
\hline & CONFERENCE AWARD & 25.02 .10 \\
\hline & DASHBOARD & 01.02 .11 \\
\hline \multirow[t]{6}{*}{ OUTCOMES } & PT SATISFACTION QUESTIONNAIRE & 26.03 .10 \\
\hline & TESTING Q & 12.03 .10 \\
\hline & ADVERSE EVENTS & 15.04 .10 \\
\hline & COST & 09.02 .10 \\
\hline & TIMELINESS & 19.03.10 \\
\hline & EQUITY & 19.03.10 \\
\hline \multirow[t]{2}{*}{ INTERVENTION } & AGREE SPECIFICS \& CUSTOMISE & $\underline{25.06 .10}$ \\
\hline & REVISE INTERVENTION \& PILOT & $\underline{07.07 .10}$ \\
\hline \multirow[t]{4}{*}{ RECRUITMENT } & IBD PT LIST GENECIS & 17.12 .09 \\
\hline & IBD PT LIST BY GP & 20.12 .09 \\
\hline & GP RECRUITMENT & 12.02 .10 \\
\hline & GP INFORMATION LETTER & 06.02 .10 \\
\hline \multirow[t]{6}{*}{ FOCUS GROUP } & ADVICE FROM PROF F RAPPORT & 10.02 .10 \\
\hline & PATIENT RECRUITMENT & 11.03 .10 \\
\hline & HOLD FOCUS GROUP & 26.05 .10 \\
\hline & FULL TRANSCRIPTION & 10.11 .10 \\
\hline & ANALYSES & 13.02.11 \\
\hline & REPORT & 12.04 .11 \\
\hline \multirow[t]{3}{*}{ PATIENT EDUCATION } & SOURCE EDUCATION PACKAGES & $\underline{28.02 .10}$ \\
\hline & NACC VISIT TO NPTH & $\underline{\underline{29.01 .10}}$ \\
\hline & REVIEW EDUCATIONAL & \\
\hline & & \\
\hline ECKUITMENT & SEND LETTERS & 02.06 .1 \\
\hline
\end{tabular}


We worked well in collaboration with the IT Scientist, and together created a clinically accurate and administratively usable extension of our electronic health record to create the ELIJAH reports. The questionnaires were functional and worked to capture and store the inputted information.

Piloting of the intervention, by two patients not eligible for inclusion in the main train, prior to roll out, enabled fine tuning of the layout and content of the intervention and ensured patient participation in the assessment of the quality of the intervention.

We accessed all patient information from the paper and electronic record in secondary care to populate the ELIJAH questionnaires and were able to send the reports to patients and GPs, and store the reports in the secondary care notes and within the GeneCIS system. We recorded the time each step took to produce the reports and logged this as a direct cost of the intervention.

All processes of the development of the intervention were reported monthly to the trial research team, and the trial manager ensured the intervention adhered to the development and implementation quality assurance process.

\section{Actual}

Fidelity of the intervention was high and we delivered the ELIJAH "My Folder" components as planned to the 41 intervention group participants. All participants and their GPs received the intervention four times over the six month trial period. The ELIJAH reports were stored within the individual patient longitudinal health record on GeneCIS and were accessible to secondary care clinicians via GeneCIS and via the paper-based hospital notes. No patients or GPs reported not receiving the reports. 


\subsection{Discussion}

We created the three part electronic folder containing the clinical history (“My History"); management plan ("My Plan"); and an update after planned and unplanned appointments and contacts ("My Update") by pragmatically extending our existing electronic health record and creating electronic questionnaires. We used the existing facility of GeneCIS to produce endoscopy reports via the completion of questionnaires, and wrote original questionnaires for IBD and linked educational content. We used the existing capability of GeneCIS to convert questionnaire information into WORD format and store information in a longitudinal electronic patient record.

The content for the questionnaires was derived from data already held on our electronic system and supplemented by data extracted from paper records and other departmental systems. We presented the IBD reports in a user-friendly and comprehensive format and supplemented the clinical information by automatically linking portions of relevant peer reviewed educational material.

\section{Strengths and limitations}

The development of the ELIJAH intervention "My folder" and its constituent parts was designed, revised, developed and implemented into a finalised useable product within the allocated budget and on time. The ELIJAH research team and especially the trial manager helped ensure that deadlines were met and progress was feedback regularly, however, the intervention was resource-intensive to develop in terms of cost and time.

We were helped to develop the intervention by primary and secondary care clinical and organisational support for the intervention, and the collaborative team working with Jane Morgan and Hayley Dickinson. It was helpful that the Principal Investigator of the project and I, had both used GeneCIS extensively over a long period of time to support our clinical practice and so were very familiar with the existing functionality of the system and the opportunities the programme presented.

We used the existing structures within GeneCIS pragmatically to build the intervention. Other systems potentially could have constructed a similar product but we did not explore this. We built new layered clinical questionnaires using IBD content and educational attachments to produce "My Folder". This process was 
largely dictated by the constraints of the software system we used i.e. GeneCIS, but the content of the questionnaires and the addition of structured educational content was novel. We understood that GeneCIS, as a generic EHR, already supported other specialties other than endoscopy i.e. urology services, and so surmised that the adaption to provide IBD reports would be feasible.

A limitation of our building of the intervention within GeneCIS is that we did not build the intervention according to national guidance or IT standards available in 2010 and this could have influenced the design, content or format. We relied on the IT developers to ensure the system complied with the most recent guidance available. As a result we may have missed an important quality recommendation that could have enhanced the intervention.

The inclusion of the patient voice throughout the development and evaluation period brought a rich and very valuable contribution to the intervention. During initial discussions and planning of the intervention we relied heavily on the patient feedback gained during the IBD focus group (see chapter two). In the sourcing of the IBD peer reviewed educational content we worked in partnership with the largest IBD charity in the UK and were very fortunate to have personal interest in the project from their Chairman. This allowed us to use reliable portions of existing IBD education to link to the individualised clinical data presented in the reports. In the testing and refinement of the intervention useful feedback was gained by the piloting of the intervention by two patients, but we did not formally evaluate the pilot intervention.

The intervention, whilst IBD specific, could if adapted be readily transferrable to other chronic disease patient groups e.g. diabetes and asthma. The principles of delivering individualised patient information in a three-part folder of "My History", "My Plan" and "My Update” with adjoining sections of educationally enriched information would be applicable to most long-term health conditions, particularly those that relapse or remit, and as such require an enhanced degree of patient information and understanding to help improve patient self-care. 


\subsection{Conclusion}

Within this chapter I have relayed how we designed the ELIJAH intervention and produced a tri-part folder of individualised and educationally enriched IBD information. We have demonstrated how the intervention was piloted by patients and refinements to the intervention made. We have acknowledged that there was little evidence, in 2010, of the testing of interventions in this field, and so we recognised there was need for rigorous testing of the intervention. 


\section{Chapter four: ELIJAH: a pragmatic randomised controlled feasibility trial}

In the previous chapter I discussed the evolution of the intervention from concept to product. In this chapter, I will discuss the application and initial testing of the intervention in a pragmatic randomised controlled feasibility trial.

Patients with inflammatory bowel disease (IBD) are routinely given generic information leaflets about their condition. The IBD Standards Update 2013, standard D: Patient Education and Support, emphatically advocates the distribution of educational literature to patients, stating that:

"All patients should be offered appropriate information about their care and treatment options at all stages of their illness" P20.

The introduction (chapter one) showed that these standard IBD educational publications often offer a background and overview of the relevant condition and are distributed to aid self-management of symptoms, but can however only give limited usable information to guide individualised patient care. This was further confirmed through patient feedback from our focus group work (which is reported in chapter two). This identified that patients- want more individualised information and knowledge about their condition, and detailed usable guides at time of need (such as during a flare-up of their condition) to take greater responsibility for their health care.

In the light of this, with the help of colleagues, I developed a method to provide personalised information to each patient, tailored to their own condition (described in chapter three). I then tested the effectiveness of this approach. In this chapter I will discuss the initial evaluation of this personalised information (the intervention), in a randomised controlled feasibility trial. I will further go on to evaluate my findings with regards to designing a fully powered definitive trial. 


\subsection{Background \& objectives}

To date there has been limited research to explore the usefulness of interventions which provide tailored patient information. Wright Oliver et al (2001) explored pain management for cancer patients and found that an individualised coaching and education package proved beneficial in reducing pain. Chi et al (2012) individualised the recommendations of types of lifestyle interventions to reduce cardiovascular risk and offered an IT system to predict the most likely effective educational package. Neither of these studies looked at a gastro-intestinal patient population, and to date there is a paucity of evidence about the development, use and outcomes of using individualised information in gastroenterology.

Having developed an approach to generate personalised educational information, the main study aim was to learn lessons from the trial processes, acceptability of the intervention and costs that would inform and determine the feasibility of running a fully powered randomised controlled trial of this intervention in patients with inflammatory bowel disease.

From discussions with IBD patients in clinic and their GPs, we identified that patients regularly requested additional information about IBD i.e.: detailed information of diagnosis and treatments, the disease process and what to action to take if a flare occurred. Whilst this detailed useful clinical information is often held within the patient paper based notes, there can be problems accessing the relevant pertinent information e.g. because of the volume of notes, disordered filing in terms of chronology and specialty grouping, missing information and time available to search. Information within the notes can be illegible or poorly structured with undefined standardisation and this can lead to further issues accessing information when needed. An example of hospital paper-based notes can be seen in figure 5 . 
Fig. 5 Example of paper-based hospital notes

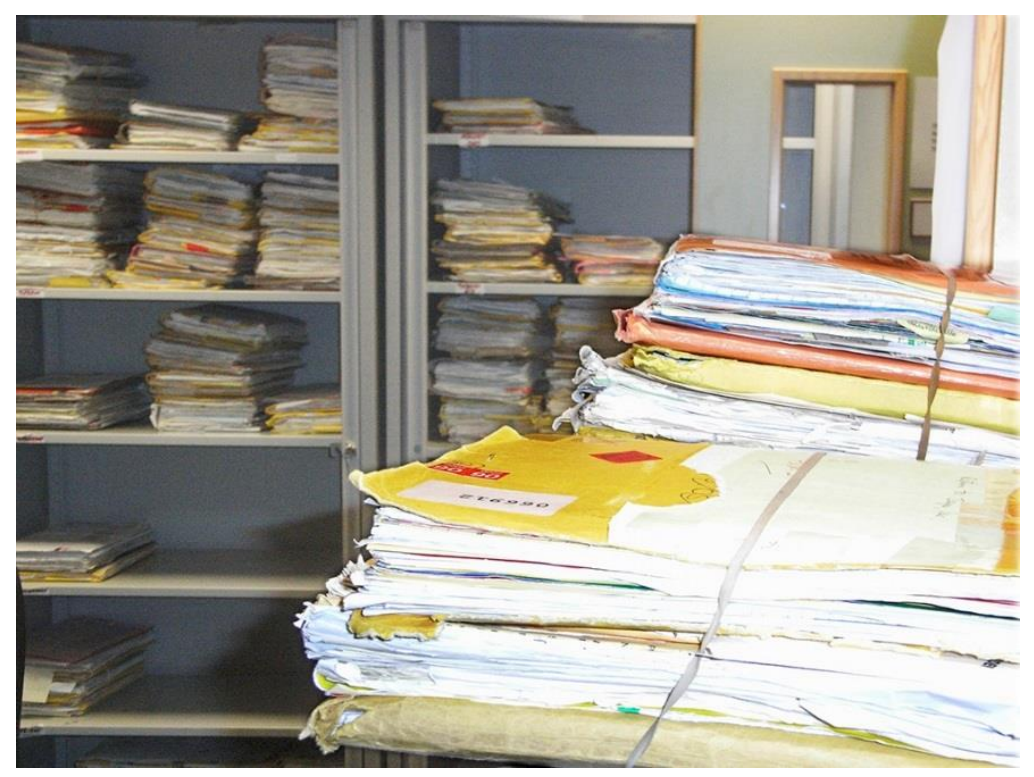

Electronic Health Records can overcome some of these issues (Litvin 2007), but many are based on an electronic replication of the paper record and so have many of the same inherent problems. There are few paper or electronic systems that provide a summary of disease history and prescribed programmes of action to be taken in the event of an increase in symptoms.

ELIJAH was developed to overcome these issues for clinicians whether in the primary or secondary care setting. It was aimed at providing individualised IBD summaries of disease history, plans for flares in symptoms and follow ups. The information was designed to be shared in the same format with patients so that patients, primary and secondary care clinical staff all had access to the same information.

We hypothesised that the implementation of the ELIJAH intervention could have possible benefits for participants, including:

- Increased empowerment arising from raised knowledge about their individualised care, gained from access to personalised reports about their health and care.

- Improved education and information about their condition.

- Improved education and knowledge about managing disease symptoms.

- Speedier access to services and advice at time of need. 
- Increased responsibility and empowerment for care decisions based upon evidence.

- More effective communication with health care professionals.

- More effective communication between primary \& secondary care professionals and patients.

- Better managed care.

- More patient centred services.

We tested these anticipated participant benefits by assessing the feasibility of the intervention, study processes and of data collection of the following outcomes: cost, patient satisfaction, safety, timeliness and equity to inform the development of a larger scale phase III trial.

The feasibility of a larger trial was tested according to the framework described by Lancaster (2015), defined by the National Institute for Health Research (2017) to answer the question "Can this study be done" (NIHR 2017 p. 2) and reported in line with the CONSORT 2010 checklist with extension for pilot or feasibility trials (2016) (see appendix 13).

Lancaster et al (2004) proposed that feasibility studies are a preparation for a fully powered phase III randomised controlled trial as demonstrated in the MRC Complex Intervention analysis (2010), see Fig 6. The pre-clinical phase, explained by the MRC in Fig 2, is described in chapter six - the literature review within this thesis, and phase I modelling within chapter two the qualitative focus group and chapter three the intervention. It is recognised that a feasibility is not the same as a phase II trial (described in Fig. 6 taken from Arain et al 2010), as a feasibility trial lacks adequate power to establish statistical significance. However, the feasibility study can help the likely success of a larger trial by testing the processes within the trial, intervention, data collection and outcome measures.

In a later publication (2015) Lancaster summarised the findings of the 2004 literature review into seven central potential outcomes of feasibility trials:

- to test the integrity of the study protocol

- to gain initial estimates for sample size calculation

- to test data collection forms or questionnaires

- to test randomisation procedure(s) 
- to estimate rates of recruitment and consent

- to determine the acceptability of the intervention

- to select the most appropriate primary outcome measure(s)

We assessed the feasibility of our study by testing the development of the intervention and its acceptability by patients. We tested the feasibility of completion of the patient questionnaire and researcher data collection forms, and assessed rates of recruitment, consent and drop-out. We also assessed each outcome measure to identify the most appropriate primary outcome measure for the main trial and to determine if any outcomes were inappropriate to extend to a larger trial.

\section{Fig. 6 MRC Complex Intervention Analysis}

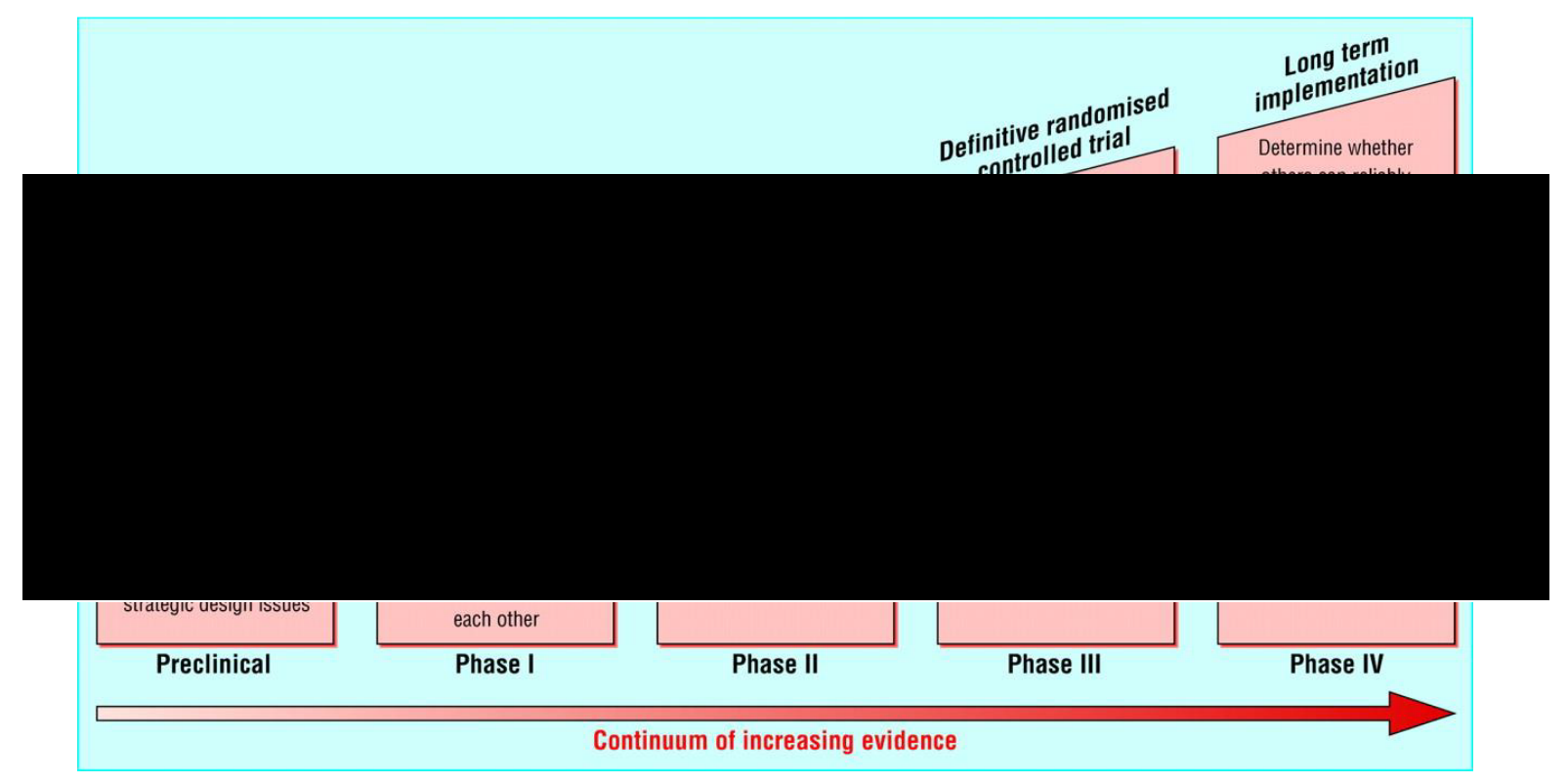

(MRC, Taken from reference Arain et al 2010 ) 


\subsection{Methods}

We designed this study in order to establish the feasibility of a fully powered randomised controlled trial to evaluate the clinical effectiveness and cost of the ELIJAH intervention.

\section{Participants}

Patients from Neath Port Talbot Hospital, Abertawe Bro-Morgannwg University Health Board (ABMUHB) were invited to participate in this feasibility trial. Recruitment began in July 2010 with the study final follow up finishing in January 2011.

Of the 77 GP practices in ABMUHB 24 are in the Neath Port Talbot area. These GP practices were judged more likely to have patients who had attended Neath Port Talbot Hospital for their IBD care as they had a direct referral pathway to gastroenterology services at Neath Port Talbot Hospital. Primary care engagement and involvement was crucial to the project, and advice and support was sought from the outset via the involvement of a GP within the research team. The GP advised of GP practices most likely to respond favourably to an invitation for their patients to participate in the study. We did not approach GP practices whose patients with IBD had been participants in the ELIJAH focus group to reduce the risk of bias (see chapter 2). Four GP practices were initially contacted and sent an invitation letter and the ELIJAH protocol and participant information sheet. These four practices agreed to participate in the study, but the yield of participants was low and so two additional practices were included.

The eligibility criteria for inclusion for patients in the ELIJAH feasibility trial, were:

- $\quad$ aged between eighteen - ninety years

- a confirmed diagnosis of IBD (specifically Ulcerative Colitis, Crohn's disease or proctitis), diagnosed via endoscopic assessment and / or radiological investigation plus histological evidence;

- on-going and recent follow up (within 18 months of the start of the trial) for IBD care at Neath Port Talbot Hospital (either via out-patient clinic, telephone review or postal review);- 
- under the care of one of six participating GP's practices within the Neath Port Talbot area.

Eligible patients were identified from the searchable coded patient database available at Neath Port Talbot Hospital (GeneCIS). The patients' electronic record in GeneCIS was then cross-checked against their diagnoses and histological reports in both their paper based medical records, and the histology electronic database INDIGO 4 Review.

Patients' records were also checked to ensure that they were still under the care of NPTH. This was done by checking on GeneCIS the date of the last recorded clinical contact with the gastroenterology department. Those patients who had been seen in a gastroenterology out-patient clinic or had postal or telephone consultations since December 2008 at Neath Port Talbot Hospital were included for potential randomisation and formed the potential sample patient list.

The six GP participating practices were: Briton Ferry Health Centre, Castle surgery, Dyfed Road Surgery, Riverside Surgery, Skewen Medical Centre and Vale of Neath Practice (see Figure 7).

Fig. 7. Location of participating GP practices, demonstrating the location of Neath Port Talbot area in Wales, and the location of ELIJAH participating GP surgeries within Neath Port Talbot.

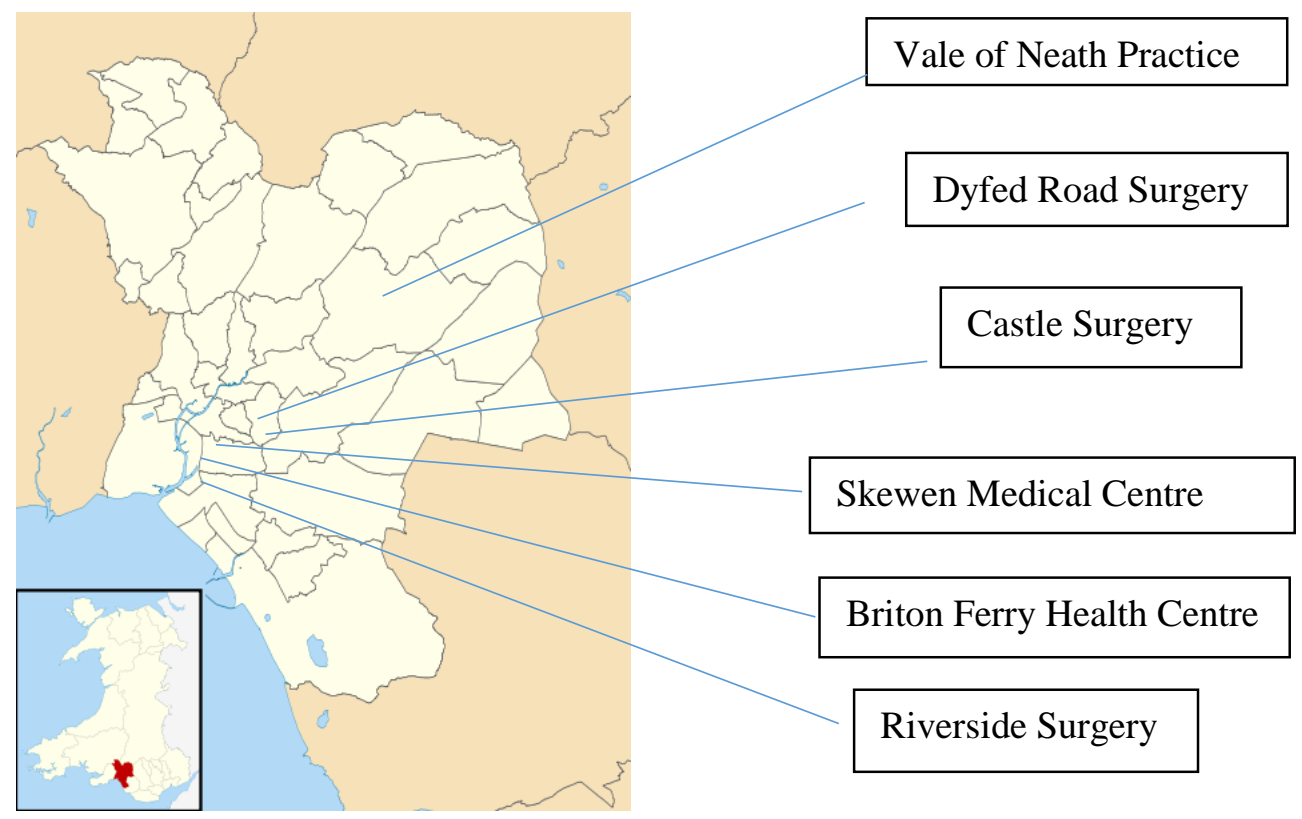


Patients deemed ineligible for participation in the feasibility trial were: those that did not meet the eligibility criteria in terms of age, diagnosis, follow up care, or GP practice; and those that could not comprehend the study.

Eligible patients were invited to participate by letter containing the ELIJAH participant information sheet (see appendix 3) and consent form (see appendix 4). The GPs of eligible patients were simultaneously sent a GP information letter and summarised protocol.

We sought consent from all eligible patients prior to their participation in the study. Consent was obtained at a face to face appointment at Neath Port Talbot Hospital gastroenterology department (the patients usual care centre for IBD). As the appointment was supplementary to their normal clinical appointments a nominal one-off payment of $£ 20.00$ was made to patients to cover their travel costs. At this appointment, we provided further clarification of the participant information sheet if required and answered any questions posed prior to informed consent being taken, including verbal re-iteration of the participant conditions of withdrawal from the study. We clarified that identifiable data already collected with consent would be retained and used in the study, but no further data would be collected or any other research procedures carried out on or in relation to the participant following withdrawal.

\section{Randomisation: sequence generation}

Following written consent, eligible participants were randomly assigned to receive either the control or the intervention. We used a web-based remote randomisation service run by Bangor University which allocated the patients between the groups. To ensure that the groups were balanced in terms of demographics we also stratified the groups by GP practice, gender and under or over retirement age (65). We randomised the patients in real time following consent.

We chose to randomise participants to a 2:1 ratio interval in favour of the intervention. This was to reduce the potential effect of any participant drop-out from the intervention group as the study had small numbers, and we wished to give the intervention to as many participants as possible, within our limited financial budget, to gain sufficient information and understanding of the intervention. Dumville et al (2006) reviewed 65 trials with an unequal randomisation ratio and found that where 
justified, other studies had an unequal ratio for similar reasoning, and moreover they recommended that more studies consider an unequal ratio to benefit the study assessment.

Remote randomisation protects against bias in the allocation of patients between groups. To protect against bias occurring before randomisation the patient participant sheet we gave stressed the equality in distribution (see participant information sheet and consent form appendix 3 and 4). Clinical staff sought and took consent, in accordance with Good Clinical Practice (GCP) guidelines and verbally reinforced the randomisation equipoise. To limit bias in the analysis and reporting of the trial, the trial statistician remained blind to patient allocations throughout analysis.

\section{The control}

The control group received care as usual for IBD follow up. In Neath Port Talbot Hospital gastroenterology department and many secondary care services across the U.K. this includes pre-scheduled follow-up outpatient clinic appointments and / or postal review, access to the telephone triage service and investigations and in-patient admissions as necessary. In primary care, care as usual included prescheduled or emergency appointments with GPs at the practice, home visits, appointments with the wider multi-disciplinary health team and investigations.

\section{The intervention}

The intervention group received care as usual plus the intervention. The intervention consists of an individualised inflammatory bowel report; "My Folder", made up of three parts; "My History", "My Plan" and "My Update". "My History" detailed participant's disease history and progress, "My Plan" offered guidance on actions for self-management during an increase in symptoms, and "My Update" provided a report of any follow up. There was also email access established for intervention patients and GPs used for helpline advice (appendix 5, 6 and 7).

The intervention was implemented across primary and secondary care. Patients, GPs and secondary care multi-disciplinary teams received the same personalised, educationally enriched patient reports. The membership of a GP within the research team enabled careful identification of the clinical information needs for GPs for IBD patients. 
The intervention group received 'care as usual' plus the intervention. We sent reports containing information about the patients' condition including educational material which offered explanation of clinical terminology, advice on health and lifestyle matters. We compiled the reports using the existing standardised patient clinical information which was gathered from the paper and electronically held hospital notes, and we loaded the information in the ELIJAH questionnaire and generated a WORD report that automatically joined the clinical information with relevant educational material. We generated the reports electronically from the patients' individual clinical record held within GeneCIS. More detailed information regarding the development and implementation of the intervention is described within chapter three.

The ELIJAH intervention patient report was produced in three parts, and collated to form a product; "My folder", of information for use by the patient, GP and secondary care team:

- The first section "My History" (example in Appendix 5) gave detailed information and education about diagnosis, previous investigations and surgery, medication, diet, co-morbidities and social history. This enabled patients, GPs and the secondary care team to gain a greater understanding of the past inflammatory bowel disease medical history.

- The second section "My Plan" (example in Appendix 6) informed patients, GP's and the secondary care team how and when to contact secondary care services to gain advice when needed and how to initiate treatment modifications. The information contained within "My Plan" detailed current medication, planned changes to treatment, investigations to be carried out, planned surgery, medication monitoring, and general health guidance, follow up arrangements and communication plan and an opportunity for feedback.

- The third section "My Update" (example in Appendix 7) provided an electronic report of any contact with the gastroenterology department, whether it be a consultation, telephone call or email. It detailed the symptoms, medication, investigation results and the GP correspondence.

At the start of the trial, intervention patients, their GPs and secondary care providers were sent the ELIJAH first two sections: "My History" and "My Plan". At 
their subsequent three follow up correspondence (at two, four and at six months) we reviewed the patients' paper and electronic notes to identify if there had been any change or review of their care and produced and then sent the additional final element of "My Folder" - "My Update" if appropriate.

Patients were given the choice to receive "My folder" and its components via email and /or in paper form sent through the post. In an accompanying cover letter sent with the intervention to the participants we detailed the elements that "My folder" included and requested that participants contact us should there be any inaccuracies of information provided.

In addition to the intervention, facilities to provide feedback and update secondary care about any changes were made available to patients and GPs via a secure NHS email Elijah.gastro@ wales.nhs.uk. This provided intervention patients and the six GP practices participating in ELIJAH use of email to ask questions, have queries answered and receive advice or triage to secondary care services. Update of condition symptoms or contact with health professionals were also reported via the secure email.

The adherence to and the fidelity of the intervention was tested and reported upon using the TIDIER checklist (see chapter three).

\section{Data collection}

We collected data using three specifically designed forms; the "ELIJAH Data Abstraction Form DAF" (see appendix 8), the "ELIJAH Adverse Events Form" (see appendix 9) and the "Inflammatory bowel disease Service Satisfaction Questionnaire (ISSQ)" (see appendix 10).

The "ELIJAH Data Abstraction Form DAF" collected information on the patient demographics and GP details, any contact with or visits to primary or secondary care services, medications prescribed and the time spent in preparing the ELIJAH "My folder" during the study. We used this combined data to test the feasibility of collecting total NHS cost used by the participants in the study period and timeliness to receiving care.

In primary care we noted visits to GPs, out of hours services and appointments with other members of the multi-disciplinary team. 
In secondary care we amassed information on services accessed i.e. open access services (via telephone or email helplines or unscheduled drop in), outpatient clinics, multi-disciplinary team appointments (e.g. physiotherapy, dietician), emergency admissions to accident and emergency or minor injuries units, investigations and in-patient episodes.

For all primary and secondary care contacts or visits we determined from the patients records the time and duration of when the patient recognised the increased or new symptom that caused them to seek help, when the symptom was reported and the time taken for primary or secondary care services to respond to the request.

We completed this data form at the end of the study and populated it by accessing primary and secondary care paper-based and electronic health records.

The "ELIJAH Adverse Events form" detailed any symptoms or problems reported by the patient and assessed seriousness of the issue and established if there was causality arising from the intervention. This information formed the safety assessment of the intervention. These data were collected on-going during the study by accessing the GeneCIS electronic patient record and the Patients Information Management system (PIMS) record 2 weekly to assess any report of symptoms or secondary care services accessed.

The "Inflammatory bowel disease Service Satisfaction Questionnaire" included the EQ5D (EuroQol five dimensions questionnaire https://euroqol.org/). This form was completed by all participants and their answers were scrutinised to assess the feasibility of collecting satisfaction regarding the IBD services accessed and the intervention.

We enquired as to whether patients knew their diagnosis and when they were diagnosed and assessed whether they had enough good quality usable information on their condition, accessing services at time of need, communication skills of health professionals, the quality of care received and their health-related quality of life.

We sent a paper based questionnaire which included the ISSQ (Inflammatory bowel disease Service Satisfaction Questionnaire and the EQ5D to the participants one week after they had received the intervention: "My folder". A stamped addressed envelope for return was included with the ISSQ. We collected information via the ISSQ on all participants at four time points - baseline and at two and four months and at the end of the trial (at six months from commencement), see Figure 8. 
Figure 8. ELIJAH flowchart which illustrates the number of patients identified and included in the study.

\section{ELIJAH flowchart.}

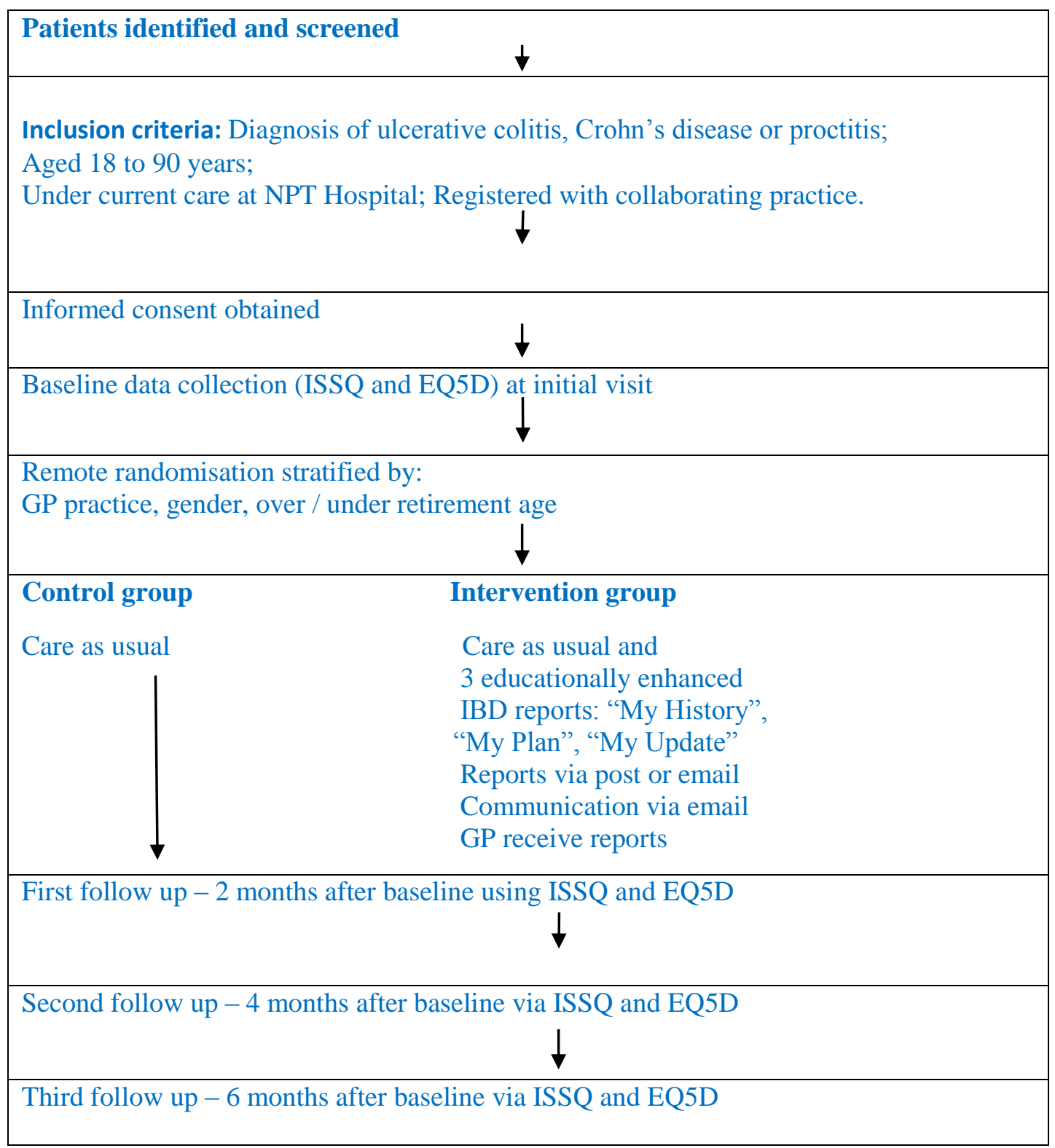




\section{Missing data}

We adopted a consistent approach and made efforts to keep missing data to a minimum.

We scoured the hospital paper and electronic patient records, and GP electronic patient records to find care episodes in the study period. We cross matched the information found to ensure a robust data set. We used these data to populate the ELIJAH Adverse Event form and Data Abstraction Form.

The ISSQ and EQ5D tools were patient reported. To minimise missing data we waited two weeks after sending the questionnaire to receive a reply, we then sent a two week reminder to patients who had not returned their questionnaire (see table 2 ELIJAH study Chronology). The patient questionnaires not returned two weeks after the reminder were treated as missing data. We employed three methods to impute missing data on a per question basis:

1. Last carried forward

2. When there was no initial score, but other scores existed for the participant, last carried back

3. When there was no score for a question for a participant, other similar questions were examined for a trend.

There were no exclusions from the analyses.

\section{Outcomes}

ELIJAH was run primarily as a highly pragmatic feasibility trial: assessing the practicality of running a trial of the intervention, using the methodology of the RCT within the allocated budget and timeframe, and applicability within the secondary care environment with the participating health settings, health professionals and patient group. We hypothesised that there may be many effects seen as a result of receiving the intervention and as such in this feasibility study we used questionnaires and methods to collect information on the outcomes of interest, not for definitive analysis but rather to determine the feasibility and practicality of collecting information for a full trial. 
The areas of feasibility for the main trial we looked at were:

- Whether we were able to recruit GPs and patients into the study

- If consent and randomisation could be carried out as proposed

- If there were any drop-outs from the study and if so why

- If we could collect data on the outcomes

- If the intervention assessment forms were completed fully and if not the amount of missing data

- The time and cost taken to produce the intervention

- Whether we could identify the most appropriate primary outcome, and as a result formulate a sample size needed for a fully powered phase III trial

These feasibility outcomes are in-line with the potential list of feasibility parameters stated by the NIHR "Guidance on Applying for Feasibility Studies" (2017).

Based on the hypothesised effects of the intervention we wanted to test the feasibility of collecting data on the following outcomes (see below). Because this was a feasibility study we did not identify a primary outcome measure but used our findings to try to identify one for the larger trial through our analyses of this study.

1. Cost - we looked at the cost of NHS resources used by participants in primary and secondary care, to identify whether the intervention reduced total NHS costs. We collected data from the patients electronic and paper based records in primary and secondary care for the six-month trial period, and documented any use of primary or secondary care including inpatient and outpatient episodes across all specialities, not just for IBD care, and added the cost of any medication prescribed. We added these joint costs to the cost of the nursing time taken to collate and prepare the ELIJAH reports. We used two national UK references to identify the precise costs: the PSSRU Unit Costs of Health and Social Care 2011, and the Department of Health National Schedule of reference costs 2010-2011. These individual costs were documented in the ELIJAH Data Abstraction Form (DAF) (see appendix 8). We collated and assessed the costs at two and four months and at the end of the trial. 
To calculate the costs, the direct cost of the intervention and time taken by the clinician to formulate the elements of "My folder" were analysed and were added to the indirect total NHS costs of the intervention which it brings about through altered patient use of other NHS services.

All direct and indirect costs were documented on-going on the ELIJAH Data Abstraction form (see appendix 8), and recorded participant details, hospital based services use, community based services use, medication, time to prepare the "My Folder" initially and subsequently.

\section{$\underline{\text { Direct costs }}$}

A costing exercise was undertaken which quantified and valued the resources used in implementing the innovation. It was surmised that the most likely clinicians to formulate the interventions within trials would be the Gastrointestinal Specialist Nurse (most likely salary Band seven pay-scale). These members of the multi-disciplinary team would have prior, on-going knowledge of the patients, could produce the individualised ELIJAH reports within their clinical activities and crucially be accurate in their assessment of the medical records.

The activities below which were carried out by a Gastrointestinal Specialist Nurse to formulate the ELIJAH intervention were cost assessed;

- preparation of a request for patient notes

- retrieval of patient notes

- reading of patient notes

- accessing GeneCIS

- data entry of the ELIJAH questionnaire on to GeneCIS

- printing and sending out ELIJAH notes to patients and GPs.

\section{$\underline{\text { Indirect costs }}$}

The indirect patient costs collected were inpatient stays, operations, outpatient clinics, GP appointments, investigations, open access service use and medication use. Data were collated from primary and secondary patient 
electronic and paper based records and were documented via the ELIJAH Data Abstraction Form.

2. Safety - we identified the number of adverse events (AE) leading to a hospital admission or that otherwise threatened the health and well-being of participating patients and that were reported to a health professional, to identify whether the causality or seriousness of an event was related to being in the intervention group. These data were collected by analysing the primary and secondary care records at two and four months from the trial commencement and at the end of the trial, and recorded upon the ELIJAH Adverse Event form (see appendix 9).

We used data from GP and hospital electronic and paper based records to obtain information relating to primary and secondary care attendances, including acute admissions to hospital. We were able to view all scheduled and unscheduled hospital and outpatient appointments. We used the ELIJAH Adverse Events form to record the adverse event description, categorisation and assessment of causality and seriousness of the event.

No stopping rules were included in the AE form; however it was assumed that due to the benign intervention nature an unexpected event with direct causality and seriousness would unlikely be due to the distribution to the patient of individualised health reports. However in the event of a suspected, unexpected serious adverse event, we agreed to report it to the trial research and development department within twenty four hours of the trial team becoming aware of the event.

3. Patient-centeredness - we assessed the satisfaction of participants with the IBD care they received at baseline, and then at two and four months and at the end of the trial. Each time point was one week after sending the intervention "My Folder" to the intervention patients. We wanted to know if it was feasible to collect information regarding patient satisfaction during the trial period and wanted to assess what patients felt about their sense of well being and their care.

We developed and piloted a questionnaire containing questions relating to satisfaction using the ISSQ, and quality of life using the EQ5D. 
Prior to implementation in ELIJAH we piloted the ISSQ in patients with inflammatory bowel disease who were not eligible to be participants of the trial because of GP practice exclusion. Patient comments and recommendations were incorporated into the final version.

We sent patients the ISSQ and the EQ5D at each of the time points (see appendix 10).The (ISSQ) contained twenty five questions in four sections. The four ISSQ sections of the questionnaire were: Your condition; Getting care when you need it; Quality of care you received recently; and General quality of the care you received. In addition five quality of life indicators were collected from the EQ-5D. Two open patient feedback boxes were also included to provide participants space to add any other information relating to their condition, treatment or experience which they deemed relevant (see appendix 10).

The ISSQ was derived from the Gastro-intestinal Endoscopy Satisfaction Questionnaire (GESQ) developed for, and validated in, the MINuET study (Cheung et al 2015).

4. Timeliness - we explored the feasibility of reviewing retrospectively, the average elapsed time between the onset of a new IBD-related issue needing health care for the participant and the start of that care. This was to determine whether we could assess if patients could better self-manage their care with the aid of the intervention in a large scale trial. We assessed the feasibility of collecting data on the time elapsed between patients recognising symptoms, reporting symptoms and receiving care for their symptoms. We recorded this information on the ELIJAH Data Abstraction Form (see appendix 8).

Data were collected on the speed of response to a patient reporting symptom, and were monitored via time differences between patients noting symptoms, duration of symptoms, patient reporting of symptoms and health professional reaction to the report of symptoms. We called this patient sequence of events the 3 R's: Recognition, Reporting and Response. Data were thus collected on the recognition of patient noting problems or increased symptoms, the time of reporting of symptoms and response time of health professionals to respond. 
The timeliness was captured within the ELIJAH Data Abstraction Form (used also for outcome 1 - cost).

5. Equity - we assessed the feasibility of collecting information regarding the social status of participants through documentation of their postcode against the Welsh Index of Multiple Deprivation 2011 for the Neath Port Talbot area (see appendix 11).

Postcodes of participants was split into 2 groups via a deprivation score.

\section{Sample size}

As the study was designed as a feasibility trial and not a definitive fully powered trial, we did not carry out a formal sample size calculation based on detecting a difference in the primary outcome measure (as we did not identify a primary outcome measure). The purpose of the feasibility study was to test processes for a larger phase III trial; to ensure the feasibility of undertaking a full-scale trial (i.e. ability to recruit patients, patient retention, data collection and processes of the study). From the literature written about feasibility studies Thabane et al (2010), offers clear guidance on how to conduct feasibility studies and states that a sample size calculation is not required for a study like this one, but rather the study participant groups should be;

"representative of the target study population ... (and) large enough to provide useful information about the aspects that are being assessed for feasibility". (p5)

and Lancaster et al (2002) suggests a number of "30 patients or greater to estimate a parameter" (p308), Tickle-Degnen (2013) supports this assertion and states that a small sample size is acceptable for feasibility studies.

On this basis we aimed to recruit at least 50 patients to the feasibility trial (out of an IBD population at Neath Port Talbot Hospital Gastroenterology department of 439), randomised in a 2:1 ratio in favour of the intervention.

\section{Ethics}

ELIJAH, as a feasibility randomised controlled trial with patient participation was classified as a research study. Full ethical and NHS Local Health Board research 
and development approvals were therefore sought and obtained before commencement of the study. The Integrated Research Application System (IRAS) application (reference number 09/WMW02/61) was submitted on December $23^{\text {rd }}$ 2009, and ELIJAH research team representatives (Phedra Dodds and Professor I. Russell) attended the South West Wales Research Ethics Committee (REC) meeting. The study was granted a full favourable ethical opinion on $5^{\text {th }}$ March 2010 (see appendix 12), following minor amendments to the patient information sheet and consent form (see appendix 3 and 4).

Following ethics approval, we submitted local Research and Development (R\&D) approvals. NHS R\&D office permission at ABMUHB was also granted. A further amendment to the protocol was submitted to REC and R\&D on 19/04/10. This amendment involved a change in the intervention. The original intervention was planned to allow patients' and their GPs access to their patient records directly into GeneCIS electronic patient system through the NHS firewall. However, feedback from the ELIJAH focus group (see chapter 2) reported that patients preferred being provided with patient educationally enhanced reports, which was developed as the ELIJAH intervention.

We ensured that care providers were adhering to the study by monitoring at regular intervals. The study was overseen on a day-to-day basis by the trial manager and monthly by the ELIJAH research management team. The study sponsor (ABMUHB) also provided governance oversight. Regular update reports were provided to The Health Foundation who funded the feasibility trial through their "Shine" programme.

\section{Study management}

Trial oversight and quality assurance of the trial was carried out by regular review in accordance with WWORTH (West Wales Organisation for Rigorous Trials in Health) approved standard operating procedures (SOPs). Because the duration of ELIJAH was only one year and was low risk, it was decided that WWORTH review would be more pragmatic and effective than setting up a data monitoring committee.

Independent scientific external review for ELIJAH was carried out via the funder of the trial: The Health Foundation as part of the competitive funding application to the SHINE Award programme. 


\section{Progression rules and stopping guidance}

The following criteria was explored to determine whether the ELIJAH feasibility study could be progressed to be designed as a fully powered phase III trial (see Table 1 ELIJAH progression criteria). The blue highlighted area within table 1 denote the ELIJAH feasibility criteria, the remaining criteria are clinical outcomes.

Table 1: ELIJAH progression criteria highlighting the ELIJAH feasibility criteria

\begin{tabular}{|c|c|}
\hline Criteria & Derivation \\
\hline $\begin{array}{l}50 \% \text { or more of individual clinicians } \\
\text { approached agree to take part in the } \\
\text { study }\end{array}$ & Determined from site records \\
\hline $\begin{array}{l}50 \% \text { or more of patients eligible to take } \\
\text { part in the study are consented }\end{array}$ & Calculated from patient screening data \\
\hline $\begin{array}{l}75 \% \text { or more of patients are consented } \\
\text { and randomised in real time at the same } \\
\text { appointment }\end{array}$ & Calculated from patient screening data \\
\hline $\begin{array}{l}\text { Less than } 20 \% \text { of patients drop out from } \\
\text { the study }\end{array}$ & Calculated from patient screening data \\
\hline $\begin{array}{l}\text { Data are collected on all outcome } \\
\text { measures for over } 80 \% \text { of patients }\end{array}$ & $\begin{array}{l}\text { Calculated from ISSQ and EQ5D, } \\
\text { ELIJAH Adverse Events form and Data } \\
\text { Abstraction form }\end{array}$ \\
\hline $\begin{array}{l}75 \% \text { or more of patient data for direct } \\
\text { and indirect costs (cost) can be collected } \\
\text { over primary and secondary care }\end{array}$ & $\begin{array}{l}\text { Calculated from the Data Abstraction } \\
\text { form }\end{array}$ \\
\hline $\begin{array}{l}\text { Adverse events show no Suspected } \\
\text { Unexpected Serious Adverse Reactions } \\
\text { (SUSARs) resulting from the } \\
\text { intervention }\end{array}$ & $\begin{array}{l}\text { Calculated from the ELIJAH Adverse } \\
\text { Events form }\end{array}$ \\
\hline $\begin{array}{l}\text { Less than } 20 \% \text { difference between the } \\
\text { intervention and control group for } \\
\text { adverse events, including Serious } \\
\text { Adverse Events (SAE) with causality } \\
\text { related to the ELIJAH intervention. }\end{array}$ & $\begin{array}{l}\text { Calculated from the ELIJAH Adverse } \\
\text { Events form }\end{array}$ \\
\hline $\begin{array}{l}\text { Patient reported data (ISSQ and EQ5D) } \\
\text { can be collected for more than } 75 \% \text { of } \\
\text { participants across the control and } \\
\text { intervention groups }\end{array}$ & $\begin{array}{l}\text { Calculated from the amount of missing } \\
\text { data within the Data Abstraction Form }\end{array}$ \\
\hline $\begin{array}{l}\text { Less than } 20 \% \text { difference between the } \\
\text { intervention and control group for } \\
\text { timeliness in recognition of symptoms, } \\
\text { reporting of symptoms and receiving } \\
\text { care }\end{array}$ & $\begin{array}{l}\text { Calculated from the Data Abstraction } \\
\text { Form }\end{array}$ \\
\hline $\begin{array}{l}\text { Feasibility study findings indicate that at } \\
\text { least } 3 \text { out of } 4 \text { outcome measures were } \\
\text { feasible to collect in the intervention }\end{array}$ & $\begin{array}{l}\text { Calculated from the ISSQ and EQ5D, } \\
\text { ELIJAH Adverse Events form and Data } \\
\text { Abstraction Form }\end{array}$ \\
\hline
\end{tabular}




group and the control group.
Identification of potential primary
outcome.
(The outcome measures are cost, safety,
patient centeredness, timeliness)

The criteria for judging the ELIJAH feasibility study a success is based on the analysis of the study feasibility outcomes (highlighted in blue) and the clinical outcome measures (without highlight) included in the table above. These criteria provide the basis for the analysis of the study and decision whether the advance to a fully powered phase III randomised controlled trial. Thabane et al (2010) suggest four feasibility study outcomes, which we have adopted as the decision model for progression to a phase III ELIJAH trial;

- Stop-do not advance to main trial

- Continue, but modify protocol

- Continue without modifications, but monitor closely

- Continue without modifications

\section{Descriptive statistical analysis}

The primary outcomes of ELIJAH are feasibility outcomes that will contribute toward the decision to plan for a fully powered, definitive phase III trial: cost, safety, patient centeredness, timeliness and equity.

As this study is based upon feasibility; with a small cohort size in both arms, and is not powered for the production of definitive statistically significant results, we did not include any comparative sub-group analysis in the results. Rather, we provided a brief descriptive analysis in numbers and percentages, and where applicable mean, standard deviation and range, of the study population based on the feasibility outcomes and clinical outcome measures. 


\subsection{Results}

\section{Patient recruitment and retention}

708 patients with a documented confirmed diagnosis for inflammatory bowel disease were screened against the eligibility criteria for inclusion in the study. 431 were excluded because they did not have their care managed in primary care by one of the participating GP practices. Of the remaining 277 patients:

- $3(1 \%)$ were excluded because they did not meet the inclusion criteria: 1 $(0.4 \%)$ because they could not comprehend the study, $2(0.8 \%)$ because they did not have documented IBD (one had a colectomy for reasons other then IBD, 1 had microscopic colitis),

- $37(13 \%)$ were excluded because they declined to take part in the study,

- $120(43 \%)$ were excluded because they had not attended Neath-Port Talbot Hospital in the previous 18 months for an IBD outpatient appointment and so were not current patients,

- 47 (17\%) did not answer the invitation letter.

Invitations for participants to attend for consent were sent between the $21^{\text {st }}$ of May 2010 and the $11^{\text {th }}$ June 2010. GPs were informed of which participants who were their patients and who had agreed to attend for the consent appointment between the $2^{\text {nd }}$ June 2010 , and the $22^{\text {nd }}$ June 2010 . Consent was held between $7^{\text {th }}$ June 2010 and the $27^{\text {th }}$ July 2010, (see Table 2: ELIJAH study chronology).

70 patients agreed to attend for consent, of these 61 attended, were consented and randomised in a 2:1 ratio in favour of the intervention, (see fig. 9 ELIJAH CONSORT diagram).

Participants commenced the trial between $20^{\text {th }}$ July 2010 and the $22^{\text {nd }}$ August 2010 .

There were differences between the dates for patient recruitment, sending of GP information, participant consent and study commencement, because we needed to include 2 additional GP practices to the original 4, because of lower than expected recruitment rates. 
Table 2: ELIJAH study chronology

\begin{tabular}{|c|c|}
\hline Activity & Date/s \\
\hline $\begin{array}{l}\text { Invitations for consent sent to eligible } \\
\text { patients }\end{array}$ & $21 / 5 / 2010-11 / 6 / 2010$ \\
\hline $\begin{array}{l}\text { GPs informed of their patients who had } \\
\text { agreed to take part in ELIJAH }\end{array}$ & $2 / 6 / 2010-22 / 6 / 2010$ \\
\hline $\begin{array}{l}\text { Patients consented and randomised at } \\
\text { Neath Port Talbot Hospital }\end{array}$ & $7 / 6 / 2010-27 / 7 / 2010$ \\
\hline ELIJAH study commenced & $20 / 7 / 2010-22 / 08 / 2010$ \\
\hline $\begin{array}{l}1^{\text {st }} \text { follow up: } 2 \text { months from } \\
\text { commencement of study } \\
\text { - } \\
\text { ELIJAH folder sent to } \\
\text { participants and GPs } \\
\text { - } \text { ISSQ and EQ5D sent to } \\
\text { participants } \\
\text { - } \text { ISSQ and EQ5D reminder sent to } \\
\text { participants who had not } \\
\text { responded and returned the } \\
\text { questionnaire }\end{array}$ & $\begin{array}{l}1 / 10 / 2010-5 / 10 / 2010 \\
25 / 10 / 2010 \\
9 / 11 / 2010\end{array}$ \\
\hline $\begin{array}{l}2^{\text {nd }} \text { follow up: } 4 \text { months from } \\
\text { commencement of study } \\
\text { - } \text { ELIJAH folder sent to } \\
\text { participants and GPs } \\
\text { - } \text { ISSQ and EQ5D sent to } \\
\text { participants } \\
\text { - } \text { ISSQ and EQ5D reminder sent to } \\
\text { participants who had not } \\
\text { responded and returned the } \\
\text { questionnaire }\end{array}$ & $\begin{array}{l}2 / 12 / 2010 \\
6 / 12 / 2010 \\
6 / 1 / 2011\end{array}$ \\
\hline $\begin{array}{l}3^{\text {rd }} \text { follow up: } 6 \text { months from } \\
\text { commencement of study } \\
\text { - } \\
\text { ELIJAH folder sent to } \\
\text { participants and GPs } \\
\text { - } \text { ISSQ and EQ5D sent to } \\
\text { participants } \\
\text { - } \\
\text { ISSQ and EQ5D reminder sent to } \\
\text { participants who had not } \\
\text { responded and returned the } \\
\text { questionnaire } \\
\end{array}$ & $\begin{array}{l}\text { 28/1/2011-1/2/2011 } \\
3 / 2 / 2011 \\
21 / 2 / 2011\end{array}$ \\
\hline $\begin{array}{l}\text { Completion of baseline and follow- } \\
\text { intervention patients received "My Folder" } \\
\text { full } 6 \text { months planned and was not ended p } \\
\text { feasibility objective and clinical objective } \\
\text { data from the control group and } 21 \text { sets fror }\end{array}$ & $\begin{array}{l}\text { ip questionnaires was achieved and all } \\
\text { on schedule. The study was run for the } \\
\text { ematurely, nor was stopped. Each } \\
\text { as reviewed using data from } 40 \text { sets of } \\
\text { n the intervention group (see fig. } 9\end{array}$ \\
\hline LLIJAH CONSORT diagram). & \\
\hline
\end{tabular}


Fig. 9. ELIJAH CONSORT diagram, adapted from Eldridge et al (2016)
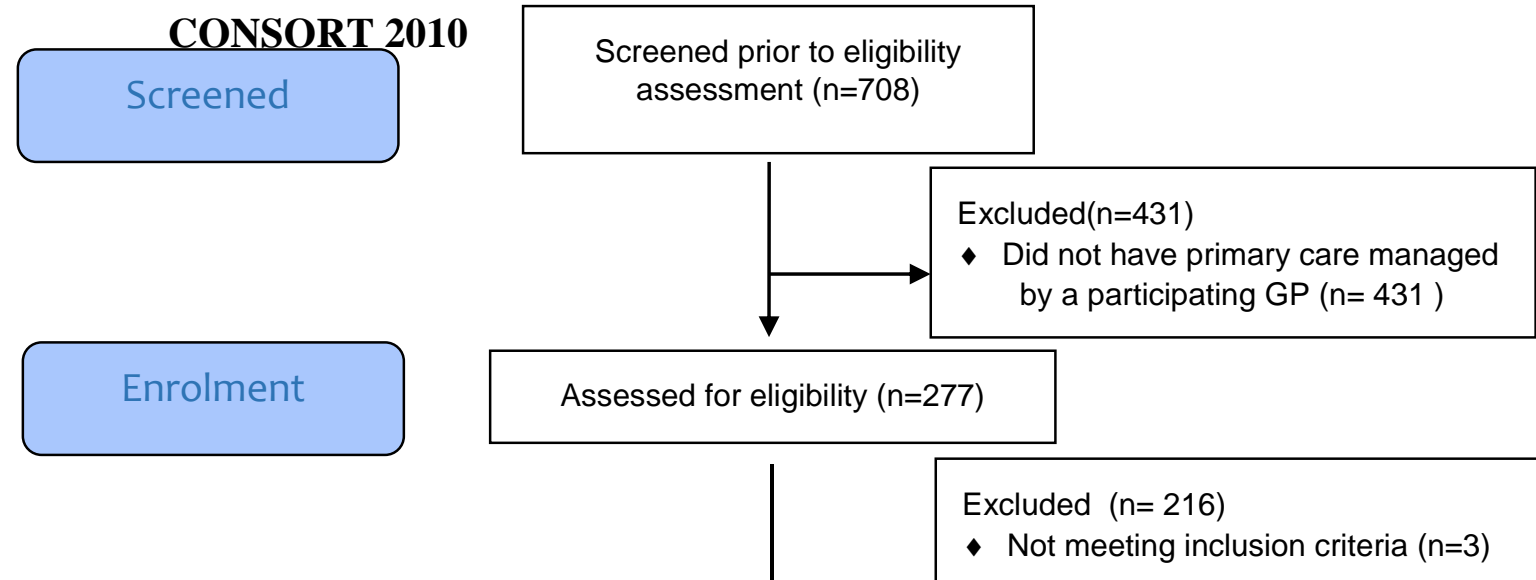

L

$A$
$A$
$A$
$A$
$A$
$p$
$A$
ti 
There was no negative feedback regarding the content of the intervention and no patient drop-out from the trial.

\section{Baseline data}

Details of the baseline demographics of the patients included in the study within the intervention and control groups are illustrated in Table 3. We collected data on the gender, age, diagnosis and deprivation score to determine the general characteristics of the ELIJAH patient group and looked at whether the findings would be generalisable compared to epidemiological data on IBD.

Table 3: ELIJAH participant demographics

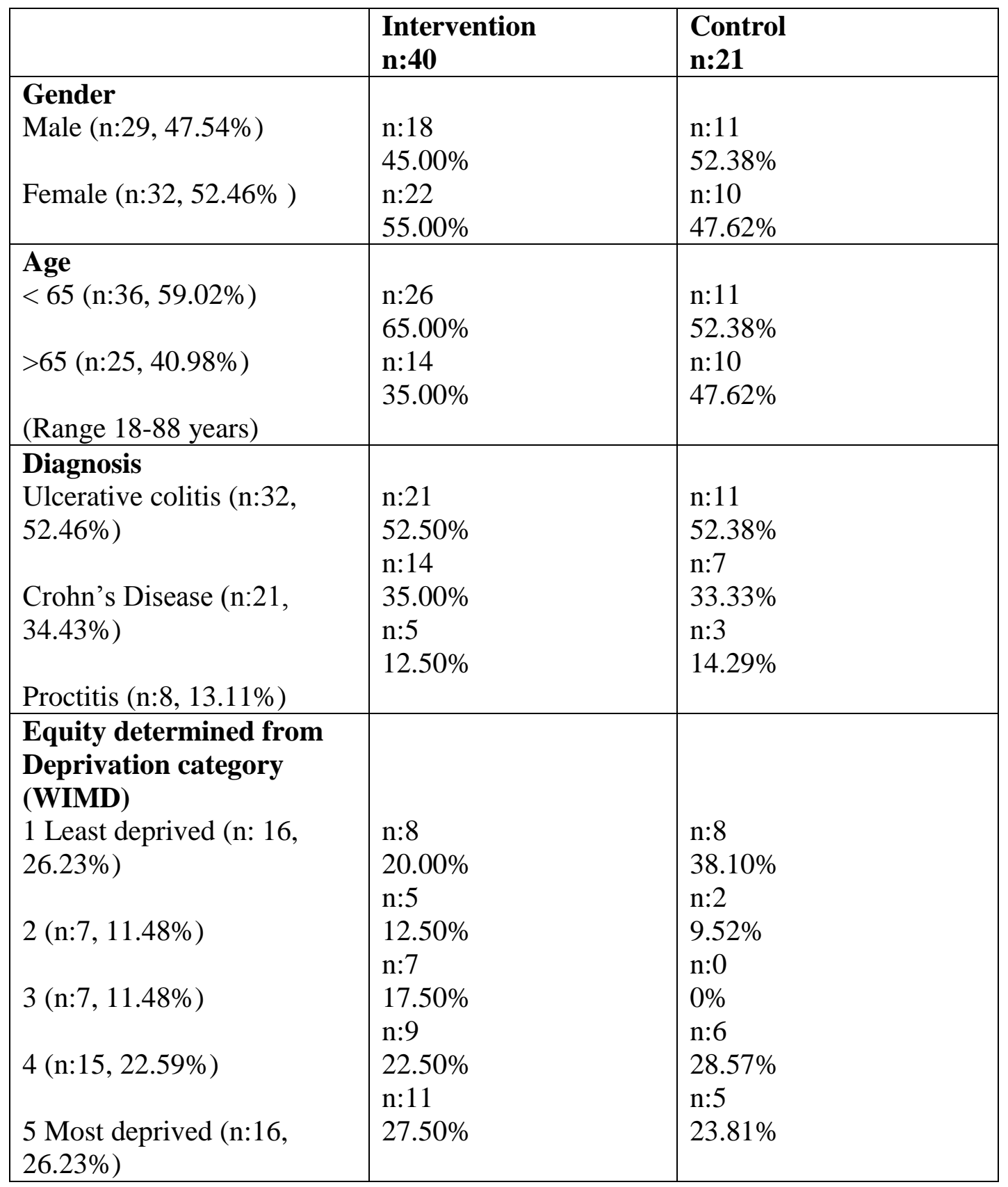


Table 4: ELIJAH participants by GP practice

\begin{tabular}{|l|l|l|}
\hline GP Practice & $\begin{array}{l}\text { Intervention } \\
\text { n:40 }\end{array}$ & $\begin{array}{l}\text { Control } \\
\text { n:21 }\end{array}$ \\
\hline Briton Ferry Health & $\mathrm{n}: 6$ & $\mathrm{n}: 3$ \\
Centre & $15.00 \%$ & $14.29 \%$ \\
(n:9, $14.75 \%)$ & $\mathrm{n}: 4$ & $\mathrm{n}: 1$ \\
Riverside Surgery & $10.00 \%$ & $4.76 \%$ \\
(n:5, 8.2\%) & $\mathrm{n}: 8$ & $\mathrm{n}: 7$ \\
Castle Surgery & $20.00 \%$ & $33.33 \%$ \\
(n:15, 24.59\%) & $\mathrm{n}: 9$ & $\mathrm{n}: 4$ \\
Skewen Medical Centre & $22.50 \%$ & $19.05 \%$ \\
(n:13, 21.31\%) & $\mathrm{n}: 4$ & $\mathrm{n}: 3$ \\
Vale of Neath Practice & $10.00 \%$ & $14.29 \%$ \\
(n:7, 11.48\%) & $\mathrm{n}: 9$ & $\mathrm{n}: 3$ \\
Dyfed Road Practice & $22.50 \%$ & $14.29 \%$ \\
(n:12, $19.67 \%$ ) & & \\
\hline
\end{tabular}

Participants chose how to receive the intervention "My folder" and its component parts: in electronic form via email, in paper form via post or both.

Table 5: ELIJAH participants by choice of contact method

\begin{tabular}{|l|l|l|}
\hline $\begin{array}{l}\text { Choice of contact } \\
\text { method }\end{array}$ & $\begin{array}{l}\text { Intervention } \\
\text { n:40 }\end{array}$ & $\begin{array}{l}\text { Control } \\
\text { n:21 }\end{array}$ \\
\hline Email & $\mathrm{n}: 15$ & $\mathrm{n}: 8$ \\
$(\mathrm{n}: 23,37.70 \%)$ & $37.50 \%$ & $38.10 \%$ \\
Post & $\mathrm{n}: 21$ & $\mathrm{n}: 11$ \\
(n: $32,52.46 \%)$ & $52.50 \%$ & $52.38 \%$ \\
Email and post & $\mathrm{n}: 4$ & $\mathrm{n}: 2$ \\
(n:6, $9.84 \%)$ & $10.00 \%$ & $9.52 \%$ \\
\hline
\end{tabular}




\section{Outcomes and estimation}

\section{Feasibility outcomes}

Feasibility outcomes are reported as numbers and percentages of the study clinicians and screened, eligible and consented patients (see Table 6: Results of ELIJAH feasibility outcomes).

Table 6: Results of ELIJAH feasibility outcomes

\begin{tabular}{|l|l|l|}
\hline Criteria & Findings & Result \\
\hline $\begin{array}{l}\text { 50\% or more of individual } \\
\text { clinicians approached agree } \\
\text { to take part in the study }\end{array}$ & n:6 & Yes \\
\hline $\begin{array}{l}50 \% \text { or more of patients } \\
\text { eligible to take part in the } \\
\text { study are consented }\end{array}$ & $\begin{array}{l}\text { n:70 eligible patients } \\
87.14 \%\end{array}$ & Yes \\
\hline $\begin{array}{l}\text { 75\% or more of patients are } \\
\text { consented and randomised } \\
\text { in real time at the same } \\
\text { appointment }\end{array}$ & $100 \%$ & Yes \\
\hline $\begin{array}{l}\text { Less than 20\% of patients } \\
\text { drop out from the study }\end{array}$ & n:0 \\
$0 \%$ & \\
\hline $\begin{array}{l}\text { Some data are collected on } \\
\text { all outcome measures for } \\
\text { over } 80 \% \text { of patients }\end{array}$ & $100 \%$ & Yes \\
\hline
\end{tabular}

\section{Clinical outcomes}

Clinical outcomes were analysed and reported individually for each outcome measure. As this was a feasibility study, each outcome was reported in numbers, percentages by randomised group.

1. Cost data

We collected information and amassed data on all participants (the intervention and control groups) and analysed these to identify the feasibility of collecting data of the total cost of NHS resources used by participants in primary and secondary care. We collated the cost in local currency (U.K. sterling) and have noted these in each cost table. We did not formally analyse, or provide statistical analysis on the costs as the trial was based on exploring feasibility. We have included the cost data to provide a more complete data set. 
We used the current existing patient data from primary and secondary care held within the patient records.

In primary care we accessed information held in the GP electronic record. This record covered all GP treatments, visits and communications with the patient across all specialties and all NHS locations (UK wide). The records contained letters from secondary care services regarding admissions, outpatient visits and secondary care treatments. All the patient records were accessed. There were no missing records.

In secondary care we used the patient paper records to access treatment, investigation and inpatient and outpatient episodes covering all specialities. We also accessed the GeneCIS electronic patient record to extract specific data about the patients' IBD care including outpatient and in-patient episodes, medication and endoscopy investigations. All paper based and GeneCIS records were accessed. There were no missing records.

We verified the secondary care data against the gathered primary care data to ensure there were no missing data.

We recorded all the costs and documented these on the Data Abstraction Form (see appendix 8). Each form was completed for the identified direct and indirect NHS costs, and at each study time point (at 2, 4 months and at the end of the trial). We assessed the health economic impact of the direct and indirect costs using PSSRU Unit costs (Curtis, L. (2011) and the National Schedule of reference costs $2010-$ 2011 for NHS Trusts and PCT's combined (Department of Health 2011).

To assess the direct costs of the study, we looked at the times taken to produce the intervention: the 3 elements of "My folder". We collected data for the intervention group (as the control group had care as usual), and looked at the four stages in production of the intervention - the request of the secondary care medical record, reading and analysis of the notes for pertinent information, the access of the electronic patient record (GeneCIS) which held the gastroenterology (IBD) and endoscopy information, the time taken to complete the ELIJAH questionnaire to produce the ELIJAH report, and the time taken to print and send the report to the patient and GP (see appendix 17 Time taken to produce the ELIJAH intervention). We 
calculated the cost of producing the intervention using the cost of a Gastro Intestinal Nurse Practitioner (Band 7) carrying out the required activities. All timing data were recorded (see table 7. Timings of ELIJAH production).

Table 7. Timings of ELIJAH production

\begin{tabular}{|c|c|c|c|}
\hline & $\begin{array}{l}\text { Time taken in } \\
\text { minutes } \\
\text { Min - max }\end{array}$ & Missing data & $\begin{array}{l}\text { Total time in } \\
\text { minutes for all } 40 \\
\text { intervention patients }\end{array}$ \\
\hline Requesting of notes & $1-30$ minutes & $\begin{array}{l}\text { nmiss:0 } \\
0 \%\end{array}$ & $\begin{array}{l}126 \text { mins } \\
\text { Total: } £ 94.50 \\
\text { m: } £ 2.36 \text { (SD 4.33) }\end{array}$ \\
\hline Reading notes & $2-24$ minutes & $\begin{array}{l}\text { nmiss:0 } \\
0 \%\end{array}$ & $\begin{array}{l}398 \text { mins } \\
\text { Total: } £ 298.50 \\
\text { m: } £ 7.46 \text { (SD 4.77) }\end{array}$ \\
\hline $\begin{array}{l}\text { Accessing GeneCIS } \\
\text { information }\end{array}$ & $1-17$ minutes & $\begin{array}{l}\text { nmiss:0 } \\
0 \%\end{array}$ & $\begin{array}{l}114 \text { mins } \\
\text { Total: } £ 85.50 \\
\text { m: } £ 2.14 \text { (SD 2.26) }\end{array}$ \\
\hline $\begin{array}{l}\text { Completing } \\
\text { ELIJAH } \\
\text { questionnaire }\end{array}$ & $2-45$ minutes & $\begin{array}{l}\text { nmiss:0 } \\
0 \%\end{array}$ & $\begin{array}{l}410 \text { mins } \\
\text { Total: } £ 307.50 \\
\text { m: } £ 7.69 \text { (SD 5.91) }\end{array}$ \\
\hline $\begin{array}{l}\text { Printing and } \\
\text { sending reports }\end{array}$ & $1-13$ minutes & $\begin{array}{l}\text { nmiss:0 } \\
0 \%\end{array}$ & $\begin{array}{l}146 \text { mins } \\
\text { Total: } £ 109.50 \\
\text { m: } £ 2.74 \text { (SD 1.91) }\end{array}$ \\
\hline Total & & & $\begin{array}{l}1194 \text { mins } \\
\text { Total: } £ 895.00 \\
\text { m: } £ 22.39 \text { (SD 10.11) }\end{array}$ \\
\hline
\end{tabular}

m: mean, SD: standard deviation

There were no missing data. The 2 stages of production of the ELIJAH intervention that required the most time, and therefore cost, were the reading of the paper based hospital records and the completion of the ELIJAH questionnaire. The total cost of the production of the ELIJAH intervention was $£ 895.50$ based on a band 7 Nurse Practitioner completing each task, if a more junior Nurse were completing the activities i.e. band 5, the costing's would be reduced to $£ 513.42$.

We collected indirect cost data on all participants (across the control and intervention groups) across primary and secondary care. We identified primary and secondary care appointments, treatments and investigations and medications.

In primary care there were 342 accessed appointments, 194 were provided by a GP, 140 by a Nurse and 8 by a Health Care Support Worker (see appendix 15 Primary and secondary care appointments and frequency). A range of appointment methods were used: 292 face to face visits at the GP surgery, 43 remotely accessed appointment via telephone and 7 home or out of hour visits. 
Out of a cohort of 61 patients, 52 accessed primary care appointments at least once in the 6 month study period (see Table 8 primary care appointments).

Table 8. Primary care appointments.

\begin{tabular}{|c|c|c|c|c|}
\hline & $\begin{array}{l}\text { Total } \\
\text { n:342 }\end{array}$ & $\begin{array}{l}\text { Intervention } \\
\mathrm{n}: 209\end{array}$ & $\begin{array}{l}\text { Control } \\
\text { n:133 }\end{array}$ & $\begin{array}{l}\text { Missing } \\
\text { data }\end{array}$ \\
\hline $\begin{array}{l}\text { GP appointment, } \\
\text { minor surgery, out } \\
\text { of hours }(£ 53.00)\end{array}$ & $\begin{array}{l}\mathrm{n}: 154 \\
45.03 \%\end{array}$ & $\begin{array}{l}\mathrm{n}: 104 \\
49.76 \% \\
\text { Total:£3850.00 } \\
\text { m: } 96.25 \\
\text { (SD 88.53) }\end{array}$ & $\begin{array}{l}\mathrm{n}: 50 \\
37.59 \% \\
\text { Total: } £ 1656.00 \\
\mathrm{~m}: £ 78.86 \\
(\mathrm{SD} 77.73)\end{array}$ & $\begin{array}{l}\text { nmiss:0 } \\
0 \%\end{array}$ \\
\hline $\begin{array}{l}\text { Telephone call with } \\
\text { GP }(£ 22.00)\end{array}$ & $\begin{array}{l}\mathrm{n}: 33 \\
9.65 \%\end{array}$ & $\begin{array}{l}\mathrm{n}: 27 \\
12.92 \% \\
\text { Total: } £ 594.00 \\
\text { m: } 114.85 \\
\text { (SD 37.08) }\end{array}$ & $\begin{array}{l}\mathrm{n}: 6 \\
4.51 \% \\
\text { Total: } £ 132.00 \\
\text { m: £6.29 } \\
\text { (SD 12.33) }\end{array}$ & $\begin{array}{l}\text { nmiss:0 } \\
0 \%\end{array}$ \\
\hline $\begin{array}{l}\text { Home visit from GP } \\
(£ 120)\end{array}$ & $\begin{array}{l}\mathrm{n}: 7 \\
2.05 \%\end{array}$ & $\begin{array}{l}\mathrm{n}: 7 \\
3.35 \% \\
\text { Total: } £ 840.00 \\
\text { m: } £ 21.00 \\
\text { (SD 114.93) }\end{array}$ & $\begin{array}{l}\mathrm{n}: 0 \\
0 \% \\
\text { Total: } £ 0.00 \\
\text { m: } £ 00.00 \\
\text { (SD 0.00) }\end{array}$ & $\begin{array}{l}\text { nmiss:0 } \\
0 \%\end{array}$ \\
\hline $\begin{array}{l}\text { Nurse appointment } \\
(£ 22.00)\end{array}$ & $\begin{array}{l}\mathrm{n}: 130 \\
38.01 \%\end{array}$ & $\begin{array}{l}\mathrm{n}: 58 \\
27.75 \% \\
\text { Total: } £ 696.00 \\
\text { m: } £ 17.40 \\
\text { (SD 18.22) } \\
\end{array}$ & $\begin{array}{l}\mathrm{n}: 72 \\
54.14 \% \\
\text { Total: } £ 874.00 \\
\text { m: } £ 41.62 \\
\text { (SD 55.52) }\end{array}$ & $\begin{array}{l}\text { nmiss:0 } \\
0 \%\end{array}$ \\
\hline $\begin{array}{l}\text { Telephone call with } \\
\text { Nurse } \\
(£ 6.00)\end{array}$ & $\begin{array}{l}\mathrm{n}: 10 \\
2.92 \%\end{array}$ & $\begin{array}{l}\mathrm{n}: 5 \\
2.39 \% \\
\text { Total: } £ 30.00 \\
\text { m: } £ 0.75 \\
\text { (SD 2.43) }\end{array}$ & $\begin{array}{l}\mathrm{n}: 5 \\
3.76 \% \\
\text { Total: } £ 30.00 \\
\mathrm{~m}: £ 1.43 \\
\text { (SD 3.23) }\end{array}$ & $\begin{array}{l}\text { nmiss:0 } \\
0 \%\end{array}$ \\
\hline $\begin{array}{l}\text { Appointment with } \\
\text { HCSW } \\
(£ 8.00)\end{array}$ & $\begin{array}{l}\mathrm{n}: 8 \\
2.34 \%\end{array}$ & $\begin{array}{l}\mathrm{n}: 8 \\
3.83 \% \\
\text { Total: } £ 64.00 \\
\mathrm{~m}: £ 1.60 \\
\text { (SD 5.49) }\end{array}$ & $\begin{array}{l}\text { n:0 } \\
0 \% \\
\text { Total: } £ 0.00 \\
\text { m: } £ 0.00 \\
\text { (SD 0.00) }\end{array}$ & $\begin{array}{l}\text { nmiss:0 } \\
0 \%\end{array}$ \\
\hline $\begin{array}{l}\text { Primary care } \\
\text { appointment costs }\end{array}$ & $\begin{array}{l}£ 8766.00 \\
\text { Mean }(£) \text { : } \\
280.04\end{array}$ & $\begin{array}{l}£ 6074.00 \\
\text { Mean }(£): \\
151.85 \\
54.22 \% \\
\text { Min }(£): 0.00 \\
\operatorname{Max}(£): \\
1317.00 \\
(\text { SD 212.69) }\end{array}$ & $\begin{array}{l}£ 2692.00 \\
\text { Mean (£): } \\
128.19 \\
45.78 \% \\
\text { Min (£): } 0.00 \\
\text { Max (£): } 382.00 \\
(\text { SD 108.51) }\end{array}$ & $\begin{array}{l}\text { nmiss:0 } \\
0 \%\end{array}$ \\
\hline
\end{tabular}

m: mean, SD: standard deviation 
We found it was feasible to cost the primary care appointments for all participants, there were no missing data. The interventions provided by Nurses were lower in cost than those provided by GPs.

In secondary care there were 84 gastroenterology appointments for IBD accessed by patients from across the control and intervention groups. 43 were provided by a Medical Consultant and 41 by a Nurse Practitioner (see appendix 15 Primary and secondary care appointments and frequency). A range of appointment methods were used: 60 face to face visits at the hospital and 24 remotely accessed appointment via telephone, postal review and email.

Across the 61 participants, 32 accessed secondary care appointments (see table 9 secondary care appointments).

Table 9. Secondary care appointments.

\begin{tabular}{|c|c|c|c|c|}
\hline & $\begin{array}{l}\text { Total } \\
\text { n:84 }\end{array}$ & $\begin{array}{l}\text { Intervention } \\
\mathrm{n}: 63\end{array}$ & $\begin{array}{l}\text { Control } \\
\mathrm{n}: 21\end{array}$ & $\begin{array}{l}\text { Missing } \\
\text { data }\end{array}$ \\
\hline $\begin{array}{l}\text { Outpatient } \\
\text { appointment with } \\
\text { Medical Consultant } \\
(£ 106.00)\end{array}$ & $\begin{array}{l}\mathrm{n}: 43 \\
51.19 \%\end{array}$ & $\begin{array}{l}\mathrm{n}: 33 \\
52.38 \% \\
\text { Total: } £ 3498.00 \\
\text { m: } £ 87.45 \\
\text { (SD 223.75) }\end{array}$ & $\begin{array}{l}\mathrm{n}: 10 \\
47.62 \% \\
\text { Total: } \\
£ 1060.00 \\
\mathrm{~m}: £ 50.48 \\
(\mathrm{SD} 103.96)\end{array}$ & $\begin{array}{l}\text { nmiss:0 } \\
0 \%\end{array}$ \\
\hline $\begin{array}{l}\text { Outpatient } \\
\text { appointment with } \\
\text { Nurse Practitioner } \\
(£ 52.00)\end{array}$ & $\begin{array}{l}\mathrm{n}: 17 \\
20.24 \%\end{array}$ & $\begin{array}{l}\mathrm{n}: 12 \\
19.05 \% \\
\text { Total: } £ 624.00 \\
\mathrm{~m}: £ 15.60 \\
\text { (SD 29.32) }\end{array}$ & $\begin{array}{l}\text { n:5 } \\
23.81 \% \\
\text { Total: } \\
£ 260.00 \\
\text { m: } £ 12.38 \\
\text { (SD 22.69) }\end{array}$ & $\begin{array}{l}\text { nmiss:0 } \\
0 \%\end{array}$ \\
\hline $\begin{array}{l}\text { Telephone call with } \\
\text { Nurse Practitioner } \\
(£ 17.00)\end{array}$ & $\begin{array}{l}\mathrm{n}: 20 \\
23.81 \%\end{array}$ & $\begin{array}{l}\mathrm{n}: 14 \\
22.22 \% \\
\text { Total: } £ 594.00 \\
\mathrm{~m}: £ 14.85 \\
\text { (SD 37.08) }\end{array}$ & $\begin{array}{l}\mathrm{n}: 6 \\
28.57 \% \\
\text { Total: } \\
£ 102.00 \\
\mathrm{~m}: £ 4.86 \\
\text { (SD 15.34) }\end{array}$ & $\begin{array}{l}\text { nmiss: } 0 \\
0 \%\end{array}$ \\
\hline $\begin{array}{l}\text { Postal review } \\
(£ 17.00)\end{array}$ & $\begin{array}{l}\mathrm{n}: 2 \\
2.38 \%\end{array}$ & $\begin{array}{l}\mathrm{n}: 2 \\
3.17 \% \\
\text { Total: } £ 22.00 \\
\mathrm{~m}: £ 0.55 \\
\text { (SD 2.43) }\end{array}$ & $\begin{array}{l}\mathrm{n}: 0 \\
0 \% \\
\text { Total: } £ 0.00 \\
\mathrm{~m}: £ 0.00 \\
\text { (SD 0.00) }\end{array}$ & $\begin{array}{l}\text { nmiss:0 } \\
0 \%\end{array}$ \\
\hline $\begin{array}{l}\text { Email with Nurse } \\
\text { Practitioner } \\
(£ 11.00)\end{array}$ & $\begin{array}{l}\mathrm{n}: 2 \\
2.38 \%\end{array}$ & $\begin{array}{l}\mathrm{n}: 2 \\
3.17 \% \\
\text { Total: } £ 22.00 \\
\mathrm{~m}: £ 0.55 \\
\text { (SD 2.43) }\end{array}$ & $\begin{array}{l}\mathrm{n}: 0 \\
0 \% \\
\text { Total: } £ 0.00 \\
\mathrm{~m}: £ 0.00 \\
\text { (SD } 0.00)\end{array}$ & $\begin{array}{l}\text { nmiss:0 } \\
0 \%\end{array}$ \\
\hline $\begin{array}{l}\text { Secondary care } \\
\text { appointment costs }\end{array}$ & $£ 5838.00$ & $£ 4416.00$ & $£ 1422.00$ & $\begin{array}{l}\text { nmiss:0 } \\
0 \%\end{array}$ \\
\hline
\end{tabular}




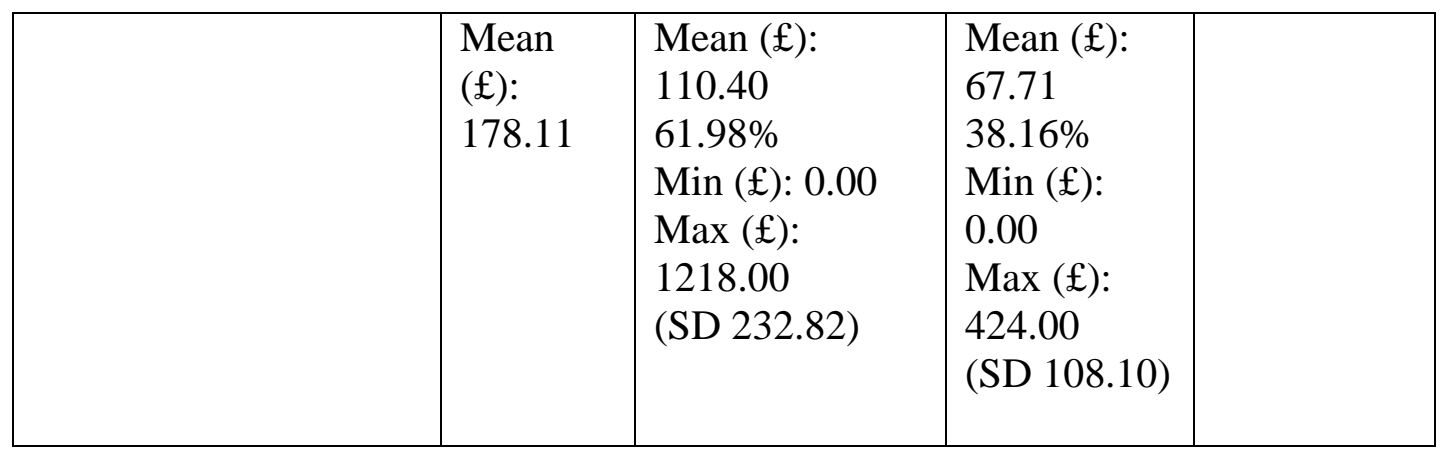

m: mean, SD: standard deviation

It was feasible to cost the secondary care appointments for all participants and there were no missing data.

The number of treatments and investigations patients attended and whether they were likely due to have been caused by, or as an effect of IBD was investigated. Overall 51 patients out of a total cohort of 61 patients, access treatments or investigations during the study period, 10 did not. There were 265 treatments or investigations identified from the primary and secondary care notes. Of these, 218 were likely due to be linked to the patients IBD care, (please see appendix 14 List of treatments and investigations, frequency and likely linked to IBD). The highest frequency of investigation / treatment was for patients blood tests at 176 during the study period (see table 10 treatments and investigations).

Table 10. Treatments and Investigations.

\begin{tabular}{|c|c|c|c|c|}
\hline & Total & Intervention & Control & $\begin{array}{l}\text { Missing } \\
\text { data }\end{array}$ \\
\hline $\begin{array}{l}\text { Number of patients } \\
\text { accessing treatments } \\
\text { and investigations }\end{array}$ & $\mathrm{n}: 51$ & $\begin{array}{l}\mathrm{n}: 32 \\
80.00 \%\end{array}$ & $\begin{array}{l}\mathrm{n}: 19 \\
90.48 \%\end{array}$ & $\begin{array}{l}\text { nmiss:0 } \\
0 \%\end{array}$ \\
\hline $\begin{array}{l}\text { Number of } \\
\text { treatments and } \\
\text { investigations }\end{array}$ & $\mathrm{n}: 265$ & $\begin{array}{l}\mathrm{n}: 198 \\
74.72 \%\end{array}$ & $\begin{array}{l}\mathrm{n}: 67 \\
25.28 \%\end{array}$ & $\begin{array}{l}\text { nmiss:0 } \\
0 \%\end{array}$ \\
\hline $\begin{array}{l}\text { Range of treatments } \\
\text { and investigations/ } \\
\text { patient }\end{array}$ & $0-55$ & $\begin{array}{l}\min : 0 \\
\max : 55\end{array}$ & $\begin{array}{l}\min : 0 \\
\max : 10\end{array}$ & $\begin{array}{l}\text { nmiss:0 } \\
0 \%\end{array}$ \\
\hline Likely linked to IBD & $\mathrm{n}: 218$ & $\begin{array}{l}\mathrm{n}: 162 \\
74.31 \%\end{array}$ & $\begin{array}{l}\mathrm{n}: 52 \\
23.85 \%\end{array}$ & $\begin{array}{l}\text { nmiss:0 } \\
0 \%\end{array}$ \\
\hline $\begin{array}{l}\text { Treatment and } \\
\text { intervention costs }\end{array}$ & $\begin{array}{l}£ 24920.00 \\
\text { Mean (£): } \\
798.21\end{array}$ & $\begin{array}{l}£ 17174.00 \\
\text { Mean (£): } \\
429.35 \\
53.79 \% \\
\text { Min (£): } 0.00\end{array}$ & $\begin{array}{l}£ 7746.00 \\
\text { Mean (£): } \\
368.86 \\
46.21 \% \\
\text { Min (£): } 0.00\end{array}$ & $\begin{array}{l}\text { nmiss:0 } \\
0 \%\end{array}$ \\
\hline
\end{tabular}




\begin{tabular}{|l|l|l|l|l|}
\hline & & Max (f): & Max (f): & \\
& & 12272.00 & 5861.00 & \\
& $($ SD 1941.57) & (SD 1275.80) & \\
\hline
\end{tabular}

SD: standard deviation

The intervention group had higher rates of patients accessing greater numbers of treatments and investigations and these were more likely to be linked to IBD. There were no missing data and it was feasible to collect the data.

We collected data on the medication the patients were prescribed (see appendix 16 List of medications). Data were collected on the drug title, strength, dose, frequency and duration. We accessed each patients' primary and secondary records to identify the date, there were no missing data. We noted if there were missing data within the prescription details e.g. the frequency was missing or dose. We judged whether the medication was used to treat the patients IBD or wider effects of IBD e.g. anaemia, osteoporosis prevention. (See table 11, Medications).

We identified 117 different medications the patients were collectively taking. Of these, 23 were medications used to treat IBD. 12 patients were not taking any medication.

Table 11. Medications

\begin{tabular}{|c|c|c|c|c|}
\hline & Total & $\begin{array}{l}\text { Intervention } \\
\mathrm{n}: 40\end{array}$ & $\begin{array}{l}\text { Control } \\
\mathrm{n}: 21\end{array}$ & $\begin{array}{l}\text { Missing } \\
\text { data }\end{array}$ \\
\hline $\begin{array}{l}\text { Number of patients } \\
\text { prescribed } \\
\text { medication }\end{array}$ & $\mathrm{n}: 51$ & $\begin{array}{l}\mathrm{n}: 32 \\
80.00 \%\end{array}$ & $\begin{array}{l}\mathrm{n}: 19 \\
90.48 \%\end{array}$ & $\begin{array}{l}\text { nmiss:0 } \\
0 \%\end{array}$ \\
\hline $\begin{array}{lr}\text { Number of } & \text { patients } \\
\text { prescribed } & \text { IBD } \\
\text { medications } & \end{array}$ & $\mathrm{n}: 23$ & $\begin{array}{l}\mathrm{n}: 31 \\
96.88 \%\end{array}$ & $\begin{array}{l}\mathrm{n}: 17 \\
89.47 \%\end{array}$ & $\begin{array}{l}\text { nmiss:0 } \\
0 \%\end{array}$ \\
\hline $\begin{array}{l}\text { Missing information } \\
\text { on IBD prescription }\end{array}$ & $\mathrm{n}: 61$ & $\begin{array}{l}\mathrm{n}: 31 \\
50.82 \%\end{array}$ & $\begin{array}{l}\mathrm{n}: 30 \\
49.18 \%\end{array}$ & $\begin{array}{l}\text { nmiss:61 } \\
44.85 \%\end{array}$ \\
\hline Medication costs & $\begin{array}{l}£ 24070.00 \\
\text { Mean (£): } \\
719.22\end{array}$ & 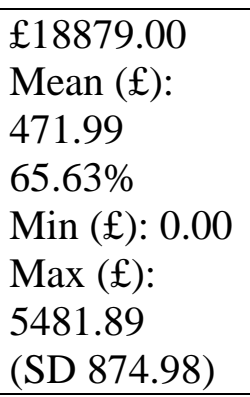 & $\begin{array}{l}£ 5191.00 \\
\text { Mean (f): } \\
247.23 \\
34.37 \% \\
\text { Min (f): } 0.00 \\
\text { Max (£): } \\
618.49 \\
(\text { SD 179.80) }\end{array}$ & $\begin{array}{l}\text { nmiss:0 } \\
0 \%\end{array}$ \\
\hline
\end{tabular}

SD: standard deviation 
There were 136 discrepancies in the prescription of IBD medication due to missing data. The highest frequency of data missing within the prescription was frequency of medication (see appendix 16 List of medications).

There were no missing data of number of patients taking medication and the information and data were feasible to collect.

2. Safety data

We gained information, and collated data on all ELIJAH participants (within the control and intervention groups) and analysed these for Serious Adverse Events. There were no expected adverse events or Serious Adverse Events arising from the ELIJAH intervention. All adverse events and the number of participants affected were reported.

In total, 197 adverse events were reported, or identified from the primary and secondary care notes. Of these 33 were likely related to IBD, (see appendix 18 list of adverse events). Out of a cohort of 61 participants, 47 reported or had at least 1 event. The cohort range was 0-21 events. See Table 12: ELIJAH adverse events. There were no missing Adverse Event data.

Table 12: ELIJAH adverse events

\begin{tabular}{|c|c|c|c|c|}
\hline Outcome & Total & Intervention & Control & $\begin{array}{l}<20 \% \\
\text { difference } \\
\text { between } \\
\text { intervention } \\
\text { and control } \\
\text { group }\end{array}$ \\
\hline $\begin{array}{l}\text { ELIJAH } \\
\text { Participants }\end{array}$ & $\mathrm{n}: 61$ & $\mathrm{n}: 40$ & $\mathrm{n}: 21$ & \\
\hline $\begin{array}{l}\text { ELIJAH } \\
\text { participants having } \\
\text { Adverse events }\end{array}$ & $\begin{array}{l}\text { n: } 47 \\
77.05 \%\end{array}$ & $\begin{array}{l}\mathrm{n}: 31 \\
77.5 \%\end{array}$ & $\begin{array}{l}\text { n:16 } \\
76.19 \%\end{array}$ & Yes \\
\hline Adverse events & n: 197 & $\begin{array}{l}\mathrm{n}: 134 \\
\text { mean: } 4.32 \mathrm{AE} \\
\text { / participant }\end{array}$ & $\begin{array}{l}\text { n:63 } \\
\text { mean: } 3.94 \\
\text { AE / } \\
\text { participant }\end{array}$ & Yes \\
\hline $\begin{array}{l}\text { Criteria of Adverse } \\
\text { event: } \\
\text { 1. } \\
\text { Known } \\
\text { undesirable } \\
\text { effect of IBD }\end{array}$ & $\begin{array}{l}\mathrm{n}: 26 \\
13.20 \% \\
\mathrm{n}: 8\end{array}$ & $\begin{array}{l}\mathrm{n}: 17 \\
12.69 \% \\
\mathrm{n}: 7\end{array}$ & $\begin{array}{l}\mathrm{n}: 9 \\
14.29 \% \\
\mathrm{n}: 1\end{array}$ & $\begin{array}{l}\text { Yes } \\
\text { Yes }\end{array}$ \\
\hline
\end{tabular}




\begin{tabular}{|c|c|c|c|c|}
\hline $\begin{array}{ll}\text { 2. } & \begin{array}{l}\text { Exacerbation } \\
\text { of known IBD }\end{array} \\
\text { 3. } & \text { Stable } \\
\text { symptom of } \\
\text { other pre- } \\
\text { existing } \\
\text { condition } \\
\text { 4. } \\
\text { Medical / } \\
\text { Surgical } \\
\text { procedure } \\
\text { 5. } \\
\text { Other }\end{array}$ & $\begin{array}{l}4.06 \% \\
\mathrm{n}: 23 \\
11.68 \% \\
\\
\mathrm{n}: 36 \\
18.27 \% \\
\mathrm{n}: 104 \\
52.79 \%\end{array}$ & $\begin{array}{l}5.22 \% \\
\text { n: } 19 \\
14.18 \% \\
\\
\text { n: } 24 \\
17.91 \% \\
\text { n: } 67 \\
50.0 \%\end{array}$ & $\begin{array}{l}1.6 \% \\
\mathrm{n}: 4 \\
6.35 \% \\
\\
\mathrm{n}: 12 \\
19.05 \% \\
\mathrm{n}: 37 \\
58.73 \%\end{array}$ & $\begin{array}{l}\text { Yes } \\
\text { Yes }\end{array}$ \\
\hline $\begin{array}{l}\text { Timing in ELIJAH } \\
\text { trimesters } \\
1 \text { (0-2 months) } \\
2 \text { (2-4 months) } \\
3 \text { (4-6 months) }\end{array}$ & $\begin{array}{l}\mathrm{n}: 61 \\
30.96 \% \\
\mathrm{n}: 72 \\
36.55 \% \\
\mathrm{n}: 64 \\
32.49 \%\end{array}$ & $\begin{array}{l}\text { n: } 40 \\
29.85 \% \\
\text { n: } 50 \\
37.31 \% \\
\text { n: } 44 \\
32.84 \%\end{array}$ & $\begin{array}{l}\text { n: } 21 \\
33.33 \% \\
\text { n: } 22 \\
34.92 \% \\
\text { n: } 20 \\
31.75 \%\end{array}$ & $\begin{array}{l}\text { Yes } \\
\text { Yes } \\
\text { Yes }\end{array}$ \\
\hline
\end{tabular}

There was a less than $20 \%$ difference in number of participants across the control and intervention group having adverse events and each criteria of the adverse events. Each trimester of the study showed no significant difference in number of adverse events, nor between the control and intervention groups.

The number of Serious Adverse Events was recorded and causality to the ELIJAH intervention was assessed. No deaths were recorded within the study period of the ELIJAH participants (see Table 13, ELIJAH Serious Adverse Events).

Table 13: ELIJAH Serious Adverse Events

\begin{tabular}{|c|c|c|c|c|}
\hline Serious adverse event & $\begin{array}{l}\text { Total } \\
\text { serious } \\
\text { adverse } \\
\text { events } \\
\text { n: } 92\end{array}$ & $\begin{array}{l}\text { Intervention } \\
\text { Adverse events } \\
\text { n: } 74\end{array}$ & $\begin{array}{l}\text { Control } \\
\text { Adverse } \\
\text { events } \\
\text { n: } 18\end{array}$ & $\begin{array}{l}<\quad 20 \% \\
\text { difference } \\
\text { between } \\
\text { intervention } \\
\text { and control } \\
\text { group }\end{array}$ \\
\hline $\begin{array}{l}\text { Serious adverse } \\
\text { events: } \\
\text { 1. Not serious } \\
\text { 2. } \begin{array}{l}\text { Required } \\
\text { hospitalisation }\end{array} \\
\text { 3. } \begin{array}{l}\text { Resulted in } \\
\text { incapacity }\end{array} \\
\text { 4. Was life } \\
\text { threatening }\end{array}$ & $\begin{array}{l}\text { n: } 78 \\
84.78 \% \\
\text { n: } 11 \\
11.96 \% \\
\text { n: } 2 \\
2.17 \% \\
\text { n: } 1\end{array}$ & $\begin{array}{l}\text { n: } 61 \\
82.43 \% \\
\text { n: } 10 \\
13.51 \% \\
\text { n: } 2 \\
2.70 \% \\
\text { n: } 1\end{array}$ & $\begin{array}{l}\mathrm{n}: 17 \\
94.44 \% \\
\mathrm{n}: 1 \\
5.56 \% \\
\mathrm{n}: 0 \\
0 \% \\
\mathrm{n}: 0\end{array}$ & Yes \\
\hline
\end{tabular}




\begin{tabular}{|l|l|l|l|l|}
\hline & $1.09 \%$ & $1.35 \%$ & $0 \%$ & \\
\hline $\begin{array}{l}\text { Causality } \\
\begin{array}{l}\text { Related to } \\
\text { intervention }\end{array}\end{array}$ & $\mathrm{n:0}$ & $\mathrm{n}: 0$ & & \\
$\begin{array}{l}\text { Not related to } 0 \% \\
\text { intervention }\end{array}$ & $0 \%$ & $0 \%$ & $\mathrm{n}: 0$ & Yes \\
& $\mathrm{n}: 92$ & $\mathrm{n}: 74$ & $\mathrm{n}: 18$ & Yes \\
& $100 \%$ & $100 \%$ & $100 \%$ & \\
\hline
\end{tabular}

The number of unexpected events was recorded and causality to the ELIJAH intervention was assessed. (See Table 14: ELIJAH Unexpected Adverse Events).

Table 14: ELIJAH Unexpected Adverse Events

\begin{tabular}{|c|c|c|c|c|}
\hline $\begin{array}{l}\text { Unexpected adverse } \\
\text { event }\end{array}$ & $\begin{array}{l}\text { Total } \\
\text { n: } 105\end{array}$ & $\begin{array}{l}\text { Intervention } \\
\mathrm{n}: 78\end{array}$ & $\begin{array}{l}\text { Control } \\
\text { n: } 27\end{array}$ & $\begin{array}{l}<\quad 20 \% \\
\text { difference } \\
\text { between } \\
\text { intervention } \\
\text { and control } \\
\text { group }\end{array}$ \\
\hline $\begin{array}{l}\text { Unexpected adverse } \\
\text { events: } \\
\text { 1. Not serious } \\
\text { 2. Required } \\
\text { hospitalisation } \\
\text { 5. } \begin{array}{l}\text { Resulted in } \\
\text { incapacity } \\
\text { 6. Was life } \\
\text { threatening }\end{array}\end{array}$ & $\begin{array}{l}\text { n: } 99 \\
94.29 \% \\
\text { n: } 5 \\
4.76 \% \\
\text { n: } 1 \\
0.95 \% \\
\text { n:0 } \\
0 \%\end{array}$ & $\begin{array}{l}\text { n: } 73 \\
93.59 \% \\
\text { n: } 4 \\
5.13 \% \\
\text { n: } 1 \\
1.28 \% \\
\text { n:0 } \\
0 \%\end{array}$ & $\begin{array}{l}\text { n: } 26 \\
96.30 \% \\
\text { n: } 1 \\
3.70 \% \\
\text { n: } 0 \\
0 \% \\
\text { n:0 } \\
0 \%\end{array}$ & Yes \\
\hline $\begin{array}{l}\text { Causality } \\
\text { 1. Related to } \\
\text { intervention } \\
\text { 2. Not related to } \\
\text { intervention }\end{array}$ & $\begin{array}{l}\mathrm{n}: 0 \\
0 \% \\
\mathrm{n}: 105 \\
100 \%\end{array}$ & $\begin{array}{l}\text { n: } 0 \\
0 \% \\
\text { n: } 78 \\
100 \%\end{array}$ & $\begin{array}{l}\text { n: } 0 \\
0 \% \\
\text { n: } 27 \\
100 \%\end{array}$ & Yes \\
\hline
\end{tabular}

No Suspected Unexpected Serious Adverse Reactions (SUSARs) were recorded. We did not find any increased risks to patients from having their own electronic, individualised educationally enhanced IBD health reports. No patients found access to their reports emotionally burdensome, this was evaluated by patients recording this as an adverse event. 


\section{Patient centeredness}

We gained patient reported information from the Inflammatory Bowel Disease Service Satisfaction Questionnaire (ISSQ), and collated data on all ELIJAH participants (within the control and intervention groups). The ISSQ was given to patients at baseline (i.e. at consent and randomisation), and sent by post to all participants ( 2 weeks after the intervention patients had received their "My Folder") at the study follow up intervals: 2, 4 and 6 months. If the ISSQ was not received back within 2 weeks of the sending date, a reminder letter with the ISSQ was sent. All patients completed the baseline ISSQ. In total 64 ISSQ reminders were sent (see table 15, ISSQ reminders and non-responders), and 15 participants did not respond and send back the completed ISSQ after the reminder. Overall more reminders (as a percentage total), were sent to the intervention group than the control group.

Throughout the ELIJAH trimester follow up periods the number of reminders sent remained similar.

Table 15: ISSQ reminders and non-responders

\begin{tabular}{|l|l|l|}
\hline & $\begin{array}{l}\text { Intervention } \\
\text { n:40 }\end{array}$ & $\begin{array}{l}\text { Control } \\
\text { n:21 }\end{array}$ \\
\hline $\begin{array}{l}\text { Total patient reminders } \\
\text { sent } \\
\text { n:64 }\end{array}$ & n:44 & $\mathrm{n}: 20$ \\
& $68.75 \%$ & $31.25 \%$ \\
\hline Study trimester & & \\
1 & $\mathrm{n}: 15$ & $\mathrm{n}: 7$ \\
n:22, 34.38\% & $34.09 \%$ & $35.00 \%$ \\
2 & $\mathrm{n}: 14$ & $\mathrm{n}: 6$ \\
n:20, 31.25\% & $31.82 \%$ & $30.00 \%$ \\
3 & $\mathrm{n}: 14$ & $\mathrm{n}: 8$ \\
n:22, 34.38\% & $31.82 \%$ & $40.00 \%$ \\
\hline Total non-responders & $\mathrm{nmiss:10}$ & $\mathrm{nmiss}: 5$ \\
after reminder. & $66.67 \%$ & $33.33 \%$ \\
nmiss:15 & Min 1, max 3/ patient & Min 1, max 3/ patient \\
Min 1, max 3/ patient & & \\
\hline Study trimester & & \\
1 & nmiss:5 & nmiss:1 \\
nmiss:22, 34.38\% & $50.00 \%$ & $20.00 \%$ \\
2 & nmiss:2 & nmiss:2 \\
nmiss:20, 31.25\% & $20.00 \%$ & $40.00 \%$ \\
3 & nmiss:3 & nmiss:2 \\
nmiss:22, 34.38\% & $30.00 \%$ & $40.00 \%$ \\
\hline
\end{tabular}


More participants in the intervention group did not respond to the reminder and return the questionnaire. 2 participants, 1 from the intervention group, 1 from the control group completed the baseline ISSQ, but did not complete any subsequent follow up ISSQ.

The ISSQ was analysed by section: ISSQ introductory answers, satisfaction questionnaire and EQ5D.

The ISSQ introductory answers (see Table 16. ISSQ introductory answers) looked at whether patients knew, with accuracy, their diagnosis and date of diagnosis, these data were verified against their medical record.

Table 16. ISSQ introductory answers

\begin{tabular}{|c|c|c|c|c|c|c|}
\hline & $\begin{array}{l}\text { Total } \\
\text { incorrect } \\
\text { answers }\end{array}$ & $\begin{array}{l}\text { Total } \\
\text { correct } \\
\text { answers }\end{array}$ & $\begin{array}{l}\text { Correct } \\
\text { answers } \\
\text { Intervention }\end{array}$ & $\begin{array}{l}\text { Correct } \\
\text { answers } \\
\text { control }\end{array}$ & $\begin{array}{l}\text { Missing } \\
\text { data }\end{array}$ & $\begin{array}{l}\text { Data } \\
\text { collected } \\
\text { for more } \\
\text { than } 75 \% \\
\text { of } \\
\text { participants }\end{array}$ \\
\hline $\begin{array}{l}\text { Total } \\
\mathrm{n}: 244\end{array}$ & $\begin{array}{l}\mathrm{n}: 21 \\
8.61 \%\end{array}$ & $\begin{array}{l}\mathrm{n}: 198 \\
81.15 \%\end{array}$ & $\mathrm{n}: 131$ & n:67 & $\begin{array}{l}\text { nmiss: } 25 \\
10.24 \%\end{array}$ & Yes \\
\hline $\begin{array}{l}\text { Study } \\
\text { trimester } \\
\text { Baseline } \\
1 \\
2 \\
3\end{array}$ & $\begin{array}{l}\mathrm{n}: 10 \\
47.62 \% \\
\mathrm{n}: 3 \\
14.29 \% \\
\mathrm{n}: 4 \\
19.05 \% \\
\mathrm{n}: 4 \\
19.05 \%\end{array}$ & $\begin{array}{l}\mathrm{n}: 49 \\
24.75 \% \\
\mathrm{n}: 48 \\
24.24 \% \\
\mathrm{n}: 52 \\
26.26 \% \\
\mathrm{n}: 49 \\
24.75 \%\end{array}$ & $\begin{array}{l}\mathrm{n}: 31 \\
23.66 \% \\
\mathrm{n}: 33 \\
25.19 \% \\
\mathrm{n}: 34 \\
25.95 \% \\
\mathrm{n}: 33 \\
25.19 \%\end{array}$ & $\begin{array}{l}\mathrm{n}: 18 \\
26.87 \% \\
\mathrm{n}: 15 \\
22.39 \% \\
\mathrm{n}: 18 \\
26.87 \% \\
\mathrm{n}: 16 \\
23.88 \%\end{array}$ & $\begin{array}{l}\text { nmiss:2 } \\
8.00 \% \\
\text { nmiss: } 10 \\
40.00 \% \\
\text { nmiss:5 } \\
20.00 \% \\
\text { nmiss:8 } \\
32.00 \%\end{array}$ & Yes \\
\hline
\end{tabular}

Of the completed answers most (over $80 \%$ ) were correct. Of the incorrect answers (8\%), more were noted at baseline than in subsequent follow-ups. There was little difference between the intervention and control group in amount of correct answers.

Over $10 \%$ of participants did not answer these introductory questions (see table 17. ISSQ introductory answers: missing data). 
Table 17. ISSQ introductory answers: missing data

\begin{tabular}{|l|l|l|}
\hline & $\begin{array}{l}\text { Intervention } \\
\text { missing data }\end{array}$ & $\begin{array}{l}\text { Control } \\
\text { missing data }\end{array}$ \\
\hline Total & nmiss:18 & nmiss:7 \\
nmiss:25, $10.24 \%$ & $11.25 \%$ & $83 \%$ \\
\hline Study trimester & nmiss:2 & \\
Baseline & $11.11 \%$ & nmiss:0 \\
nmiss:4, 16.00\% & nmiss:6 & $0 \%$ \\
1 & $33.33 \%$ & nmiss:4 \\
nmiss:10, $40.00 \%$ & nmiss:4 & $19.04 \%$ \\
2 & $22.22 \%$ & nmiss: 1 \\
nmiss:5, $20.00 \%$ & nmiss:6 & $4.76 \%$ \\
3 & $33.33 \%$ & nmiss: 2 \\
nmiss:8, 32.00\% & $9.52 \%$ \\
\hline
\end{tabular}

There were more missing data for both the intervention and control groups in the first trimester than in subsequent trimesters.

The ISSQ questions were split into 4 sections: Your condition, Getting care when you need it, Quality of the care you received recently, and General quality of the care you receive. 23 questions were distributed across these 4 sections (see table 18. ISSQ answers).

We looked at the amount of incomplete and missing answer data across both groups and at each time point. The total complete data set, if all patients answered all questions (61 patients X 4 time points) would be 244 answers per question.

Questions 4 and 5 did not need to be answered if the patient had not received any information about their IBD since diagnosis. 
Table 18. ISSQ answers

\begin{tabular}{|c|c|c|c|c|}
\hline $\begin{array}{l}\text { Question sections, } \\
\text { number and question } \\
\text { description } \\
\text { Potential n: } 244\end{array}$ & $\begin{array}{l}\text { Total } \\
\text { Missing } \\
\text { data }\end{array}$ & $\begin{array}{l}\text { Intervention } \\
\text { Missing data } \\
\text { Potential } \\
\text { n:160 }\end{array}$ & $\begin{array}{l}\text { Control } \\
\text { Missing } \\
\text { data } \\
\text { Potential } \\
\text { n:84 } \\
\end{array}$ & $\begin{array}{l}\text { Data } \\
\text { collected for } \\
\text { more than } \\
75 \% \text { of } \\
\text { participants }\end{array}$ \\
\hline $\begin{array}{l}\text { Your condition } \\
\text { 1. Amount of } \\
\text { information } \\
\text { 2. Ease of } \\
\text { understanding } \\
\text { 3. Usefulness } \\
\text { 4. Opportunity to } \\
\text { ask questions }\end{array}$ & $\begin{array}{l}\text { nmiss: } 16 \\
6.56 \% \\
\text { nmiss:26 } \\
10.66 \% \\
\text { nmiss:23 } \\
9.43 \% \\
\text { nmiss:14 } \\
5.74 \%\end{array}$ & $\begin{array}{l}\text { nmiss: } 11 \\
6.88 \% \\
\text { nmiss: } 16 \\
10 \% \\
\text { nmiss: } 15 \\
9.38 \% \\
\text { nmiss: } 10 \\
6.25 \%\end{array}$ & $\begin{array}{l}\text { nmiss:5 } \\
5.95 \% \\
\text { nmiss:10 } \\
11.90 \% \\
\text { nmiss:8 } \\
9.52 \% \\
\text { nmiss:4 } \\
4.76 \%\end{array}$ & Yes \\
\hline $\begin{array}{l}\text { Getting care when you } \\
\text { need it } \\
\text { 5. Explanation } \\
\text { about getting } \\
\text { care } \\
\text { 6. Ease of } \\
\text { Understanding } \\
\text { 7. Usefulness } \\
\text { 8. Communication } \\
\text { skills of person } \\
\text { 9. Difficulty in } \\
\text { accessing care } \\
\text { Free text }\end{array}$ & $\begin{array}{l}\text { nmiss: } 14 \\
5.74 \% \\
\text { nmiss: } 18 \\
7.38 \% \\
\text { nmiss: } 17 \\
6.97 \% \\
\text { nmiss: } 16 \\
6.56 \% \\
\text { nmiss:30 } \\
12.30 \%\end{array}$ & $\begin{array}{l}\text { nmiss: } 10 \\
6.25 \% \\
\text { nmiss: } 11 \\
6.88 \% \\
\text { nmiss: } 11 \\
6.88 \% \\
\text { nmiss:9 } \\
5.63 \% \\
\text { nmiss: } 15 \\
9.38 \%\end{array}$ & $\begin{array}{l}\text { nmiss:4 } \\
4.76 \% \\
\text { nmiss:7 } \\
8.33 \% \\
\text { nmiss:6 } \\
7.14 \% \\
\text { nmiss:7 } \\
8.33 \% \\
\text { nmiss: } 15 \\
17.86 \%\end{array}$ & Yes \\
\hline $\begin{array}{l}\text { Quality of the care } \\
\text { you received recently } \\
\text { 10. Quality } \\
\text { 11. Communication } \\
\text { skills of person } \\
\text { 12. Discomfort } \\
\text { noted } \\
\text { 13. Pain noted } \\
\text { 14. Discomfort in } \\
\text { week following } \\
\text { symptoms } \\
\text { 15. Pain in week } \\
\text { following } \\
\text { symptoms } \\
\text { 16. Opportunity to } \\
\text { ask questions } \\
\text { 17. Explanation }\end{array}$ & $\begin{array}{l}\text { nmiss: } 18 \\
7.38 \% \\
\text { nmiss: } 18 \\
7.38 \% \\
\text { nmiss: } 28 \\
11.48 \% \\
\text { nmiss: } 21 \\
8.61 \% \\
\text { nmiss: } 25 \\
10.25 \% \\
\text { nmiss: } 25 \\
10.25 \% \\
\text { nmiss:26 } \\
10.66 \% \\
\text { nmiss: } 26\end{array}$ & $\begin{array}{l}\text { nmiss: } 10 \\
6.25 \% \\
\text { nmiss: } 10 \\
6.25 \% \\
\text { nmiss: } 13 \\
8.13 \% \\
\text { nmiss:9 } \\
5.63 \% \\
\text { nmiss: } 13 \\
8.13 \% \\
\text { nmiss: } 13 \\
8.13 \% \\
\text { nmiss: } 13 \\
8.13 \% \\
\text { nmiss: } 13\end{array}$ & $\begin{array}{l}\text { nmiss:8 } \\
9.52 \% \\
\text { nmiss:8 } \\
9.52 \% \\
\text { nmiss:15 } \\
17.86 \% \\
\text { nmiss:12 } \\
14.29 \% \\
\text { nmiss:12 } \\
14.29 \% \\
\text { nmiss: } 12 \\
14.29 \% \\
\text { nmiss:13 } \\
15.48 \% \\
\text { nmiss:13 }\end{array}$ & Yes \\
\hline
\end{tabular}




\begin{tabular}{|c|c|c|c|c|}
\hline $\begin{array}{l}\text { 18. Understanding } \\
\text { of } \\
\text { understanding } \\
\text { 19. Usefulness }\end{array}$ & $\begin{array}{l}10.66 \% \\
\text { nmiss:28 } \\
11.48 \% \\
\text { nmiss: } 29 \\
11.89 \%\end{array}$ & $\begin{array}{l}8.13 \% \\
\text { nmiss: } 15 \\
9.38 \% \\
\text { nmiss: } 15 \\
9.38 \%\end{array}$ & $\begin{array}{l}15.48 \% \\
\text { nmiss: } 13 \\
15.48 \% \\
\text { nmiss: } 14 \\
16.67 \%\end{array}$ & \\
\hline $\begin{array}{l}\text { General quality of the } \\
\text { care you receive } \\
\text { 20. Availability of } \\
\text { care } \\
\text { 21. Satisfaction } \\
\text { 22. Happy to repeat } \\
\text { care } \\
\text { 23. Quality of IBD } \\
\text { care }\end{array}$ & $\begin{array}{l}\text { nmiss:21 } \\
8.61 \% \\
\text { nmiss:23 } \\
9.43 \% \\
\text { nmiss: } 24 \\
9.84 \% \\
\text { nmiss:20 } \\
8.20 \%\end{array}$ & $\begin{array}{l}\text { nmiss: } 12 \\
7.50 \% \\
\text { nmiss: } 12 \\
7.50 \% \\
\text { nmiss: } 12 \\
7.50 \% \\
\text { nmiss: } 12 \\
7.50 \%\end{array}$ & $\begin{array}{l}\text { nmiss:9 } \\
10.71 \% \\
\text { nmiss: } 11 \\
13.10 \% \\
\text { nmiss: } 12 \\
14.29 \% \\
\text { nmiss: } 8 \\
9.52 \%\end{array}$ & Yes \\
\hline
\end{tabular}

We collected data on each question from over $75 \%$ of all participants, and within the intervention and control group. Mostly, there were more missing data per question in the control than intervention group. The section with most missing data was that asking questions of the IBD care most recently received.

We looked at the ISSQ questionnaire missing data across the baseline collection of data and the 3 trimester data collection points: at month 2, 4 and 6 (see table 19).

Table 19. ISSQ missing data across ELIJAH trimesters

\begin{tabular}{|c|c|c|c|c|c|}
\hline Questions and section, & $\begin{array}{l}\text { Total } \\
\text { Missing data } \\
\text { Number } \\
\text { potential n: } \mathbf{2 4 4}\end{array}$ & Baseline & Trimester 1 & Trimester 2 & Trimester 3 \\
\hline $\begin{array}{l}\text { Your condition } \\
3 \\
4 \\
5 \\
6\end{array}$ & $\begin{array}{l}\text { nmiss: } 16 \\
6.56 \% \\
\text { nmiss:26 } \\
10.66 \% \\
\text { nmiss: } 23 \\
9.43 \% \\
\text { nmiss: } 14 \\
5.74 \%\end{array}$ & $\begin{array}{l}\text { nmiss:0 } \\
0 \% \\
\text { nmiss:4 } \\
6.56 \% \\
\text { nmiss:3 } \\
4.92 \% \\
\text { nmiss:0 } \\
0 \%\end{array}$ & $\begin{array}{l}\text { nmiss:6 } \\
9.83 \% \\
\text { nmiss:9 } \\
14.75 \% \\
\text { nmiss: } 10 \\
16.39 \% \\
\text { nmiss:6 } \\
9.83 \%\end{array}$ & $\begin{array}{l}\text { nmiss:5 } \\
8.20 \% \\
\text { nmiss:6 } \\
9.83 \% \\
\text { nmiss:5 } \\
8.20 \% \\
\text { nmiss:4 } \\
6.56 \%\end{array}$ & $\begin{array}{l}\text { nmiss:5 } \\
8.20 \% \\
\text { nmiss:7 } \\
11.48 \% \\
\text { nmiss:5 } \\
8.20 \% \\
\text { nmiss:4 } \\
6.56 \%\end{array}$ \\
\hline $\begin{array}{l}\text { Data collected for more than } \\
75 \% \text { of participants }\end{array}$ & Yes & Yes & Yes & Yes & Yes \\
\hline $\begin{array}{l}\text { Getting care when you need } \\
\text { it } \\
7 \\
8\end{array}$ & $\begin{array}{l}\text { nmiss: } 14 \\
5.74 \% \\
\text { nmiss: } 18 \\
7.38 \%\end{array}$ & $\begin{array}{l}\text { nmiss:0 } \\
0 \% \\
\text { nmiss:0 } \\
0 \%\end{array}$ & $\begin{array}{l}\text { nmiss:6 } \\
9.83 \% \\
\text { nmiss:8 } \\
13.11 \%\end{array}$ & $\begin{array}{l}\text { nmiss:4 } \\
6.56 \% \\
\text { nmiss:5 } \\
8.20 \%\end{array}$ & $\begin{array}{l}\text { nmiss:4 } \\
6.56 \% \\
\text { nmiss:5 } \\
8.20 \%\end{array}$ \\
\hline
\end{tabular}




\begin{tabular}{|c|c|c|c|c|c|}
\hline $\begin{array}{l}10 \\
11\end{array}$ & $\begin{array}{l}\text { nmiss: } 17 \\
6.97 \% \\
\text { nmiss:16 } \\
6.56 \% \\
\text { nmiss:30 } \\
12.30 \%\end{array}$ & $\begin{array}{l}\text { nmiss:0 } \\
0 \% \\
\text { nmiss:0 } \\
0 \% \\
\text { nmiss:3 } \\
4.92 \%\end{array}$ & $\begin{array}{l}\text { nmiss: } 8 \\
13.11 \% \\
\text { nmiss:6 } \\
9.83 \% \\
\text { nmiss: } 11 \\
18.03 \%\end{array}$ & $\begin{array}{l}\text { nmiss:5 } \\
8.20 \% \\
\text { nmiss:5 } \\
8.20 \% \\
\text { nmiss: } 8 \\
13.11 \%\end{array}$ & $\begin{array}{l}\text { nmiss:4 } \\
6.56 \% \\
\text { nmiss:5 } \\
8.20 \% \\
\text { nmiss:8 } \\
13.11 \%\end{array}$ \\
\hline $\begin{array}{l}\text { Data collected for more than } \\
75 \% \text { of participants }\end{array}$ & Yes & Yes & Yes & Yes & Yes \\
\hline $\begin{array}{l}\text { Quality of the care you } \\
\text { received recently } \\
12 \\
13 \\
14 \\
15 \\
16 \\
17 \\
18 \\
19 \\
20 \\
21\end{array}$ & $\begin{array}{l}\text { nmiss: } 18 \\
7.38 \% \\
\text { nmiss: } 18 \\
7.38 \% \\
\text { nmiss: } 28 \\
11.48 \% \\
\text { nmiss: } 21 \\
8.61 \% \\
\text { nmiss: } 25 \\
10.25 \% \\
\text { nmiss: } 25 \\
10.25 \% \\
\text { nmiss: } 26 \\
10.66 \% \\
\text { nmiss:26 } \\
10.66 \% \\
\text { nmiss:28 } \\
11.48 \% \\
\text { nmiss: } 29 \\
11.89 \%\end{array}$ & $\begin{array}{l}\text { nmiss:0 } \\
0 \% \\
\text { nmiss:0 } \\
0 \% \\
\text { nmiss:2 } \\
3.28 \% \\
\text { nmiss:2 } \\
3.28 \% \\
\text { nmiss:2 } \\
3.28 \% \\
\text { nmiss:2 } \\
3.28 \% \\
\text { nmiss: } 1 \\
1.64 \% \\
\text { nmiss: } 1 \\
1.64 \% \\
\text { nmiss: } 1 \\
1.64 \% \\
\text { nmiss: } 1 \\
1.64 \%\end{array}$ & $\begin{array}{l}\text { nmiss:7 } \\
11.48 \% \\
\text { nmiss:7 } \\
11.48 \% \\
\text { nmiss:10 } \\
16.39 \% \\
\text { nmiss: } 7 \\
11.48 \% \\
\text { nmiss:9 } \\
14.75 \% \\
\text { nmiss: } 10 \\
16.39 \% \\
\text { nmiss:10 } \\
16.39 \% \\
\text { nmiss: } 10 \\
16.39 \% \\
\text { nmiss: } 10 \\
16.39 \% \\
\text { nmiss: } 11 \\
18.03 \%\end{array}$ & $\begin{array}{l}\text { nmiss:6 } \\
9.83 \% \\
\text { nmiss:6 } \\
9.83 \% \\
\text { nmiss:8 } \\
13.11 \% \\
\text { nmiss:6 } \\
9.83 \% \\
\text { nmiss:7 } \\
11.48 \% \\
\text { nmiss:6 } \\
9.83 \% \\
\text { nmiss: } \\
11.48 \% \\
\text { nmiss:7 } \\
11.48 \% \\
\text { nmiss:8 } \\
13.11 \% \\
\text { nmiss:8 } \\
13.11 \%\end{array}$ & $\begin{array}{l}\text { nmiss:5 } \\
8.20 \% \\
\text { nmiss:5 } \\
8.20 \% \\
\text { nmiss:8 } \\
13.11 \% \\
\text { nmiss:6 } \\
9.83 \% \\
\text { nmiss:7 } \\
11.48 \% \\
\text { nmiss:7 } \\
11.48 \% \\
\text { nmiss: } 8 \\
13.11 \% \\
\text { nmiss:8 } \\
13.11 \% \\
\text { nmiss:9 } \\
14.75 \% \\
\text { nmiss:9 } \\
14.75 \%\end{array}$ \\
\hline $\begin{array}{l}\text { Data collected for more than } \\
75 \% \text { of participants }\end{array}$ & Yes & Yes & Yes & Yes & Yes \\
\hline $\begin{array}{l}\text { General quality of the care } \\
\text { you receive } \\
22 \\
23 \\
24 \\
25\end{array}$ & $\begin{array}{l}\text { nmiss: } 21 \\
8.61 \% \\
\text { nmiss:23 } \\
9.43 \% \\
\text { nmiss: } 24 \\
9.84 \% \\
\text { nmiss:20 } \\
8.20 \%\end{array}$ & $\begin{array}{l}\text { nmiss: } 1 \\
1.64 \% \\
\text { nmiss: } 1 \\
1.64 \% \\
\text { nmiss: } 1 \\
1.64 \% \\
\text { nmiss: } 1 \\
1.64 \%\end{array}$ & $\begin{array}{l}\text { nmiss:7 } \\
11.48 \% \\
\text { nmiss:8 } \\
13.11 \% \\
\text { nmiss:8 } \\
13.11 \% \\
\text { nmiss:7 } \\
11.48 \%\end{array}$ & $\begin{array}{l}\text { nmiss:5 } \\
8.20 \% \\
\text { nmiss:6 } \\
9.83 \% \\
\text { nmiss:7 } \\
11.48 \% \\
\text { nmiss:6 } \\
9.83 \%\end{array}$ & $\begin{array}{l}\text { nmiss: } 8 \\
13.11 \% \\
\text { nmiss: } 8 \\
13.11 \% \\
\text { nmiss:8 } \\
13.11 \% \\
\text { nmiss:6 } \\
9.83 \%\end{array}$ \\
\hline $\begin{array}{l}\text { Data collected for more than } \\
75 \% \text { of participants }\end{array}$ & Yes & Yes & Yes & Yes & Yes \\
\hline $\begin{array}{l}\text { Total data collected for more } \\
\text { than } 75 \% \text { of participants }\end{array}$ & Yes & Yes & Yes & Yes & Yes \\
\hline
\end{tabular}

We collected data on each section and each question from over $75 \%$ of all participants. Each section, and each question had some missing data across the 4 timeline periods.

We collected patient free text comments in two questionnaire boxes; one after question 11 and one at the end of the questionnaire (see appendix 10 ISSQ, see appendix 19 for patient free text comments). We looked at the number of participants 
adding comments, the number of comments, when they occurred within the study trimesters, and whether the comments were positive or negative (see table 20).

Table 20. Patient free text comments

\begin{tabular}{|l|l|l|l|}
\hline & Total & $\begin{array}{l}\text { Intervention } \\
\text { n:40 }\end{array}$ & $\begin{array}{l}\text { Control } \\
\text { n:21 }\end{array}$ \\
\hline $\begin{array}{l}\text { Number } \\
\text { participants } \\
\text { filling in the free } \\
\text { text comments }\end{array}$ & $\begin{array}{l}\mathrm{n}: 34 \\
55.74 \%\end{array}$ & $\begin{array}{l}\mathrm{n}: 22 \\
55 \%\end{array}$ & $\begin{array}{l}\mathrm{n}: 12 \\
57.14 \%\end{array}$ \\
\hline $\begin{array}{l}\text { Number of } \\
\text { comments }\end{array}$ & $\mathrm{n}: 75$ & $\mathrm{n}: 44$ & $\mathrm{n}: 31$ \\
\hline Range & $1-4$ & $58.67 \%$ & $41.33 \%$ \\
\hline $\begin{array}{l}\text { Study trimester } \\
\text { Baseline }\end{array}$ & $\mathrm{n}: 16$ & $1-4$ & $1-4$ \\
\hline 1 & $21.33 \%$ & $\mathrm{n}: 9$ & $\mathrm{n}: 7$ \\
\hline 2 & $\mathrm{n}: 19$ & $20.45 \%$ & $22.58 \%$ \\
& $25.33 \%$ & $\mathrm{n}: 10$ & $\mathrm{n}: 9$ \\
3 & $\mathrm{n}: 19$ & $22.73 \%$ & $29.03 \%$ \\
& $25.33 \%$ & $\mathrm{n}: 12$ & $\mathrm{n}: 7$ \\
\hline $\begin{array}{l}\text { Type of comment } \\
\text { Positive }\end{array}$ & $\mathrm{n}: 21$ & $\mathrm{n}: 13$ & $22.58 \%$ \\
Negative & $28 \%$ & $29.55 \%$ & $\mathrm{n}: 8$ \\
& $\mathrm{n}: 55$ & $\mathrm{n}: 32$ & $25.81 \%$ \\
\hline & $73.33 \%$ & $72.73 \%$ & $\mathrm{n}: 23$ \\
\hline & $26.67 \%$ & $\mathrm{n}: 12$ & $74.19 \%$ \\
\hline
\end{tabular}

We found that approximately half of all participants wrote free text comments. Both the intervention and control group patients provide free comments in much the same frequency. The range (1-4 comments) was the same in both groups. Comments were provided by both groups in each trimester. There were far more positive than negative comments written by participants in both groups.

We collected descriptive data of the ISSQ scores as we wanted to explore more fully the amassed information from the trial. We did not seek to test statistical significance of the data via a comparison as the trial was based on feasibility. We collected summary statistics (mean, standard deviation, range) for the intervention and control groups for each of the four time points of the trial and collectively (see table 21). 
Table 21. ISSQ summary statistics

\begin{tabular}{|c|c|c|}
\hline Question sections & $\begin{array}{l}\text { Intervention } \\
\mathrm{n}: \mathbf{4 0}\end{array}$ & \begin{tabular}{|l|} 
Control \\
n: 21
\end{tabular} \\
\hline \multicolumn{3}{|l|}{ Your condition } \\
\hline Baseline & $\begin{array}{l}\mathrm{m}: 15.38(\mathrm{SD} 3.00) \\
\mathrm{r}: 8-20\end{array}$ & $\begin{array}{l}\mathrm{m}: 16.19(\mathrm{SD} 3.50) \\
\mathrm{r}: 5-20\end{array}$ \\
\hline 2 months & $\begin{array}{l}\mathrm{m}: 15.58(\mathrm{SD} 2.13) \\
\mathrm{r}: 11-20\end{array}$ & $\begin{array}{l}\text { m: } 16.00(S D 2.92) \\
\text { r: } 7-20\end{array}$ \\
\hline 4 months & $\begin{array}{l}\mathrm{m}: 16.65(\mathrm{SD} 1.94) \\
\mathrm{r}: 13-20\end{array}$ & $\begin{array}{l}\text { m: } 15.90(\mathrm{SD} 3.10) \\
\mathrm{r}: 6-20\end{array}$ \\
\hline 6 months & $\begin{array}{l}\mathrm{m}: 16.68(\mathrm{SD} 1.79) \\
\mathrm{r}: 12-20\end{array}$ & $\begin{array}{l}\mathrm{m}: 16.24(\mathrm{SD} 3.13) \\
\mathrm{r}: 6-20\end{array}$ \\
\hline Total & $\mathrm{m}: 16.07(\mathrm{SD} 0.69)$ & m: $16.08($ SD 0.16) \\
\hline \multicolumn{3}{|l|}{ Getting Care when you need it } \\
\hline Baseline & $\begin{array}{l}\mathrm{m}: 22.6(\mathrm{SD} 2.18) \\
\mathrm{r}: 15-25\end{array}$ & $\begin{array}{l}\text { m: } 22.19(\text { SD } 2.19) \\
\text { r: } 12-25\end{array}$ \\
\hline 2 months & $\begin{array}{l}\mathrm{m}: 22.43(\mathrm{SD} 2.07) \\
\mathrm{r}: 17-25\end{array}$ & $\begin{array}{l}\text { m: } 21.95(\text { SD } 3.43) \\
\text { r: } 10-25\end{array}$ \\
\hline 4 months & $\begin{array}{l}\mathrm{m}: 22.10(\mathrm{SD} 2.23) \\
\mathrm{r}: 16-25\end{array}$ & $\begin{array}{l}\text { m: } 21.62 \text { (SD 3.99) } \\
\text { r: 9-25 }\end{array}$ \\
\hline 6 months & $\begin{array}{l}\mathrm{m}: 22.43(\mathrm{SD} 2.10) \\
\mathrm{r}: 16-25\end{array}$ & $\begin{array}{l}\mathrm{m}: 21.86(\mathrm{SD} 2.76) \\
\mathrm{r}: 12-25\end{array}$ \\
\hline Total & $\mathrm{m}: 22.39(\mathrm{SD} 0.21)$ & m: $21.91($ SD 0.24) \\
\hline \multicolumn{3}{|l|}{$\begin{array}{l}\text { Quality of the care you received } \\
\text { recently }\end{array}$} \\
\hline Baseline & $\begin{array}{l}\mathrm{m}: 40.10(\mathrm{SD} 5.46) \\
\mathrm{r}: 23-48\end{array}$ & $\begin{array}{l}\mathrm{m}: 38.76(\mathrm{SD} 4.88) \\
\mathrm{r}: 23-46\end{array}$ \\
\hline 2 months & $\begin{array}{l}\mathrm{m}: 39.92(\mathrm{SD} 4.62) \\
\mathrm{r}: 31-50\end{array}$ & $\begin{array}{l}\text { m: } 39.29(\mathrm{SD} 6.56) \\
\mathrm{r}: 21-49\end{array}$ \\
\hline 4 months & $\begin{array}{l}\mathrm{m}: 39.54(\mathrm{SD} 4.89) \\
\mathrm{r}: 28-46\end{array}$ & $\begin{array}{l}\text { m: 39.52 (SD 5.97) } \\
\text { r: 21-49 }\end{array}$ \\
\hline 6 months & $\begin{array}{l}\mathrm{m}: 40.10(\mathrm{SD} 4.25) \\
\mathrm{r}: 32-47\end{array}$ & $\begin{array}{l}\mathrm{m}: 40.48(\mathrm{SD} 5.63) \\
\mathrm{r}: 24-49\end{array}$ \\
\hline Total & m: $39.92(\mathrm{SD} 0.26)$ & m: 39.51 (SD 0.72) \\
\hline \multicolumn{3}{|l|}{$\begin{array}{l}\text { General quality of the care you } \\
\text { received }\end{array}$} \\
\hline Baseline & $\begin{array}{l}\mathrm{m}: 18.00(\mathrm{SD} 2.47) \\
\mathrm{r}: 11-20\end{array}$ & $\begin{array}{l}\text { m: } 17.45(\mathrm{SD} 3.70) \\
\mathrm{r}: 8-20\end{array}$ \\
\hline 2 months & $\begin{array}{l}\mathrm{m}: 17.58(\mathrm{SD} 2.17) \\
\mathrm{r}: 12-20\end{array}$ & $\begin{array}{l}\text { m: } 17.05(\text { SD 3.14) } \\
\text { r: } 8-20\end{array}$ \\
\hline 4 months & $\begin{array}{l}\mathrm{m}: 17.35(\mathrm{SD} 2.36) \\
\mathrm{r}: 9-20\end{array}$ & $\begin{array}{l}\text { m: } 16.90(\mathrm{SD} 2.88) \\
\mathrm{r}: 8-20\end{array}$ \\
\hline 6 months & $\begin{array}{l}\mathrm{m}: 17.73(\mathrm{SD} 2.12) \\
\mathrm{r}: 13-20\end{array}$ & $\begin{array}{l}\mathrm{m}: 17.62(\mathrm{SD} 2.82) \\
\mathrm{r}: 8-20\end{array}$ \\
\hline Total & $\mathrm{m}: 17.67(\mathrm{SD} 0.27)$ & $\mathrm{m}: 17.26(\mathrm{SD} 0.34)$ \\
\hline
\end{tabular}


m: mean, SD: standard deviation, r: range.

A lower mean score indicates worse patient satisfaction. Baseline satisfaction was moderately high in all four sections. We found that overall mean scores were similar for the intervention and control groups in each of the four ISSQ question sections. Within each question section there was small variability noted between the intervention and control groups. The overall standard deviation scores would indicate that data results are close to the expected value for the population. But we did not explore the statistical significance of this data set.

We collected health related quality of life data using the EQ5D to assess participants' general well-being. We positioned the EQ5D questions at the end of the ISSQ questionnaire and before a comment box (see appendix 10 ISSQ). We utilised the EQ5D five quality of life questions, but not the thermometer. We looked at the amount of missing data across the intervention and control group (see Table 242).

Table 22. EQ5D missing data

\begin{tabular}{|c|c|c|c|c|}
\hline EQ5D Question & $\begin{array}{l}\text { Total } \\
\text { Missing } \\
\text { data } \\
\text { Potential } \\
\text { n:244 }\end{array}$ & $\begin{array}{l}\text { Intervention } \\
\text { Missing data } \\
\text { Potential } \\
\text { n:160 }\end{array}$ & $\begin{array}{l}\text { Control } \\
\text { Missing } \\
\text { data } \\
\text { Potential } \\
\text { n:84 }\end{array}$ & $\begin{array}{l}\text { Data collected } \\
\text { for more than } \\
75 \% \text { of } \\
\text { participants }\end{array}$ \\
\hline 1. Mobility & $\begin{array}{l}\text { nmiss: } 19 \\
7.79 \%\end{array}$ & $\begin{array}{l}\text { nmiss: } 14 \\
8.75 \%\end{array}$ & $\begin{array}{l}\text { nmiss:5 } \\
5.95 \%\end{array}$ & Yes \\
\hline 2. Self-care & $\begin{array}{l}\text { nmiss:21 } \\
8.61 \%\end{array}$ & $\begin{array}{l}\text { nmiss: } 16 \\
10 \%\end{array}$ & $\begin{array}{l}\text { nmiss:5 } \\
5.95 \%\end{array}$ & Yes \\
\hline $\begin{array}{ll}\text { 3. Usual } \\
\text { activities }\end{array}$ & $\begin{array}{l}\text { nmiss: } 19 \\
7.79 \%\end{array}$ & $\begin{array}{l}\text { nmiss: } 14 \\
8.75 \%\end{array}$ & $\begin{array}{l}\text { nmiss:5 } \\
5.95 \%\end{array}$ & Yes \\
\hline 4. $\begin{array}{l}\text { Pain or } \\
\text { discomfort }\end{array}$ & $\begin{array}{l}\text { nmiss: } 18 \\
7.38 \%\end{array}$ & $\begin{array}{l}\text { nmiss: } 13 \\
8.13 \%\end{array}$ & $\begin{array}{l}\text { nmiss:5 } \\
5.95 \%\end{array}$ & Yes \\
\hline 5. $\begin{array}{l}\text { Anxiety / } \\
\text { depression }\end{array}$ & $\begin{array}{l}\text { nmiss: } 19 \\
7.79 \%\end{array}$ & $\begin{array}{l}\text { nmiss: } 14 \\
8.75 \%\end{array}$ & $\begin{array}{l}\text { nmiss:5 } \\
5.95 \%\end{array}$ & Yes \\
\hline
\end{tabular}

We collected data on each question from over $75 \%$ of all participants, from across the intervention and control group. Mostly, there were more missing data per question in the intervention than control group.

We looked at EQ5D data completion across the 4 timelines; at baseline, at month 2, 4 and 6 at completion of the study (see table 23). 
Table 23. EQ5D missing data across ELIJAH trimesters

\begin{tabular}{|c|c|c|c|c|c|}
\hline EQ5D Question & \begin{tabular}{|l} 
Total \\
Missing data \\
Number \\
potential n: $\mathbf{2 4 4}$
\end{tabular} & Baseline & $\begin{array}{l}\text { Trimester } \\
1\end{array}$ & $\begin{array}{l}\text { Trimester } \\
2\end{array}$ & $\begin{array}{l}\text { Trimester } \\
3\end{array}$ \\
\hline 1. Mobility & $\begin{array}{l}\text { nmiss: } 19 \\
7.79 \%\end{array}$ & $\begin{array}{l}\text { nmiss:0 } \\
0 \%\end{array}$ & $\begin{array}{l}\text { nmiss:6 } \\
9.84 \%\end{array}$ & $\begin{array}{l}\text { nmiss:6 } \\
9.84 \%\end{array}$ & $\begin{array}{l}\text { nmiss:7 } \\
11.48 \%\end{array}$ \\
\hline 2. Self-care & $\begin{array}{l}\text { nmiss:21 } \\
8.61 \%\end{array}$ & $\begin{array}{l}\text { nmiss:0 } \\
0 \%\end{array}$ & $\begin{array}{l}\text { nmiss: } 6 \\
9.84 \%\end{array}$ & $\begin{array}{l}\text { nmiss: } 7 \\
11.48 \%\end{array}$ & $\begin{array}{l}\text { nmiss: } 8 \\
13.11 \%\end{array}$ \\
\hline $\begin{array}{ll}\text { 3. } & \text { Usual } \\
\text { activities }\end{array}$ & $\begin{array}{l}\text { nmiss: } 19 \\
7.79 \%\end{array}$ & $\begin{array}{l}\text { nmiss:0 } \\
0 \%\end{array}$ & $\begin{array}{l}\text { nmiss: } 6 \\
9.84 \%\end{array}$ & \begin{tabular}{|l|} 
nmiss:6 \\
$9.84 \%$ \\
\end{tabular} & $\begin{array}{l}\text { nmiss:7 } \\
11.48 \%\end{array}$ \\
\hline $\begin{array}{ll}\text { 4. Pain or } \\
\text { discomfort }\end{array}$ & $\begin{array}{l}\text { nmiss: } 18 \\
7.38 \% \\
\end{array}$ & $\begin{array}{l}\text { nmiss:0 } \\
0 \%\end{array}$ & $\begin{array}{l}\text { nmiss: } 6 \\
9.84 \%\end{array}$ & $\begin{array}{l}\text { nmiss:6 } \\
9.84 \%\end{array}$ & $\begin{array}{l}\text { nmiss: } 6 \\
9.84 \%\end{array}$ \\
\hline $\begin{array}{l}\text { 5. Anxiety / } \\
\text { depression }\end{array}$ & $\begin{array}{l}\text { nmiss: } 19 \\
7.79 \% \\
\end{array}$ & $\begin{array}{l}\text { nmiss:0 } \\
0 \%\end{array}$ & $\begin{array}{l}\text { nmiss: } 6 \\
9.84 \% \\
\end{array}$ & \begin{tabular}{|l|} 
nmiss:6 \\
$9.84 \%$ \\
\end{tabular} & $\begin{array}{l}\text { nmiss:7 } \\
11.48 \% \\
\end{array}$ \\
\hline $\begin{array}{l}\text { Data collected for } \\
\text { more than } 75 \% \text { of } \\
\text { participants }\end{array}$ & Yes & Yes & Yes & Yes & Yes \\
\hline
\end{tabular}

We collected data each question from over $75 \%$ of all participants across the four timeline points. . Each question had some missing data.

We gathered summary statistics for the EQ5D scores at baseline and each of the two monthly timelines during the trial period. We did not formally statistically analyse the data as the trial was designed to test feasibility (see table 24).

Table 24. EQ5D summary statistics

\begin{tabular}{|l|l|l|}
\hline & $\begin{array}{l}\text { Intervention } \\
\mathbf{n : ~ 4 0}\end{array}$ & $\begin{array}{l}\text { Control } \\
\mathbf{n : ~ 2 1}\end{array}$ \\
\hline Baseline & 0.86 & 0.76 \\
\hline 2 months & 0.81 & 0.77 \\
\hline 4 months & 0.80 & 0.76 \\
\hline 6 months & 0.80 & 0.77 \\
\hline
\end{tabular}

We found there were little differences between the two groups in EQ5D scores at each time period during the trial. The intervention group had slightly higher scores at each time period. The intervention and control group scores remained largely unchanged for the trial periods.

4. Timeliness

We gained information from primary and secondary care patient records, and collected data on all ELIJAH participants (within the control and intervention 
groups) for timeliness of action from reporting of symptoms to response. We based this timeliness analysis upon the ELIJAH adverse events (see appendix 18. List of ELIJAH Adverse Events). In many cases the timings were missing in the records. The range was 1 to 120 days. We split the timings identified into time periods (see Table 25: ELIJAH timeliness).

Table 25: ELIJAH Timeliness

\begin{tabular}{|c|c|c|c|c|}
\hline $\begin{array}{l}\text { Time period from } \\
\text { recognising symptoms } \\
\text { to reporting and } \\
\text { response to symptoms }\end{array}$ & $\begin{array}{l}\text { Total } \\
\text { n:197 }\end{array}$ & $\begin{array}{l}\text { Intervention } \\
\mathrm{n}: 134\end{array}$ & $\begin{array}{l}\text { Control } \\
\mathrm{n}: 63\end{array}$ & $\begin{array}{l}<20 \% \\
\text { difference } \\
\text { between } \\
\text { intervention } \\
\text { and control } \\
\text { group }\end{array}$ \\
\hline Not Known & $\begin{array}{l}\text { nmiss: } 91 \\
46.19 \%\end{array}$ & $\begin{array}{l}\text { nmiss: } 54 \\
40.30 \%\end{array}$ & $\begin{array}{l}\text { nmiss: } 37 \\
58.73 \%\end{array}$ & Yes \\
\hline 1 day & $\begin{array}{l}\text { n: } 85 \\
43.15 \%\end{array}$ & $\begin{array}{l}\text { n: } 64 \\
47.76 \% \\
\end{array}$ & $\begin{array}{l}\text { n: } 21 \\
33.33 \%\end{array}$ & Yes \\
\hline 2-7 days & $\begin{array}{l}\mathrm{n}: 10 \\
5.08 \% \\
\end{array}$ & $\begin{array}{l}\mathrm{n}: 8 \\
5.97 \%\end{array}$ & $\begin{array}{l}\text { n: } 2 \\
3.17 \%\end{array}$ & Yes \\
\hline 8-14 days & $\begin{array}{l}\mathrm{n}: 4 \\
2.03 \% \\
\end{array}$ & $\begin{array}{l}\mathrm{n}: 4 \\
2.99 \% \\
\end{array}$ & $\begin{array}{l}\text { n: } 0 \\
0 \%\end{array}$ & Yes \\
\hline 15-21 days & $\begin{array}{l}\mathrm{n}: 2 \\
1.02 \%\end{array}$ & $\begin{array}{l}\mathrm{n}: 2 \\
1.49 \% \\
\end{array}$ & $\begin{array}{l}\text { n: } 0 \\
0 \%\end{array}$ & Yes \\
\hline 22-28 days & $\begin{array}{l}\text { n: } 0 \\
0 \%\end{array}$ & $\begin{array}{l}\mathrm{n}: 0 \\
0 \%\end{array}$ & $\begin{array}{l}\mathrm{n}: 0 \\
0 \%\end{array}$ & Yes \\
\hline Over 28 days & $\begin{array}{l}\mathrm{n}: 5 \\
2.54 \% \\
\end{array}$ & $\begin{array}{l}\mathrm{n}: 2 \\
1.49 \% \\
\end{array}$ & $\begin{array}{l}\mathrm{n}: 3 \\
4.76 \% \\
\end{array}$ & Yes \\
\hline
\end{tabular}

There was a less than $20 \%$ difference in number of participants across the control and intervention group in the timeliness of recognising, reporting and response for symptoms. However, there were a substantial amount of missing data that could not be found across the primary and secondary paper and electronic patient records (46.19\%). Clinicians, in nearly half of all entries into the patient record, documented symptoms but not the start of symptoms, or the duration.

\section{Missing data}

Overall there were more missing data in the patient reported clinical outcome (patient centeredness) than in clinical outcome information derived from the patient records (cost, safety) but in one outcome (timeliness) there was significant missing data. 
The most easily obtainable and complete data sets were in cost and safety.

\section{Clinical outcomes summary}

A summary of the clinical outcomes data, amount of missing data, and the relation to the progression criteria is displayed below (Table 26 Summary of ELIJAH results).

Table 26: Summary ELIJAH results; clinical outcomes, missing data and attainment of progression criteria

\begin{tabular}{|c|c|c|c|c|c|c|}
\hline Clinical outcome & Target criteria & $\begin{array}{l}\text { Total } \\
\text { number } \\
\text { patients }\end{array}$ & $\begin{array}{l}\text { Intervention } \\
\text { group }\end{array}$ & \begin{tabular}{|l} 
Control \\
group
\end{tabular} & $\begin{array}{l}\text { Missing } \\
\text { data }\end{array}$ & $\begin{array}{l}\text { Progression } \\
\text { criteria met }\end{array}$ \\
\hline 1. Cost & $\begin{array}{l}75 \% \text { or more of } \\
\text { patient data for } \\
\text { direct and } \\
\text { indirect costs } \\
\text { can be collected } \\
\text { over primary } \\
\text { and secondary } \\
\text { care }\end{array}$ & $\begin{array}{l}\mathrm{n}: 61 \\
100 \%\end{array}$ & $\begin{array}{l}\text { n: } 40 \\
100 \%\end{array}$ & $\begin{array}{l}\mathrm{n}: 21 \\
100 \%\end{array}$ & None & Yes \\
\hline 2. Safety & $\begin{array}{l}\text { Adverse events } \\
\text { show no } \\
\text { Suspected } \\
\text { Unexpected } \\
\text { Serious Adverse } \\
\text { Reactions } \\
\text { (SUSARs)result } \\
\text { ing from the } \\
\text { intervention }\end{array}$ & $\begin{array}{l}\text { n:0 } \\
0 \%\end{array}$ & $\begin{array}{l}\text { n:0 } \\
0 \%\end{array}$ & n:0 & None & Yes \\
\hline $\begin{array}{l}\text { 3. Patient } \\
\text { centeredness }\end{array}$ & $\begin{array}{l}\text { Patient reported } \\
\text { data (ISSQ and } \\
\text { EQ5D) can be } \\
\text { collected for } \\
\text { more than } 75 \% \\
\text { of patients } \\
\text { across the } \\
\text { control and } \\
\text { intervention } \\
\text { groups }\end{array}$ & n: 61 & $\begin{array}{l}\text { n:40 } \\
\text { ISSQ } \\
\text { missing data: } \\
5.63 \%- \\
10.00 \% \\
\text { EQ5D } \\
\text { missing data: } \\
8.75 \%- \\
10.00 \%\end{array}$ & $\begin{array}{l}\text { n:21 } \\
\text { ISSQ } \\
\text { missing } \\
\text { data: } \\
4.76 \%- \\
17.86 \% \\
\text { EQ5D } \\
\text { missing } \\
\text { data: } \\
5.95 \% \\
\end{array}$ & $\begin{array}{l}\text { Yes } \\
\text { variable }\end{array}$ & Yes \\
\hline 4. Timeliness & $\begin{array}{l}75 \% \text { or more of } \\
\text { patient data for } \\
\text { timeliness can } \\
\text { be collected } \\
\text { over primary } \\
\text { and secondary } \\
\text { care }\end{array}$ & $\begin{array}{l}\text { n:61 } \\
100 \%\end{array}$ & $\begin{array}{l}\text { n:54 } \\
40.43 \%\end{array}$ & $\begin{array}{l}\text { n:37 } \\
58.73 \%\end{array}$ & $46.19 \%$ & No \\
\hline
\end{tabular}


This concludes that it was feasible to collect data on each outcome for the intervention and control group. Cost data was easily accessible, ELIJAH participant adverse events were collected without any data missing, patient satisfaction was collected across the two study groups, and only in the timeliness outcome measure was there a proportion of missing data within the primary and secondary care records.

Overall the data collected from the intervention and control group were found to be much the same (within $20 \%$ of each other) for the safety, patient centeredness and timeliness clinical outcomes.

Feasibility study findings indicate that three out of four clinical outcomes were met for progression: cost (based on resource use), safety and patient centeredness. Timeliness did not meet the progression criteria because of the amount of missing data. The most complete data sets were cost and safety.

Cost and safety could each be considered as the potential primary outcome for a fully powered phase III trial because of the completeness of data, and attainment of the progression criteria. Cost and safety data proved easy to collect from the primary and secondary care patient records, and did not require patient reported outcomes.

There were no expected, or identified SUSARs resulting from the intervention, and the intervention was not found to be emotionally burdensome upon the patient. 


\subsection{Discussion}

\section{Summary of main findings}

The ELIJAH study was able to meet the majority of the clinical outcomes feasibility criteria. We had less than $25 \%$ missing data for both the intervention and control group for 2 out of 3 clinical outcomes judged by these criteria (cost, and patient centeredness). In addition the feasibility outcome for safety was also met, as analysis of the patients' adverse events within the trial period show there were no Suspected Unexpected Serious Adverse Reactions (SUSARs) resulting from the intervention.

We were unable to meet the progression criteria for only 1 clinical outcome measure; timeliness, as there were less than $75 \%$ of data collected. There were a large proportion of data missing across the 3 R's (see appendix 8. Data Abstraction Form and table 23. ELIJAH timeliness). We judged a complete data set for the 3R's (recognition, reporting, response to symptoms) as having information in all 3 areas. Often 1 or 2 areas had incomplete data.

Each of the study feasibility outcome criteria were met: all clinicians approached agreed to participate in the study and there were no clinician drop outs. Over $50 \%$ of patients approached to take part in the study were consented, there were no formal patient drop outs from the study, although there were missing questionnaire data in the patient reported outcome of patient centeredness. The consent and randomisation processes were effective and all patients received a combined consent and randomisation appointment that was not delayed. Some data were collected on all patients on all outcome measures. There were no whole missing data sets for any patient.

\section{Context of findings with existing literature}

The ELIJAH study did aim to compare to the real world in terms of reflecting the national IBD patient population demographic, disease distribution and care services and were mindful of the need for the study design to be representative of the typical IBD patient in terms of patient background, care delivery and health care experience.

Nationally IBD is a major cause of mortality and morbidity for men and women equally and affects and wide age range - from early teens to old age (BSG 
2005 p.2).There are about 150,000 cases in the UK with more patients with Ulcerative Colitis than Crohn's disease. The patients may have debilitating symptoms from the disease and treatments and may make frequent demands on health services from their GP's and secondary care providers (Williams et al $2007 \mathrm{p}$ 1) as patients often require close communication with long-term specialist follow up and seek and require significant involvement with their health-care providers. We found that the ELIJAH study population was generally equally balanced for gender and disease type, but for age there was a difference; there was a higher number of participants aged over 65 in the control group. We found the participants did access both primary and secondary care and required a range of interventions, medications, treatments and investigations. Most IBD care in the UK is delivered by hospital based secondary care, and integrated multi-disciplinary and multi-professional teams and this national experience was reflected and evidenced within the participant cohort. Neath Port Talbot Hospital, the setting for the study is a District General Hospital operating within the Local Health Board scenario of NHS Wales and the study participating GP practices have a care pathway to the gastroenterology services at the Hospital. Neath Port Talbot Hospital refers patients to larger tertiary centres for specialised care. This pattern of care delivery is replicated throughout the UK. The GP practices and study participants location were spread amongst semi-rural and urban districts and covered more deprived and less deprived areas, this again is replicable among the UK.

There is a paucity of existing literature regarding feasibility randomised controlled trials of the type of intervention explored.

\section{Strengths and limitations}

The clinician engagement in ELIJAH was good with no clinician within the trial across primary and secondary care withdrawing from the study or withdrawing their patients. We found no clinical resistance to the intervention or lack of clinical engagement. Evidence from work of the Royal College of Physicians (2016) is that colleagues are very keen to collect and use analysable data about their patients and increasingly supportive of the concept of the patient focused record. The involvement of a primary care clinician (a local participating GP), and participating secondary care clinicians (a Consultant Gastroenterologist and Nurse Practitioner) 
may have contributed to this success as there was local available knowledge of patient and clinical communities willing to participate in the research.

The ELIJAH study team was a multi-disciplinary and multi-professional team with core members spanning academia and clinical care. Many within the team had collaborated in high quality research projects (using mainly pragmatic randomised controlled methodology) over the previous two decades and had a cando philosophy underpinned by experience of running trials. We worked together as a team to collate the application for the study and completed the qualitative ELIJAH focus group. The team had clear demarcation of role and responsibility and was democratic and pragmatic in the approach to decision making and delegation. We met regularly (monthly), and were available for discussion at short notice should this be needed. Therefore rapid alteration and amendment where needed was carried out without affecting the set timescales. This proved very effective when the protocol amendment was required to be passed by the ethics committee (see appendix 12 . Letter of confirmation of full ethical approval). The nature of our team working contributed to the completion of the research, Shneiderman (2016) concurs that successful research teams have many of the characteristics that our team displayed;

"previous successful collaborations... mixtures of senior and junior members... (with a) shared vision... (and) schedule... regular and open discussion... (and) good communication... (all guided by) trained experienced leadership".

We maintained a tight timescale of a 6 month intervention period and a 6 month planning and reporting period. We delivered the randomised feasibility trial and intervention within a tight budget that equated to approximately $£ 1200$ per patient (61 patients, trial budget of $£ 75,000$ ) (see appendix 20. ELIJAH budget). We did not request an extension of trial period or budget.

However, because of the tight financial and time constraints of the study funding, many of the trial team generously worked more than could be funded, and many worked more hours than accounted for.

Conducting a small scale pragmatic randomised controlled trial feasibility trial was of academic interest to the trial team, as many of their previous projects had been on RCT studies many times larger than ELIJAH. Yet, the interest lay in the trial methodology as well as the intervention. We discussed as a study team whether 
carrying out the study was feasible, whether we could provide a valid trial for such limited funding, whether the intervention could be developed and implemented in such a short time period, and whether the trial team could work effectively to deliver a small RCT on a much reduced budget and time frame than they were used to. Whilst a fully powered RCT would have provided a more rigorous evaluation of effectiveness of the intervention it would have also necessitated more intensive resources in terms of time, money and participant numbers.

For ELIJAH we decided to run a pragmatic feasibility randomised trial to ensure we could remain within the budgetary and timing limitations, scrutinise the feasibility of study processes, and learn from the experience for the development of a larger trial. We keenly understood that rigorous statistical significance could not be obtained reliably from such small study numbers and the trial lacked the power to do this. However we were mindful that decisions regarding the feasibility of progression to a full trial could be gleaned from this feasibility study.

Patient recruitment was from 6 local participating GP surgeries within the same Health Board. In our planning we had originally anticipated higher recruitment rates, with the expectation that four surgeries would suffice to recruit the stipulated patient cohort. This was not the case but with the help of our GP we were quickly able to identify two further GP surgeries that were willing to participate and whose patients were willing to be consented into the feasibility trial. Consent was completed for all patients without issues. Even though all patients approached to take part in the study were under the care of the clinicians within the study team there were some reluctance of some patients to participate, perhaps because they felt the study too onerous in terms of completion of questionnaires, but we did not investigate this.

We decided to randomise patients to provide comparison data of the feasibility of data collection and implementation of the intervention. The remote randomisation process worked well and in real-time. Many feasibility studies do not randomise patients to two arms. Arain et al (2010) found that in 2007-8, out of the 54 pilot and feasibility studies critically examined in their review, just over half did randomise participants within feasibility studies. However, as this study was to inform a larger RCT we felt it important to test the feasibility of the RCT 
methodology to be used in the scaled up study that would be powered to elicit and demonstrate effectiveness of the intervention. We randomised the intervention in a 2:1 ratio in favour of the intervention to ensure a higher number of patients receive the intervention. We aimed, from the ELIJAH outcomes (feasibility and clinical), to ensure that we could present supporting data for a full trial protocol development and acknowledge this would likely involve multiple centres to ensure the numbers needed to ensure a fully powered trial.

The development of the intervention (see chapter 3) was pragmatic. We designed the ELIJAH folder and outputs in conjunction with patients and the intervention concept ideas were supported by the focus group (see chapter 2 ). The content of the folder used existing individual patient clinical data and the accompanying educationally enhanced paragraphs were taken and adapted, with permission from existing IBD patient literature from the National Association of Crohn's and Colitis (NACC). This ensured that we could provide detailed individualised personalised IBD information and education in a reliable, accepted way.

The production of the elements of My Folder: My History, My Plan and My Update were achieved with ease, but My Update proved more difficult to produce in a timely way following each visit of the patient for IBD care. The three parts of My Folder proved easier to complete from the electronic patient record than from the paper record as this took more time, and therefore more cost to produce.

It proved difficult to keep track of the 40 intervention patients IBD care pathway as there were no automatic notification system of a patient seeking help, attending an appointment, receiving an investigation or being admitted for their IBD care. Whilst it is was worthy to create a longitudinal patient record of their IBD care, perhaps in a wider trial "My History" and "My Plan" should be evaluated without "My Update" in order to pragmatically and feasibly provide clinicians and patients with summarised educationally enhanced IBD information, but potentially reduce time and cost load.

We did anticipate problems in participant compliance with the intervention and potential barriers and challenges. We thought that a larger number of patients would choose to receive the ELIJAH folder in electronic form rather than on paper, 
but this did not prove so (see table 5. Choice of method of contact). This could be because of lower levels of patient acceptance of IT delivery methods of patient information, rates of IT literacy or issues of security and confidentiality. Leahy (2009) ${ }^{17}$ stated that $75 \%$ of all American adults have access to the internet, and with the age range of IBD patients known to range from teenagers to the elderly (and reflected within the patient demographic see Table 3. Patient demographic) it was anticipated that access to internet services will be viable for at least half the patients. However, the study area of Neath Port Talbot had a mix of areas of deprivation, the participants had mostly moderate to high levels of deprivation and so may not have had access to IT services at home. No patients reported difficulties or queries regarding the security of their health information as displayed within the ELIJAH folder.

The clinical outcome data proved easy to obtain across primary and secondary care by generous access to the electronic patient records (EPR) and paper based notes. During the study period I worked within the unit from which we recruited patients, and I was used to using the GeneCIS EPR that held the IBD information, INDIGO that held pathology and histology results and PAS (Patient Administration System) that stored information on appointments and investigations, and therefore the hospital data were able to be accessed efficiently. Although I did not work in primary care, because I was employed within the Health Board the GPs were very generous in allowing me to access their EPRs without hindrance. The secondary care data were verified against the primary care data to ensure validity of the information.

The Data Abstraction Form and Adverse Events form (appendix 8 and 9), both worked well as data collection recording tools across primary and secondary care. However improvements could be made by moving from paper-based forms to electronic versions, perhaps automatically populated by existing electronic patient records e.g. the upload of medication from primary care databases.

The DAF was used to collect two clinical outcomes - cost and timeliness and this proved successful as it meant one fewer form to complete and core location of data ready for analysis. 
Timeliness was recorded on the DAF but proved difficult to identify and record across primary and secondary care. The recording of when patients noted increased symptoms was particularly hard to ascertain. In many cases there were reporting of symptoms, but not when they were noted. The response to symptoms was more regularly recorded i.e.: adjustment or prescription of medication, initiation of investigations or referral from primary to secondary care, but there was regularly missing data.

The patient reported data collected on the ISSQ (see appendix 10), was documented well by participants and there were no adverse comments made by participants about the form within the free text comment boxes. We did meet the clinical outcome criteria of over $75 \%$ collected data for the ISSQ, but improvements to the questionnaire in terms of length of questionnaire, delivery method and frequency of questionnaire sent to participants could be made for a full trial.

The ISSQ is seven pages in length, and this could be reduced by adjustment of the layout or reduction in the number of the questions whilst maintain the four key question areas. The EQ5D was completed by over $75 \%$ participants and was positioned on the last page of the ISSQ. We did not include the EQ5D thermometer but in an adapted and shortened ISSQ this could be included for more insightful patient data.

The ISSQ was paper based and in a main trial could be completed on-line or via email which would enable easier collation of data and identification of nonresponders and missing data. The ISSQ was sent to participants three times over a six month period and they were required to complete the questionnaire at baseline after consent and randomisation. This may prove too frequent in a main trial for researchers and patients, however, if the study period is elongated to e.g. a year, the frequency could be maintained but the interval between questionnaires lengthened. We sent completion reminders two weeks after sending the questionnaire if we had not received a reply, this proved effective in maximising the data yield.

The clinical outcomes were based on feasibility rather than as comparators of effectiveness of the intervention, as the study was not powered in terms of patient numbers, funding or time to make statistically significant conclusions. 
We identified that two clinical outcome measures could serve as the primary outcome measures in a larger trial (cost or safety). There were no SUSARs arising from the intervention and no adverse events, and this is in keeping with the low risk intervention design. However as was demonstrated in the focus group analysis the sharing of patient information with patients can result in raised anxiety or stress (see chapter two).

This feasibility study did not look at comparative cost data of the intervention, nor did it look at whether the cost of production of the intervention would be off set by a patient reduction in total NHS costs. For the intervention to be adopted widely a careful cost - benefit assessment would need to be calculated, especially in a National Health Service in times of austerity.

\section{Future recommendations}

The ELIJAH study has met the feasibility criteria, three out of four of the clinical outcomes. There are strengths and weaknesses of the study methodology, and for the study to be replicated or progressed to a fully powered trial, learning and adaptations to the trial protocol would be required.

Our research team integrated approach was central to the planning and development of the study. A future research team should consider a multiprofessional structure of academics and health care professionals including participation of primary and secondary care clinicians (doctors and nurses) who can give local knowledge of healthcare settings and patient populations. However, a more realistic accounting of the cost of required personnel and expertise would be required to ensure professional costs are covered.

Whilst our team consulted with patient representative groups and piloted the intervention with patients, we did not have a patient representative within the research team, this would be a recommendation for future teams to ensure highlevels of patient engagement and participation throughout the research trial.

I worked within the research team as a researcher-practitioner. I was employed as a Nurse Practitioner (Band 7 on the Agenda for Change pay-scale) delivering IBD care to the patient population included within this study. The advantages were that I had experience or working with the patient population and Health Board structures and could plan and implement the intervention using local 
knowledge. However, if replicated, the practitioner implementing the intervention would not need to be a researcher, and trial teams may assign the collation of information and production of the intervention to a band 6 nurse, perhaps most appropriately a nurse specialist in IBD. This would ensure the nurse has a subspecialised knowledge of IBD and the local population and structures, be used to using the medical notes and EPR for pertinent data, and be able to act autonomously, whilst being cost effective. A general band 5 nurse may not have the skill set to deliver the intervention, a band 7 nurse may be too un-necessarily expensive and skew the cost analysis.

We did not explore the feedback of health professionals about their opinions of the ELIJAH intervention, nor their use of it. Collection and analysis of this would be a key recommendation for future research to ensure joint care givers and patient satisfaction is correlated.

This study provided feasibility data about the intervention but not rigorous evaluation of the intervention effectiveness. In order to obtain this information a fully powered RCT would need to be undertaken. This would require more resources in terms of time, money and sites and participant numbers. A fully powered RCT would be required to obtain statistical significance of the intervention and some of the methodology, intervention product design and delivery methods be altered.

A control and intervention group would be required again but a 1:1 ratio would be adequate to obtain comparison between the two groups of participants.

The ease of production of the elements of "My folder" were variable. "My History" and "My Plan" information proved relatively easy to glean from the patient notes and EPR but "My Update" proved more difficult as there were no automatic notification of when the patient had attended primary or secondary care. In a larger trial, an electronic notification system would be needed or if not possible, the "My Update" component be dropped from the intervention. "My Plan" could be updated as changes occurred without the need to complete the third part of the intervention to pragmatically and feasibly provide clinicians and patients with summarised educationally enhanced IBD information, but potentially reduce time and cost load.

Patient notes proved feasible to obtain and analyse, but more time consuming than accessing the primary and secondary care EPR. A future recommendation 
would be for data to be obtained from the primary and secondary care EPR. The intervention was offered to participants as a paper and/ or electronic version a future recommendation would be to offer the intervention in electronic version only as an email attachment to participants and clinicians.

Cost, safety and patient centeredness clinical outcomes were met by the study but timeliness was not. Timeliness was recorded on the DAF but proved difficult to identify from the primary and secondary care records, especially the time between recognition of symptoms and reporting of symptoms. In a larger trial this clinical outcome measure should not be included.

The Data Abstraction Form and Adverse Events form (appendix 8 and 9), both worked well but again were paper based, in a full multi-centre trial it would be prudent to move to electronic versions, some of which could be automatically completed by links to the EPR.

The ISSQ was paper based too, and in a main trial could be completed by participants on-line or via email. It was completed by participants immediately after consent and randomisation and this should be replicated in a larger trial as it enables a baseline to be established. It was then sent to patients three times - at two, four months from baseline and at the end of the trial at 6 months. This close interval may prove too frequent in a main trial for researchers and patients, the study period should be elongated to one year, and the frequency of ISSQ completion be maintained but the interval between questionnaires lengthened. Sending reminders to patients after two weeks if the ISSQ had not been returned proved effective and should be followed in a larger trial.

The ISSQ was seven pages long with the EQ5D at the end of the questionnaire. The questionnaire should be shortened with less questions but maintaining the four sections. We did not include the EQ5D thermometer but in an adapted and shortened ISSQ this could be included for more insightful patient data.

The study methodology, intervention and data collection was feasible but more research would be needed to establish whether the intervention is effective. 


\subsection{Conclusion}

The study has shown that the ELIJAH intervention has met all of the feasibility criteria, that:

- $50 \%$ or more of individual clinicians approached agree to take part in the study

- $50 \%$ or more of patients eligible to take part in the study are consented

- $75 \%$ or more of patients are consented and randomised in real time at the same appointment

- Less than $20 \%$ of patients drop out from the study

- Data are collected on all outcome measures for over $80 \%$ of patients And feasibility study findings indicate that at least 3 out of 4 outcome measures were feasible to collect in the intervention group and the control group.

- $75 \%$ or more of patient data for direct and indirect costs (cost) can be collected over primary and secondary care

- Adverse events show no Suspected Unexpected Serious Adverse Reactions (SUSARs) resulting from the intervention and there is less than $20 \%$ difference between the intervention and control group for adverse events, including Serious Adverse Events (SAE) with causality related to the ELIJAH intervention.

- Patient reported data (ISSQ and EQ5D) can be collected for more than 75\% of participants across the control and intervention groups.

One clinical outcome was not met; timeliness. Recommendations within the discussion have concluded that due to difficulty in data collection, this outcome measure should not be replicated in future studies or included in a larger fully powered trial.

We have identified a potential primary outcome for a fully powered trial; cost and it has been shown feasible to collect data on this outcome measure.

The progression criteria to advance this study from a feasibility study to a fully powered phase III randomised controlled trial have been achieved but the trial protocol and methodology would require modifications: 
- The cost per participant would need to be increased.

- The timing of the trial should be increased to one year.

- The trial should be multi-centre in order to include the number of participants required to ensure the trial is fully powered.

- A band 6 IBD nurse specialist should formulate the intervention.

- The trial should explore the satisfaction of participants and health professionals.

- A 1:1 ratio of intervention to control of the intervention should be used.

- "My Update" should not be included as a part of "My folder", instead changes should be made to "My Plan".

- The intervention should be populated by information from the primary and secondary care EPR.

- The intervention should be offered via IT only.

- Timeliness should not be included as an outcome measure.

- The DAF, AE form and ISSQ should be used for data collection but in electronic form and linked to the EPR and automatically populated from it where possible.

- The ISSQ should be shortened and include the EQ5D plus thermometer.

This chapter has demonstrated how we conducted a feasibility trial using the ELIJAH intervention. We have demonstrated that the study feasibility and clinical outcomes of the intervention were largely met and that the study is feasible. I have also explored how the study should be adjusted and modified to enable progression to a phase III randomised controlled trial. There is a need for more study in this area and protocol development. We have contributed to the body of evidence in an area that has previously been little explored. 


\section{Chapter 5: A reflection on my research as a nurse practitioner.}

In the previous chapter I discussed the ELIJAH pragmatic randomised controlled feasibility trial. I described the methodology used to carry out the trial, examined the results obtained and considered issues arising from the within the discussion. One of the points made within the previous chapters' discussion was regarding the perceived effective nature in which the research team worked together. In this chapter, I will explore my experience of working within the research team whilst we conducted a feasibility trial of ELIJAH using a randomised controlled trial methodology. 


\subsection{Background}

With the success of a research application to The Health Foundation, our multi-professional research team was awarded $£ 75,000$ to carry out a pragmatic randomised controlled feasibility trial (ELIJAH, discussed in chapter 4). We initially built our research team from applicants on the research award (Chief Investigator (Consultant Gastroenterologist), Principle Investigator, Computer Scientist, Methodologist and Health Economist). We enlisted further professionals from other disciplines to provide additional support, advice and expertise (local G.P., Trial Manager, a Professor specialising in Qualitative research). We also sought the expertise of a Nurse Academic within the trial team as the intervention was to be produced and distributed by a clinical nurse and we wanted to be mindful of any nursing issues that could affect the running of the trial.

As a team we considered various ways to explore the intervention. The research team gave me insights into the potential methodologies we could employ, and after careful consideration we chose the randomised controlled trial. I acted within the team as the Principle Investigator while continuing to work within the NHS setting as an Advanced Nurse Practitioner in Gastroenterology. Patients for the study were taken from the IBD population within my workplace; some, but not all were under my care.

The enlarged and empowered research team planned the qualitative and quantitative elements of the trial together (focus group and randomised controlled feasibility trial). There however was a marked difference, and less enthusiasm from the Nurse Academic noted whilst I was undertaking the quantitative part of the research. During the qualitative focus group development, there was a high level of partnership working and engagement. In the planning and execution of the RCT feasibility trial I felt from discussion with the Nurse Academic, that our choice of RCT methodology seemed to struggle to fit in traditional nursing research. The reasons for this were explored by the student but still remain largely unclear. The Nurse did state she had a lack of experience within the research field of RCTs and was unused to working in research teams but also that the methodology did not fit in nursing research. I was interested in why this may be the case and so have reflected on the experience, with specific focus on whether the methodology can or is used by 
nurses more widely, and whether there is a reasoned disparity between nursing and the RCT.

I have used a reflective tool (Rolfe et al 2001) to explore these questions as this is a widely accepted nursing line of enquiry. 


\subsection{Reflection}

Nurses have been encouraged to use and adhere to reflective methodology to enquire about their practice (e.g. Johns 2009, Pierson 1998, Taylor 2006, BradburyJones et al 2009) and use the reflection to implement change in practice.

In the hierarchy of methodology, reflection would be classed as "expert opinion" (Dieppe 2004), because it is a subjective method whereby personal thinking and feeling is analysed and used to amend or support future action. The RCT would be classed as the gold standard of research methods in terms of rigour, replicability and minimised bias (Bench et al 2013).

Reflection can, perhaps, be viewed as the antithesis to the scientific trial method of enquiry, and especially: the randomised controlled trial (RCT). The fluidity and realism of reflection and the rigidity and artificialness of the RCT do seem to be diametrically opposed.

This reflection of an RCT can therefore, seem to be unusual and unorthodox because of the mix of two such different methodologies. However, Mantzoukas (2006), states that the two methodologies hold "very similar definitions, aims and procedures" for eliciting evidence for practice, and reflection in and on practice. The embodiment of reflection within, and upon practice, and the opportunity for truly "reflective practitioners" (Schön 1983) encourages reflection while practising all elements of a role, including conducting research.

In the nursing literature personal reflection upon carrying out or taking part in RCTs is rare; I identified only one article addressing this. Newall et al (2009) describes the discussions of a focus group of Australian nurses who had carried out an RCT. The use of a formalised reflective model for reflection of carrying out an RCT is absent.

The reflective model I chose (Rolfe et al, 2001), "addresses both the macro and micro levels of reflection" and includes "descriptive... theory and knowledge building (and is) ... action orientated". Elements within the tool build to a detailed, easy to apply list of questions. The framework is levelled at nurses and in particular Advanced Nurses due to its simple practicality and depth of insight within 3 simple questions "What ...So what... Now what" (Rolfe et al 2001). 


\section{What.....}

My role as Principle Investigator was designated and defined by the research team and defined within the "Responsibilities of Sponsor" (Russell 2010) within a Standard Operating Procedure of the trials unit overseeing the trial.

We followed The Medical Research Council two seminal documents: $A$ framework for development and evaluation of RCTs for complex interventions to improve health (2000) and update: Developing and evaluating complex interventions: new guidance (2007) and developed a mixed methods approach with a focus group and pragmatic randomised feasibility trial that contained a blend of feasibility outcome measures.

Full ethical and NHS Trust research and development approval was sought and obtained before the intervention commenced.

To summarise: I held a focus group to inform the intervention and clarify patient's preferences. Full analyses of the transcription from the discussion group was carried out using summative analysis (Rapport 2010). All members of the ELIJAH team contributed to the discussion and this was an example of the research team working very well, quickly and efficiently together with an enthusiastic 'can do' attitude.

We then worked together to develop the intervention and research methods. We implemented this with 61 participants recruited from six local GP surgeries. During this phase of the research process we noted that one member of the research team (the Nurse Academic) was uncomfortable with the research methodology of the RCT.

\section{Randomised controlled trial methodology and nursing}

The randomised controlled trial (RCT), also known as the true experiment or classic experiment, has as its main feature a comparison of the outcomes of two or more groups of participants who receive either an intervention (known as the intervention group) or placebo or treatment as usual (control group). The aim of the RCT is to maximise the elimination of bias from the study by randomising participants into comparable groups that are as similar as possible and blinding the investigators and / or participants as to what group allocation they have received 
(Bowling 2004). In comparing outcomes, the classic RCT is powered to elicit and demonstrate effectiveness of the intervention. Therefore, because of its rigor, straightforwardness of methodology for use, and ability to demonstrate unbiased effectiveness of intervention, the RCT sits at the zenith of the hierarchy of research methodologies. Robson (2002) states that the power of the RCT has led to it being recognised as the "gold standard... in the many fields of applied research", and furthermore represents the "method of choice if you seek to do quality research" (Robson 2002). Dieppe (2004) acknowledges the RCT position, and states that it attains the:

"premier position of 'top dog' in the production of high quality evidence for systematic reviews and meta-analyses"

(Dieppe 2004).

The ability of RCTs to combine to form powerful longitudinal collective evidence has constituted the bulk of the Cochrane library. Cutting, (2008 p. 216) recognises that the Cochrane library content is the basis upon which decisions in healthcare and academia are made, as they "rank evidence according to its perceived value in clinical care".

The RCT has been adopted by medicine enthusiastically and constitutes the "heartland of medical research" (Robson 2002 p. 116) with RCTs forming the substantive majority of evidence. Nursing, though, has not endorsed RCT methodology with such emphasis. Fridlund et al (2014), found a paucity of Cochrane reviews of RCTs led by nurses, and Seers, (1997) stated that only $1 \%$ of reviews within the Cochrane library were conducted by nurses or concerned nursing interventions. The reasons for this difference in approach to evidence-based practice between Medicine and Nursing evidence based research are unclear. The perceived weaknesses of the RCT methodology by nurses may account for some of the preferred use of other methods such as qualitative enquiry. Nursing research is sometimes viewed as distinct from medical research in terms of professional enquiry, and as a result has a different evidence base that reflects nursing's holistic philosophical practice. It can also be argued that nursing practice can be seen as incompatible with the RCT reductionist requirement to distinguish and test separate interventions (Hicks 1998). Traditionally, Nursing views practice as delivering complex care via a holistic intervention (Coates 2004). Specific outcomes relating to 
practice change may be difficult to implement. The RCT is more resource-intensive in terms of money, time and participant numbers than less rigorous methods, and it may be more difficult for nurses to access these essential ingredients (Bench et al 2013). Bowling (2002) suggests a fourth reason could be because "there is often professional resistance" (p. 227) to the use of the RCT and suggests this is due to ingrained and philosophical opposition.

Nursing has assumed a mainly qualitative methodology and embraced an individualised holistic approach to the accumulation of a nursing evidence base. Robson (2002), in the aptly titled Real World Research, offers unequivocal support of the RCT and urges all researchers to consider the RCT as research methodology "if you can find a feasible and ethical means of doing this" ( $p$ 114) because of its power to deliver "the best evidence for effectiveness, for whether something "works"' (Robson p116). There is acknowledgement that nursing whilst constituting the majority of healthcare employees does lack a strong voice for its evidence base. Seers (1997), recommends that a "core culture change" (p1) in nursing research is needed to rectify the imbalance between nursing developing new tested interventions and requiring a robust research base.

\section{So what}

Literature recounting reflections of nurse researchers' carrying out RCTs are rare. Brooker et al (1999) qualitatively researched why a RCT conducted within an $A \& E$ department failed to recruit enough participants to the intervention, and why the trial was discontinued. Many of the reasons were nursing related

"stress and poor morale... differences in perception concerning the value of the research"

\section{(Brooker et al 1999)}

Brooker also cites that nurses did not believe that the intervention was being tested appropriately, and that the load of work for the unit nurses was disproportionate. Newall (2009) also found that Nurses conducting an RCT found that it was more time intensive Duncan and Haig (2007) also list may difficulties encountered during their RCT. In a section entitled "reflection" they list "extraneous components" such as poor recruiters to the study and nurses who did not complete data collection adequately. It was noted however, that Nurses miss an opportunity to 
express how these difficulties made them feel. Newall (2009) does list some positive experiences of an RCT listed by the interviewees in the focus groups including finding the trial "exciting and stimulating" (p27), being able to provide enhanced patient care and "raising the profile of the organisation" (p28).

We successfully carried out the ELIJAH randomised feasibility controlled trial, and I can recognise and felt many of the frustrations and disappointments listed above, but also the positive aspects of carrying out an RCT. The experience was arduous, frustrating, challenging in the extreme, tiring and resulted in instability in existing work practices and difficulties in work and study relationships particularly within the research team.

These difficulties resulted in some professional and academic isolation resulting from an acute and repeated voicing of the unorthodox choice of a nurse to conduct an RCT. The choice was met with suspicion, fear and sometimes high emotion. The intervention and study were dismissed because they purportedly had less nursing and a more medical emphasis and my role as a nurse and position within the team was discredited.

Perhaps if the trial had been halted prematurely or been adversely affected by external influences all I would reflect is that the journey had been extremely difficult. However, ELIJAH has proved more than a chore.

The experience of working within such a long-standing, influential and generous team has provided the stability and advice needed to tackle each challenge in turn: from ethical consent to protocol writing, design of the intervention to recruitment and statistical analysis planning.

The research funds awarded paid for specialist time, health economics, methodology and information science, and gave kudos to the project.

We also had unqualified support from clinical, nursing and managerial staff within the work environment in which the intervention was applied.

My time to conduct ELIJAH was protected, was flexible, and, used effectively by holding regular and well-attended research team meetings which concentrated on planning the phased research. 
The highs of the trial period have far outweighed any lows. Educationally, I have unusually had experiential research training, rather than the more traditional front-loading of theory.

Clinically I feel I have been able to offer my patients an innovative, more patient orientated and personalised way of care. I have also learned much about patient medical, nursing history and treatment. I also feel I have improved my clinical confidence.

Personally, I feel as though I have experienced more about myself and my patients' experiences by carrying out the RCT than the usual clinical setting allows given the constraints of time and hectic schedules.

I have learnt that I have previously untapped depths of tenacity, problem solving, enthusiasm, persistence and resolve. Each step of the RCT was an exciting challenge and completing them gave me enormous personal satisfaction and confidence to approach the next task. I enjoyed the process of carrying out the RCT enormously. I have thrived professionally on the work and felt enormously proud of the project and my part in it. Lomas et al (2002) advised that research projects should be:

"of interest, exciting and innovative as well as simple in design and easy to manage"

(Lomas et al 2002 p. 35).

ELIJAH has fulfilled each of these requirements.

ELIJAH has largely achieved the feasibility criteria to allow progression to a Phase III protocol development. However, ELIJAH has delivered far more educationally, professionally and personally to me than the success of the trial.

\section{Now what}

Although a small feasibility trial, our learning from the trial has provided a robust evidence base for a phase III trial. I will refine and develop the intervention and methodology in light of the trial findings.

I would like to work in research teams in the future and aim to recreate many of the aspects that contributed to our team cohesiveness. Culotta (1993) states that research teams made up of multi-professionals who bring with them diverse 
expertise, experience and ideas are becoming more usual, and two decades later Shneiderman (2016) states that collaborative research teams are now becoming a normal way of conducting complex research.

I would like to continue as a practitioner-researcher after ELIJAH, and fully integrate these two symbiotic roles. Robson (2002) calls these roles "the true hybrid: someone whose job is officially part-practitioner, part-researcher". In ELIJAH, the service intervention arose from questions from my practice, and by working with my patients as participants I was able to provide higher clinical care to all my patients by integrating found theory and research findings into practice. I would like to evaluate practice with further RCTs and try to redress the imbalance of too few RCTs being carried out by nurses, about nursing interventions.

I also wish to provide the support and advice to others that I was fortunate to have had in abundance from the research team. Wang Vedelø and Lomborg (2010) state that there is a need for nurse researchers and clinical nurses to work more openly together and provide more "education, training and support ... (to) increase the success rate and quality of nurse-led ... RCT" (p. 199). 


\subsection{Conclusion}

In reflecting on my research journey of carrying out an RCT, and particularly the exploration of some of the nursing views of the use of the methodology, I have identified that my experience described is probably not unique. I have highlighted some of the wider nursing views about the methodology and why some nurses may not, or may not be encouraged, to choose this methodology for their research.

The RCT is possible in nursing research and can be the most appropriate methodology applied to an exploration of an intervention. It can also be enjoyable and can contribute to the evidence base for nursing and in wider contexts such as the Cochran library. Whilst nursing has not had a strong tradition of conducting RCTs, the opportunities to redress this by nurses conducting rigorous, well designed, funded and supported original research to impact patient care and experience, seems to be available, possible and necessary in order for nursing to advance its evidence base.

This chapter has explored part of my experience whilst carrying out a randomised controlled feasibility trial of the ELIJAH intervention. In the next chapter I will combine the learning from the trial (modifications identified to progress the trial) and my experiential learning, to describe a protocol for a fully powered phase III randomised controlled trial of ELIJAH. 


\section{Chapter six: Systematic literature review}

\subsection{Background}

So far within this thesis I have described how we identified a deficit in the capacity of our IBD service to meet patient demand for services and information, and I have discussed how we addressed this issue and tested our ideas. In the introduction I described the service pressures that led to our consideration of new ways to provide additional services that would inform and empower patients to better self manage their condition. In chapter two I explained the findings of a focus group that we undertook to explore patients' views of individualised patient held reports that provided additional education about IBD. The participants of the focus group endorsed the ideas we proposed and gave very useful insight into the development of personalised, educationally enriched IBD reports. The adjustment of our electronic health record to generate these reports was related in the following chapter, and the testing of the intervention via a randomised feasibility trial was relayed in chapter four. The feasibility trial found that "My folder" intervention was feasible with no adverse events or safety concerns. A reflection of the experience of conducting the trial has been included in the previous chapter.

Within this chapter I will explore how our approach to the identified problem fits with the existing body of contemporaneous evidence. In 2010 to 2011 when we held the focus group, built the intervention and carried out the feasibility trial, we conducted a short literature review of use of electronic healthcare records and looked to see if others had described similar interventions. The literature trawl identified only a few studies at that time. During this time I was enrolled on a Doctorate course in the School of Healthcare Sciences and a formal systematic literature review was not required. When the doctorate program was wound down in 2013, I took a one year sabbatical, moved to the Medical School and transferred to a $\mathrm{PhD}$ in Medical and Healthcare studies to complete my candidature. The criteria for a $\mathrm{PhD}$ in Medical Healthcare Studies did required the submission of a thesis and I undertook an additional up-to-date systematic literature review in 2018 to help inform the thesis and to illustrate any new developments in the field that would not have been apparent when we first started the research. I have included the systematic literature within the thesis here to reflect accurately the chronological order of the research. 
This systematic literature review, carried out in 2018, aimed to review the current literature pertaining to the creation and trials of individualised educationally enriched IBD information, the use of this by patients and its outcomes. Our focus was to identify and appraise the current processes and research described in the literature that addressed our area of interest, to reflect on the findings from the focus group and feasibility trial in light of this new evidence, and amass evidence to assess if further research in this field would be pertinent. 


\subsection{Methods}

\section{Search strategy}

The methods used in this systematic literature review followed the PRISMA (Preferred Reporting Items for Systematic Reviews and Meta Analysis) 2009 guidelines and statement (see appendix 21).

We wanted to ensure all relevant studies were included, and as such a wide search strategy was employed. We searched the following eleven electronic databases via Ovid SP: AMED, BNI, CINHAL, Cochrane, EMBASE, EMCARE, Google Scholar, Medline, Psychinfo, TRIP and Web of Science. The detailed search strategy per database are found in appendix 22.

A search filter was used for the databases including inclusion and exclusion criteria. Table 27 highlights the inclusion / exclusion criteria used for study selection.

Table 27: Systematic literature review inclusion and exclusion criteria

\begin{tabular}{|l|l|}
\hline Inclusion criteria & Exclusion criteria \\
\hline $\begin{array}{l}\text { Citations published between } 2000- \\
2018\end{array}$ & Citations pre 2000 \\
\hline Worldwide publications & Acute disease \\
\hline $\begin{array}{l}\text { Target population: IBD and variations } \\
\text { of IBD }\end{array}$ & \\
\hline Chronic disease & \\
\hline $\begin{array}{l}\text { Construct: Individualised patient } \\
\text { education }\end{array}$ & \\
\hline
\end{tabular}

The inclusion criteria, like the systematic literature review were broad. We did limit the search to the years 2000-2018 as we hypothesised that prior to this date there was little interest from legislators or researchers in EHR's, digitalisation of patient information or sharing of information with patients. We included international publications to capture the global developments in this area and included papers particularly reporting IBD or chronic disease as this was the condition suffered by our patient group. We were particularly interested in amassing information on any interventions and / or trials of individualised patient information as this development was closely aligned to our idea for expansion of GeneCIS. 
We employed a text search within the electronic databases to identify peerreviewed research publications. The search terms included variations of the search inclusion criteria. The search terms used were:

- Health records

- Personal health record

- Patient portal

- Medical records

- Electronic medical records

- Patient access to records

- Patient held record

- Personalised / personalized patient held

- Individual patient record

- Individualised / individualized patient record

- Chronic disease / chronic illness or Inflammatory bowel disease : Colitis / Ulcerative colitis/ Crohn's disease/ proctitis

The key search terms were created from relevant terms within three main areas: firstly, the construction of various platforms to give patient information held in records to patients, how patient could access these and effects of this, secondly, whether these records were individualised, and lastly, whether the records were for IBD or chronic disease patients. The list below shows how these search terms were grouped:

1. Health records, Personal health record, Medical records, Electronic medical records, Patient access to records, Patient held record,

2. Personalised / personalized patient held, Individual patient record, Individualised / individualized patient record, Patient portal

3. Chronic disease / chronic illness or Inflammatory bowel disease : Colitis / Ulcerative colitis/ Crohn's disease/ proctitis

These three topic areas were merged together. The search term combinations were Medical Subject Heading (MeSH) terms, text words and word variants for the three topic areas. Key word combinations were developed in consultation with a 
medical librarian and based on the topics and used in the literature search (see table 28: Key word combinations)

Table 28: Key word combinations

\begin{tabular}{|l|l|l|}
\hline Words & And & Or \\
\hline Health records & $\begin{array}{l}\text { Inflammatory bowel } \\
\text { disease }\end{array}$ & Chronic disease \\
\hline Personal health record & Colitis & Chronic illness \\
\hline Patient portal & Ulcerative colitis & \\
\hline Medical records & Crohn's disease & \\
\hline $\begin{array}{l}\text { Electronic medical } \\
\text { records }\end{array}$ & Proctitis & \\
\hline Patient access to records & & \\
\hline Patient held record & & \\
\hline $\begin{array}{l}\text { Personalised / } \\
\text { personalized patient held }\end{array}$ & & \\
\hline Individual patient record & & \\
\hline $\begin{array}{l}\text { Individualised/ } \\
\text { individualized patient } \\
\text { record }\end{array}$ & & \\
\hline
\end{tabular}

Key words were searched in each of the databases with IBD and chronic disease variations separately to maximise the opportunity of identifying citations. We hypothesised that if we searched with IBD terms only our yield of relevant articles may have been very low, unrepresentative of the wider developments and we would miss areas of development that could be relevant and transferrable from other chronic disease groups.

Targeted hand searches using publications identified in the initial searches were carried out and the references of all primary studies and review articles were hand-searched in order to identify studies missed in the electronic search. Additional publications were identified by contacting relevant clinical experts and the grey literature was sought by searching abstracts including research reports, conference publications, government reports and policy documents.

\section{Study selection}

We employed a two stage process for assessing and selecting the literature to be included in the systematic review. Two researchers independently screened the title and abstract of all citations identified by the search strategy. If there were differences in outcome of their scrutiny of the evidence, a meeting was held to 
discuss the articles and agreement was sought. We independently assessed the citations based on relevance to the identified topic areas and intervention development. The references of these articles were scrutinised to obtain any additional relevant articles. Full texts of the eligible articles were obtained and the full paper analysed by the two researches using the same two-stage process.

\section{Data collection}

Data of the evidence were collected and captured. We recorded information about the year of publication, population, location of trial or authors, study design, number of participants or articles included and quality of the paper. We then extracted topics or themes addressed by the papers and identified findings and outcomes.

The papers were grouped according to whether they were published pre or post our feasibility trial in 2011, whether the research or authors were based in the UK or were worldwide, whether the literature was from peer reviewed papers or from grey literature, whether the paper addressed IBD patient care particularly or other chronic disease and the quality of the articles. Topics and themes running through the gathered literature were identified.

\section{Quality assessment}

We included all original articles in English describing the development and / or the qualitative or quantitative evaluation of patient accessed individualised records. Articles were included if they assessed or described one element of our proposed intervention.

We decided to assess and evaluate the primary studies identified by reviewing the effectiveness of the interventions described and presented the findings as a narrative synthesis as the majority of the studies were qualitative. We adapted an existing validated relevant criteria specifically designed for this, described by Thomas et al 2004: the EPHPP instrument (Effective Public Health Practice Project), see Table 27. We changed the tool from descriptive outcomes (strong, moderate and weak) to a scoring system for easier comparison between studies and ranked the studies from the highest score (best quality) to lowest numerical score (poorest quality). Each quality marker (selection bias, design, confounding factors, blinding, use of data collection tools and number of withdrawals) was assessed using 
the two-stage process we used when selecting the studies to be included in the systematic review. I and a second independent reviewer quality assessed each paper and discussed disparities in the marking. Where there was disagreement after discussion, I met with my academic supervisor to agree the scoring.

While the EPHPP was designed specifically for use in systematic literature reviews related to public health nursing, the tool has been tested for its flexibility to adapt to up to date methods of systematic review (Thomas et al 2004). The EPHPP instrument has been used successfully in chronic disease prevention systematic reviews and so relates well to our thematic area.

The articles we identified for inclusion in the systematic review were numerically scored according to the criteria below (Table 29).

Table 29. Quality of studies

\begin{tabular}{|l|l|}
\hline Selection bias & $\begin{array}{l}\text { Selected cohort was very likely to be representative of the IBD } \\
\text { or chronic disease population and greater than 80\% } \\
\text { participation rate (2) } \\
\text { Selected cohort was somewhat likely to be representative of the } \\
\text { IBD or chronic disease population and } 69-79 \% \text { participant rate } \\
(1) \\
\text { All other responses or not stated. }\end{array}$ \\
\hline Design & $\begin{array}{l}\text { Randomised Controlled Trials and Controlled Clinical Trials } \\
\text { (2) } \\
\text { Cohort analytical, case control, cohort or an interrupted time } \\
\text { series (1) } \\
\text { All other designs or design not stated (0) }\end{array}$ \\
\hline $\begin{array}{l}\text { Confounding } \\
\text { factors }\end{array}$ & $\begin{array}{l}\text { Controlled for }>80 \% \text { of confounders (2) } \\
\text { Controlled for 60\% - 79\% of confounders (1) } \\
\text { Confounders not controlled or not accounted for (0) }\end{array}$ \\
\hline Blinding & $\begin{array}{l}\text { Blinding of outcome assessor and study participants (2) } \\
\text { Blinding of outcome assessor or study participants (1) } \\
\text { No blinding to intervention status or research question (0) }\end{array}$ \\
\hline $\begin{array}{l}\text { Data collection } \\
\text { tools }\end{array}$ & $\begin{array}{l}\text { Tools are valid and reliable (2) } \\
\text { Tools are valid but reliability not described (1) } \\
\text { No evidence of validity or reliability (0) }\end{array}$ \\
\hline $\begin{array}{l}\text { Withdrawals and } \\
\text { dropouts }\end{array}$ & $\begin{array}{l}\text { Follow up rate of }>80 \% \text { of participants (2) } \\
\text { Follow up rate of 60\% - 79\% of participants (1) } \\
\text { Follow up rate of < 60\% of participants or withdrawals and } \\
\text { dropouts not described (0) }\end{array}$ \\
\hline
\end{tabular}

The full scoring table of the articles is included in appendix 23. The maximum achievable score was 12 . No studies were removed from the systematic 
literature review because of their quality assigned scores or issues highlighted in the discussion of the results of the systematic literature review. 


\subsection{Results}

A total of 1203 citations were identified from the electronic database searches (see appendix 22) and 43 publications through other sources obtained through searches of the grey literature. Fourteen duplicates were identified and removed, and 1232 records were screened and reviewed via a title and abstract review of the paper. Of these a further 1020 were deemed ineligible for inclusion in the systematic literature review. A total of 212 full-text citations were retrieved for detailed evaluation. Following critical appraisal of the publications 65 were included in the literature review (60 of which were identified from the electronic database search, see appendix 4). A total of 147 studies were excluded; 142 were identified as off topic, three were unavailable in English and two were unobtainable. The PRISMA 2009 Flow Diagram below (see figure 10) pictorially represents these results.

Figure 10: PRISMA 2009 Flow Diagram

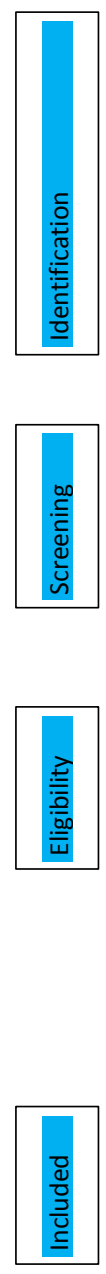

\section{Records identified through} database searching $(n=1203)$
Additional records identified through other sources $(n=43)$
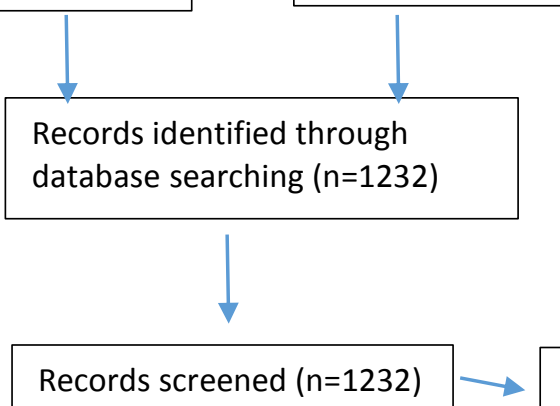

Records excluded $(n=1020)$

Full-text articles excluded, with reasons $(n=147)$

Full-text articles assessed for eligibility $(n=212)$

Off topic $(n=142)$

Not available in English $(n=3)$

Unobtainable $(n=2)$

Studies included in synthesis $(n=65)$ 
A summary of the articles included in the systematic literature review synthesis and their main characteristics are detailed below (table 30). Because of the heterogeneity of the papers found we will carry out a narrative synthesis. 
Table 30: Summary of articles included in literature review

\begin{tabular}{|c|c|c|c|c|c|c|}
\hline $\begin{array}{l}\text { Article } \\
\text { number }\end{array}$ & Author & Year & Population & Location & Study design & Number of pa \\
\hline 1. & Al-Sahan A. & 2016 & $\begin{array}{l}\text { Primary and } \\
\text { secondary care }\end{array}$ & $\begin{array}{l}\text { Saudi } \\
\text { Arabia }\end{array}$ & $\begin{array}{l}\text { Qualitative questionnaire } \\
\text { and focus group }\end{array}$ & $n=424$ patients \\
\hline 2. & Archer J.S. et al. & 2014 & Chronic illness & Canada & Systematic review & $\mathrm{n}=11$ articles \\
\hline 3. & Bartlett C. et al. & 2012 & Renal medicine & UK & Qualitative survey & $\mathrm{n}=583$ patients, $\mathrm{r}$ \\
\hline 4. & Bell S.K. et al. & 2015 & & USA & Qualitative survey & n=99 clinicians \\
\hline 5. & Bhavnani V. et al. & 2010 & Primary Care & UK & Quantitative survey & $\mathrm{n}=231$ patients \\
\hline 6. & Bidmead E. et al. & 2016 & IBD & UK & $\begin{array}{l}\text { Qualitative interviews and } \\
\text { Case study }\end{array}$ & $\begin{array}{l}n=56 \text { patients, } n= \\
\text { professionals }\end{array}$ \\
\hline 7. & Casey I. et al & 2016 & Chronic disease & USA & Qualitative questionnaire & $\mathrm{n}=50$ patients \\
\hline 8. & Chunchu J.J. et al. & 2012 & Chronic illness & USA & Pilot feasibility study & $\begin{array}{l}\text { Focus group } n= \\
\text { patients } n=14 D \\
\text { assistants }\end{array}$ \\
\hline 9. & Cimino J.J. et al. & 2000 & Secondary care & USA & Observational study & $\mathrm{n}=11$ patients \\
\hline 10. & Cimino J.J. et al. & 2002 & Secondary care & USA & $\begin{array}{l}\text { Qualitative questionnaire } \\
\text { and telephone interview }\end{array}$ & $n=13$ patients, $n=$ \\
\hline 11. & Cimino J.J. et al. & 2001 & Primary care & USA & $\begin{array}{l}\text { Qualitative questionnaire / } \\
\text { telephone interview }\end{array}$ & $n=11$ patients $n=$ \\
\hline 12. & Cruickshank J. et al & 2012 & $\begin{array}{l}\text { Chronic disease } \\
\text { and generic }\end{array}$ & UK & Qualitative survey & $n=262$ patients \\
\hline 13. & Di Marco C. et al. & 2006 & Surgery & Canada & $\begin{array}{l}\text { Description of product in } \\
\text { development }\end{array}$ & N/A \\
\hline 14. & Druss B.G. et al. & 2014 & Mental health & USA & $\begin{array}{l}\text { Quantitative Randomised } \\
\text { trial: }\end{array}$ & $\mathrm{n}=\mathbf{1 7 0}$ patients \\
\hline 15. & Farrelly S. et al. & 2013 & Mental illness & UK & Cochrane review & $n=4$ randomised \\
\hline 16. & Ferreira A. et al. & 2007 & Healthcare & UK & Systematic review & $n=14$ articles \\
\hline 17. & Fisher B. et al. & 2009 & Primary care & UK & $\begin{array}{l}\text { Qualitative study: focus } \\
\text { group and interviews }\end{array}$ & $n=43$ patients ar \\
\hline 18. & Forbes M. et al. & 2017 & Glaucoma & UK & $\begin{array}{l}\text { Randomised controlled } \\
\text { trial }\end{array}$ & $\mathrm{n}=122$ patients \\
\hline 19. & $\begin{array}{l}\text { Garcia-Lizana F. et } \\
\text { al. }\end{array}$ & 2007 & Chronic disease & Spain & Systematic review & $\mathrm{n}=24$ articles \\
\hline
\end{tabular}




\begin{tabular}{|c|c|c|c|c|c|c|}
\hline 20. & Gee P.M. et al. & 2015 & Chronic disease & USA & Qualitative interviews & $\mathrm{n}=18$ patients \\
\hline 21. & Gerard M. et al. & 2017 & Primary Care & USA & Qualitative questionnaire & $\mathrm{n}=260$ patients \\
\hline 22. & Giardina T.D. et al. & 2013 & Adult populations & USA & Systematic review & $\mathrm{n}=27$ articles \\
\hline 23. & $\begin{array}{l}\text { Greenberg A.J. et } \\
\text { al. }\end{array}$ & 2017 & Chronic disease & USA & Secondary data analysis & $n=3497$ patient $n$ \\
\hline 24. & Hassol A. et al. & 2004 & Primary care & USA & Qualitative survey & $\begin{array}{l}\text { n=1421 patients, } \\
\text { patients, Intervic }\end{array}$ \\
\hline 25. & Hemsley B. et al. & 2018 & $\begin{array}{l}\text { Primary and } \\
\text { secondary care }\end{array}$ & Australia & $\begin{array}{l}\text { Systematic literature } \\
\text { review }\end{array}$ & $\mathrm{n}=24$ articles \\
\hline 26. & Honeyman A. et al. & 2005 & Primary care & UK & Qualitative interviews & $\mathrm{n}=109$ patients \\
\hline 27. & Jeong D.E. et al. & 2015 & IBD & Korea & Retrospective audit & $\mathrm{n}=152$ patients \\
\hline 28. & Kerns J.W. et al & 2013 & Primary care & USA & Qualitative focus group & $n=3$ focus group \\
\hline 29. & Kelstrup A.M. et al. & 2014 & IBD & USA & Qualitative survey & $\mathrm{n}=197$ patients \\
\hline 30. & $\begin{array}{l}\text { Khaneghan P.A. et } \\
\text { al. }\end{array}$ & 2014 & Diabetes & Canada & Qualitative survey & $\mathrm{n}=54$ patients, $\mathrm{n}=$ \\
\hline 31. & Ko H. et al. & 2010 & Chronic disease & Australia & $\begin{array}{l}\text { Systematic literature } \\
\text { review }\end{array}$ & $\mathrm{n}=\mathbf{1 4}$ articles \\
\hline 32. & Laugesen J. et al. & 2016 & Diabetes & Canada & Qualitative survey & $n=230$ patients \\
\hline 33. & Masys D. et al. & 2002 & & USA & $\begin{array}{l}\text { Qualitative feedback \& } \\
\text { quantitative use of system }\end{array}$ & $\mathrm{n}=\mathbf{2 1 6}$ clinicians \\
\hline 34. & McKinstry B. et al. & 2006 & Hypertension & UK & $\begin{array}{l}\text { Randomised controlled } \\
\text { trial }\end{array}$ & $n=1$ site, $n=294$ \\
\hline 35. & Mold F. et al & 2015 & Primary care & UK & $\begin{array}{l}\text { Systematic literature } \\
\text { review }\end{array}$ & $\mathrm{n}=17$ articles \\
\hline 36. & $\begin{array}{l}\text { Muhammad R. et } \\
\text { al. }\end{array}$ & 2012 & IBD & UK & Description of product & N/A \\
\hline 37. & Nahm E-S. et al. & 2017 & Diabetes & USA & RCT Feasibility study & $n=74$ patients \\
\hline 38. & Palen T.E. et al. & 2012 & Primary care & USA & $\begin{array}{l}\text { Retrospective } \\
\text { observational cohort study }\end{array}$ & $\mathrm{n}=\mathbf{8 8 6 4 2}$ patient \\
\hline 39. & Papoutsi C. et al. & 2015 & $\begin{array}{l}\text { Primary and } \\
\text { secondary care }\end{array}$ & UK & Qualitative survey & $\begin{array}{l}n=2761 \text { patients } \\
\text { Focus group } n=1 \\
\text { clinicians }\end{array}$ \\
\hline 40. & Pavlik V. et al. & 2014 & Primary care & USA & $\begin{array}{l}\text { Qualitative interviews } \\
\text { Randomised trial }\end{array}$ & $\begin{array}{l}\text { Interviews } n=12 \\
\text { Trial } n=272 \text { pati }\end{array}$ \\
\hline 41. & Phelps R.G. et al. & 2014 & $\begin{array}{l}\text { Chronic Renal } \\
\text { disease }\end{array}$ & UK & $\begin{array}{l}\text { Qualitative evaluation of } \\
\text { database }\end{array}$ & $\mathrm{n}=11352$ patient \\
\hline
\end{tabular}




\begin{tabular}{|c|c|c|c|c|c|c|}
\hline 42. & Politi P. et al. & 2008 & IBD & Europe & Qualitative questionnaire & n=917 patients \\
\hline 43. & Powell H. et al. & 2002 & Asthma & Australia & Cochrane review & $\mathrm{n}=15$ trials \\
\hline 44. & Price M. et al. & 2015 & Older adults & USA & $\begin{array}{l}\text { Qualitative study diary } \\
\text { analysis }\end{array}$ & $\mathrm{n}=41$ patients \\
\hline 45. & Price M.M. et al. & 2012 & $\begin{array}{l}\text { Chronic } \\
\text { conditions }\end{array}$ & Canada & $\begin{array}{l}\text { Systematic literature } \\
\text { review }\end{array}$ & $\mathrm{n}=23$ articles \\
\hline 46. & Riippa I. et al. & 2014 & Chronic illness & Finland & Observational study & $\mathrm{n}=222$ patients \\
\hline 47. & Ross S.E. et al. & 2003 & $\begin{array}{l}\text { Medical and } \\
\text { psychiatric }\end{array}$ & USA & $\begin{array}{l}\text { Systematic literature } \\
\text { review }\end{array}$ & $\mathrm{n}=\mathbf{3 0}$ articles \\
\hline 48. & Ross S.E. et al. & 2005 & Primary care & USA & Qualitative questionnaire & $\begin{array}{l}n=601 \text { patients } \\
n=564 \text { Doctors }\end{array}$ \\
\hline 49. & $\begin{array}{l}\text { Royal College of } \\
\text { Physicians }\end{array}$ & 2016 & $\begin{array}{l}\text { UK primary and } \\
\text { secondary care }\end{array}$ & UK & $\begin{array}{l}\text { Qualitative survey, } \\
\text { literature review, case } \\
\text { studies }\end{array}$ & $\begin{array}{l}n=98 \text { clinicians } \\
n=17 \text { articles } \\
n=6 \text { case } \text { studies }\end{array}$ \\
\hline 50. & $\begin{array}{l}\text { Royal College of } \\
\text { Physicians }\end{array}$ & 2017 & Nephrology & UK & Case study & N/A \\
\hline 51. & $\begin{array}{l}\text { Royal College of } \\
\text { Physicians }\end{array}$ & 2017 & Primary care & UK & Case study & N/A \\
\hline 52. & $\begin{array}{l}\text { Royal College of } \\
\text { Physicians }\end{array}$ & 2017 & Ulcerative colitis & $\mathbf{U K}$ & $\begin{array}{l}\text { User insight \& patient } \\
\text { story }\end{array}$ & N/A \\
\hline 53. & $\begin{array}{l}\text { Royal College of } \\
\text { Physicians }\end{array}$ & 2017 & $\begin{array}{l}\text { Nephrology, IBD, } \\
\text { Cardiology, } \\
\text { Diabetes }\end{array}$ & UK & Case study & N/A \\
\hline 54. & $\begin{array}{l}\text { Royal College of } \\
\text { Physicians }\end{array}$ & 2017 & Gastroenterology & UK & Case study & N/A \\
\hline 55. & $\begin{array}{l}\text { Royal College of } \\
\text { Physicians }\end{array}$ & 2017 & $\begin{array}{l}\text { Chronic } \\
\text { conditions } \\
\text { including } \\
\text { ulcerative colitis }\end{array}$ & UK & $\begin{array}{l}\text { Qualitative study: focus } \\
\text { groups }\end{array}$ & $\begin{array}{l}\text { Focus group } n= \\
\text { Interviews } n=27\end{array}$ \\
\hline 56. & Sartain S.A. et al. & 2014 & $\begin{array}{l}\text { Primary and } \\
\text { secondary care } \\
\text { patients }\end{array}$ & UK & $\begin{array}{l}\text { Systematic literature } \\
\text { review }\end{array}$ & $\mathrm{n}=10$ articles \\
\hline 57. & Showell C. & 2017 & $\begin{array}{l}\text { Primary and } \\
\text { secondary care }\end{array}$ & Australia & $\begin{array}{l}\text { Structured literature } \\
\text { review }\end{array}$ & $\mathrm{n}=34$ articles \\
\hline 58. & Somner J.E.A. et al. & 2013 & Glaucoma & UK & $\begin{array}{l}\text { Qualitative study: focus } \\
\text { group }\end{array}$ & $\mathrm{n}=42$ patients, 3 \\
\hline
\end{tabular}




\begin{tabular}{|c|c|c|c|c|c|c|}
\hline 59. & Tenforde M. et al. & 2011 & Chronic disease & USA & $\begin{array}{l}\text { Systematic literature } \\
\text { review }\end{array}$ & $\mathbf{n}=\mathbf{3}$ articles \\
\hline 60. & Wagner P.J. et al. & 2012 & Hypertension & USA & Cluster Randomised Trial & $n=24$ Doctors, $n=$ \\
\hline 61. & Wells S. et al. & 2014 & $\begin{array}{l}\text { Health delivery } \\
\text { organisations }\end{array}$ & USA & Qualitative Interviews & $n=16$ organisati \\
\hline 62. & Wells S. et al. & 2014 & Chronic disease & USA & Qualitative interviews & $\begin{array}{l}\text { n=30 PHR leade } \\
\text { organisations }\end{array}$ \\
\hline 63. & Williams J.G. et al. & 2001 & Cancer & UK & Randomised trial & $\mathrm{n}=501$ patients \\
\hline 64. & $\begin{array}{l}\text { Winkleman W.J. et } \\
\text { al. }\end{array}$ & 2005 & IBD & Canada & Qualitative interview & $\mathrm{n}=12$ patients \\
\hline 65. & $\begin{array}{l}\text { Zarcadoolas C. et } \\
\text { al. }\end{array}$ & 2013 & Primary care & USA & Qualitative focus group & $\mathrm{n}=28$ patients \\
\hline
\end{tabular}

Key: literature from years 2000 - 2010, Pre ELIJAH feasibility study

literature from years 2011 - 2018, Post ELIJAH feasibility study 
The articles (listed in table 28.) were analysed and their main characteristics were identified as: year, population, location, study design, number of participants and articles, quality score of the article. We reported each of these categories individually.

Year

We divided the articles into two groups based on the year of publication. The two groups were 2000-2010 (pre our ELIJAH intervention detailed in chapter three), and from 2011 to current (post ELIJAH intervention). We split the articles between these groups as we were interested to identify which publications were contemporaneous at the time of our focus group, intervention and feasibility trial, and how these studies compared with our findings, we also sought to identify the literature since our feasibility trial to view the further developments and identify expansion in this area and further gaps.

From 2000 to 2010, 19 articles were identified for inclusion in the literature review. From 2010 to 2018, 46 articles were retrieved. We found that since 2000 there has been a steady increase in publications related to our area of interest. More than twice the number of articles have been published since $2010(70.77 \%)$ than pre $2010(29.23 \%)$, with half of these published in the last three years from 2015-2018.

There were differences noted between the year groupings. From 2000 to 2010 the highest number of articles were found to report findings related to patients in primary care (32\%) (e.g. Bhavnani et al 2010, Cimino et al 2001, Fisher et al 2009). From 2011 to 2018 there were only $15 \%$ of articles concerned with primary care findings and we found there had been shift toward research related to chronic disease: $26 \%$ as opposed to $11 \%$ in the earlier years. We identified that authors from 2010 to 2018 studied generic chronic disease and disease specific chronic disease more, and the range of chronic diseases specified in studies increased e.g. Forbes et al (2017) looked at Glaucoma patients, Khaneghan et al (2014) and Nahm et al (2017) studied diabetic groups of patients and Phelps et al (2014) used renal disease participants in their study.

There were similarities in the years 2000 to 2010 and 2011 to 2018 in terms of the location of studies or authors. In both year groups most papers originated from the USA (37\% and $43 \%$ respectively), and the U.K. (32\% and $39 \%$ respectively). 
The spread of research has not differed in the year differentials, and the increase in location has been marginal from six locations to seven, mostly based in Northern American or European destinations with a few notable exceptions in the Middle East (Al-Sahan 2016) or Asia (Jeong et al 2015).

When we looked at study design and distinguished the two year categories, we found that by far most studies across both 2000 to 2010 and 2011 to 2018 employed qualitative research methodology (47\% and 65\% respectively). The proportion of literature reviews carried out during both time frames remained steady at about a fifth of the articles. Surprisingly the number of quantitative studies fell in the later year group from $16 \%$ of studies in 2000 to 2010 to $11 \%$ in later years, even as the research area matured. Early researchers using rigorous quantitative methodology and carrying out randomised trials (i.e.: Williams et al (2001) studying a cohort of Cancer patients in the U.K. and McKinstry et al (2006) who looked at hypertensive participants in the U.K.) were rare, and their pioneering work had not been greatly expanded upon in the intervening years. Later RCTs in this area include Wagner et.al (2012) who studied patients with hypertension, Druss et al (2014) looking at mental health, Pavlik et al (2014) using primary care patients and Forbes et al (2017) including glaucoma patients. Chunchu et al 2012 carried out the only identified pilot feasibility study, and used chronic disease as their patient population.

The small number of identified quantitative studies reflects, and correlates well with our findings of the quality of the articles. Most studies had low scoring when analysed for the quality of the article. Most papers across both year groupings scored two or less. In both year groups the highest score was eight: McKinstry et al in 2006, and Pavlik et al in 2014 reporting findings from a study conducted within a primary care setting.

The maturation of this area of research has seen an increase number of studies from 2000 to 2018. When divided into our two timelines of interest (pre and post the ELIJAH feasibility study), we have found that there has been a shift in research population from primary care to chronic disease and disease specific research, the location where research has taken place has remained the same with concentration in the USA or U.K. and most studies use qualitative methodology and 
are of poor quality. These main characteristics will be discussed individually below for the total year group 2000 to 2018 .

\section{Population}

Within the articles we noted the populations studied by the authors. We found 16 different population types (see table 31: Population).

Table 31. Population

\begin{tabular}{|l|l|}
\hline Population & Number of articles \\
\hline Chronic illness and / or chronic disease & $\mathrm{n}=13(20.00 \%)$ \\
\hline Primary care & $\mathrm{n}=13(20.00 \%)$ \\
\hline Primary and secondary care & $\mathrm{n}=10(15.38 \%)$ \\
\hline Inflammatory bowel disease & $\mathrm{n}=8(12.31 \%)$ \\
\hline Diabetes & $\mathrm{n}=3(4.12 \%)$ \\
\hline Mental health & $\mathrm{n}=3(4.12 \%)$ \\
\hline Renal disease & $\mathrm{n}=3(4.12 \%)$ \\
\hline Glaucoma & $\mathrm{n}=2(3.08 \%)$ \\
\hline Hypertension & $\mathrm{n}=2(3.08 \%)$ \\
\hline Secondary care & $\mathrm{n}=2(3.08 \%)$ \\
\hline Asthma & $\mathrm{n}=1(1.54 \%)$ \\
\hline Cancer & $\mathrm{n}=1(1.54 \%)$ \\
\hline Gastroenterology & $\mathrm{n}=1(1.54 \%)$ \\
\hline Other & $\mathrm{n}=1(1.54 \%)$ \\
\hline Older adults & $\mathrm{n}=1(1.54 \%)$ \\
\hline Surgery & $\mathrm{n}=1(1.54 \%)$ \\
\hline
\end{tabular}

The different population types were spread over differing health sectors: primary, and / or secondary care $(58.46 \%)$, and a minority of articles were disease or specialty specific (38.53\%). The highest number of disease specific articles were found for inflammatory bowel disease. This was expected as this was our area of interest and was a key word search within the systematic literature review.

There were only two studies looking specifically at IBD in the years before our ELIJAH feasibility study. Both conducted their research using qualitative methodology and both scored low for the quality of the article. Winkleman et al (2005) reported a study that explored via interview, whether twelve Canadian IBD patients found access to their on-line records valuable. Four themes arose from the study all in support of the initiative, but the study concluded that there was "little usefulness on its own" (p306). The authors hypothesised that information alone was meaningless, and tailoring of information would be necessary to improve outcomes. 
The anticipated transformational benefits of the patient access to their information was not realised but provided an early assessment of an information technology system acceptance by patients.

Three years later, in 2008, Politi et al, in a larger study of nearly a thousand European IBD patient questionnaires, found that communication of information to IBD patients should be increasingly be via electronic methods, even though they found most patients wanted paper-based communication. They concurred with Winkleman (2005) that the information whilst acceptable to patients needs to be individualised to their needs.

Post the ELIJAH feasibility trial, most of the seven reported articles including IBD patients were from the U.K. We found there had been a stepped approach in the development of the quality of IBD research, from a description of product, to qualitative testing and then larger testing and mixed methods research supported by a national clinical organisation (The Royal College of Physicians).

In 2012 Muhammad et al described a product "The IBD passport" (261), which was designed to be held by patients when travelling and detailed the main pertinent points of the patients' disease including "IBD diagnosis ... history ... investigations .... (and) medication". But the article does not state if it has been, or will be tested. No further papers describing the product were found, and so it can be assumed the product remained a local, un-tested innovation. Bidmead et al (2016) did test a new innovation "Patients Know Best (PKB)" via interviews with clinicians and a survey of patients. However, only five clinicians were interviewed and the response rate of patients was low at $17 \%$. They found clinicians were supportive of the innovation as it was expected that better self-management would result from it, and patients concurred with this, but several issues were identified that were thought to contribute to possible lack of use of the system "security ... perceptions .... (and) Data integration" (p. 8-10) One finding that the authors did note was that "patients were more frank and to the point in emails" (p. 10) especially when relaying information of a sensitive nature, which was found to be beneficial to the clinician as they had a more holistic and full knowledge of the symptoms of the patient, and more benefit to the patient in being empowered to discuss it and get the appropriate help. 
The finding of increased patient empowerment was replicated by The Royal College of Physicians in 2017 in the published range of case studies giving exemplars of systems using personal health records. Two of these case studies included IBD patients. The final report of the range of case studies reported findings of a focus group that included IBD patients. One case study described how a PHR for chronic disease was developed and is used by patients, the other case study follows one patient's IBD journey supported by a PHR. The patient with ulcerative colitis describes, in diary form, her use and her perceived benefits of using a PHR, including how she has maintained privacy of her disease information, and how "she feels more equipped to control her condition" (p. 2). She also uses the PHR to communicate with her clinical team. She relays how help was initially required to use the system but now it delivers on the anticipated functions. The Royal College of Physicians final report, collating the case studies thematically and reporting a qualitative study of chronic disease patients (nine focus groups and 27 interviews), found that patients used a PHR because they believed it would enhance their empowerment to "take control of health and improve health" (p. 7) and also help communication. But barriers to use came from lack of education and knowledge of systems and reluctance of clinicians. There were data and security concerns, but the report stated that many of these concerns could be overcome from increased awareness, training and help when needed. However, the report very clearly states that the use of a PHR and increased patient empowerment and self-care does not negate the importance of a combined and varied approach to providing care. The PHR would not replace the need for traditional care-giving and would work best and be a tool and used "best if it forms part of a person-centred service" (p. 10).

Other IBD populations worldwide, when studied, found similar findings to the U.K. experience. In 2014, Kelstrup et al reported findings of a survey of 197 IBD patients in the USA looking at whether the participants were reliable in reporting their disease history, and it found they were especially for "type of disease and surgical procedures" ( $\mathrm{p}$ 349). But, when scrutinised carefully they found that those who were better educated were more able to provide more accurate information and found their patient cohort were not representative of wider populations because of variations in educational attainment and self-selected bias. 
A year later Jeong et al (2015) reported a retrospective audit of 152 Korean IBD patients using an extended IBD symptom diary that was further developed to include a free text area for questioning to the clinician or updating of events. The system enabled two-way communication between patients and their Doctors. The outcome was that patients were more likely to receive advice outside of the scheduled outpatient appointment and a small minority of patients (7.3\%) necessitated additional or expedited appointments, but communication was enhanced.

The IBD population was found to have been researched, especially in the U.K. the studies found that IBD patients largely favoured having a PHR as part of their care package and found it empowered them within their care to better selfmanage and communicate more effectively.

\section{Location}

We identified the country in which the included studies were conducted, or, in the case of a systematic review or case study where the article authors were from. We found a wide geographical spread covering nine countries (see table 32. Location of articles/ authors).

Table 32. Location of articles / authors

\begin{tabular}{|l|l|}
\hline Country & Number of articles \\
\hline USA & $\mathrm{n}=26(40.00 \%)$ \\
\hline U.K. & $\mathrm{n}=24(36.92 \%)$ \\
\hline Canada & $\mathrm{n}=6(9.23 \%)$ \\
\hline Australia & $\mathrm{n}=4(6.15 \%)$ \\
\hline Europe wide & $\mathrm{n}=1(1.54 \%)$ \\
\hline Finland & $\mathrm{n}=1(1.54 \%)$ \\
\hline South Korea & $\mathrm{n}=1(1.54 \%)$ \\
\hline Saudi Arabia & $\mathrm{n}=1(1.54 \%)$ \\
\hline
\end{tabular}

The majority of articles were from North America (49.23\%) and Europe (40.00\%), with few from Australia (6.15\%), Asia (1.54\%) and the Middle East $(1.54 \%)$. One of this reasons for these findings may have been the legal developments around PHR by the USA.

Of the 26 articles that originated from the USA, 18 in the introductions propose that one of the reasons for carrying out the research was to illustrate whether 
the legislature around the use of PHR, and central financial incentives for the use of PHR had been realised. We found papers dating from the early 2000's through to 2017 consistently stating that their research was needed to address the impact of national legal frameworks around patient access to records.

The country noted to have the second highest number of articles found in this literature review was the UK. Perhaps this is because my search base is within the UK, as there has not been the central push toward PHR development and implementation by the British government and embedding of this into the legal rights of patients.

The development of PHRs have been slower in the UK than in the USA between 2000 to $1-2018$, but in the last few years the pace has been gathering.

\section{Study design}

We categorised articles by their stated study design. From analysis of the literature we found four main groups: qualitative, quantitative, mixed methods, systematic review or case study. Within these groups we identified the methodologies employed by the researchers (see table 33. Study design).

Table 33. Study design.

\begin{tabular}{|c|c|c|c|}
\hline Study design & Methodology & $\begin{array}{l}\text { Number of } \\
\text { articles }\end{array}$ & Total \\
\hline \multirow[t]{8}{*}{ Qualitative study } & Survey & $\mathrm{n}=9(13.85 \%)$ & \\
\hline & Interviews & $\mathrm{n}=5(7.69 \%)$ & \\
\hline & Case study & $\mathrm{n}=5(7.69 \%)$ & \\
\hline & Focus group & $\mathrm{n}=4(6.15 \%)$ & \\
\hline & Questionnaire & $\mathrm{n}=4(6.15 \%)$ & \\
\hline & Observational study & $\mathrm{n}=3(4.62 \%)$ & \\
\hline & Diary analysis & $\mathrm{n}=1(1.54 \%)$ & \\
\hline & & & $\begin{array}{l}n=31 \\
(47.69 \%)\end{array}$ \\
\hline \multirow[t]{6}{*}{ Quantitative study } & Randomised controlled trial & $\mathrm{n}=5(7.69 \%)$ & \\
\hline & Feasibility study & $\mathrm{n}=2(3.08 \%)$ & \\
\hline & Secondary data analysis & $\mathrm{n}=1(1.54 \%)$ & \\
\hline & Retrospective audit & $\mathrm{n}=1(1.54 \%)$ & \\
\hline & Database evaluation & $\mathrm{n}=1(1.54 \%)$ & \\
\hline & & & $\begin{array}{l}\mathrm{n}=10 \\
(15.38 \%)\end{array}$ \\
\hline \multirow[t]{2}{*}{ Mixed methods } & $\begin{array}{l}\text { Questionnaire and } \\
\text { interviews }\end{array}$ & $\mathrm{n}=2(3.08 \%)$ & \\
\hline & Focus group and interview & $\mathrm{n}=1(1.54 \%)$ & \\
\hline
\end{tabular}




\begin{tabular}{|l|l|l|l|}
\hline & $\begin{array}{l}\text { Survey and quantitative use } \\
\text { of product }\end{array}$ & $\mathrm{n}=1(1.54 \%)$ & \\
\hline & Interviews and case study & $\mathrm{n}=1(1.54 \%)$ & \\
\hline & $\begin{array}{l}\text { Interviews and randomised } \\
\text { controlled trial }\end{array}$ & $\mathrm{n}=1(1.54 \%)$ & \\
\hline & $\begin{array}{l}\text { Questionnaire and focus } \\
\text { group }\end{array}$ & $\mathrm{n}=1(1.54 \%)$ & \\
\hline & Survey and case study & $\mathrm{n}=1(1.54 \%)$ & $\mathrm{n}=8$ \\
& & $\mathrm{n}=11(16.92 \%)$ & \\
\hline & Systematic literature review & $\mathrm{n}=2(3.08 \%)$ & \\
\hline & Cochrane review & $\mathrm{n}=1(1.54 \%)$ & $\mathrm{n}=14$ \\
\hline & Structured literature review & & $(21.54 \%)$ \\
\hline & & $\mathrm{n}=2(3.08 \%)$ & \\
\hline & Description of product & & $\mathrm{n}=2(3.08 \%)$ \\
\hline & & & \\
\hline
\end{tabular}

The results show that the majority of articles described research studies $(75.38 \%)$. These studies were executed using a range of methodologies, most notably qualitative methods. Surveys were the most used research methodology.

Surveys have been conducted throughout the search years of this literature review (e.g. by Hassol et al (2004), by Bell et al (2015) and by Laugesen et at (2016)). The surveys have been carried out mostly in the two main locations identified as the research origin: the USA and UK. The surveys carried out encompass qualitative research results deduced from analysis of patient or clinician participation, and sometimes a mixture of the two (e.g. Bartlett et al 2012, Khaneghan et al 2014, and Royal College of Physicians 2016).

In the largest survey of patients and clinicians (Bartlett et al 2012), 583 UK based patients and 99 staff were asked their opinions on receiving raw investigative blood results electronically. Overwhelmingly the renal patients reported that they felt more knowledgeable about their disease, a few patients "had security concerns" (p. 1), but these fears were mostly alleviated after use of the system. Clinicians endorsed the system and reported better disease management was facilitated as a result.

The largest survey was carried out by Papoutsi et al (2015), and sought feedback from 2761 UK patients about their views on the security of their electronic health records and the privacy of their personal information. The questions were 
hypothetical as the patients did not have access to a system to enable this, and they were asked questions about a proposed available system to be located in a national PHR programme run by the NHS. More than three quarters of patients had concerns in two areas: security and privacy, however, just over half of the patients endorsed the development of a system which would allow them to access their information electronically. Of note is that these results arise from questioning of a conceptual system that is a concept, rather than a useable product. These findings contradict those of If Bartlett et al 2012 who showed that when patients' use PHRs their confidence grows in the security measures embedded in systems, and fears are allayed with system use.

More rigorous research methodologies i.e. those employing a randomised controlled trial accounted for only $9.23 \%$ of the articles. Of the six studies, two were conducted before our ELIJAH feasibility trial; Williams et al 2001, and McKinstry et al 2006. Both these studies were carried out in the UK, and both looked a disease specific participant population (cancer and hypertension respectively). Neither study found statistically significant outcomes of their trials. Williams et al (2001) powered the study to identify differences in quality of life and health resource use, and McKinstry's outcome measures sought to highlight differences in clinical outcomes, primarily a lowering of blood pressure. In each study good recruitment numbers and low numbers of drop outs were noted, and yet they concluded no discernable difference between their control and intervention groups. No randomised controlled trials of IBD were found within the literature search period 2000 to 2010.

From 2011, four further randomised controlled trials of PHR had been trialled. Again, none used an IBD patient population. Hypertension was studied again by Wagner et al (2012), Pavlik et al (2014) studied adult primary care patients with at least one chronic disease such as diabetes or hypertension, psychiatric patients were included in the trial reported by Druss et al (2014), and Forbes studied patients with glaucoma. Of these studies only one found a significant outcome of a patient having a PHR. Druss et al (2014) found that patients diagnosed with "a serious mental disorder" did benefit from having a PHR. Patients had "significantly improved quality of medical care and increased use of medical services" and statistically significant increased education levels about their care. 
Few studies ran mixed methods research, and where this was carried out few combined a qualitative and quantitative approach (3.08\%). Of these only one, Pavlik et al (2014) combined a randomised trial with interviews. This study scored highly for quality of the article (8) but the trial methodology has not be replicated in the intervening years from the study.

Reviews of the literature, whether using a systematic or structured approach have been explored by many authors ( $18.46 \%$ of the articles). There have been more literature reviews carried out in this area of research (14) than rigorous trials of the effects of PHRs. Of these studies: twelve systematic literature reviews and two Cochrane reviews were carried out.

The literature reviews were conducted from a broad geographical spread and are fairly evenly spread between the UK (4), USA (3), Australia (4), Canada (2), and Spain (1). Some literature reviews looked at general chronic disease patient populations; Garcia-Lizana (2007), Ko et al (2010), Tenforde et al (2011) and Archer (2014). Price et al (2012) studied older patients, Showell (2017) limited the search to "marginalised populations" (p. 1), and primary care patients were the focus of the literature search by Mold (2015).

Sartain et al (2014) looked at general patient populations across primary and secondary care, as did Ross et al (2003), Ferreira et al (2007) Giardina et al (2013) and Hemsley et al (2018).

None of the literature reviews specifically sought articles related to IBD.

Within the systematic literature reviews there is general broad consensus that PHRs can have some patient benefits, especially in increasing the level of patient understanding of their condition (Ross 2003, Ferreira et al 2007, Price et al 2012, Mold et al 2015). However, there was a paucity of evidence to support the assertion that PHRs can improve quality of life or disease outcomes (Garcia-Lizana et al 2007, Giardina et al 2014), and Ko et al 2010 disputes that any positive outcomes have yet been demonstrated. Ko et al (2010) argues that "there is no clear benefit of implementing a PHR" (e. 41), and deduces this because many of the 14 studies they identified had low quality and high levels of bias and so were not definitive. This finding of poor quality of studies was also shown, seven years earlier by Ross et al (2003). 
The most recent, and most comprehensive, systematic literature review was conducted by Hemsley et al in 2018. They found 24 studies that they analysed and synthesised. They found six themes emerged from their exploration that they stated could have an effect on the use of PHRs by patients. These topics were patient

"level of education ... computer literacy ... attitudes to sharing health information, ... executive function, verbal expression, and understanding of .. language". (p. 2)

Showell (2017) concurred and noted many of these themes could be due to low socio-economic factors.

Hemsley et al (2018) concluded that further rigorous research, specifically trials, are required to demonstrate the impact of PHRs on patients. They insinuate that rather than more qualitative studies: finding out what participants think of the systems they are using, testing should employ head to head methodologies, such as the randomised controlled trial, to aim to statistically significantly prove outcomes. This is a repetition of Tenforde et al conclusions of 2011 and Sartain et al in 2014.

There were few Cochrane reviews (3.08\%). Neither include IBD within the patient population groups (asthma, Powell et al 2009 and mental illness, Farrelly et al 2013).

Farrelly et al (2013) found no effect of patient having personalised information, and Powell et al (2009) concluded that a similar intervention was equal to outcomes noted when patients regularly attended outpatient clinic. Neither report concluded there was evidence of a demonstrable improvement in patient outcomes when patients had their individualised information.

\section{Number of participants / articles}

We looked at how many participants had been included within the studies, or, if the article reported a systematic review, how many articles were included (see table 34. Number of participants / articles). We divided the number of participants or articles by study design and methodology, and divided the participants into patients or healthcare professionals. We looked at the range within each group

We found that the highest number of participants was within the qualitative study design group. This was anticipated as this was the group with the highest number of articles found as identified by study design. Within the qualitative study 
design group the highest number of participants was within the observation study sub-group. Palen et al (2012) conducted a retrospective audit of electronic communication to clinicians by patients. They paired 88,642 patients. One of the pair used the electronic communication method, one of the pair did not have access to the innovation. They found that the group with access to the enhanced communication methods utilised greater health services than those who lacked the facilities.

Few research findings based on survey results included patient data from large numbers of patients. Only two studies included thousands of patients (Hassol et al 2004, Papoutsi et al 2015).

Within the quantitative group the highest number of participants was within the database evaluation sub-set.

The questionnaire and focus group methodology type within the mixed methods study design group had the largest number of participants.

Consistently across these three groups of study design more patients than healthcare professionals were included and studied and more articles were included in systematic and structured literature reviews than in Cochrane reviews, but numbers remain relatively low. 
Table 34. Number of participants / articles

\begin{tabular}{|c|c|c|c|c|}
\hline Study design & Methodology & Number of Particip: & & Num \\
\hline & & Patients & $\begin{array}{l}\text { Healthcare } \\
\text { professionals }\end{array}$ & \\
\hline Qualitative study & Survey & $\mathrm{n}=5739(\mathrm{r}=54-2761)$ & $\mathrm{n}=207(\mathrm{r}=9-99)$ & \\
\hline & Interviews & $\mathrm{n}=166(\mathrm{r}=12-109)$ & $\mathrm{n}=70(\mathrm{r}=10-30)$ & \\
\hline & Case study & $\mathrm{n}=5$ & $\mathrm{n}=0$ & \\
\hline & Focus group & $\mathrm{n}=325(\mathrm{r}=25-114)$ & $\mathrm{n}=20(\mathrm{r}=6-14)$ & \\
\hline & Questionnaire & $\mathrm{n}=1828(\mathrm{r}=50-917)$ & $\mathrm{n}=564(\mathrm{r}=\mathrm{N} / \mathrm{A})$ & \\
\hline & Observational study & $\mathrm{n}=88875(\mathrm{r}=11-88642)$ & N/A & \\
\hline & Diary analysis & $\mathrm{n}=41$ & N/A & \\
\hline Quantitative study & Randomised controlled trial & $\mathrm{n}=1604(\mathrm{r}=74-501)$ & $\mathrm{n}=24(\mathrm{r}=\mathrm{N} / \mathrm{A})$ & \\
\hline & Feasibility study & $\mathrm{n}=66(\mathrm{r}=8-58)$ & $n=16(r=N / A)$ & \\
\hline & Secondary data analysis & $\mathrm{n}=3497(\mathrm{r}=\mathrm{N} / \mathrm{A})$ & N/A & \\
\hline & Retrospective audit & $\mathrm{n}=152(\mathrm{r}=\mathrm{N} / \mathrm{A})$ & N/A & \\
\hline & Database evaluation & $\mathrm{n}=11352(\mathrm{r}=\mathrm{N} / \mathrm{A})$ & $\mathrm{N} / \mathrm{A}$ & \\
\hline Mixed methods & Questionnaire and interviews & $\mathrm{n}=24(\mathrm{r}=11-13)$ & $\mathrm{n}=6(\mathrm{r}=3)$ & \\
\hline & Focus group and interview & $\mathrm{n}=43(\mathrm{r}=\mathrm{N} / \mathrm{A})$ & N/A & \\
\hline & $\begin{array}{l}\text { Survey and quantitative use of } \\
\text { product }\end{array}$ & $\mathrm{n}=41(\mathrm{r}=\mathrm{N} / \mathrm{A})$ & $\mathrm{n}=216(\mathrm{r}=\mathrm{N} / \mathrm{A})$ & \\
\hline & Interviews and case study & $\mathrm{n}=56(\mathrm{r}=\mathrm{N} / \mathrm{A})$ & $\mathrm{n}=5(\mathrm{r}=\mathrm{N} / \mathrm{A})$ & \\
\hline & $\begin{array}{l}\text { Interviews and randomised controlled } \\
\text { trial }\end{array}$ & $\begin{array}{l}\mathrm{n}=48(\mathrm{r}=\mathrm{N} / \mathrm{A}) \text { Interview } \\
\mathrm{n}=272(\mathrm{r}=\mathrm{N} / \mathrm{A}) \mathrm{RCT}\end{array}$ & $\mathrm{n}=12(\mathrm{r}=\mathrm{N} / \mathrm{A})$ & \\
\hline & Questionnaire and focus group & $\mathrm{n}=424(\mathrm{r}=\mathrm{N} / \mathrm{A})$ & N/A & \\
\hline & Survey and case study & $n=6(r=N / A)$ & $\mathrm{n}=98(\mathrm{r}=\mathrm{N} / \mathrm{A})$ & \\
\hline Literature review & Systematic literature review & & & $\mathrm{n}=21$ \\
\hline & Cochrane review & & & $\mathrm{n}=19$ \\
\hline & Structured literature review & & & $\mathrm{n}=34$ \\
\hline
\end{tabular}




\section{Quality score of the article}

We score the articles according to the quality scoring grid (see table 29. Quality of studies). Literature reviews were deemed ineligible for assessment scoring as they were not research trials and so did not report the criteria of selection bias, design, confounders, blinding, data collection and withdrawals, these are scored as not applicable (N/A). A full table of the quality scoring of the articles can be found in Appendix. 23.

A summary of the number of articles and their quality score is displayed in table 35. (Quality score)

Table 35. Quality score

\begin{tabular}{|l|l|}
\hline Quality score & Number of articles \\
\hline N/A & $\mathrm{n}=23(35.38 \%)$ \\
\hline 0 & $\mathrm{n}=6(9.23 \%)$ \\
\hline 1 & $\mathrm{n}=8(12.31 \%)$ \\
\hline 2 & $\mathrm{n}=12(18.46 \%)$ \\
\hline 3 & $\mathrm{n}=4(6.15 \%)$ \\
\hline 4 & $\mathrm{n}=3(4.62 \%)$ \\
\hline 5 & $\mathrm{n}=2(3.08 \%)$ \\
\hline 6 & $\mathrm{n}=2(3.08 \%)$ \\
\hline 7 & $\mathrm{n}=3(4.62 \%)$ \\
\hline 8 & $\mathrm{n}=2(3.08 \%)$ \\
\hline 9 & $\mathrm{n}=0$ \\
\hline 10 & $\mathrm{n}=0$ \\
\hline 11 & $\mathrm{n}=0$ \\
\hline 12 & $\mathrm{n}=0$ \\
\hline
\end{tabular}

The scores of the research studies varied from zero to the highest scoring of eight. The scoring with the highest number of studies was two with $18.46 \%$, mostly these were qualitative studies. As the study scores rose from zero to eight, the higher number denoting the higher quality of the article, the numbers in the categories scoring the higher scores lessened.

The highest scoring articles were those reporting randomised controlled trials (McKinstry et al 2006 and Pavlik et al 2014). 


\section{Thematic analysis}

We identified themes within the 65 papers of the literature search and grouped these into main themes and sub-themes. We reported the main findings of the papers (see table 36 . Thematic identification). 
Table 36. Thematic identification

\begin{tabular}{|c|c|c|c|}
\hline Theme category & Sub-theme & Findings of paper & Examples \\
\hline \multirow[t]{2}{*}{ Self management } & Self management support by IT & $\begin{array}{l}\text { Patients with chronic illness may find difficulties } \\
\text { using IT for self management }\end{array}$ & 2 \\
\hline & & Improved self-management & $6,8,20,35$ \\
\hline \multirow[t]{21}{*}{$\begin{array}{lrr}\text { Patient } \quad \text { access } & \text { to } \\
\text { medical records } & \text { via } \\
\text { EHR or PHR } & \\
\end{array}$} & Preferences & $\begin{array}{l}\text { Feasible and popular with patients and } \\
\text { professionals. }\end{array}$ & $\begin{array}{l}3,10,18,21 \\
64\end{array}$ \\
\hline & & Not popular with Clinicians & $24,33,48,5$ \\
\hline & Use of healthcare & Decreased use of healthcare services. & 3,54 \\
\hline & & Increased use of healthcare services & 14,38 \\
\hline & & No change & 63 \\
\hline & $\begin{array}{l}\text { Outcomes of patients use of } \\
\text { access to their records }\end{array}$ & $\begin{array}{l}\text { Access did not harm the patient / Doctor } \\
\text { relationship }\end{array}$ & 4 \\
\hline & & Improved patient trust in Doctors & 17,27 \\
\hline & & $\begin{array}{l}\text { Patients felt more partners in care, increased } \\
\text { collaboration \& empowerment }\end{array}$ & $5,17,21,35$ \\
\hline & & Improved health care advice adherence & 5,30 \\
\hline & & Enhanced communication and understanding & $5,10,11,16$ \\
\hline & & Improved sharing of information & $21,27,56$ \\
\hline & & Increased patient knowledge & 28,56 \\
\hline & & Unwanted responsibility & 56 \\
\hline & Health improvement & No improvement in health condition & $6,15,18,19$ \\
\hline & & Improved health condition & 60 \\
\hline & Safety & No increased anxiety noted & $3,10,14,55$ \\
\hline & & No risks / adverse events & 3,35 \\
\hline & Health education & Improved & $9,19,45,47$ \\
\hline & & No change & 20 \\
\hline & $\begin{array}{l}\text { Differences noted in patient } \\
\text { groups }\end{array}$ & Disabled and vulnerable patients & $25,37,40$ \\
\hline & & Deprivation & $23,41,48,5$ \\
\hline $\begin{array}{l}\text { Design and } \\
\text { implementation of PHR }\end{array}$ & Support required & Needs organisational \& IT support & $14,55,61,6$ \\
\hline
\end{tabular}




\begin{tabular}{|l|l|l|l|}
\hline & & & \\
\hline & Generic PHR & Educational support needed about PHR & $7,32,50$ \\
\hline & & Few condition specific examples & 61 \\
\hline & Legislature drivers for PHRs & USA & $7,9,10,11$, \\
& & UK & $3,5,12,26$, \\
\hline Security & & Patient control & 20 \\
\hline & Control of records & Security measures trusted \& successful & $26,33,44,5$ \\
\hline & & Patient concerns & $12,28,40,5$ \\
\hline $\begin{array}{l}\text { Pccuracy } \\
\text { record }\end{array}$ & Completion of record & Patient trust & 1,64 \\
\hline
\end{tabular}


We identified six main themes and 14 sub-themes from the review of the articles.

Papers mostly reported themes related to legislature in the USA driving the development of PHRs and patients access to medical records or information via either an electronic health record or personal health record. The thematic category which had the most number of sub-themes (seven) was regarding patient access to medical information. The sub-themes with the highest number of articles: were those concerned with testing the implementation of PHRs to meet the US legislative requirements for patient accessed information.

One of the earliest papers found during the literature review regarding the US legal requirements for patient accessed information was by Cimino et al (2000). They stated that the "Health Insurance Portability and Accountability Act of 1998" (HIPAA) (p.151) has led the way in the USA for patients to access their electronic health records. Centrally, at national and state government level there had been the expectation that with greater access to their information patients' knowledge of their health and disease would result in reduced health service use. Clinicians were expected to embrace this development positively as a result of this entitled access. However, Cimino et al (2000) recognised that these expectations were hypothetical and had not been tested. Over the following two years $(2001,2002)$ Cimino et al trialled interventions that enabled the consequences of the legal framework to be realised. They found no adverse events from patient electronic access to their information, better levels of patient knowledge and improved patient / doctor communication consistently. But, the studies were small with less than 15 subjects enrolled in each one and were conducted in single centres, and so were of poor quality. Nevertheless this early research did provide a limited case for the expansion of the research area in years to come.

Many other authors commented on the positive influence of the HIPAA and its fundamental impact on patient's freedom to access health records. The authors cited the legislature within their papers as justification for their research (Ross et al 2003, Ross et al 2005).

Masys et al (2002) reported on a system development of a PHR and how this abided by the statutory requirements of the "existing and emerging federal and state 
laws and regulations regarding health information security and patient privacy" (p. 182). They describe in detail how they built the IT system and then tested it both conceptually and in real life with patients and doctors. The system was found to be safe but was difficult to use by doctors, however patients liked it more than traditional forms of care that did not involve automatic free access to health records online.

Ross et al (2003) acknowledge that the USA, at this time, was ahead of other initiatives worldwide. The UK at this time was considering, but had not yet implemented the legal right of patients to easily view their records, and enable patients to make changes as deemed necessary by the patient.

From 2013, papers cite new legal requirements introduced at this time to recognise patient-centred care; the "Meaningful Use Roadmap" (Kerns et al 2013). Kerns 2013 explains how financial incentives had been interwoven with the legislation to introduce PHRs. The aim by government was to increase the use and proliferation of the technological advances and increase patient autonomy to access information. The interweaving of legislature as a push to encourage keepers of the information to release information, and payment to providers as a pull to comply, may have been because uptake of these new options by patients had been low. Tenforde et al (2011) concludes that in the period 2009 to 2010 "only $7 \%$ of Americans reported having used a PHR" despite the national importance given to this area of health.

The researchers following 2013, including Pavlik et al (2014), Wells et al (2014) and Zarcadoolas et al (2013) state that further legislation, notable the "Health Information Technology for Economic and Clinical Health (HITECH)" (p. e169), has effectively married payments for providers with the enablement of patients to "access ... their health record with the ability to access, print, share or download their health information" (p. e169). Gee et al (2015) gives useful historical context and explains that the introduction of HITECH was as a result of lost medical records from the hurricane Katrina and the subsequent implementation of policies to avoid a similar event following a disaster. They state that financial incentives of up to "\$44,000" (Gee et al $2015 \mathrm{p} 230$ ) are payable for implementation of PHRs that enable this, and there are financial penalties to organisations if a PHR is not enabled. 
Yet still, with products in place and unilateral legally sanctioned support, researchers state that there had not been sufficient research of the effect of PHR introduction on patient and clinical staff (Casey et al 2016, Greenberg et al 2017, Nahm et al 2017). Gerard et al (2017) makes the point that although there has been widespread coverage of patients using PHRs , "over 15 million patients in 40 states ... we understand little about what they value in doing so" and so research continues.

In the U.K. Bhavnavi et al (2010) and Bartlett (2012) both acknowledge the legal precedents set by the experience of USA in terms of formalising the requirement for PHR introduction, and they state that the UK is following the trend by aiming for similar adoption. Cruikshank et al (2012) state that the UK government aimed to enable all primary care patients electronic access to their EHR by 2015, and in their study found that patients were generally in favour of using a PHR but there were a paucity of health providers equipped with the facilities to provide this. Cruikshank et al found only $1 \%$ of primary care facilities ready for the change. Honeyman et al (2005) stipulates that patients in the UK have had the right to access their records since 1984 as stated within "the Data Protection Act" (p55), but the processes for patients to enact access have been laborious and difficult to negotiate and as a result low numbers of patients have sought access.

In the UK, many products and systems have emerged from lone interested health organisations pioneering the concepts of patient accessed PHR, and have done so without the formal guidance from government. There have not been the financial incentives to encourage the system developments, nor any penalties if healthcare providers don't provide patient access (McKinstry et al 2006, Muhammed et al 2012, Phelps et al 2014, and Royal College of Physicians 2017).

In the UK it seems research is being conducted prior to statutory requirement to implement PHRs, but legislature is expected. In the USA it seems legal requirements came prior to the bulk of research carried out. Both the UK and USA do seem to be leaders in this area of research in terms of articles included in this literature review.

Within the sub-theme addressing whether patients and clinicians found access to their medical record feasible or popular, overwhelmingly the response was positive (e.g. Bartlett et al (2012), Cimino et al (2002), Hassol et al (2004)). This 
finding was identified even when there had been no improvement in clinical outcome shown. Forbes et al (2017) studied the effects of a disease specific PHR (for glaucoma), and found that there was equivalence in results when patient knowledge was assessed, and yet patients still "welcomed" (p. 546) the innovation of accessing their own records. Somner et al (2013), four years earlier, and studying patients with the same disease group (glaucoma), echoed these findings and found patients demonstrated "enthusiasm for PHRs".

Patients were asked why they liked accessing their records by Gerard et al (2017), and it was found that four broad reasons were identified: patients were more able to remember future health plans, they could have quicker investigative results, were able to more fully discuss and share the information received and had "positive emotions" (pe238). These findings were reminiscent of Winkleman et al (2005) who also elicited four similar broad themes that support the use of PHRs by IBD patients: “illness ownership ... patient-driven communication ... personalized support, and ... mutual trust" (p. 306).

No papers reported patients disliking access to their records, but there were articles relaying that clinicians had concerns with patients accessing their information. Hassol et al (2004) found that clinicians were unsupportive of patients having access to their clinician via email because of a perceived increased workload, and clinicians preferred more traditional methods of contact such as telephone or letter. Patients though, resolutely preferred electronic access. Ross et al (2005) concurs with this finding, and reports that patients had fewer worries about access than clinicians, and patients identified more potential improvements in care. Indeed the Ross et al (2005) conclude that the two opposing groups (patients and clinicians) "may need to be reconciled" (p. e.14) for broad integration of the PHR into everyday healthcare. The Royal College of Physicians (2017) outlined that one of the reasons for these differences between the groups may be that the clinicians have not fully tried PHR systems and so have not incorporated the PHR into everyday clinical practice, but patients are eager for the benefits of a PHR, whether perceived or envisaged. However, even when a system was used, Masys et al (2002) found significant discrepancy between the clinicians and patients: patients found the system they were using worked well, providers did not. 
There was broad positive consensus within the sub-theme category addressing the outcomes of patients' use of an EHR or PHR to access information. The majority of papers illustrated that patients using a PHR felt more trust in their doctor (Fisher et al 2009), with increased levels of collaboration between patients and clinicians (e.g. Bhavnavi et al 2010, Mold et al 2015). Perhaps as a by product of this there was greater empowerment of patients to control their healthcare and improved self-management. Gee et al (2015) appraised the experiences of chronically ill patients using a PHR and found complete agreement of the participants "all found ... the PHR ... useful for self-management ... and for productive interactions". This emphatic endorsement does have a caveat and there was acknowledgement that there were some difficulties in use of the PHR.

Patients found improved communication with their healthcare providers and gained greater understanding of their disease or condition, with few identified adverse outcomes (e.g. Ferreira et al 2007) and the knowledge patient's hold of their health had improved overall with raised levels of health education (Garcia-Lizana et al 2007). Conversely, one systematic review paper reported that patients found the ability to view, hold and assimilate their information a burden (Sartain 2014), but this lone paper did acknowledge that there was poor quality research in the area.

The majority of articles reported improved self-management of disease, communication with doctors and understanding of information, potential the health improvement value of this was realised by only one paper. Wagner et al (2012) in a randomised trial of PHRs and hypertension found that overall there was no impact on blood pressure measurements of patients having a PHR, but in a sub-analysis of intervention patients, a small difference and lowering of blood pressure was noted. However, the authors discuss that this may be because few patients within the study used the PHR regularly and this sub-group of patients may be more pre-disposed to lowering of blood pressure i.e. are younger. These findings re-iterate McKinstry et al (2006) who had not found any clinical benefit from a PHR for patients with hypertension.

The other disease groups in which no discernable clinical benefit of a PHR was identified were: IBD (Bidmead et al 2016), mental illness (Farrelly et al 2013, 
glaucoma (Forbes et al 2017, chronic disease (Garcia-Lizana et al 2007, Ko 2010, Tenforde et al 20111) and asthma (Powell et al 2009).

Some papers looked at other and different patient groups in an attempt to identify which patient groups would most benefit from PHRs and how systems could be tailored to meet differing patient needs. Hemsley et al (2018) conducted a systematic literature review of "The health literacy demands of electronic ... (PHRs)" $\mathrm{p}$ 2. They found that the expansion of the PHR to provide electronic information access to large scale health populations, that could include many disease types, age groups, geographical and socio -economic patient variations, may prove challenging and rely upon more than the patients IT skills. They identified factors such as "executive function, verbal expression, and understanding of spoken and written language" (p. 2) and testified that these could prove central to the imbedding of PHRs into patient care, and would most probably affect the successful implementation of PHRs. Greenberg et al (2017) outlined that patients with lower incomes and/ or greater age were less likely to use a PHR. But when these patients did use a PHR, they may have the greatest potential benefits. Phelps et al (2014) supports this finding, and showed that patients with higher levels of deprivation and lower socio-economic status were less likely to use the PHR but those that did used the system more often and did not withdraw from using the PHR. Pavlik et al (2014) looked at whether there were differences in satisfaction and recall following use of a PHR between different gender and ethnic groups (Hispanic and African American). They found that gender and ethnicity did not affect the outcomes.

There was broad consensus that patients accessing a PHR was safe; with no significant risks, adverse events or increase in patient anxiety reported (e.g. Bartlett et al 2012).

Whilst system planning, implementation, testing and use of PHRs and patient access to information was reported, it was in a minority of papers only. Most articles discussed security and control of systems, and release of information to patients, and differences were noted in the findings. Some papers reported that patients and clinicians trusted the governance measures that existed for the sharing of information with patients. Honeyman et al (2005) found that UK based patients were pragmatic in their expectations of access to their electronic records. Patients wanted to see their 
information and "generally trusted in the security of their records" (p. 55), but also accepted there may be errors within the information. The patients wanted to correct these errors and also update the records themselves to provide up-to-date information to their clinicians. Zarcadoolas et al (2013) echoes these findings and suggests that from their qualitative research from the USA, patients were eager to have their information and security was not a major worry. When security measures were specifically tested (i.e. Masys et al 2002), the systems held up well against targeted attacks. There were papers however, that refuted these findings and they outlined evidence that patients did have worries over the security of their information and the accuracy of their information. Cruikshank et al (2012) reported that over $70 \%$ of the patients they polled did have anxiety about security and the accuracy of the information, and Kerns et al (2013) relayed similar findings.

Generally the systematic literature review thematic analysis found broad consensus but also areas of disparate findings. Patient access to medical information was broadly well received and the use of systems was mostly feasible and popular, but some clinicians voiced concerns. It was found that use of PHRs principally increased collaboration in care between patients and clinicians, enhanced communication and improved patient empowerment. The studies found the systems that enable patient access were safe, but most reported no improvement in health outcomes or status as a result. Patients sometimes trusted the systems security but there were some concerns about this and the accuracy of information held within the records. 


\subsection{Discussion}

\section{Summary of the results}

We conducted this systematic literature review to identify and summarise the contemporaneous evidence for individually enriched IBD information and the use of this by patients and their health care professionals. We wanted compare the published evidence with the outcomes of our focus group, design of intervention and feasibility trial (chapters two, three and four), to deduce if there had been significant advances since our trial in 2011 and identify further areas of research in this area.

We carried out a broad literature search over eleven electronic databases, using worldwide publications and an 18-year time limit (2000-2018). Our search terms were also broad. We had anticipated few literature finds if more narrow searches and terms were used. Whilst IBD was our main focus of our disease population search, as this was the disease population studied within our research, we widened the search terms to include chronic illness and disease, as IBD is a gastroenterological chronic disease. We also used broad search terms for the ways that patients might access their medical information or records. We used 'and' and 'or' key word combinations to try to ensure we retrieved as comprehensive a literature search within the keyword parameters.

We carried out a two-stage process for the study selection and to assess the quality of the articles, and collated comparable data from the literature over six categories and classified common themes.

Of the 1203 examined citations, 65 were identified for inclusion in the systematic literature review. We found that of these papers less than $30 \%$ were published before our trials in 2010, and less than $13 \%$ reported findings related to IBD. Most articles were published in the USA and nearly half of the research papers reported qualitative studies with few quantitative or mixed methods studies. The numbers of participants within the studies was variable but some large $(>1000$ participants) studies had been carried out. The quality analysis of the papers found that less than $10 \%$ of the studies scored six out of 12 or over, and so were of poor data quality with few reporting in each of the scoring criteria and we found few peer reviewed studies had been carried out in this area that were of high quality. 


\section{Main themes}

The studies identified varied greatly in terms of their characteristics, and there was a high degree of heterogeneity found. We identified six high-level criteria for comparing the papers; year, population, location, study design, number of participants / articles and quality score of the article. We found variation within each category.

From 2000 to 2018 we identified a steadily growing interest in the area of patient access to information and in the last three years we found a noticeably more rapid increase in the number of studies. The bulk of the studies had been carried out from 2011 - 2018 (46), and half of these (23 studies) have been published in the last three years, from 2015 onwards. The trend is increasing, potentially because of different factors.

From 2000 to 2010 we identified studies looked at mostly primary care patients (e.g. Ciminio et al 2001), but from 2010 there was a shift toward research into chronic disease patients. The pioneering work of the early 2000's has now become a more mainstream research area. This was probably because of the recognition of the rising global incidence of chronic disease, associated with an increasing aging population. There was no evidence to suggest that research into primary care patients had been exhausted or conclusive, and we found most studies were of poor quality. The pressure upon healthcare systems to meet the challenges of chronic diseases within finite resources was stipulated by authors as a reason for their studies (i.e. Chunchu et al 2012) and had prompted health providers to look at new and innovative ways of providing care and including improved patient selfempowerment and self-management.

Most of the literature, identified originating in the later years of the literature search parameters, centred on chronic disease or a disease specific exemplar of chronic disease (e.g. Forbes et al 2017, patients with glaucoma, Nahm 2017 patients with diabetes). Consistently the main way that was identified to encourage and enable patient to better self-manage and consequently have less load upon healthcare services was via access to their information and in particular a PHR (e.g. Bartlett et al 2012, Bidmead et al 2012, and Royal College of Physicians 2017). 
Shifts in technological use and increasing legal requirements since 2000 were identified as a driving force in the development and investigation of PHRs (Hassol et al 2004). The information technology developments within the last 18 years have been wide-ranging, swift-moving and all-encompassing, within healthcare and wider society but paradoxically, it was noted by many studies, that uptake of PHRs were low (Tenforde et al 2011). It was noted that patients use technology to access, use and control their own information in a variety of different areas e.g. on-line banking, shopping and IT was viewed as accepted and available within the work and home environments but underused by patients in healthcare (Cruikshank et al 2012). Many studies aimed to identify product alterations that may counter this pattern but few identified crucial factors that could unlock the potential. Indeed, Winkleman (2005) alluded to the breakthrough coming through cultural shifts and more subtle integration of patient accessed electronic records with traditional care rather than a replacement of the care; "simply providing access ... has little usefulness on its own". It was identified that patients do want access to their records (Gerard et al 2017) but there was some reluctance from their clinicians to endorse this (Hassol et al 2004), because of increased workload commitments and worries about legal issues or complaints.

The infrastructure and technology to enable patient access to their information was described as increasingly sophisticated and more embedded as a concept in modern healthcare. This resulted in more systems being available for research and this may account for growth within this area. Legislation in the USA, enforcing the introduction of PHRs by incentivising the introduction and financially penalising providers who do not comply, was identified as a key push toward the widespread use of the PHR (Pavlik et al 2014). Worldwide, governments had identified the potential to control resource spending by empowering patients to access their information, better self manage and reduce load upon healthcare services. In the UK the underlying ethical concepts of partnership in care between patients and doctors, a move away from paternalism and increased autonomy for patients to control their information was appreciated, however it was not enshrined in law yet, but was expected. Perhaps because of this, few systems allowing patients access had been developed (Royal College of Physicians 2017), and most were reported as case studies (Cruikshank 2012) rather than trialled. 
The literature identified indicated that few studies were of high quality and a small number were carried out using rigorous research methodology. There were many surveys of patients and clinicians use, or anticipated thoughts of use of PHRs (e.g. Bell et al 2015), some large (Papoutsi et al 2015), but mostly small, and none were of high quality. Overwhelmingly patients were in favour of PHRs. The randomised controlled trials carried out scored higher in terms of quality (McKinstry et al 2006 and Pavlik et al 2014), but the trials were carried out less frequently in the later years of the literature search parameters than in earlier years. The randomised trials mostly aimed to identify a disease effect from patients having increased information. McKinstry et al (2006) and Wagner et al (2012) studied patients with hypertension, Forbes et al (2017) included patients with glaucoma, Williams et al (2001) looked at patients with a diagnosis of cancer, Nahm et al (2017) involved patients with diabetes and Pavlik et al (2014) more broadly included primary care patients.

Only one study found clinical benefit of patients with mental health issues holding more of their own information (Druss et al 2014). No study found a detectable improvement in physical clinical outcomes. Likewise our ELIJAH trial, although not powered to detect statistically significant findings as it was designed as a feasibility trial, did not detect any obvious improvement in patient symptoms. This could be because patient specific information can affect the way patients feel about their care, and increase their knowledge base, but it does not substitute for medical intervention and treatment and so does not impact on quality of life of the patient or resource use. We could not find evidence of a demonstrable link between patients liking having more information and being clinically better.

Largely the literature concentrated on patient accessing their information electronically via a PHR. No studies were identified in the later years of the search years that provided information in paper form. The use of technology to give patients access and information was universal, probably due to ease of production and dissemination of the information to patients and the ability to control security and privacy via built in controls such as passwords and secure logins (Masys et al 2002). Research has largely covered the safety of patients and we found agreement within the literature that there were no adverse effects on patients of them receiving their 
information and patients were unilaterally in favour of receiving more health information.

Positive outcomes of patients receiving their information were plentiful. Patients levels of communication with their doctors improved (Ferrier et al 2006), with improved trust (Fisher et al 2009) and greater enablement of patients and empowerment. Even when the IT systems were difficult to use (Gee et al 2015), or security concerns were raised (Zarcadoolas et al 2013), patients still wanted to access their information. Patients perhaps are realistic in expectations of health providers to provide safe systems, but appreciate these may not be perfect, or conversely patients can relate to experiences of having paper notes only and appreciate that there were issues with the storage and security of these too. Surprisingly it was found that patients voiced more concerns if discussing the hypothetical introduction of access to records rather than when they had them. Perhaps because using a PHR gave reassurance and allowed facilities to amend mistakes (Honeyman et al 2005).

Overall the systematic literature review found that patients liked access to their information, but clinicians remain more sceptical. Governments back the introduction of increased access particularly through PHRs but there remains a paucity of evidence to show this will significantly improve patients' clinical outcomes. The concerns regarding security of the information are less prevalent than expected and providers have taken these issues into account. The systems are safe and are feasible but not yet widely used. The literature base is small, with considerable variation and the majority of sourced literature is of low quality and not comprehensive, however our detailed analysis has shown that research in this area is still in development, and there is a growing and emerging research base with more research needed.

\section{Strengths and weaknesses}

We performed the literature search systematically to identify all IBD and chronic disease patient access to records. We acknowledge this could be a limitation of the review because of inherent bias within the process such as publication bias. We included a number of methods to reduce publication bias and our systematic literature search strategy was broad, and this proved both a strength and weakness within the review. We deliberately cast our search widely within the specified search 
areas, as we hypothesised we may retrieve only a small amount of literature with a narrower strategy, and used several strategies to achieve this.

We pragmatically decided to use 'and' in the search strategy to net a maximum yield of papers.

We employed an 18 year time period to encompass papers published pre and post our ELIJAH feasibility trial. This enabled us to identify the evidence that compared to our trial, and importantly, view developments in the areas subsequent to our trial. The review year parameters (2000-2018) may have inadvertently excluded some studies from the search strategy. There may have been earlier papers we missed that were seminal in the pioneering of patient accessed records. But, we recognise that patient access to information, particularly via electronic methods; via an EHR or PHR is a relatively new innovation.

We included 'chronic disease' as a separate key word from 'IBD', and searched using these terms within each electronic database, and this proved a strength as very few papers looked at IBD. We excluded acute disease from the search and we may have missed literature included within this category. We included all papers reporting findings, not only trials, and we did not limit the search to those papers written and published in English only.

A strength of our deliberate broad search strategy was that we identified a large number of papers. Many of the identified systematic reviews in this area found smaller numbers of articles. However, we did not find consensus or homogeneity between the literature. There were high levels of variation between the literature in terms of the six main characteristics identified, main themes and sub-themes. No paper emerged as a definitive study or seminal trial and we were mindful to interpret each study individually and collectively with caution. Heterogeneity was noted in terms of the IT systems used, patient populations studied, locations of studies, outcome measures and research methodology used.

We adjusted the EPHPP instrument (see table 27. Quality of studies), to differentiate the amassed literature in terms of quality using six markers. Very few high quality studies were identified and many of the studies scored extremely poorly or were not eligible for scoring as they were not trials. Few other systematic reviews had scored articles for quality. Most of the papers were of low quality and only one 
study had carried out mixed methods research employing both quantitative and qualitative methodology. The findings of this literature review are based, therefore, on only a small number of high quality studies and because of this we carried out a narrative analysis and not meta-analysis. A meta-analysis would have strengthened the review but was not possible because of the paucity of good quality papers with comparable data for analysis.

Previous systematic reviews within this area have concentrated on PHRs specifically, or looked at generic patient populations such as chronic disease. There is no review in the literature that has specifically looked at IBD. One of the strengths of this systematic review is that it did not focus on only on one intervention for the delivery of patient specific accessed records, but took into account different ways patients may access their information.

To our knowledge, this is the first systematic review that has specifically looked at IBD patients and chronic disease patients and access to records using a robust and standardised approach. New research is emerging within this field and our review contributes to the evidence base.

\section{How our research findings compare to the literature review results}

We carried out two research trials looking at the outcomes of IBD patient having access to their health records. We carried out a focus group with IBD patients to find out what patients want from access to their health records, this is reported in chapter two, we developed an intervention to enable access to the health reports (reported in chapter three), and then tested this via a randomised controlled feasibility study (see chapter four).

\section{Focus group}

We identified one focus group that was carried out prior to our study (Fisher et al 2009). This UK based research looked at patient access to records and gathered views on this from primary care patients and their clinicians. Our focus group, in 2010, reported that IBD patients were eager to receive more personalised information and they wanted access to their health information. These findings were substantiated by Fisher et al (2009), and there were many qualitative studies, using different methods to capture opinions, carried out after our study in 2010 to corroborate our conclusions (e.g. Royal College of Physicians 2017). The majority of other articles 
pre 2010 reported findings from primary care. Post 2010 there was a switch to papers reporting chronic disease and disease specific conditions (e.g. Nahm et al 2017).

Our findings suggested that patients felt they would be more able to understand their health information, have greater empowerment, and quicker access to relevant information. Participants stated they may be more able to self manage their condition particularly at time of need because of having increased access to their health reports. Four years after our study, Kelstrup et al (2014) found similar outcomes when surveying IBD patients from the USA. Our participants did voice concerns over privacy and security though, and these findings were echoed by other authors (e.g. Zarcadoolas et al 2013), but similarly we found that these fears did not over-ride their desire to have access to their records.

\section{The intervention}

Pre 2010 two articles were sourced that included patients with inflammatory bowel disease. Winkleman et al (2005) reported that patient required individualised information and Politi et al (2008) endorsed the sharing of this information by electronic means. These findings were influential for our trial preparation in 2010. We incorporated these design recommendations into our intervention and offered paper based and electronic information, and found it was feasible to produce individualised information.

There was only one paper that discussed the building of an intervention allowing patients access to records pre our 2010 trial; Di Marco et al 2006, but their system was for surgical patients and the product was designed to fit with the Canadian health care environment.

After our ELIJAH product development there was one paper describing an idea for an "IBD passport" (Muhammad et al 2012), it is unknown if the product was tested. There were other descriptions of product innovation to enable patient access to health information, but only one was specifically for IBD patients but was not rigorously tested and reported only as a case study (Royal College of Physicians 2017).

Many of the articles reported findings from the implementation of PHR and our intervention differed considerably from this. Our development of GeneCIS; to 
produce individualised patient reports, did not include patients having direct access through the fire-wall to the electronic health record. The intervention was not designed to enable patients to view their medical records, but rather to hold an individualised educationally enriched IBD report. There were no papers describing a similar intervention.

The randomised controlled feasibility trial

As far as we know, no other study had sought to test a similar intervention with IBD patients, nor were there any mixed methodology studies identified that included IBD patients.

Only 1 feasibility study was published (Chunchu et al 2012), and there were very few randomised trials. The Chunchu et al (2012) feasibility trial differed for our trial in numerous ways. The trial was based in a US primary care setting rather than our UK secondary care environment. Whilst patients with chronic disease were included in the trial the details of the patient diagnoses were not described. Most patients in the Chunchu et al trial had upwards of four chronic disease diagnosis. We included patients specifically with a diagnosis of IBD, although it is acknowledged the patients may have had other concurrent co-morbidities. The intervention differed for our patient groups in the ELIJAH feasibility trial from the Chunchu et al intervention. Our intervention was specifically aimed at sharing individual educationally information with patients, the Chunchu et al trial intervention focused on applying the EHR information throughout a multi-disciplinary team and testing whether this could be used to enhance patient care. Their findings and ours were similar in terms of meeting feasibility outcomes.

None of the rigorous randomised trials included IBD patients.

Two trials had been carried out using rigorous methodology prior to our trial (i.e. Williams et al 2001, McKinstry et al 2006). Both were based within the UK but neither included IBD populations. Both trials reported equivocal results for quality of life improvement and / or reduced resource use. Williams et al (2001) looked at patients with cancer and McKinstry et al (2006) included patients with hypertension. These patient groups differ from our IBD patient cohort in terms severity of disease of site of treatment, follow up and age range. The intervention used by the two studies and ours differed. Whilst all three provided extra information to patients 
McKinstry et al (2006) provided a generic leaflet for hypertensive patients plus a written guidance on how healthcare professions should manage their care and ways to question their care if needed. Williams et al (2001) gave intervention patients a patient held record which was held by the patients and was designed to be carried by patients to appointments, completed by patients and health care professionals and was designed to be used as a diary. Our intervention was more extensive than Williams or McKinstry interventions and provided educationally enhanced individualised information that covered a patients IBD history, a plan if symptoms arose and a summary of recent IBD care interventions.

There may be different reasons why Williams et al, McKinstry et al randomised controlled trials and our ELIJAH feasibility trial did not show any improvement in patient outcomes related to quality of life, nor reductions in healthcare resource expenditure as a result of the different interventions. It may be that whilst patients may favour having more information about their care (in whatever way it is packaged or presented), this constitutes a benign addition to the central elements of formal medical interventions. Interventions that may have more effect on patient quality of life or resource use could be a clinical consultation, the patient ability to ask questions and receiving answers in real time from health professionals, treatment regimes and the interpersonal relationship between clinician and patient. It can be speculated that whilst some patients may gain some reassurance from holding more information about their care they may want to verify the information with their health provider and some may not be confident to use information independently. However, further research would be needed to explore these theories in full.

From 2010, four further randomised trials had been published, but none included IBD patients and none found significant improvement of physical symptoms within the intervention group (e.g. Wagner et al 2012, Druss et al 2014). There was only one other study that carried out mixed methods research, and only one used a combination of qualitative and quantitative methodology (Pavlik et al 2014).

In our ELIJAH feasibility trial we found similar outcomes to the published literature - that patients liked the intervention (Hassol et al 2004), but there was no 
detectable physical improvement (Forbes et al 2017), and the intervention was safe (Bartlett et al 2012).

Our research findings did compare well when compared to the existing literature and we concluded that we had produced evidence that could contribute to the contemporaneous body of evidence surrounding the topics explored in this literature review in terms of rigorous methodology, patient population, intervention and outcomes.

\section{Identified need for further research}

This systematic review will better guide the use of patient access to individualised information for IBD patients and chronic disease patients. It can be used to help clinicians, researchers and national policy makers to better assess the current literature on what patients want from access to their health information, particularly from a PHR, and what likely outcomes of the introduction of such systems may be.

Research in this area remains to be evolving and is gathering pace. Different systems for providing patients with more information and wider variety of communication methods are being developed. As yet, there has been no formal testing of these systems published. One example of these developments is 'My IBD Portal' which has been developed by the IBD team at Salford Royal Hospital Foundation Trust (Mclaughlin et al 2018). The web based system is much evolved from the ELIJAH intervention developed eight years earlier in 2010 which was largely paper based and prescriptive in the information shared. My IBD portal delivers patients the ability to access a broader amount of their information on line. Patients can access links to information resources and real-time retrieval of investigations and full clinic letters. Access to clinician opinion can be requested through the portal and patients can track their disease progression over time via PROMs. Similarly to the ELIJAH intervention patients can glean diagnosis information, visual aids and have an individualised care plan. The Salford My IBD Portal does not provide educationally enhanced information, nor provides summary reports of patient information, so patients may have to review a large amount of information to gain pertinent information. 
As yet the "My IBD Portal" is used in one site in the U.K. and has had not been formally evaluated in a RCT to determine effectiveness, although usability and satisfaction have been noted to be high.

There are a paucity of published rigorous trials in IBD and PHRs. It may be that technological advancements are being developed far quicker than research in this area can keep up with. Developments in this area are often created by single teams or small clinical and research collaborative groups who may not be able to co-ordinate swift clinical developments and high level research simultaneously possibly because of time and cost constraints. The risk of running research trials in this fast moving area is that once the trial is conducted and published the intervention has been superseded.

Research in IBD and PHRs may prove an important area of future global health policy and could influence future legislature, but further studies are required. The information gathered and relayed within this literature review concludes that there is no seminal paper or conclusive research paper, and many of the studies are of low quality. There is also a paucity of rigorous testing of interventions, particularly with large disease specific patient populations. For the PHR or similar interventions to be widely used and implemented, and the potential benefits of them to be realised (i.e. reduced health costs, greater patient empowerment and self-management and increased health status), further research is required. The trials could reduce the risk of expensive system development with little secure evidence to support innovation direction.

There does seem to be a trans-Atlantic move toward the use of PHRs by patients, and further multi-centre, international trials are required that utilise a rigorous mixed methods approach. Studies based within the UK are required prior to government directives for implementation of PHRs. In the USA, where legislation has largely preceded system implementation, studies are required post implementation to inform tailoring of services that could enhance patient take up of systems and increase clinician confidence.

It can be interpreted that PHRs are wanted by patients and liked when they are used, but so far the evidence shows that this does not translate into improved patient outcomes such as improved quality of life, lower healthcare resource use. 
There are findings that suggest the anticipated results of patient access to their information resulting in reduce illness burden on patients and healthcare providers, less use of healthcare resources and reduced healthcare budgets have not yet been shown. As a result trials are required into various diseases to identify which ones respond more favourably to PHRs and why.

Within trials there is a need to focus on health economic evaluation for patients and healthcare systems that gives answers as to whether PHRs are a cost effective way to provide healthcare, particularly as system development can be very costly to develop and implement. Clinicians and patients need to be involved in future research to try to marry their system requirements and tailor information and communication pathways that meet both groups needs.

Further prospective studies are required to complete validation of the findings of the selected studies discussed within this systematic literature review. 


\subsection{Conclusion}

The evidence presented in this chapter/ literature review indicates that patients want access to their medical health records and like having this opportunity. Patients can envisage, or report experiencing, more benefits of this access than clinicians, and are more comfortable accepting they may be some risks concerning security of the systems. Patients report increased levels of empowerment, improved communication with their clinicians and are better able to self manage, and there have been no reported adverse events. But no trials found significant improvement in physical symptoms or condition as a result of patients having access to their information.

Governments, particularly in the USA and UK, have looked at this issue and there is legislation that enables patients to have these facilities, and as a result patients increasingly access their information via a PHR. However, there remains a paucity of high quality, rigorous trials in this area. Many of the existing trials have low participant numbers or are exclusively qualitative in methodology.

Further prospective mixed methods and randomised controlled trials are required to assess outcomes of this approach, especially in disease specific conditions such as IBD care, as this has been under-represented in the literature. 


\section{Chapter seven: Future research protocol design and conclusion}

\subsection{Introduction}

The previous chapter of this thesis reported a systematic literature review of patient accessed health information, with a particular focus on IBD patients and those with chronic disease. We concluded that patients welcomed and liked interventions that could facilitate greater access to their own information (substantiated by Phelps et al 2014), systems were safe for patients (supported by Bartlett et al findings 2012), and benefits were envisaged by patients and governmental health care legislators (echoed by Forbes et al 2017), but few studies had shown significant benefits on physical symptoms and health improvements (McKinstry et al 2006).

We compared our experience of conducting mixed methods research (a focus group and randomised controlled feasibility trial) with IBD patients, with the contemporaneous literature and found few similar studies. We identified a need for further research in this area, because there were few high quality prospective rigorous trials reported, none that specifically included IBD participants, and a dearth of secure evidence base (Tenforde et al 2011) to substantiate the hypothesised health economic benefits of patient accessed information (Wagner et al 2012).

Within this chapter we will build upon our experience of our feasibility trial, apply the learning gained and propose undertaking a cluster-randomised controlled trial with IBD participants to address these gaps noted in the existing evidence. 


\subsection{Background}

We identified, (in chapter one: Introduction), that there is a global phenomenon of a rising incidence of chronic illness, and this is mirrored within the UK. It was recognised that there is an urgent need to find innovative ways to meet the increased demand upon services, particularly in healthcare systems that are stretched and have finite funding due to periods of national austerity.

We recognised IBD as an exemplar of a gastroenterological chronic disease and included this as our disease group population for our research. We found that the two largest disease groups within the umbrella term of IBD are; Ulcerative Colitis and Crohn's disease and that in the UK alone there are 150,000 known patients with IBD, with 8,500 new diagnoses made annually (Carter et al 2004). We recognised there is no known cure. IBD, we reported, is characterised as a chronic gastro-intestinal disease that can have unpredictable episodes of remission and acute relapse, and can display mild to severe, and occasional catastrophic symptoms, including frequent urgent bloody diarrhoea, weight loss, nutritional depletion, anaemia, bowel obstruction and stricturing, fistulation and rarely death. The high degrees of morbidity and mortality associated with IBD and the medical and surgical interventions for disease control and treatment can have varying success rates and are not without additional physical and psychological effects on the patients (Carter et al 2004).

We discussed how, until now, the majority of IBD follow up care had been traditionally delivered in routine outpatient clinics based in secondary care, with some appointments available for urgent assessment. Most IBD services were found to have remote telephone helplines established to answer patient queries or triage contact particularly at time of need and IBD patient information is largely generic. Although this organisation of care remains prevalent in the UK, we explained how IBD care remains costly as it relies heavily on primary and secondary care resources, and patients require long-term specialised follow up. The current systems we stated, are mostly inflexible to demand as they are dependent upon rapid availability of clinic appointments or swift contact with healthcare professionals especially during times of unpredictable flare and potentially risky exacerbation of symptoms. These schemes we predicted, could result in patients having appointments when well but 
finding difficulty in securing appointments when needed to address increased symptoms (Hall 2007).

We proposed that new ways to provide patients with their individualised information were needed; to enable patients to better self-manage especially at time of need, in conjunction with better access to outpatient clinics and open access services. We understood though, that for this to be realised, patients would need to be well-educated in their own disease history and care pathway, understand an agreed medical escalation plan of care, be able to take responsibility for their care, and be able to communicate easily with their clinicians to report their health status. Such arrangements, we postulated, could help reduce patients' symptoms more quickly than via traditional follow up methods, and may circumnavigate the need for clinical intervention in secondary care. This could be achieved by arming patients with the knowledge of how to quickly initiate prescribed treatment programmes and so try to limit the effects of increased symptoms. These self-care programmes could, we hypothesised, reduce costs by decreasing the load upon secondary care services, preserve the safety profile of IBD care, and increase patient satisfaction. We noted that few innovations like this had been tested rigorously.

One way we identified to achieve better patient self-care was through increasing patients understanding and knowledge of their own disease by giving them and their GPs personalised and educationally enriched IBD information. In our literature review (chapter six) we discovered that currently, worldwide, there seems to be a move toward providing this individualised patient information via a PHR.

In 2010, we developed an intervention (detailed in chapter three) that extended our existing EHR facility (ELIJAH) to provide a detailed patient history, agreed individualised care plan with particular focus on what patients were to do at time of flare, and provided an update of each IBD care episode. This tri-part product was called "My Folder". Each part was educationally enriched in order to provide patients with an opportunity to gain greater knowledge and understanding of their disease, and better self manage through improved patient empowerment. We tested this unique intervention using mixed methods research.

We first held a patient focus group (see chapter two) consisting of IBD patients. We sought to identify views from patients about IBD information, care 
planning, and communication. We also asked patients to give their views on a prototype intervention that had not been formally evaluated. We then developed the intervention (see chapter three) and then conducted a randomised controlled feasibility trial (see chapter four) of the intervention in a single site, using a small number of participants.

We found the intervention was feasible to produce, we were able to recruit clinicians and patients and trial the intervention. Our data collection tools (ELIJAH Adverse Events form, Data Abstraction Form (DAF) and Inflammatory bowel disease Service Satisfaction Questionnaire were found to be efficient. We identified that of the four outcomes measures, three were feasible to collate reliably (cost, safety, and satisfaction), with one: timeliness, proving not to meet the feasibility criteria due to difficulty in sourcing data in this area. The intervention was deemed safe for patients with no significant unexpected serious adverse reactions (SUSAR's).

All feasibility criteria were met and we were able to identify a potential primary outcome: cost. The trial also met the progression criteria required to advance to a fully powered randomised trial and we acknowledged that modifications were required to our feasibility protocol to achieve this. Our trial progression recommendations were that:

- The total trial costs need to be increased resulting in an increased cost per participant in the trial.

- The length of patient follow up of the trial should be increased to one year.

- The trial should be multi-centre in order to include a range of patients to ensure wider generalizability of the findings and have enough participants to ensure that the trial is fully powered.

- A band 6 IBD nurse specialist should deliver the intervention.

- The trial should explore the satisfaction of participants and health professionals.

- "My Update" should not be included as a part of "My folder", instead changes should be made to "My Plan".

- The intervention should be populated by information from the primary and secondary care EPR. 
- The intervention should be offered via IT only.

- Timeliness should not be included as an outcome measure.

- The DAF, AE form and ISSQ should be used for data collection but in electronic form and linked to the EPR and automatically populated from it where possible.

- The ISSQ should be shortened and include the EQ5D plus thermometer.

Within this chapter we will reflect on the outcomes from the findings and incorporate our learning of our focus group, intervention, randomised feasibility trial and systematic literature review. We will discuss a proposed future trial protocol that acknowledges our reported strengths and addresses the issues identified.

\section{Study aim}

The aim of the project is to evaluate the extent to which shared IBD educationally enriched health reports and access to an IBD PHR will reduce demand on health resources, by facilitating better patient understanding and knowledge, improving communication and greater patient empowerment and individual patient responsibility for self- care.

\section{Objectives}

1. To gather views from clinicians and patients on the proposed introduction of patient accessed IBD reports via a PHR.

2. To estimate the cost of implementing ELIJAH, and evaluate the reduction or increase in total NHS health resource use and cost.

3. To assess the cost effectiveness of ELIJAH by identifying cost per qualityadjusted life year based on patient reported changes in health status.

4. To evaluate the safety of ELIJAH by the collation and analysis of patient adverse events.

5. To assess the effect of ELIJAH upon patient and clinician satisfaction rates.

6. To reassessment of the perspective of patients and clinicians of ELIJAH post use.

\section{Design}

Our learning, from the focus group and prospective randomised controlled feasibility trial, told us that this research methodology is feasible when studying IBD 
patients who are given individualised educationally enriched health reports as an intervention. When carrying out a larger trial in this area we will replicate the basis of the intervention but change some of the elements.

We will increase the size and range of the trial to enable greater numbers of patients to be included as we recognised that our feasibility trial was not planned, or powered to detect statistically significant results of the outcome measures. We found that there were few examples of high quality mixed methods research in this area that had been carried out, and that there is a gap in the evidence base that we will address with our trial. We will plan for a large scale, multi-centre, cluster (step-wedge) randomised controlled trial that has adequate power.

The trial will be sited across the UK, in identified centres that provide large scale IBD care within secondary care settings (i.e. district general hospitals, acute hospitals and tertiary referral centres). We will aim to recruit patients from a wide range of geographically disparate sites $(n=20)$ with the aim of a yield of large numbers per site. This approach will reduce the risk of cross infection of participating locations.

Similarly, to our previous mixed methods research, we will hold qualitative focus groups with IBD patients, but will also separately interview clinicians. We did not include clinicians in the qualitative research initially, and it could be that we missed important information that could have affected our intervention development and feasibility trial. The literature review did show there is some evidence to suggest there are differences in clinician and patient views about patient accessed information (Hassol et al 2004, Ross et al 2005). In our study we conducted one focus group, but in the full trial we will hold multiple patient focus group and conduct clinician interviews in half of the study sites. We will carry out the focus groups and interviews before the trial starts as we did in our studies, but will additionally hold them also at the end of the study period. This will enable us to identify expectations of patients and clinicians prior to receiving the intervention (as we collected in our focus group), but also collate patient and clinician views of the intervention and their experiences of using the intervention as part of their IBD care package. 
We will use the useful patient and clinician views gathered prior to the trial to further develop and refine the intervention as we did in our building of the intervention.

We will test the intervention using a randomised controlled approach as we found this quantitative methodology was feasible to carry out for the intervention. Within the reflective chapter (chapter five) we acknowledged that the RCT was the gold standard of clinical evaluation as it had an essential feature of a division of participants into subgroups to enable comparison: those receiving the intervention and the control group who have care as usual.

The identification of intervention participants via remote electronic randomisation process worked well within our feasibility trial for the small number of participants included. However, we realised there were issues with slow recruitment and we identified a potential for 'resentful demoralisation' of the control group who did not receive the intervention. In the full trial we will again use a randomised approach, but this time we will carry out a step-wedge cluster randomised trial (Brown et al 2006, Beard et al 2015). This design modification could address our identified issues, and will enable each site to receive the intervention. It will reduce potential bias and differences in study sites, reduce potential contamination between sites and minimise the effects of any national health policy shifts during the trial period.

All sites will begin as control sites and participants will receive IBD care as usual. Sites will be randomly allocated staggered timings for commencement of the intervention (see Fig. 11 randomised multiple interrupted time series study design overview). 
Figure 11. Randomised cluster step-wedge study design overview MONTH

\begin{tabular}{|c|c|c|c|c|c|c|c|c|c|c|c|c|c|c|}
\hline 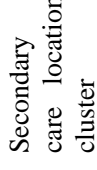 & 0 & 1 & 2 & 3 & 4 & 5 & 6 & 7 & 8 & 9 & 10 & 11 & 12 & 13 \\
\hline 1 & \multirow{7}{*}{$\begin{array}{l}0 \\
0 \\
0 \\
0 \\
0 \\
0 \\
0 \\
0 \\
0\end{array}$} & $\mathrm{~T}$ & & & $Q$ & & & $Q$ & & & & & & \multirow{5}{*}{ 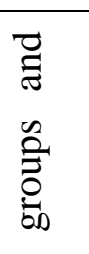 } \\
\hline 2 & & $\mathrm{~T}$ & & & $\mathrm{Q}$ & & & $\mathrm{Q}$ & & & & & & \\
\hline 3 & & \multirow[t]{2}{*}{$T$} & & & $\mathrm{Q}$ & & & $\mathrm{Q}$ & & & & & & \\
\hline 4 & & & $\mathrm{~T}$ & & & $\mathrm{Q}$ & & & $\mathrm{Q}$ & & & & & \\
\hline 5 & & & $\mathrm{~T}$ & & & $\mathrm{Q}$ & & & $\mathrm{Q}$ & & & & & \\
\hline 6 & & & $\mathrm{~T}$ & & & $\mathrm{Q}$ & & & $\mathrm{Q}$ & & & & & \multirow{2}{*}{$\begin{array}{l}\mathscr{U} \\
\overline{0}\end{array}$} \\
\hline 7 & & & & $\mathrm{~T}$ & & & $\mathrm{Q}$ & & & $\mathrm{Q}$ & & & & \\
\hline 8 & \multirow{3}{*}{ م્ } & & & $\mathrm{T}$ & & & $\mathrm{Q}$ & & & $\mathrm{Q}$ & & & & \multirow{3}{*}{$\stackrel{\overrightarrow{0}}{\stackrel{\overrightarrow{0}}{E}}$} \\
\hline 9 & & & & $\mathrm{~T}$ & & & $\mathrm{Q}$ & & & $\mathrm{Q}$ & & & & \\
\hline 10 & & & & & $\mathrm{~T}$ & & & $\mathrm{Q}$ & & & Q & & & \\
\hline 11 & \multirow{2}{*}{$\begin{array}{l}0 \\
\overline{0} \\
0\end{array}$} & & & & $\mathrm{~T}$ & & & $\mathrm{Q}$ & & & $\mathrm{Q}$ & & & \multirow{5}{*}{ 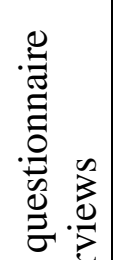 } \\
\hline 12 & & & & & $\mathrm{~T}$ & & & $\mathrm{Q}$ & & & $\mathrm{Q}$ & & & \\
\hline 13 & \multirow{8}{*}{ 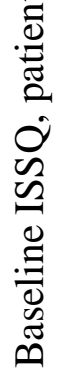 } & & & & & $\mathrm{T}$ & & & $\mathrm{Q}$ & & & $\mathrm{Q}$ & & \\
\hline 14 & & & & & & $\mathrm{~T}$ & & & $\mathrm{Q}$ & & & Q & & \\
\hline 15 & & & & & & $\mathrm{~T}$ & & & $\mathrm{Q}$ & & & Q & & \\
\hline 16 & & & & & & & $\mathrm{~T}$ & & & $\mathrm{Q}$ & & & $\mathrm{Q}$ & \multirow{5}{*}{ 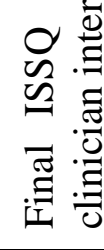 } \\
\hline 17 & & & & & & & $\mathrm{~T}$ & & & $\mathrm{Q}$ & & & $\mathrm{Q}$ & \\
\hline 18 & & & & & & & $\mathrm{~T}$ & & & $\mathrm{Q}$ & & & $\mathrm{Q}$ & \\
\hline 19 & & & & & & & & $\mathrm{~T}$ & & & $\mathrm{Q}$ & & $\mathrm{Q}$ & \\
\hline 20 & & & & & & & & $\mathrm{~T}$ & & & $\mathrm{Q}$ & & $\mathrm{Q}$ & \\
\hline
\end{tabular}

Key: Control period

Clinician and patient training period

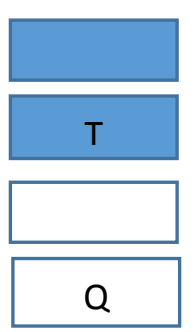

Intervention period

ISSQ patient questionnaire

Training will take place before the implementation of the intervention. Six weeks before sites start the intervention they will receive notification of their date of training dates and date of commencement of the intervention. Immediately prior to sites converting from control to intervention sites, clinician and participant training will take place to ensure both groups can effectively use the system. This training will be via e-learning for patients and e-learning plus site study days for clinicians. 
The staggering of site education and training will help the intervention trainers to ensure that adequate time can be spent with each site and queries can be addressed before the intervention is started. The sites and participants will, after training, be able to access the remote centralised technical support facility.

Each site will have training for clinicians and patients on use of the ELIJAH system including the log-in functionality, usability and built in security measures. It is expected this will increase use of the intervention and limit queries once the trial has commenced. We found evidence within the systematic literature review that this combined approach of training and support was wanted by patients to enable them to better use systems that allowed access to their health information (Casey et al 2016, Laugesen et al 2016, and Royal College of Physicians 2017).

Four times during the year long trial period patients will be asked to complete a satisfaction questionnaire - the ISSQ - Inflammatory bowel disease Service Satisfaction Questionnaire, i.e.: before trial commencement, then twice within the intervention period, and at completion of the trial. Within our feasibility trial we found this was a feasible method of collecting satisfaction data, but we identified there may have been some participant fatigue with completion of the questionnaire, as we had asked our participants to complete it four times in six months. This time we will require participants to complete the questionnaire the same amount of times but over an elongated trial period time of one year. We will repeat our reminder process to participants who have not returned their ISSQ within two weeks after dispatch, and shorten the ISSQ, this we believe may reduce the amount of missing or incomplete data.

We will, once again use the EQ5D, but this time, utilise the complete quality of life measurement and include the health thermometer. This will provide additional detail and evidence.

In our feasibility trial we sent the ISSQ in paper form, but in the main trial we will send and collect the forms electronically through the PHR with notification of this via participants email. 


\section{The ELIJAH intervention}

We developed the ELIJAH intervention with the aid of very useful patient feedback received during the focus group (see chapter 2). Patients reported that they were very keen to receive individualised IBD information as the generic leaflets and booklets given as education material were too generic. Patients felt frustrated having to repeat their information with multiple professionals at different appointments and found it difficult to contact health professionals at time of need to get advice and guidance on how to treat flares. Patients believed they could look after their records more carefully than healthcare providers had, as many had reported experiencing lost, inaccurate or disparate notes. They voiced concerns over the lack of sharing of important information between primary and secondary care and particularly they felt left out of important clinical knowledge that they could use to better self treat.

"Information ... should be uniform right through the NHS, every place should have exactly the same information wherever you go" (participant number 019).

Many of these views and opinions were echoed within the findings of the systematic literature review.

As a result of this learning, we developed a modified output of our existing EHR to create educationally enriched individualised IBD reports. These were created in three parts (My History, My Plan and My Update), and combined formed "My folder". These products were created by manual entry into the EHR of information extracted from the patient paper notes, secondary care EHR GeneCIS, patient information system, and from investigative results stored on another separate IT system. We found this method of manual transference of data from different IT sources to one programme time consuming and laborious. We also identified there could be a potential for inaccuracies of data input through human error. In the full trial we will automate this system to allow population of the reports directly from the patient record system and primary and secondary care IT systems.

In trialling the feasibility of the intervention we found that two of the three reports (My History and My Plan) were feasible to produce from the available patient information. However the third part of the package "My update" was too difficult to produce because sometimes we were unaware of patients visiting for IBD care, and it proved difficult to provide updates to patients in a timely fashion. 
We recognise that in the intervening eight years since we developed our ELIJAH intervention there have been vast technological advances and increasing IT functionality, and so we harness these advances with a modification of the ELIJAH intervention. We would preserve the structural integrity of "My History" and "My Plan" and remain producing these as electronic reports, but enable patients to access "My Update" information directly into a PHR, rather than using reports (see Figure 12. Components of the intervention). Patients would access clinician letters to primary care providers and their investigative results directly. Information security will be preserved via secure log-ins with preserved security features for the healthcare providers. The systematic review showed that this approach using patient accessed PHRs is used currently, is safe and trusted (Masys et al 2002, Price et al 2012, Zarcadoolas et al 2013). Clinicians and patients will, once again, receive exactly the same IBD information in the same way.

Figure 12. Proposed components of the intervention

\begin{tabular}{|l|l|}
\hline Patient and clinician training & $\begin{array}{l}\text { An e-learning package available to } \\
\text { patients and clinicians available } \\
\text { immediately prior to commencing the } \\
\text { intervention. }\end{array}$ \\
\hline ELIJAH reports & $\begin{array}{l}\text { My History and My Plan available to } \\
\text { patients and clinicians electronically }\end{array}$ \\
\hline ELIJAH PHR & $\begin{array}{l}\text { Available as an app or via a PC allowing } \\
\text { patient access to their most recent } \\
\text { clinical information including clinic } \\
\text { letters to GPs and investigative results. }\end{array}$ \\
\hline Technical support & $\begin{array}{l}\text { Remote centralised support for patients } \\
\text { and clinicians to report inaccuracies in } \\
\text { the data and receive support with using } \\
\text { the system. }\end{array}$ \\
\hline
\end{tabular}

In 2010 we offered the intervention in paper and electronic form via email, but for the full trial we will reflect the eight year hiatus, the growing use of IT within the wider society and the acceptance of IT integration into every day life, and offer the intervention by electronic means only. We will provide information via an app for ease of transportation which could be especially helpful for patients requiring their IBD information at clinical appointments in primary and secondary care and when travelling. Patients and clinicians will also be able to access the intervention via PC's. There will be a facility for patients and clinicians to print the information 
as a PDF if wished. We will test the new intervention elements fidelity prior to the trial commencement, with participants who would not be included in the main trial.

We will, again, provide patients with an email facility through the portal to contact their IBD provider so that patients can get queries answered, give health updates, receive advice or triage to other appropriate services quickly without the need for a secondary care appointment. Patients who already have email access to their clinical team will be able to access this without any change. Patients or staff will be enabled to report inaccuracies or seek help using the system by contact with remote IT technical support, this will be separate from the email facility for clinical advice.

The intervention will for a second time be built using ELIJAH educationally enriched IBD reports (My History and My Plan), but will additionally include patient and clinician access to an IBD personal health record that will provide updates of care. Structured training and support when using the system will be available.

\section{Outcomes}

As we did in the feasibility study, we will have a pragmatic, defined set of outcomes. Following the commencement of sites converting from to intervention sites, we will compare outcomes between the intervention and control group. Our outcome measures will be:

Primary outcome

Cost-effectiveness - our primary outcome with will be a health economic evaluation of total NHS resource use and costs per patient, including use of all primary and secondary care health resources, combined with QALYs (QualityAdjusted Life Year) as determined using the EQ5D. Cost resource use data was identified within our feasibility study as a suitable primary outcome because of ease of data capture and acknowledgement of the financial frontloading required to develop and implement the intervention. We will expand upon the cost use data set used in our feasibility trial and carry out a full health economic evaluation of the intervention, testing cost and effectiveness. 
Secondary outcomes

- $\quad$ Safety - the number of adverse events leading to hospital admission or otherwise threatening the health and well-being of participating patients that have been reported to a health professional.

- $\quad$ Patient centeredness - the satisfaction of participants with the care they receive over the study period.

We will collect data on these outcome measures using a rigorous electronic data collection system such as REDCap (Harris 2018). We will use different forms to collect data per outcome measure via the following means:

- $\quad$ Cost effectiveness will be captured using two forms. Total NHS cost resource data will be collated via the ELIJAH Data Abstraction Form. Although the process of formulating the two ELIJAH reports will be automated, any additional clinical time to formulate the elements of "My folder" will be captured. Total NHS costs of participants across primary and secondary services will be collected; including inpatient, outpatient, GP appointments, open access service use and medication use. Effectiveness data will be captured via the EQ5D included within the IBD Service Satisfaction Questionnaire (ISSQ).

- $\quad$ Safety will be assessed via the monitoring of IBD patient adverse events. Electronic GP and hospital records for the patient will automatically populate the ELIJAH Adverse Events form and provide information relating to primary and secondary care attendances. We will search for all admissions to acute care facilities and identify any hospital admissions and outpatient visits.

- $\quad$ Patient centeredness. Data will be collected from participants at baseline, twice during the intervention period and at the end of the study at 1 year trial period using the validated, adapted and shortened IBD Service Satisfaction Questionnaire (ISSQ). These will be sent to patients, and returned to the researchers electronically.

Timeliness was included as an outcome measure in our feasibility trial. We had looked at the speed of response by health care providers to patient reporting of 
symptoms. We monitored this by assessing the time differences between patients' duration of symptoms, patient reporting of symptoms and health professional reaction to symptoms. However, we found did not find this outcome measure feasible to collect data because of difficulty in accessing the information and there was a large degree of missing data for this outcome measure. We therefore will not include it within the full trial. 


\subsection{Methods / design}

\section{Summary of the proposed trial}

\section{Figure 13. Summary of the proposed trial}

\begin{tabular}{|c|c|}
\hline Aim: & $\begin{array}{l}\text { The aim of the project is to evaluate the extent to which shared } \\
\text { IBD educationally enriched health reports and access to an } \\
\text { IBD PHR will reduce demand on health resources, by } \\
\text { facilitating better patient understanding and knowledge, } \\
\text { improving communication and greater patient empowerment } \\
\text { and individual patient responsibility for self- care. }\end{array}$ \\
\hline Objectives: & $\begin{array}{l}\text { 1. To gain better understanding of what patients and } \\
\text { clinicians want from access to IBD health reports and PHRs. } \\
\text { 2. To develop personalised health reports and enable access } \\
\text { to an IBD PHR, and to make these available to patients, } \\
\text { hospital doctors, and general practitioners (GPs). } \\
\text { 3. To use this to facilitate better communication, and to } \\
\text { enable patients to take greater responsibility for their health } \\
\text { care. } \\
\text { 4. To evaluate the effects of this intervention on patients; } \\
\text { primarily on the use of health service resources and costs, } \\
\text { and also on safety and satisfaction. } \\
\text { 5. To evaluate the effects of this intervention qualitatively via } \\
\text { focus groups with patients and interviews with clinicians. } \\
\text { 6. To evaluate the wider benefits. }\end{array}$ \\
\hline Design: & $\begin{array}{l}\text { A. Qualitative patient focus group and clinician interviews } \\
\text { B. Pragmatic cluster randomised controlled trial, phase III. } 2 \\
\text { arms: } 1 \text { intervention, } 1 \text { control. } \\
\text { C. Qualitative patient focus group and clinician interviews }\end{array}$ \\
\hline Setting: & 20 IBD sites in the UK \\
\hline Participants: & $\begin{array}{l}\text { A. } 10 \text { randomised patients from } 10 \text { of the trial sites. } 3 \\
\text { Clinicians from the same } 10 \text { trial sites. } \\
\text { B. Trial patients from each of the } 20 \text { sites will be sought to } \\
\text { meet the sample size requirements. Sites randomised to } \\
\text { timing of commencement of intervention. } \\
\text { C. Same } 10 \text { randomised patients from } 10 \text { of the trial sites. } 3 \\
\text { Clinicians from the same } 10 \text { trial sites as included in A. } \\
\text { Replacement may be necessary for some contacts if originals } \\
\text { are unobtainable. } \\
\text { Inclusion / exclusion criteria: } \\
\text { Inclusion: } \\
\text { Patient with confirmed diagnosis of Ulcerative Colitis or } \\
\text { Crohn's Disease } \\
\text { Aged } 18 \text { to } 90 \text { years. } \\
\text { Under current IBD secondary follow up care } \\
\text { Patient registered with collaborating site. }\end{array}$ \\
\hline
\end{tabular}




\begin{tabular}{|l|l|}
\hline & $\begin{array}{l}\text { Exclusion: } \\
\text { Patients who are unable to comprehend the study. }\end{array}$ \\
\hline $\begin{array}{l}\text { Method of } \\
\text { randomisation: }\end{array}$ & $\begin{array}{l}\text { At the beginning of the study 100 patients will divided into 10 } \\
\text { geographically disparate focus groups to ensure we have a } \\
\text { clear picture of what information patients would like to access } \\
\text { via their electronic health record. } \\
\text { Interventions: } \\
\text { Patients gathered from 20 IBD sites will be included in the } \\
\text { randomised controlled trial. Randomisation will assign sites to } \\
\text { a staggered commencement of the intervention. All } \\
\text { participants and all sites will receive the intervention. All } \\
\text { participants will be asked to complete the "IBD Service } \\
\text { Satisfaction Questionnaire" with integrated EQ5D at the start, } \\
\text { twice during the intervention, and at the end of the study, to } \\
\text { monitor impact of the intervention on satisfaction with IBD } \\
\text { care, and general health related quality of life. The patients and } \\
\text { their clinicians in primary and secondary care will receive } \\
\text { electronic individualised educationally enriched IBD health } \\
\text { reports, have access to an IBD PHR. } \\
\text { During the control period each site and their patients will } \\
\text { receive care as usual. }\end{array}$ \\
\hline
\end{tabular}

Random sampling of the IBD population of each site will be carried out and then assessed for suitability to be trial participants against the inclusion and exclusion criteria. For the full trial our inclusion and exclusion criteria will remain the same as that used within our feasibility trial, as it proved practicable to stratify patients by this means.

The patients identified will be anonymised and coded for the study. A research assistant will invite potential ELIJAH patients to take part in the study by sending participant information sheets and consent forms sent by post. A clinician information invitation letter and summarised protocol will be sent simultaneously.

Consent will be sought by local research assistants from eligible patients at agreed meetings with the participants. The research assistant will provide further clarification of the participant information sheet if needed and answer any questions they may have.

A central randomisation through the coordinating trials unit will allocate the timing of sites to join the intervention. 


\section{Data collection and sources}

Focus groups and interviews

We will collect qualitative data from patients participating in focus groups, and from clinicians during interviews to enable us to identify differences in data over time. The focus groups and interviews will be carried out at two time points: at baseline, and then immediately after the intervention period has completed.

We will explore patient and clinician views on expectations of increased patient access to IBD information prior to the trial. After the trial we will investigate whether these expectations had been met and whether there were other unexpected findings from use of the intervention. We will gather the feedback to inform future developments.

Questions pre-intervention will centre on how the intervention was expected to change the way patients' access and use their information to better self-manage and post-trial whether this expectation was realised. We will seek detailed information on facilitators that helped influence patients use of the intervention and identify barriers that restricted their use of the intervention.

The patient focus groups will be held in geographically disparate areas to reduce cross-contamination bias. The ten randomised participants per focus group will enable us to garner and explore different views, experiences and encourage group discussion.

The one-to-one, face-to-face clinician interviews will be held prior to, and then post the trial intervention period. Where face-to-face interviews are not possible we will hold the interview by video conferencing. The interviews will enable us to explore the historical and cultural views of clinicians on patient accessed records and how they feel it may impact on their clinical practice and patient relationship.

Cluster randomised step-wedge controlled trial

Cost effectiveness data for analysis will be collected. Costs will be collated using the ELIJAH Data Abstraction Form (DAF) designed for our feasibility trial. However, in the full trial, this form will be populated electronically from direct communications with primary and secondary care EHR's. Effectiveness will be 
assessed using data collected from the EQ5D included in the ISSQ patient questionnaire.

The time taken to formulate the elements of "My folder" will be analysed. This is the direct cost of the intervention. In our feasibility trial a sister-grade Band 7 Nurse developed each ELIJAH "My Folder" intervention for patients. In the full trial the intervention will be populated electronically from EHR's and so we would be able to employ a lower band nurse to deliver the intervention i.e.: a band 6 IBD nurse specialist.

As we did in the feasibility study we will also collate data on the indirect costs of the intervention. We will amass data on the total NHS use by participants across primary and secondary services. We will include all GP appointments, inpatient stays, operations, outpatient visits, investigations, A\&E attendances, investigations, open access service use and medication used. Similarly we will again assess health related quality of life data using the EuroQol (EQ-5D) tool, but also include the EQ5D thermometer.

We will replicate our safety data collection method used in our feasibility study and capture data via the monitoring of Adverse Events. Where possible electronic GP and hospital patient records will automatically populate the ELIJAH AE form. We will look for information relating to primary and secondary care attendances, acute admissions and outpatient visits.

We will seek IBD patient centeredness information by analysing patient service satisfaction. We will seek this at four trial timeline points: at baseline, twice during the intervention period and at completion of the intervention period, as we did in our feasibility trial, but the full trial will extend for one year, rather than the six months of the feasibility trial.

During our feasibility trial the ISSQ was piloted and validated by patients with inflammatory bowel disease. These patients were not included in our feasibility trial because of GP practice exclusion. Within the full trial we will adopt the same validation process of the shortened ISSQ.

If the participant wishes to be withdrawn from the study, identifiable data already collected with consent would be retained and used in the study. No further 
data would be collected or any other research procedures carried out on or in relation to the participant.

\section{Data management}

We will use a rigorous data collection systems i.e.: REDCap www.projectredcap.org that will be managed by the registered trials unit (Swansea Trials Unit). Using REDCap will enable us to gather and securely store our sensitive trial data using a validated and auditable data management system.

\section{Sample size and power}

We will base our sample size calculation on our primary outcome. We identified cost as a primary outcome for a full trial during our feasibility trial. The feasibility trial was not designed or powered to detect differences between the intervention and control group, but in a larger trial we would expect cost differences between the two groups. We will replicate our collation of total NHS resource use (cost) and extend this to include effectiveness as assessed by QALYs evaluated using the EQ5D.

We project a fall in individual consultations across primary and secondary care for IBD patients (resource use) when using the intervention. It is anticipated that patients having increased access to their educationally enriched information and electronic access to their clinicians will increase patient empowerment, self-care and self-management, particularly at time of need. The increased self-management will lead to a reduced need to use primary and secondary care services such as GP appointments, follow up outpatient appointments and remote services such as telephone help-lines.

We acknowledge that outliers (such as a small number of emergency inpatient admissions or significant escalation in treatment) could skew the results, however we will collect and analyse all cost data. We will analyse the costeffectiveness data with, and without outlier data to minimise the effect upon the outcome results.

The full trial will have adequate statistical power to detect the resulting difference between the intervention and control groups. The sample size will need to reflect current IBD practice at the time of the trial. We will base our calculations on 
the latest data from pertinent literature at the time of the trial and use local hospital data gleaned from consultations with local clinical teams and patients to be included in the trial.

All participant data will be analysed whether or not the intervention participants complete the trial documentation, receive treatment or withdraw from the trial.

\section{Analysis}

The trial will comply with the Standard Operating Procedures (SOPs) of the Swansea Trials Unit, based at Swansea University. We will fully utilise and adhere to the range of SOPs for the conduct, management and monitoring of the trial e.g. for the development of the full protocol and statistical analysis plan, production of participant information, informed consent, randomisation, user inclusion, and data collection and management .

To minimise the amount of missing data we will encourage all participants to provide data wherever possible. As in our feasibility trial we will send reminders two weeks after a non-response from patients. We will use a response analysis to check that the people who replied are not demographically or clinically different from those who did not, to minimise bias.

To reduce bias we will check the retention rate and missing data rate between the 2 groups to avoid bias and secure an independent statistician to verify the analysis. Our rules for calculating derived variables will follow the published standard EuroQol procedure for calculating EQ5D scores. Within the analysis of ISSQ data we will give equal weight to each question.

\section{Project management}

The trial will be adopted by the Swansea Trial Unit and comply with its relevant SOPs.

From learning during our feasibility trial, we will ensure early set up of a Research Management Group (RMG). The success of our feasibility trial relied heavily upon the well co-ordinated multi-disciplinary and multi-professional nature of our trial team, and the pervasive can-do attitude of the members. We will source and recruit a similar range of expertise to form our RMG, including a health 
economist, statistician, methodologist in qualitative and quantitative trials and health economics, a clinical gastroenterologist (Chief Investigator), G.P. and patient representatives. More widely we will recruit research staff and local clinical health workers; doctors and nurses.

The RMG will be responsible for the strategic management of the trial and will meet quarterly. Operational meetings will be held monthly by the Research Team (RT). The RT will be a pared down version of the RMG and have as members the Principal Investigator, researchers and a co-applicant. A research manager will be employed to ensure timescales, data management and analysis are adhered to.

An independent Trial Steering Committee (TSC) and Data Monitoring and Ethics Committee (DMC) will meet bi-annually to ensure oversight, safety and reporting of the trial. Membership of this group will include appropriate expertise as outlined in the NIHR guidance.

During the feasibility trial it was recognised that the funding of the trial was financially tight in terms of overall budget and per participant. In a full trial the cost per participant would need to be carefully accounted to reflect the evolved intervention and larger multi-site trial and the staff input required.

\section{Including service and research users}

We will adhere to the Swansea Trials Unit SOP for Service User Inclusion during the trial.

During the focus group, piloting of the intervention and development of the data collection tools we found patient feedback incredibly insightful and valuable. We carefully listened to all comments and criticism, and adapted and modified the intervention and data collection resources in line with the feedback given. We will replicate these forms of service user inclusion within the full trial, and extend the involvement of service users to enable the patient voice to be heard fully in the RMG and TSC/ DMC. In the feasibility trial we did not have a patient representative within the research team and we may as a result have lost valuable advice and opinion. We will recruit the patient representatives through The Involving People Network (www.gov.uk/healthandcareresearch/public ) and reimburse appropriately according to recommended rates and include travel costs. Support and training will be provided 
and individual needs will be considered when planning and booking meetings and seeking input.

As in the feasibility trial, we will have early involvement from the patients' charity Crohn's \& Colitis UK, the leading IBD charity in the UK. The organisation provides educational material which we used, with permission, to develop our educational enriched individualised patient information. The charity also supports IBD research to improve patient lives with IBD and provides health professional information and forums.

All trial participants will be given a copy of the trial results and a final report of the trial will be produced for the funding body and the Research Ethics Committee.

\section{Ethics and dissemination}

The trial will be carried out in strict accordance with the principles of the Declaration of Helsinki and Good Clinical Practice. We will apply for full ethical approval for the trial from the Multi-Centre Research Ethics (MREC) Committee for Wales. We will seek research and development $(R \& D)$ permissions from each participating site and liaise with each NHS Trust (England, Scotland and Northern Ireland), and NHS Health Board (Wales) to achieve this.

If there are amendments to the trial design or processes we will submit amendments to the MREC and R\&D committees as needed and we will adhere to CONSORT guidelines for the reporting of the trial.

Written informed consent will be sought from all participants prior to the trial commencement. Any serious adverse events identified will be reported to the Swansea Trials Unit and the ethics committee and to the DMC and TSC, all participating research trial sites will be notified of the occurrence.

We plan to submit our findings and evaluation of the trial to peer reviewed journals for publication. By conducting a randomised controlled trial we aim to evidence a lack of bias, and that the intervention was the cause of the outcome results rather than other factors such as NHS redesign. In publishing the trial in journals, and presenting the findings at national and international conferences, we aim to disseminate our findings as widely as possible. We hope this will stimulate the 
introduction of similar interventions in other disciplines, thereby increasing multiprofessional seamless working, and providing evidence based personalised patient information that can be shared by all in the multi-disciplinary team. 


\subsection{Discussion}

We found during the systematic literature review (chapter six), that there is a lack of high quality evidence from large and randomised trials regarding individualised information for IBD patients. There is a paucity of reliable trial data to suggest this intervention has an effect on cost-effectiveness, safety and patient centeredness.

Our unique format and delivery of educationally enriched patient information has proved feasible to produce and trial in a small scale, single centre feasibility trial. The proposed study, detailed in this chapter, of a large, fully powered, multi-centred, randomised controlled, cluster step-wedge will provide information on cost via comparison of total NHS use, safety by the evaluation of adverse events, and patient centeredness by the assessment of patient satisfaction. We will evaluate how the intervention works in the clinical setting, how it used and viewed by health professionals and patients and identify the barriers and facilitators to its imbedding in IBD patient care.

We will identify the cost-effectiveness of the intervention and also gather useful qualitative information about the perceived value of the sharing of patient information in this way for patients and health professionals. We will aim to uncover cultural norms that may hinder or benefit the adoption of the intervention by engaging patients and professionals in discussions before and after the intervention phase of the trial.

The trial will provide important evidence to support the future direction of patient interaction with their health providers and guide predictive modelling in this area. The findings will have national and international bearing on the future management of patients and applicability to change current guidelines. The trial is timely as there is currently a heightened focus by health providers and governments on chronic disease, IBD care, PHRs and increased patient access to their own health information. 


\subsection{Conclusion}

In this chapter we have explored how a larger, fully powered trial is now needed to consolidate the feasibility trial of the ELIJAH intervention. This will make a major contribution to the existing lack of evidence around chronic disease including IBD, PHR and the way this can help empower patients to make informed decisions in their care, and enable patients to better self-care.

This final chapter of my thesis represents the culmination of my ELIJAH research that commenced in 2010. This chapter exemplifies my experiences and embodies my learning gained during the last eight years.

In the introduction (chapter one), I explained how our rising demand for IBD outpatient services, and lack of opportunities to traditionally expand the service by employing additional staff, challenged our clinical team and led us to explore new ways of delivering care. We identified that our electronic patient record could be expanded to facilitate the delivery of improved individualised and educationally enriched patient information, and this could empower patients enabling them to better self-manage through increased understanding of their own disease pathway and treatment. In chapter two (the focus group), I discussed how we held a focus group to gauge patient opinion about the proposed intervention. We found that patients were overwhelmingly supportive of the development of an intervention to facilitate them having increased IBD information and they welcomed knowing more about their IBD and what to do if symptoms increased.

The development of the intervention via adaptation of the existing EHR was described in chapter three, and in chapter four the testing of the intervention via a randomised feasibility trial was presented. The intervention was found to be feasible to produce and test. The feasibility and progression criteria were met with recommended modifications. My reflection relayed in chapter five extolled my experiences of carrying out the trial.

A systematic literature review laid out in chapter six, found that there is a lack of high quality trials in the area of IBD and chronic disease individualised patient information. Conversely, there is much UK and international interest in the area of PHR and patients accessing their own information and using this to better self-care. Chapter seven provides a protocol to address the paucity of evidence 
available to policy makers, legislators and health care providers to decide how best patients and clinicians wish to develop interventions in this field, and the trial will provide reliable data that can be used to inform future developments.

Conducting the research detailed in this thesis has allowed me the opportunity to be part of a great research team, to extend and apply my learning to enhance my clinical practice, and most importantly, to provide additional opportunities and better care for my patients. 


\section{Appendix 1. Consolidated criteria for reporting qualitative studies (COREQ):}

\section{2-item checklist}

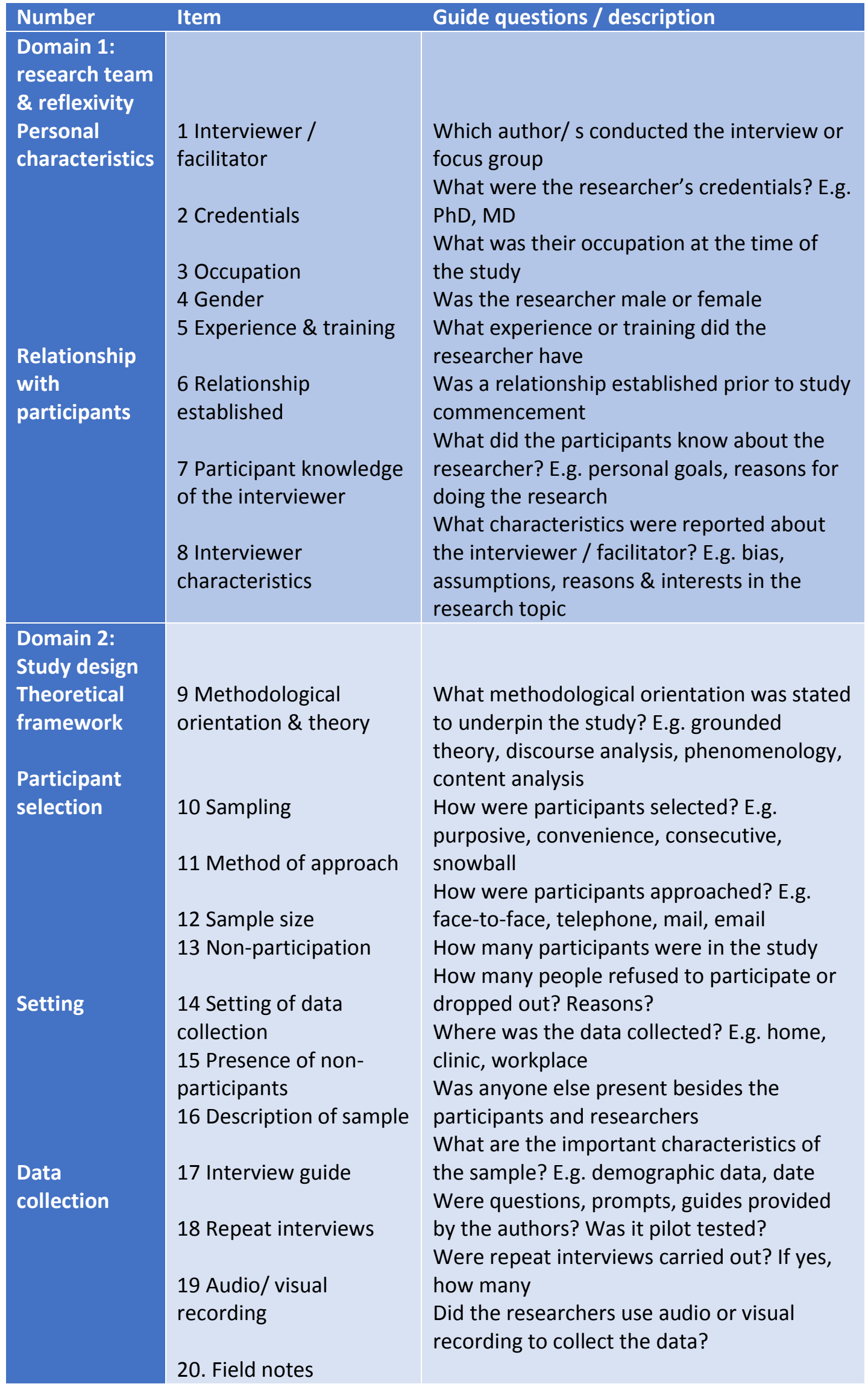




\begin{tabular}{|c|c|c|}
\hline & $\begin{array}{l}21 \text { Duration } \\
22 \text { Data saturation } \\
23 \text { Transcripts returned }\end{array}$ & $\begin{array}{l}\text { Were field notes made during \& / or after } \\
\text { the interview or focus group } \\
\text { What was the duration of the interviews or } \\
\text { focus group } \\
\text { Was the data saturation discussed } \\
\text { Were transcripts returned to participants for } \\
\text { comment and / or correction }\end{array}$ \\
\hline $\begin{array}{l}\text { Domain 3: } \\
\text { analysis \& } \\
\text { findings } \\
\text { Data analysis }\end{array}$ & $\begin{array}{l}24 \text { Number of data } \\
\text { coders } \\
25 \text { Description of the } \\
\text { coding tree } \\
26 \text { Derivation of themes } \\
27 \text { Software } \\
28 \text { Participant checking } \\
29 \text { Quotations } \\
\text { presented } \\
30 \text { Data \& findings } \\
\text { consistent } \\
31 \text { Clarity of major } \\
\text { themes } \\
32 \text { Clarity of minor } \\
\text { themes }\end{array}$ & $\begin{array}{l}\text { How many data coders coded the data } \\
\text { Did authors provide a description of the } \\
\text { coding tree } \\
\text { Were themes identified in advance or } \\
\text { derived from the data } \\
\text { What software, if applicable, was used to } \\
\text { manage the data } \\
\text { Did participants provide feedback on the } \\
\text { findings } \\
\text { Were participant quotations presented to } \\
\text { illustrate the themes / findings? Was each } \\
\text { quotation identified? E.g. participant } \\
\text { number } \\
\text { Was there consistency between the data } \\
\text { presented and the findings } \\
\text { Were major themes clearly presented in the } \\
\text { findings } \\
\text { Is there a description of diverse cases or } \\
\text { discussion of minor themes }\end{array}$ \\
\hline
\end{tabular}

Ref: Tong A. , Sainsbury P., Craig J. (2007) Consolidated criteria for reporting qualitative research (COREQ): a 32 - item checklist for interviews $\&$ focus groups 


\section{Appendix 2. TIDier checklist}

Items included in the Template for Intervention Description and Replication (TIDieR) checklist: infor describing an intervention.

\section{Item No Item}

Brief name

1 Provide the name or a phrase that describes the intervention

Why

2 Describe any rationale, theory, or goal of the elements essential to the intervention

\section{What}

3 Materials: Describe any physical or informational materials used in the intervention, including those provid or used in intervention delivery or in training of intervention providers. Provide information on where the ma accessed (such as online appendix, URL)

4 Procedures: Describe each of the procedures, activities, and/or processes used in the intervention, including or support activities

\section{Who provided}

5 For each category of intervention provider (such as psychologist, nursing assistant), describe their expertise and any specific training given

How

6 Describe the modes of delivery (such as face to face or by some other mechanism, such as internet or telep intervention and whether it was provided individually or in a group

Where

7 Describe the type(s) of location(s) where the intervention occurred, including any necessary infrastructure When and How Much

8 Describe the number of times the intervention was delivered and over what period of time including the nu their schedule, and their duration, intensity, or dose

Tailoring

9 If the intervention was planned to be personalised, titrated or adapted, then describe what, why, when, and 


\section{Modifications}

10* If the intervention was modified during the course of the study, describe the changes (what, why, when,

\section{How well}

11 Planned: If intervention adherence or fidelity was assessed, describe how and by whom, and if any strateg maintain or improve fidelity, describe them

12 *Actual: If intervention adherence or fidelity was assessed, describe the extent to which the intervention v planned

*If checklist is completed for a protocol, these items are not relevant to protocol and cannot be described unt For 
Appendix 3. ELIJAH participation information sheet

$$
\text { PIN }
$$

\author{
Participant Information Sheet \\ Electronic Linkage for Inflammatory bowel disease to deliver \\ Joint Access to Health records (ELIJAH)
}

\title{
Protocol reference Version $5 \quad$ Date 14/04/2010
}

Dear

We would like to invite you to take part in our research study on

the Endoscopy unit , Neath Port Talbot Hospital

June

2010 at

at

. We will reimburse your travel and time expenses by giving you $£ 20.00$ for attending this appointment. Before you decide to take part we would like to explain why the research is being done and what it would involve for you. One of our team will go through this information sheet with you and answer any questions you have. We expect this to take about 30 minutes. Talk to other people about the study if you think it will help you to decide.

Part 1 of this participant information sheet will tell you why we are doing the research, part 2 will tell you how the study will take place.

The research is looking at the effect of greater sharing of hospital reports about patients with inflammatory bowel disease with patients and their GPs. Inflammatory bowel disease (IBD) is the name used to describe the type of bowel problems that can cover Ulcerative Colitis, Crohn's Disease and proctitis.

This research study is being carried out by Professor J.G. Williams, Consultant Gastroenterologist Neath Port Talbot Hospital (01639 862041) and by Sister Phedra Dodds, Advanced Nurse Practitioner for Gastroenterology \& Endoscopy, Neath Port Talbot Hospital (01639 862551).

Please ask us if any of the information we give to you or talk to you about is unclear. If you have any queries please contact us on our direct line 01639862551 and we will be happy to answer them.

If you are not willing to take part in this research study it will not affect your on-going care from the hospital or your GP in any way.

Please would you confirm your attendance by ringing Sister Phedra Dodds on 01639 862551.

Yours Sincerely

Sister Phedra Dodds, Advanced Nurse Practitioner for Gastroenterology and Endoscopy, Neath Port Talbot Hospital

Part 1. 


\section{What does the research study look at?}

We have records of your care from your gastroenterology clinic appointments and endoscopy tests. We keep these records on a computer system called GeneCIS and store them under your patient number. In this study we will give you and your GP the ability to have a report of the information we have and add to the information that we hold. You will be able to have an account of your past hospital records for IBD, with education about the management of your condition, a plan of what to do if your symptoms increase, and you will be able to up-date your records with any changes you have, ask questions about your care via email or telephone, and have information on how to get help if you need it.

The aim of our study is to assess whether this is a good and efficient way of providing care. To do this we are using a research method called a randomised trial which means that out of about 100 patients taking part, you will have an equal chance of getting to view your records or continuing as at present. We will put people who agree to take part in the study into the two groups by equal chance. One group (the computer assisted group) will have access to their records. The other group (the control group) will receive care as normal. We will compare the effect on your care and your satisfaction with it, and see if there is a difference between the two groups.

\section{Why have I been asked to take part in the research study?}

You are under the care of Professor Williams or Dr Lai at the Endoscopy Unit, Neath Port Talbot Hospital because you have Ulcerative Colitis, Crohn's Disease or proctitis and we have a record of your care on our computer system. We are inviting up to 102 patients who are registered with five GP practices in the Neath Port Talbot area to take part in the trial.

\section{Do I have to take part?}

It is up to you to decide to join the study. We will describe the study and go through this information sheet with you. If you agree to take part, we will then ask you to sign a consent form. You are free to withdraw from the study at any time without giving a reason. Not agreeing to take part in the study or withdrawing from the study will not affect the standard of care you receive.

\section{What will happen to me if I take part?}

If you take part in the trial, you will be involved in the study for 6 months. You will be asked to complete a questionnaire at the beginning and end of the study. In between you will either receive care as at present (control group), or be given reports of your care (report assisted group), with education and encouragement to make more decisions about your care yourself, keeping us and your GP informed when your health changes, or you alter your treatment. You will have the same access to care from your GP or the hospital if you need it.

\section{What will I have to do in the trial?}

You will see the information either on your computer or in a paper copy referring to your clinic appointments for IBD and any endoscopies you may have. There will also be education how to manage your condition, and a care-plan for you to look at and use. This will be personal to you and take into account your diagnosis, treatment so far and medication. It will list what to do if you have increased symptoms and how and when to get in touch with your Doctor or Specialist Nurse.

There will be space so you can tell us about any changes to your symptoms.

You will be able to call us on the helpline or use email to tell us of changes or ask questions.

At the beginning and end of the study we will ask you to complete a questionnaire. For the research to be worthwhile we need at least 40 patients to complete both questionnaires. 


\section{What are the alternatives for care?}

If you decide not to take part, your care will be the same as usual, with follow up appointments in clinic and the telephone helpline available at times of need or for questions.

\section{What are the possible disadvantages and risks of taking part?}

We know that patients with IBD can have times of wellness and times of increased symptoms, often without warning. The way that we provide care at time of increased symptoms will not change. If you are in the trial you will still be able to contact your GP or Hospital Consultant or Specialist Nurse. If you have increased symptoms or questions about your care you can email or telephone the Specialist Nurse. If you need a hospital outpatient appointment or endoscopy you will still have this.

\section{What are the possible benefits of taking part?}

We think that by taking part in the study you will have more information about IBD and more ways to contact a Doctor or Specialist Nurse if needed. We hope this will make you feel more in control of your condition and enable you to change your treatment with confidence when necessary.

\section{What happens when the research study stops?}

If the research proves that giving patients access to the information in their reports is a safe and effective use of NHS resources we will give all IBD patients a choice to have this type of care. If you take part in the study as part of the control group and do not have access to your record because you are in the treatment as usual group you will be one of the first to be offered this opportunity when the study is finished.

\section{What if there is a problem?}

Any complaint about the way you have been dealt with during the study or any possible harm you might suffer will be addressed. This information is provided in more detail in Part 2.

\section{Will my taking part in the study be kept confidential?}

Yes. We will follow ethical and legal practice and all information about you will be handled in confidence. This information is provided in more detail in part 2.

This completes part 1. If this information has interested you and you are considering taking part in the research, please read the additional information in Part 2 before making any decision.

If you have decided not to take part in the study after considering the information we would like to thank you for reading the information.

\section{Part 2.}

\section{What if I don't want to carry on with the study?}

If you withdraw from the study we will return your follow-up to the original method and the quality of care you receive will not be affected. We will need to use the information you have given us up to the point of your withdrawal for the research study.

\section{What if there is a problem?}

If you have a concern about any aspect of this study, you should contact the researcher Phedra Dodds on 01639862551 who will try her best to answer your questions. If you remain unhappy and wish to complain formally you can do this by following the Abertawe Bro Morgannwg 
University Health Board advice in "A guide to making a complaint, or a compliment". If you do not wish to discuss your concerns with a member of the research team you can contact the Trust Governance Support Unit on 01639683316 during office hours. If you wish to make a formal complaint you may wish to put your concerns in writing to the Chief Executive of the Health Board David Sissling at:

\author{
ABMU Health Board \\ One Talbot Gateway \\ Seaway Parade \\ Baglan Energy Park \\ Port Talbot \\ SA12 7BR
}

Tel no: 01639683326

Your complaint will then be dealt with under the NHS Complaints Procedure.

In the event that something does go wrong and you are harmed during the research and this is due to someone's negligence then you may have grounds for a legal action for compensation against $A B M U$ Health Board but you may have to pay your legal costs.

\title{
Will my taking part in this study be kept confidential?
}

All information which is collected about you during the course of the research will be kept strictly confidential. The questionnaires that you fill in will be coded so it does not have any of your personal details and will be anonymous. The way that you will look at and update your records will be secure and the email link between you and the hospital will be encrypted to ensure confidentiality.

Any data from the research will be kept securely and if it is needed for further research it will have to be applied for through the appropriate channels.

\section{Does my GP know that I am taking part in the research?}

Yes. Your GP will also have access to the record so that he/she is informed about changes in your condition or treatment, and can also send you \& your specialist and relevant information.

\section{What will happen to the results of the research study?}

The results will tell us whether it will be a good thing to introduce this change for all patients as a matter of routine. We will publish the results in Nursing and Medical journals, feedback through conference presentations and exhibit a poster in the Endoscopy Unit Neath Port Talbot Hospital. You will be able to request a copy of the results and or articles about the results. You will not be personally identified in the results.

\section{Who is funding the research?}

The Health Foundation SHINE Award scheme is funding the research. Swansea University is organising the research. Your Doctor (Professor Williams) and Specialist Nurse (Phedra Dodds) are not being paid by The Health Foundation for this research.

\section{Who has reviewed this study?}


All research in the NHS is looked at by an independent group of people, called a Research Ethics Committee, to protect your interests. This research has been reviewed and given favourable opinion by South West Wales Research Ethics Committee.

If you take part in the study you will be given a copy of this information sheet and a signed consent form to keep. 


\section{Appendix 4. ELIJAH consent form}

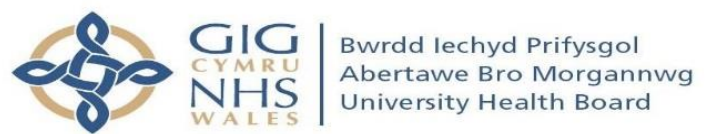

Centre Number:

Study Number:

Patient Identification Number for this trial:

\section{Consent Form}

Title of Project: Electronic Linkage for Inflammatory bowel disease to deliver Joint Access to Health records (ELIJAH)

Name of Researcher: Professor J G Williams

Please initial box

1. I confirm that I have read and understand the information sheet dated 04/02/10 (version 4) for the above study. I have had the opportunity to

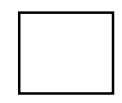
consider the information, ask questions and have had these answered satisfactorily.

2. I understand that my participation is voluntary and that I am free to withdraw at any time without giving any reason, without my medical care or legal rights being affected.

3. I understand that relevant sections of my medical notes and data collected during the study, may be looked at by individuals from The Health Foundation, from regulatory authorities or from the NHS Trust, where it is relevant to my taking part in this research. I give permission for these individuals to have access to my records.

4. I understand that any spoken or written information I give can be used as quotes in the research. These quotes will be anonymised, and I will not be identified as the source of the quote.

5. I agree to my GP being informed of my participation in the study and I am

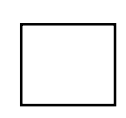
aware that if I participate, my GP will have full access to my records.

6. I agree to take part in the above study.

Name of Patient

Name of Person taking consent
Date

Date
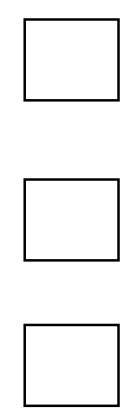

When completed: 1 for participant; 1 for researcher site file; 1 (original) to be kept in medical notes. 
Hospital ID:

NHS Number:

Date of Birth:

Date: $\quad 10$ December 2010

Dear

This summary of your inflammatory bowel disease condition to date is intended for you to keep as a record to help you and your doctor or nurse make decisions about your future management. Please let us know if there are any inaccuracies. Copies will also be held in your hospital and GP records. Future changes in your condition and treatment will recorded in a new document called "My Update".

\section{Diagnosis: $\quad$ Crohn's disease}

Crohn's Disease is a type of Inflammatory Bowel Disease (IBD). Crohn's disease affects about 55,000 people in the UK. Crohn's disease is not an infectious illness and cannot be passed from one person to another. In Crohn's disease the lining of the affected part of the gut or intestine becomes inflamed and swollen. This swelling can cause the intestine to narrow, which is called a stricture. Ulcers and abscesses can also develop on the surface of the intestine, which may bleed and produce pus. The gut can be affected anywhere and in different places. The symptoms may include diarrhoea, blood in the motions, pain in the tummy, tiredness and weight loss.

\section{Pattern of disease: Stricturing}

A stricture is present in the descending colon. The inflammation has caused narrowing of the intestine.

\begin{tabular}{ll}
\hline $\begin{array}{l}\text { Distribution/extent } \\
\text { of disease: }\end{array}$ & $\begin{array}{l}\text { Pan-colitis (whole colon): Patchy } \\
\text { segments of ulceration \& inflammation } \\
\text { throughout the colon. }\end{array}$
\end{tabular}

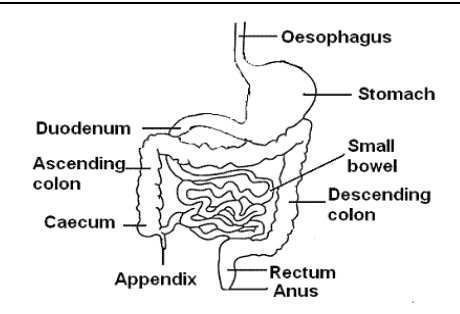

\begin{tabular}{lll}
\hline Year diagnosed: 2009 & $\begin{array}{l}\text { Year symptoms } \\
\text { started: }\end{array}$
\end{tabular}

Method of $\quad$ Colonoscopy: and biopsies
diagnosis:

Colonoscopy is an inspection of the intestine using a colonoscope inserted into the back passage. 


\title{
Most recent Colonoscopy in 08/2010 \\ investigations \& \\ procedures:
}

\section{IBD surveillance: IBD surveillance not yet required}

Regular inspection of the bowel is recommended when the inflammation has been present for more than eight years, because there is a small risk of developing colorectal cancer. The inspection (usually by colonoscopy) can detect unstable cells before cancer develops.

\section{Relevant surgical}

history:

\author{
Relevant Oral 5 ASA: Mezavant XL 2.4g per day now stopped. Pentasa 500mg 2 four \\ medication history: times a day. \\ Oral prednisolone \\ Oral azathioprine \\ GI medication history: Ferrous sulphate
}

\begin{tabular}{ll}
\hline $\begin{array}{l}\text { Medication } \\
\text { monitoring: }\end{array}$ & FBC monitoring: weekly \\
& U\&E monitoring: weekly \\
& Liver function monitoring: weekly
\end{tabular}

A full blood count is taken to check for anaemia and evidence of active inflammation.

The blood urea and salts are checked to assess kidney function.

Liver function tests are taken to check the health of the liver.

\section{Medication No known medication sensitivities sensitivities:}

\section{Past history of IBD No history of IBD related problems related problems:}

Inflammatory bowel disease can also cause problems that do not involve the bowel. They can occur in about $20-30 \%$ of people with IBD.

There is no past history of IBD related problems.

\section{Past history of non No history of non IBD health problems IBD problems:}

\section{Smoking history: Non-smoker}

You are twice as likely to have Crohn's disease if you smoke. We do not know why this happens but it may be because nicotine alters the way the blood flows through the gut. Stopping smoking helps you to have fewer flare ups, less need for immunosuppressant drugs and surgery. For more information please ask your 
doctor or nurse or see the National Association of Colitis and Crohn's (NACC) information about this. On their website www.NACC.org.uk, click the tab 'information' and the leaflet 'Smoking and IBD'.

Dietary history: Normal diet history

Family history: $\quad$ No relevant family history

$15 \%$ of patients with Crohn's disease or ulcerative colitis have a relative who also has IBD, but only 10\% of children will get IBD if a parent has it.

\section{Additional \\ comments:}

No additional comments recorded.

If you have any queries, please contact Sister Phedra Dodds by telephone on or email her at elijah.gastro@wales.nhs.uk. 
Hospital ID:

NHS Number:

Date of Birth:

\section{Date: $\quad 10$ December 2010}

\section{Dear}

This plan is intended to summarise current plans for the investigation, treatment and care of your inflammatory bowel disease. Copies will be held in your hospital and GP notes.

\section{Your action plan has been changed}

\begin{tabular}{ll}
\hline Diagnosis: & Crohn's disease \\
\hline Current medication: & PT Mesalazine / Pentasa tablets \\
& 1000 milligrams (mg) \\
& Four time daily (QDS) \\
& PN Prednisolone \\
5 milligrams (mg) & Once in morning (OD mane)
\end{tabular}

$\begin{array}{ll}\begin{array}{l}\text { Changes to current } \\ \text { medication: }\end{array} & \text { Changes made to current medication } \\ \text { Medication stopped: Pentasa. }\end{array}$

There have been changes to your medication.

Some or all of your medication has been stopped, as shown in the current medication section.

Medication $\quad$ No known medication sensitivities
sensitivities:

Planned No planned investigations

investigations:

Planned surgery: $\quad$ No GI surgery planned

\begin{tabular}{ll}
\hline $\begin{array}{l}\text { Medication } \\
\text { monitoring: }\end{array}$ & FBC monitoring: 3 weeks \\
& U\&E monitoring: 3 weeks \\
& Liver function monitoring: 3 weeks
\end{tabular}

A full blood count is taken to check for anaemia and evidence of active inflammation.

The blood urea and salts are checked to assess kidney function. 
Liver function tests are taken to check the health of the liver.

IBD surveillance: $\quad$ IBD surveillance not yet required

Regular inspection of the bowel is recommended when the inflammation has been present for more than eight years, because there is a small risk of developing colorectal cancer. The inspection (usually by colonoscopy) can detect unstable cells before cancer develops.

\begin{tabular}{ll}
\hline Dietary advice: & Normal/usual diet advised \\
\hline Activity advice: & Normal activity advised
\end{tabular}

Work advice: Continue work as at present

$\begin{array}{ll}\begin{array}{l}\text { Communication } \\ \text { plan: }\end{array} & \text { Email contact offered } \\ & \text { Telephone contact offered } \\ & \text { Open access appointment offered }\end{array}$

Please tell us about any increase in your symptoms and what you have done about it by emailing us at ELIJAH@abm-tr.wales.nhs.uk.

Please tell us about any increase in your symptoms and what you have done about it by telephoning specialist nurse Phedra Dodds on

Please let us know if you want to see someone in the gastroenterology department and we will arrange an appointment for you as soon as we can.

Follow up / review: You will be seen in the gastroenterology outpatients clinic in 3weeks: With Dr Lai

Other review arrangement required (state): For infliximab infusion tomorrow.

\begin{tabular}{ll}
\hline Referrals: & Referral not required \\
\hline $\begin{array}{l}\text { Additional } \\
\text { comments: }\end{array}$ & No additional comments recorded. \\
\hline
\end{tabular}

If you have any queries, please contact Sister Phedra Dodds by telephone on or email to elijah.gastro@,wales.nhs.uk 
Hospital ID:

NHS Number:

Date of Birth:

Date: $\quad 10$ December 2010

Dear

This update of your inflammatory bowel disease condition is intended to summarise recent changes in your health, lifestyle or treatment. Copies will be held in your hospital and GP notes.

Diagnosis: Crohn's disease

Healthcare contacts Last gastroenterology outpatient clinic visit on: Y: 24/11/2010 since last update:

Overall change in Overall health has been worse for 1 weeks.

health status:

Current symptoms: Intermittent abdominal pain

Decreased appetite

Malaise

Intermittent pain in the abdomen.

Decreased appetite.

Feeling generally unwell.

\begin{tabular}{ll}
\hline $\begin{array}{l}\text { Weight: } \\
\text { Activity lifestyle: }\end{array}$ & $\begin{array}{l}66 \text { kilograms } \\
\text { No activity or lifestyle changes due to IBD }\end{array}$ \\
\hline $\begin{array}{l}\text { Other changes in } \\
\text { condition: }\end{array}$ & Condition changed: Increased CRP from baseline of 50 to 84. \\
\hline
\end{tabular}

Relevant surgery No relevant surgical history recorded

since last update:

\section{Current medication:}

\subsection{PT Mesalazine / Pentasa tablets \\ 1.21000 milligrams (mg)}

Four time daily (QDS)

PN Prednisolone 
5 milligrams (mg)

Once in morning (OD mane)

\section{Medication \\ No known medication sensitivities \\ sensitivities:}

\section{Investigation} results:

Haemoglobin

Result: 13.9 (g/dl)

Date: $24 / 11 / 2010$

White cell count

Result: $7.0 \times 10^{\wedge} 9 / 1$

Date: $24 / 11 / 2010$

Platelets

Result: $229 \times 10^{\wedge} 9 / 1$

Date: $24 / 11 / 2010$

CRP

Result: $98 \mathrm{mg} / \mathrm{L}$

Date: $24 / 11 / 2010$

Urea

Result: $3.6 \mathrm{mmol} / \mathrm{L}$

Date: $24 / 11 / 2010$

Creatinine

Result: 76 umol/L

Date: $24 / 11 / 2010$

Albumin

Result: $40 \mathrm{~g} / \mathrm{L}$

Date: $24 / 11 / 2010$

Bilirubin

Result: 6 umol/L

Date: $24 / 11 / 2010$

Imaging

Result: A Imaging findings: Normal small bowel. Contracted caecum, abnormality in transverse colon.

Date: $22 / 11 / 2010$

Haemoglobin can suggest anaemia if low. 
White cell count can suggest inflammation if low.

C-Reactive Protein is a measure of inflammation.

Albumin can be low if there is inflammation or malnutrition.

Bilirubin can cause jaundice if high.

\section{Additional \\ No additional comments recorded. \\ comments:}

If you have any queries, please contact Sister Phedra Dodds by telephone on elijah.gastro@wales.nhs.uk 


\section{Appendix 8. ELIJAH Data Abstraction Form DAF}

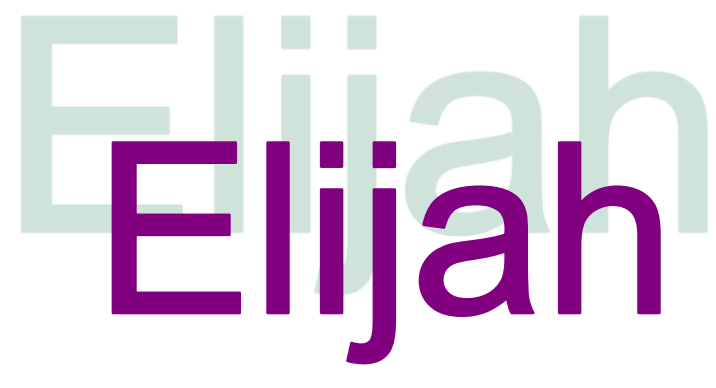

Data Abstraction Form

Email: Elijah.gastro@wales.nhs.uk

Participant study ID:

\section{Section 1: Participant details}

1a: Participant demographics

Name

Date of Birth

Gender

NHS number

Hospital number

Home address \& postcode

1b: GP details

GP full name

GP ID code

GP Practice name in full

GP Practice Code

GP Practice address \& postcode

Section 2: Hospital based services:

2a. Open access services: 
Telephone call/ email/ unscheduled NOTE: Date, time attended, ? if transport needed. drop in

Time \& duration of Recognition of problem

Time \& duration of Reporting of problem

Time \& duration of Response to problem

\section{2b. Outpatient services:}

Gastroenterology / other

Time \& duration of Recognition of problem

Time \& duration of Reporting of problem

Time \& duration of Response to problem

2c. Multi-disciplinary team appointments

E.g. dietician, physio

Time \& duration of Recognition of problem

Time \& duration of Reporting of problem

Time \& duration of Response to problem

\section{2d. A\&E attendances}

$\underline{\text { Gastroenterology / other }}$ 
Time \& duration of Recognition of problem

Time \& duration of Reporting of problem

Time \& duration of Response to problem

\section{2e. Investigation appointments}

Gastroenterology / other

Time \& duration of Recognition of problem

Time \& duration of Reporting of problem

Time \& duration of Response to problem

\section{2f. Inpatient episodes}

\section{Gastroenterology / other}

Time \& duration of Recognition of problem

Time \& duration of Reporting of problem

Time \& duration of Response to problem

\section{Section 3: Community based services}

\section{3a. GP attendances}

\section{Gastroenterology / other}

Time \& duration of Recognition of problem
NOTE: Any surgery, LOS ( definition overnight stay= 1 day, otherwise day episode), ward title, admitting diagnosis 
Time \& duration of Reporting of problem

Time \& duration of Response to problem

\section{3b Out of hours GP services}

Gastroenterology / other

Note: home visit or to e.g. prime care

Time \& duration of Recognition of problem

Time \& duration of Reporting of problem

Time \& duration of Response to problem

\section{3c Multi-disciplinary team appointments}

E.g. dietician, physio, dentist

Time \& duration of Recognition of problem

Time \& duration of Reporting of problem

Time \& duration of Response to problem

\section{Medication History}


(Note: known compliance with medication is not required. No PRN medications to be listed)

\section{Time of ANP spend preparing My folder: Preparation number:}

Date, time \& duration request notes

Time \& duration taken to read notes

Time \& duration taken to access GeneCIS patient history

Time \& duration taken to answer GeneCIS Elijah

questionnaires

Time \& duration taken to print and send questionnaires

\section{First Follow up}

Date, time \& duration taken to check GeneCIS for contacts

Time \& duration taken to update My Plan \& My Update

Time taken to print and send questionnaires

\section{Second Follow up}


Date, time \& duration taken to check GeneCIS for contacts

Time \& duration taken to update My Plan \& My Update

Time taken to print and send questionnaires

\section{Third Follow up}

Date, time \& duration taken to check GeneCIS for contacts

Time \& duration taken to update My Plan \& My Update

Time taken to print and send questionnaires 


\section{Appendix 9 ELIJAH Adverse Events form}

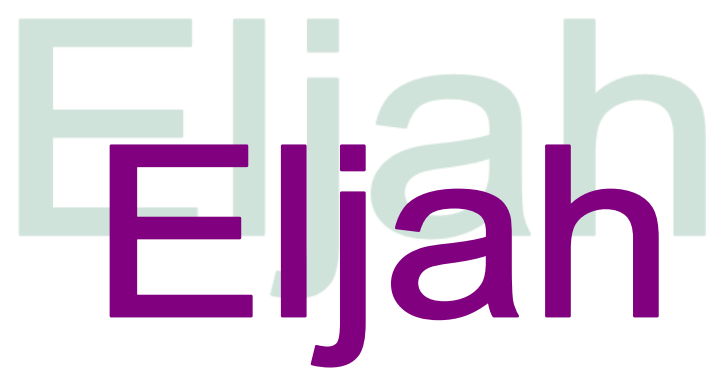

Adverse Event (AE) Screening Form

Email: Elijah.gastro@wales.nhs.uk

Participant study ID :

Please complete this form if the participant reports untoward signs or symptoms and email it to the trial manager at Elijah@swansea.ac.uk.

Event description

Start date: DD MM YYYY End Date: DD MM YYY (Code for on-going 8888 8888)

Question 1- Is the symptom/ problem a known, undesirable effect of IBD in terms of its nature and severity? (e.g. PR bleed, surveillance)

$$
\text { Yes (Only complete question } 4 \mathrm{a} \text { and } 4 \mathrm{~b}) \quad \text { No (Go to question 2) }
$$

Question 2 - Is the symptom/ problem in keeping with an exacerbation or progression of the underlying IBD? NOTE: This does not include clinical consequences of disease progression. In such cases, the answer should be "no". (e.g. extra-intestinal manifestations of IBD).

Yes (Only complete question $4 a$ and $4 b) \quad$ No (Go to question 3 )

Question 3 - Is the symptom / problem a stable symptom of a pre-existing condition other than IBD? This question only concerns symptoms of medical conditions (other than IBD) that were identified prior to the start of the trial, and have NOT significantly worsened since the trial commenced. If symptoms of a pre-existing condition e.g. asthma, diabetes have worsened following the start of the trial, this question should be answered "no".

Yes (Only complete question $4 a$ and $4 b)$

No (Go to question 4)

Question 4 - Is the event an admission for a medical or surgical procedure? NOTE: This does not include the "triggering event" that leads to the procedure (which should be considered under its own merit). 
4a Relation to Elijah (causality)

Not related

Unlikely to be related

Possibly related

Probably related

Definitely related

\section{4b Seriousness of event}

Is/was life threatening

Resulted in disability/incapacity

Required

hospitalisation/prolonged hospital stay

Not serious/ none of the above

\section{Question 5 - AT THIS POINT THE EVENT HAS BEEN CATEGORISED AS AN UNEXPECTED EVENT. Please}

indicate the causality and seriousness of the event below e.g. fell off ladder.

4a Relation to Elijah (causality)
$4 b$ Seriousness of event

\author{
1.Is/was life threatening \\ 2.Resulted in disability/incapacity \\ 3. Required hospitalisation / prolonged hospital stay \\ Not serious/ none of the above
}

\author{
1.Not related \\ 2.Unlikely to be related \\ 3.Possibly related \\ 4.Probably related \\ 5.Definitely related
}


NOTE: If causality $\mathbf{3 , 4}$ or 5 AND seriousness $=1,2$ or 3 the event is a Suspected Unexpected Serious Adverse Reaction. Proceed to complete a SUSAR Report Form \& send both forms to the Trial Office within $\mathbf{2 4}$ hours of becoming aware of the event.

Initials of person completing this form:
Signature:

Date:

口 
Appendix 10. Inflammatory bowel disease Service Satisfaction Questionnaire (ISSQ)

\section{YOUR Feedback - to Neath Port Talbot Hospital}

We should be most grateful for YOUR views based on YOUR experience of having care for your condition, so we can improve the hospital service by taking full account of the replies from you and many other patients. We shall treat your answers as strictly confidential. They will not affect your treatment in any way.

Answer every question by putting a tick in the appropriate box. Do not tick more than one box in reply to each question. If you are unsure about how to answer a question, please give the best answer you can. If you want to say more, please use the large box at the end of the questionnaire.

1. What bowel condition do you have?

2. When were you diagnosed? DD MM YYYY

\section{Your condition}

3. How much information have you had about your condition since you were diagnosed?
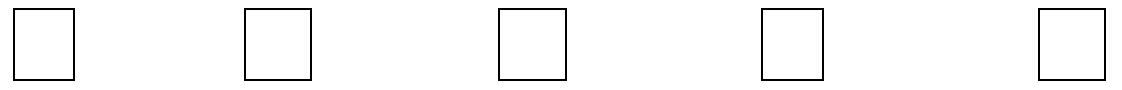

\begin{tabular}{|c|c|c|c|}
\hline $\begin{array}{c}\text { Far too } \\
\text { much }\end{array}$ & $\begin{array}{c}\text { A bit } \\
\text { too } \\
\text { much }\end{array}$ & Enough & A little \\
\hline
\end{tabular}

If none please go direct to question 6 .

4. How easy to understand was the information?
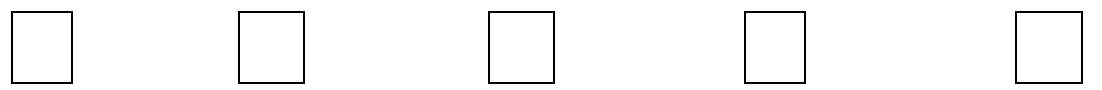

$\begin{array}{llllc}\begin{array}{l}\text { Very } \\ \text { easy }\end{array} & \text { Easy } & \text { Fair } & \text { Difficult } & \begin{array}{c}\text { Very } \\ \text { difficult }\end{array}\end{array}$

5. How useful was the information?
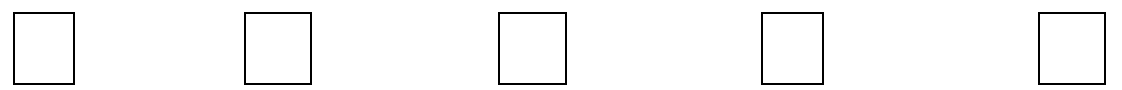

$\begin{array}{cccc}\begin{array}{c}\text { Very } \\ \text { useful }\end{array} & \text { Useful } & \text { Fair } & \begin{array}{c}\text { Not very } \\ \text { useful }\end{array}\end{array}$


6. How much opportunity have you had to ask questions about your condition?

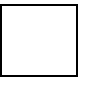

Very
many
$\begin{gathered}\text { opportunit } \\ \text { ies }\end{gathered}$

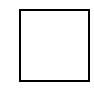

Many

opportunit

ies

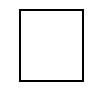

Several opportunit ies

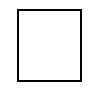

Few

No

opportunit ies opportuni

ty

\section{Getting care when you need it}

7. How much explanation have you received about getting care when you need it?

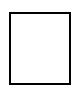

Far too much

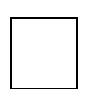

A bit

too much
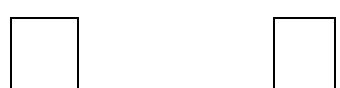

A little

Enough

\section{A little}

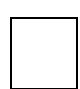

None

If none, please go direct to question 10 .

8. How easy was it to understand the explanation of how to get care when you need it?

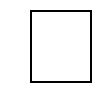

Very easy

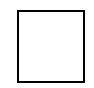

Easy

Fair

Difficult
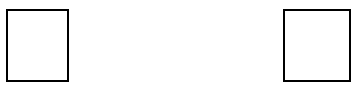

Very difficult

9. How useful was the explanation of how to get care when you need it?

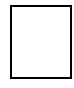

Very useful

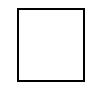

Useful

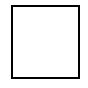

Fair

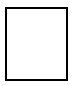

Not very useful

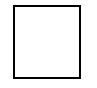

Not useful 
10. How would you rate the communication skills (for example courtesy and friendliness) of the last person who gave you information about getting care when you need it?

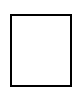

Very good

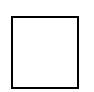

Good

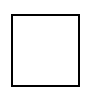

Fair

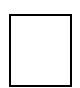

Poor

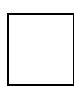

Very poor

11. How much difficulty did you experience in getting care the last time you needed it?

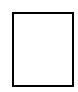

Extensiv

e difficulty

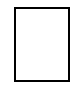

A lot of difficult

y

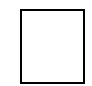

Some

difficult

y
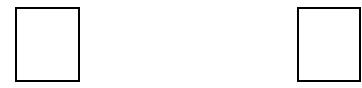

Little

difficult

y
No

difficult

y

Please describe your experience if you wish:

\section{Quality of the care you received recently.}

12. How would you rate the quality (for example carefulness and competence) of the care you received on your last contact (visit or phone call) with Neath Port Talbot Endoscopy Unit?
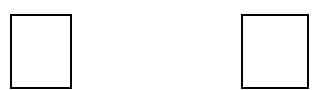

Good

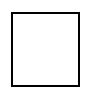

Fair

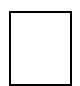

Poor

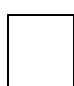

Very poor

13. How would you rate the communication skills (for example courtesy and friendliness) of the main person you spoke to on that last contact?
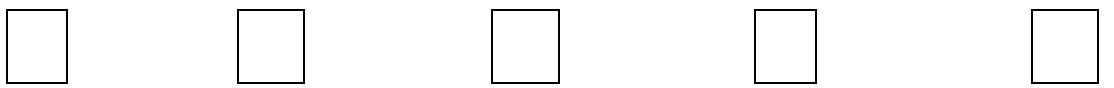

Very good Good $\quad$ Fair $\quad$ Poor $\quad$ Very poor 
14. The last time you needed care, how much discomfort did you experience from your symptoms?

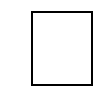

None

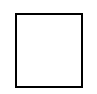

Mild

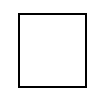

Moderate

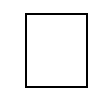

Severe

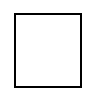

Very

severe

15. The last time you needed care, how much pain did you experience from your symptoms?

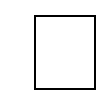

None

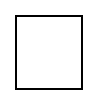

Mild

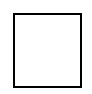

Moderate

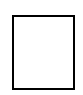

Severe

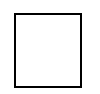

Very severe

16. How much discomfort did you have in the week following that experience?
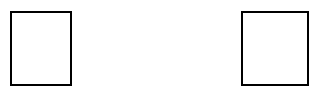

None

Mild

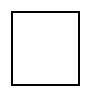

Moderate

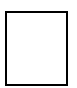

Severe

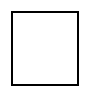

Very severe

17. How much pain did you have in the week following that experience?

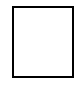

None

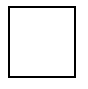

Mild

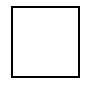

Moderate

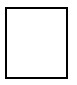

Severe

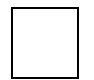

Very severe

18. Still thinking about the last time you needed care, how much opportunity did you have to ask questions?<smiles>C1CCC1</smiles><smiles>C1CCC1</smiles><smiles>C1CCC1</smiles><smiles>C1CCC1</smiles>

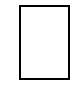

\begin{tabular}{|c|c|c|c|c|}
\hline $\begin{array}{l}\text { Very } \\
\text { good } \\
\text { pportun } \\
\text { ity }\end{array}$ & $\begin{array}{c}\text { Good } \\
\text { opportun } \\
\text { ity }\end{array}$ & $\begin{array}{c}\text { Fair } \\
\text { opportun } \\
\text { ity }\end{array}$ & $\begin{array}{c}\text { Limited } \\
\text { opportun } \\
\text { ity }\end{array}$ & $\begin{array}{l}\text { No } \\
\text { opportun } \\
\text { ity }\end{array}$ \\
\hline
\end{tabular}


19. Still thinking about the last time you needed care, how much explanation did you receive?

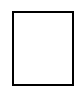

Far too much

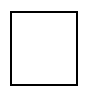

A bit

too much

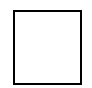

Enough

Too

little

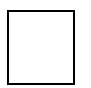

Far too

little

If you did not receive an explanation, then please go direct to question 21 .

20. How easy to understand was the explanation given to you the last time you needed care?
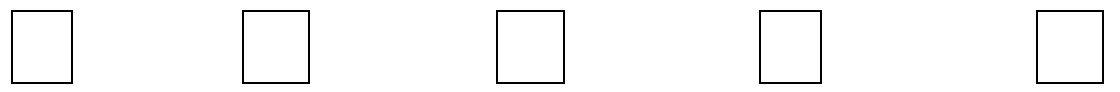

Very
easy

Easy

Fair

Difficult

Very

21. Was that explanation useful in answering your questions?
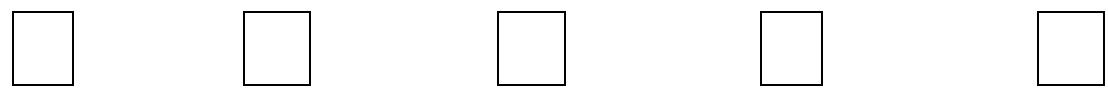

Very
useful

Useful

Fair

Not very

useful

Not at all

useful

\section{General quality of the care you receive}

22. In general, how easy is it to get care when you need it?
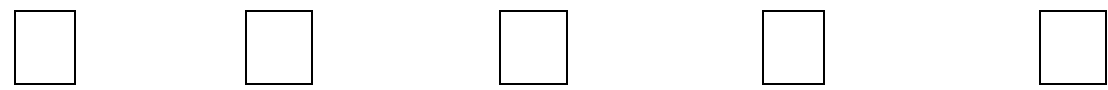

Very good

Good

Fair

Poor

Very poor 
23. In general, how satisfied are you with getting care when you need it?

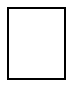

Very satisfie

d

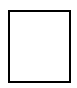

Satisfie

d

Neither

satisfied

nor

dissatisfi

ed

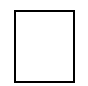

Dissatisfi

ed

Very

dissatisfi

ed

24. How happy would you be to get care in the same way as last time, in future?
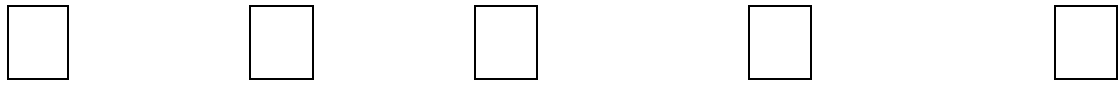

Very

happy
Happy

Neither

happy

nor

unhappy
Very

unhappy

25. In general how good is the care you receive for your bowel condition?
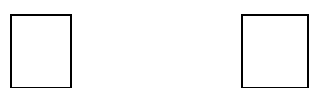

Very good

Good

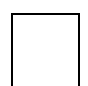

Fair

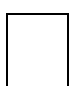

Poor

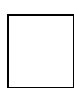

Very poor

\section{Your general well being}

26. Please tick which statement best describes your own health state today.

\section{Mobility}

I have no problems in walking about

I have some problems in walking about

I am confined to bed 


\section{Self-Care}

I have no problems with self-care

I have some problems washing or dressing myself

I am unable to wash or dress myself activities)

Usual Activities (e.g. work, study, housework, family or leisure

I have no problems with performing my usual activities

I have some problems with performing my usual activities

I am unable to perform my usual activities

\section{Pain or Discomfort}

I have no pain or discomfort

I have moderate pain or discomfort

I have extreme pain or discomfort

\section{Anxiety / Depression}

I am not anxious or depressed

I am moderately anxious or depressed

I am extremely anxious or depressed

Please use the following box if you want to say more about any question or any other aspect of your condition

Many thanks for your invaluable help! 


\section{Appendix 11. Welsh Index of multiple deprivation - Neath Port Talbot}

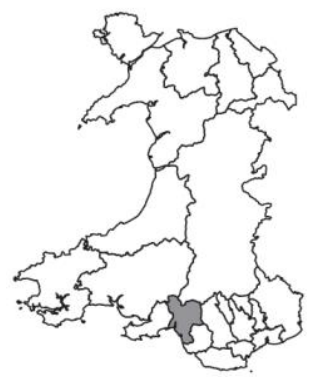

Welsh Index of Multiple Deprivation 2011

\section{Welsh Index of Multiple Deprivation}

Neath Port Talbot

By Lower Level Super Output Areas

Rank

Most Deprived

1 to 190

191 to 380

381 to 570

571 to 950

951 to 1896
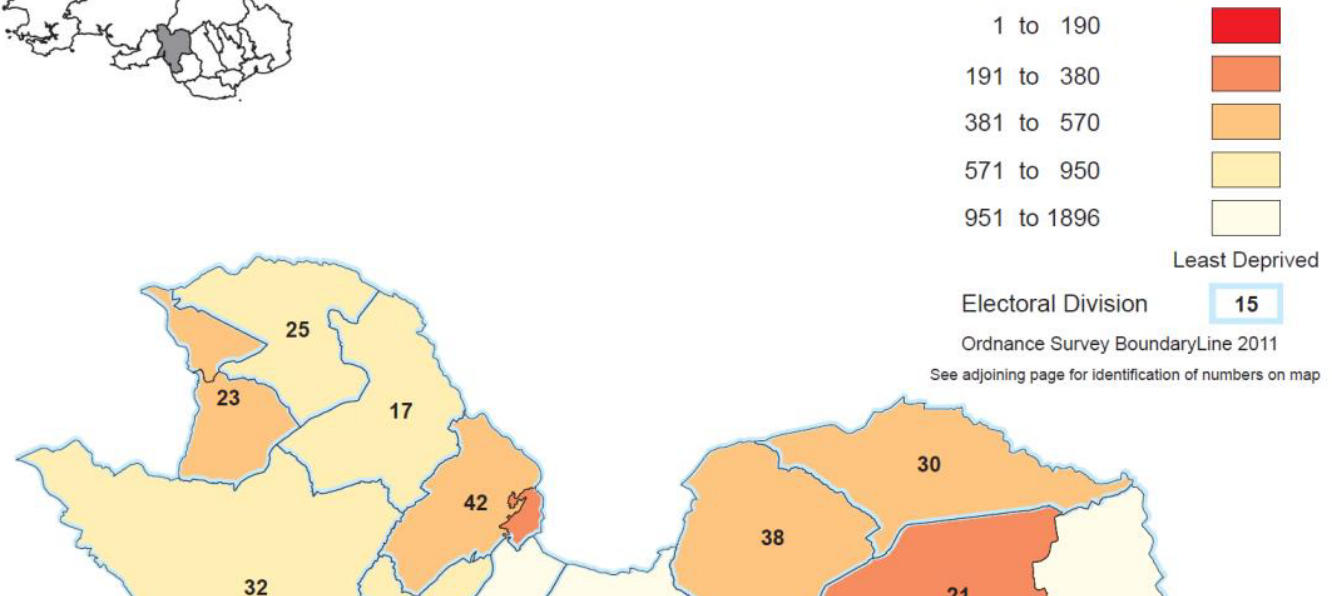

Least Deprived

Electoral Division

15

Ordnance Survey BoundaryLine 2011

See adjoining page for identification of numbers on map

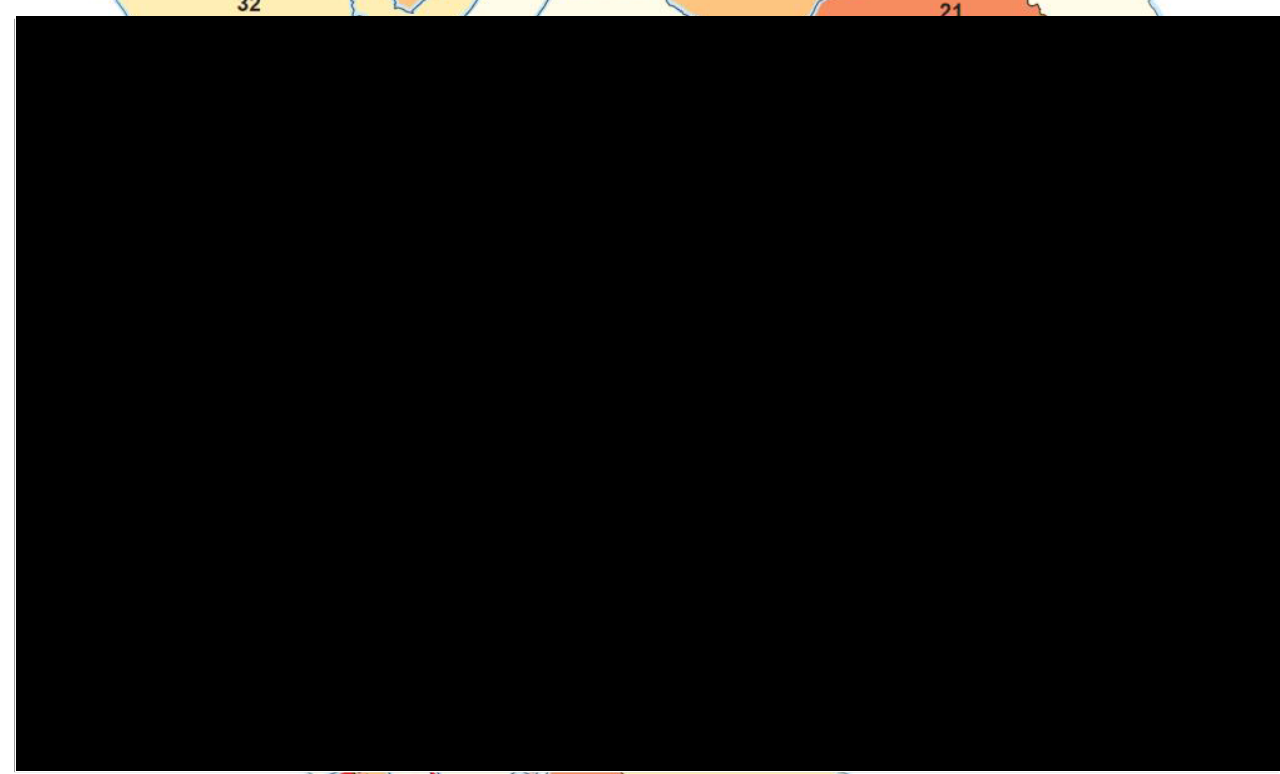

38

30

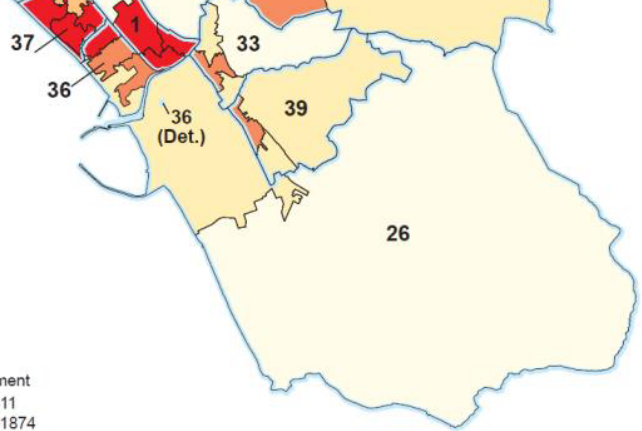

\&echnology, Welsh Govern Crown Copyright and database right 2011

StatsWales $>$ Community safety and social inclusion $>$ Welsh Index of Multiple Deprivation $>$ Archive $>$ WIMD 2011 > Local authority maps.gov.uk 


\section{Appendix 12. Letter of confirmation of full ethical approval}

\section{South West Wales REC}

Swansea

36 Orchard Street

SWANSEA

SA1 5AQ

Telephone: 01792607416

Facsimile: 01792607533

05 March 2010

Professor J G Williams

Professor of Health Services Research

Swansea University

School of Medicine

Grove Building

Swansea University

\section{SA2 8PP}

Dear Professor Williams

Study Title:

REC reference number:

Protocol number:
Electronic linkage for inflammatory bowel disease to deliver joint access to health records (ELIJAH)

09/WMW02/61

1

Thank you for your letter of 04 February 2010, responding to the Committee's request for further information on the above research and submitting revised documentation.

The further information has been considered on behalf of the Committee by the Chairman.

\section{Confirmation of ethical opinion}

On behalf of the Committee, I am pleased to confirm a favourable ethical opinion for the above research on the basis described in the application form, protocol and supporting documentation as revised, subject to the conditions specified below.

\section{Ethical review of research sites}

The favourable opinion applies to all NHS sites taking part in the study, subject to management permission being obtained from the NHS/HSC R\&D office prior to the start of the study (see "Conditions of the favourable opinion" below).

Conditions of the favourable opinion 
The favourable opinion is subject to the following conditions being met prior to the start of the study.

Management permission or approval must be obtained from each host organisation prior to the start of the study at the site concerned.

For NHS research sites only, management permission for research ("R\&D approval") should be obtained from the relevant care organisation(s) in accordance with NHS research governance arrangements. Guidance on applying for NHS permission for research is available in the Integrated Research Application System or at http://www.rdforum.nhs.uk. Where the only involvement of the NHS organisation is as a Participant Identification Centre, management permission for research is not required but the R\&D office should be notified of the study. Guidance should be sought from the R\&D office where necessary.

Sponsors are not required to notify the Committee of approvals from host organisations.

It is the responsibility of the sponsor to ensure that all the conditions are complied with before the start of the study or its initiation at a particular site (as applicable).

\section{Approved documents}

The final list of documents reviewed and approved by the Committee is as follows:

\begin{tabular}{|l|l|l|l|}
\hline Document & Version & Date \\
\hline Covering Letter & 1 & 04 February 2010 \\
\hline REC application & 1 & 04 January 2010 \\
\hline Protocol & 1 & 28 December 2009 & \\
\hline Investigator CV & 1 & 28 December 2009 & \\
\hline Participant Information Sheet & 2 & 22 April 2010 \\
\hline Participant Consent Form & 2 & 28 December 2009 & \\
\hline Shine email & 1 & 17 December 2009 & \\
\hline Response to Request for Further Information & 1 & 04 February 2010 & \\
\hline sponsor declaration & 1 & 04 March 2010 \\
\hline
\end{tabular}

\section{Statement of compliance}

The Committee is constituted in accordance with the Governance Arrangements for Research Ethics Committees (July 2001) and complies fully with the Standard Operating Procedures for Research Ethics Committees in the UK.

\section{After ethical review}

Now that you have completed the application process please visit the National Research Ethics Service website > After Review 
You are invited to give your view of the service that you have received from the National Research Ethics Service and the application procedure. If you wish to make your views known please use the feedback form available on the website.

The attached document "After ethical review - guidance for researchers" gives detailed guidance on reporting requirements for studies with a favourable opinion, including:

- Notifying substantial amendments

- Adding new sites and investigators

- Progress and safety reports

- Notifying the end of the study

The NRES website also provides guidance on these topics, which is updated in the light of changes in reporting requirements or procedures.

We would also like to inform you that we consult regularly with stakeholders to improve our service. If you would like to join our Reference Group please email referencegroup@nres.npsa.nhs.uk.

09/WMW02/61

Please quote this number on all correspondence

Yours sincerely

\section{Mr Roy L. Evans}

\section{Chairman}

Email: penny.beresford@bscs.wales.nhs.uk

Enclosures: $\quad$ "After ethical review - guidance for researchers"

Copy to:

Mrs Phedra Dodds, Abertawe Bro Morgannwg University Local Health Board

[R\&D office for NHS care organisation at lead site] 


\section{Appendix 13 combined CONSORT reporting outline with appropriate extensions for the ELIJAH RCT feasibility trial}

(CONSORT

2010 outline + extensions for patient reported outcomes, non-pharmacological treatment, pragmatic trials, parallel group randomised trials

Excel \& SPSS: re-run data files (outputs as appendix)

CLINICAL TRIALS REGISTRY: Clinicaltrials.gov \& portfolio status

FUNDING SOURCE, AMOUNT, TRIAL TEAM)

\section{CONSORT 2010, CENT 2015}

Extension: pilot or feasibility trial

Extension: Patient reported outcomes

Extension: Reporting of Harms (safety)

Extension: Nonpharmacologic treatments

Extension: Pragmatic trials

(Checklist in appendix)

\begin{tabular}{|c|c|c|}
\hline \multirow[t]{2}{*}{ Section / topic } & CONSORT 2010 & CENT 2015 \& extensions \\
\hline & Item & No. Item \\
\hline \multirow[t]{2}{*}{ Title \& abstract } & $\begin{array}{l}\text { 1a Identification as a randomised } \\
\text { trial in title }\end{array}$ & $\begin{array}{l}\text { Identification as a pilot or } \\
\text { feasibility randomised trial in } \\
\text { the title }\end{array}$ \\
\hline & $\begin{array}{l}\text { 1b Structured summary of trial } \\
\text { design, methods, results, } \\
\text { conclusions (see CONSORT for } \\
\text { abstracts) }\end{array}$ & $\begin{array}{l}\text { Structured summary of pilot } \\
\text { trial design, methods, results } \\
\text { and conslusions } \\
\text { P1b The PRO should be } \\
\text { identified in the abstract as a } \\
\text { primary or secondary outcome } \\
\text { If the study collected data on } \\
\text { harms \& benefits the title or } \\
\text { abstract should state } \\
\text { Description of the } \\
\text { experimental treatment, } \\
\text { comparator, care providers, } \\
\text { centres, \& blinding status }\end{array}$ \\
\hline \multirow{2}{*}{$\begin{array}{l}\text { Introduction } \\
\text { Background \& } \\
\text { objectives }\end{array}$} & & \\
\hline & $\begin{array}{l}\text { 2a Scientific background \& } \\
\text { explanation of rationale }\end{array}$ & $\begin{array}{l}\text { Scientific background \& } \\
\text { explanation of rationale for } \\
\text { future definitive trial, \& } \\
\text { reasons for randomised pilot } \\
\text { trial } \\
\text { Including background \& } \\
\text { rationale for PRO assessment } \\
\text { Specific objectives or research } \\
\text { questions for pilot trial }\end{array}$ \\
\hline
\end{tabular}




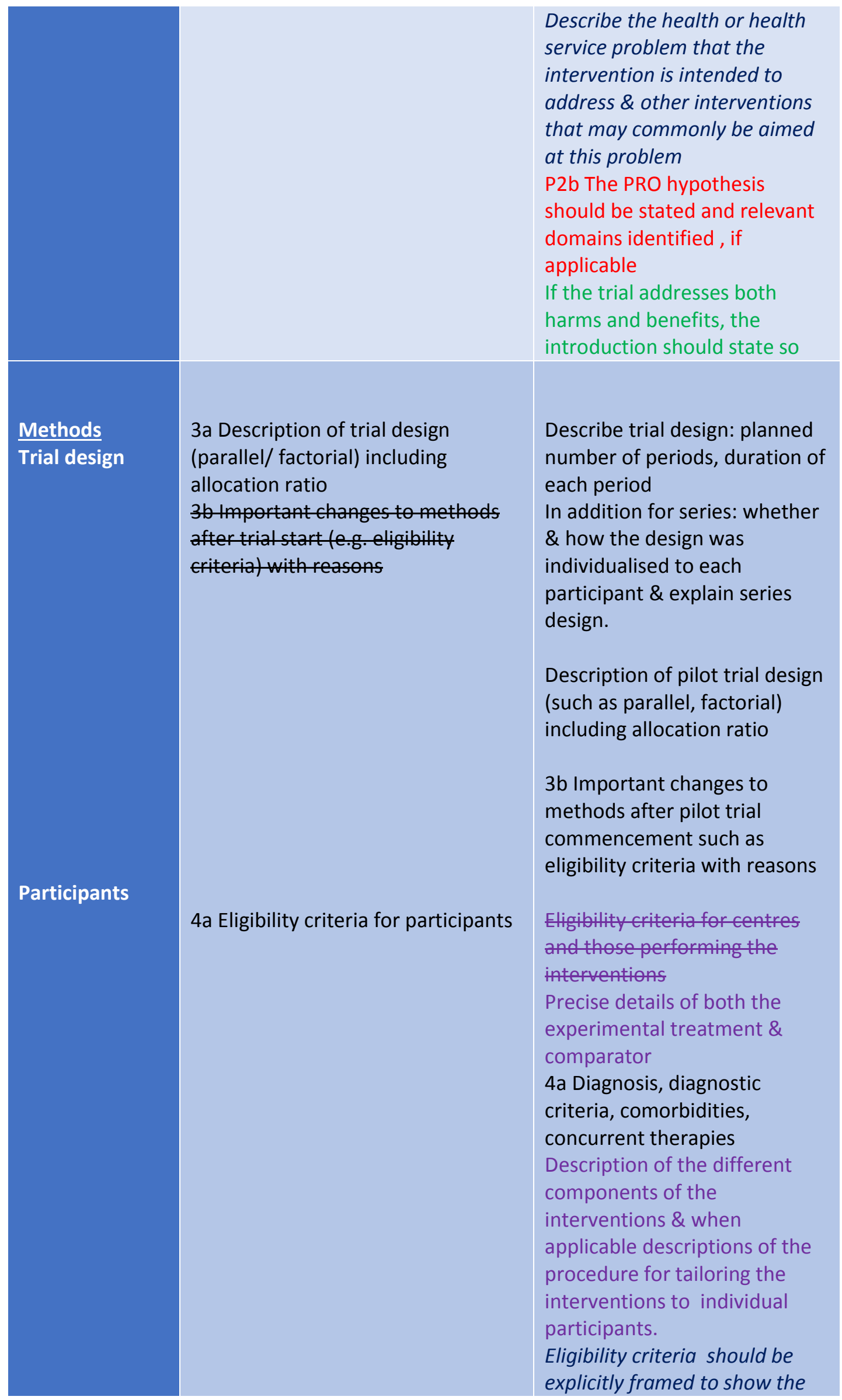




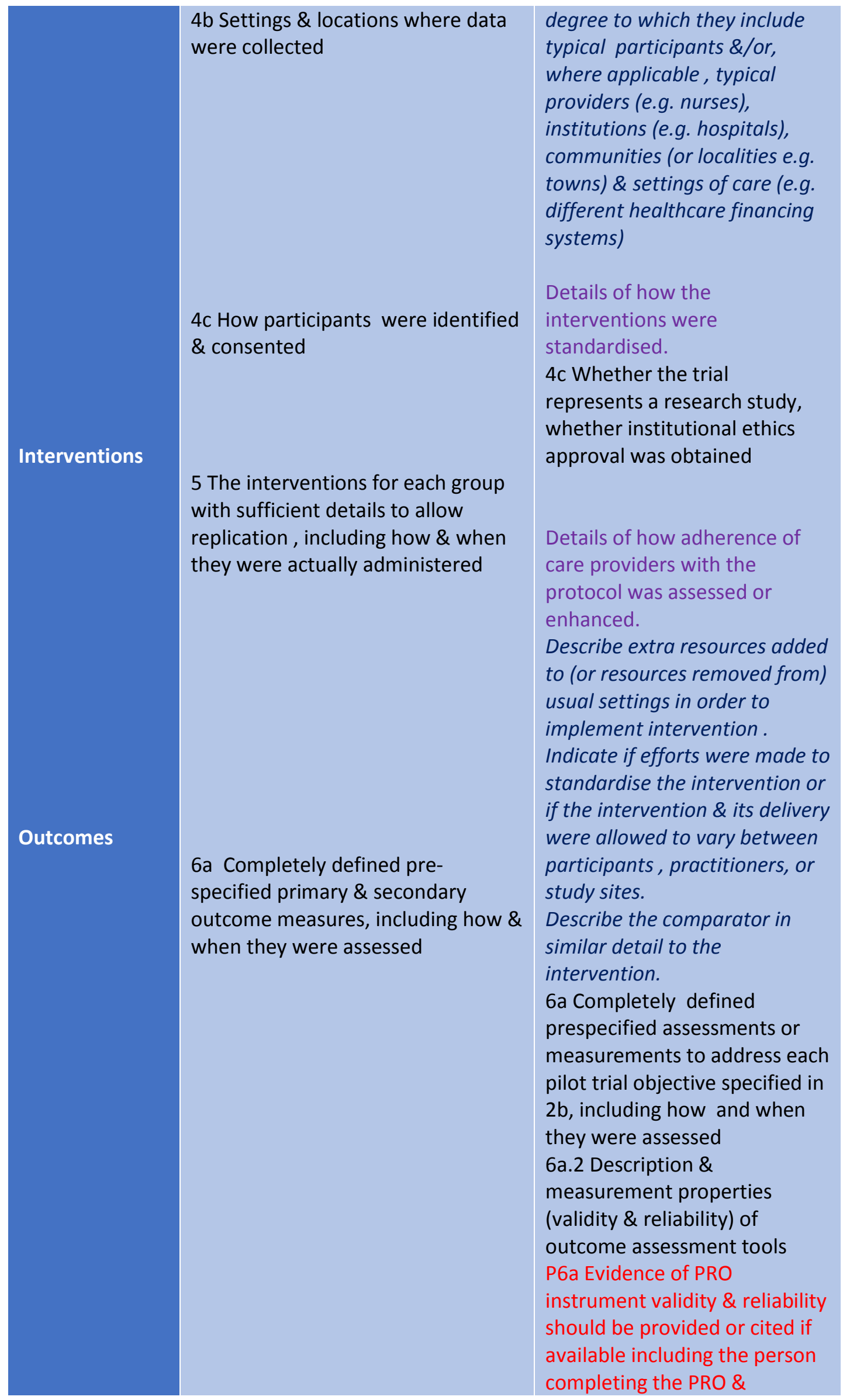




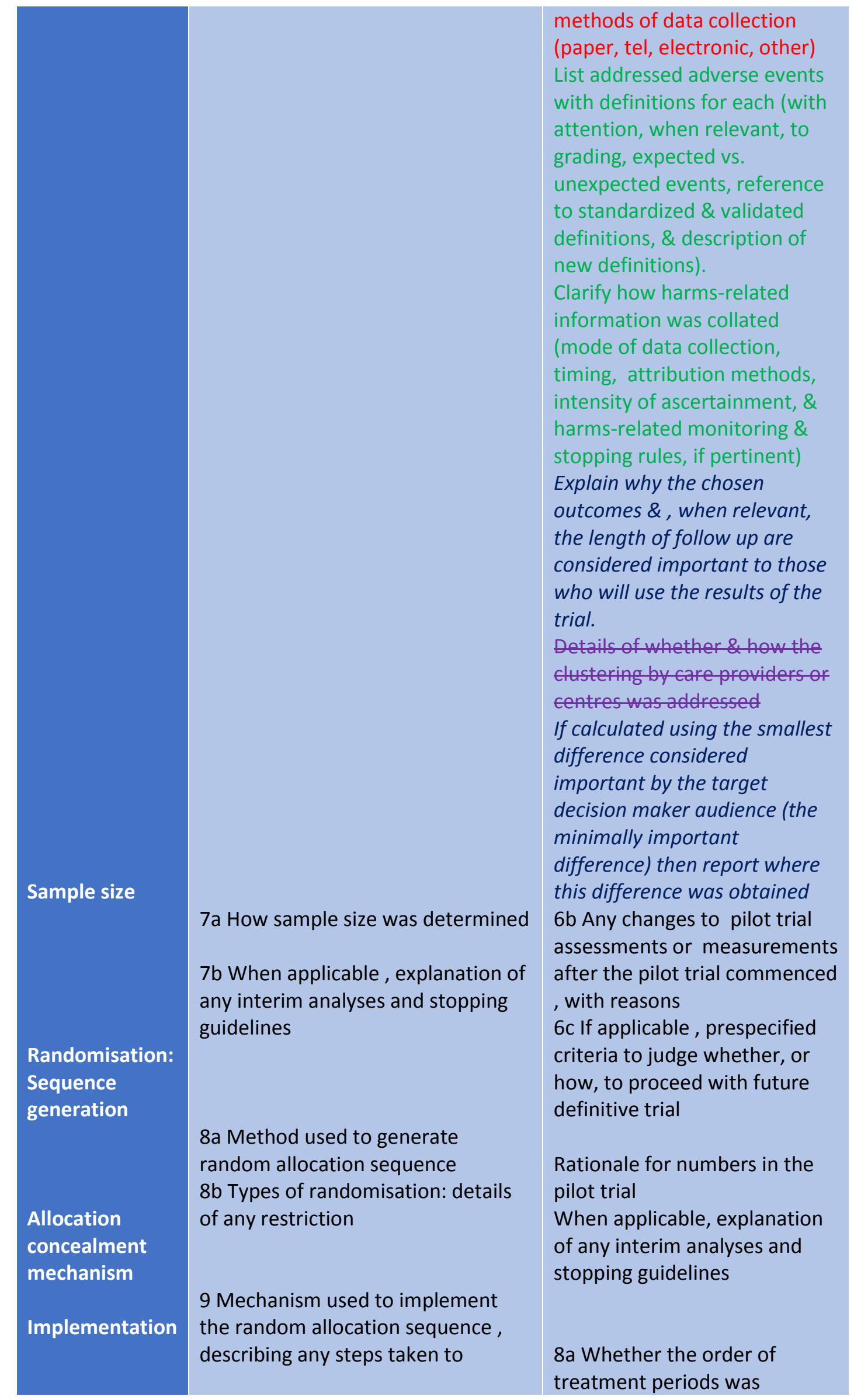




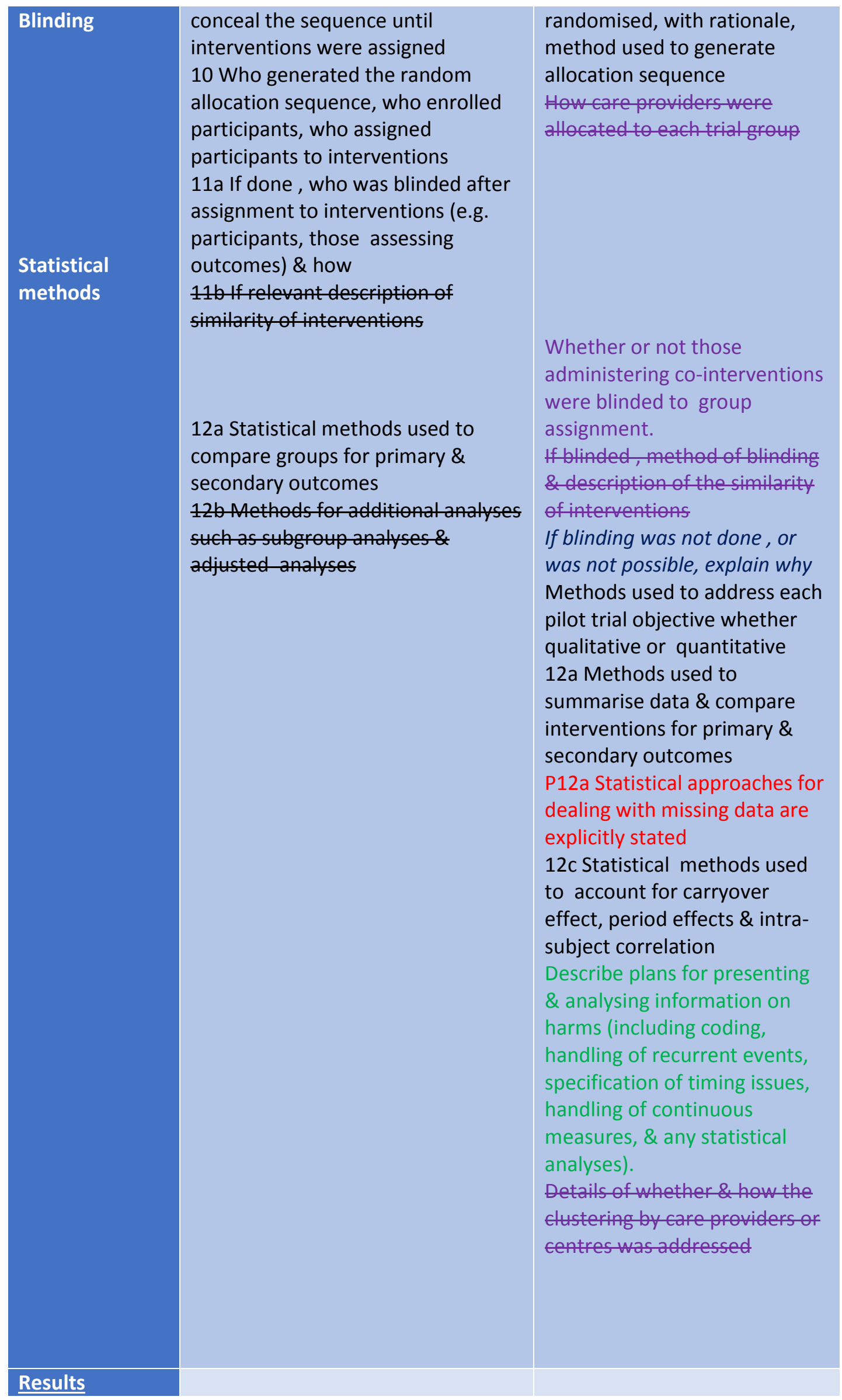




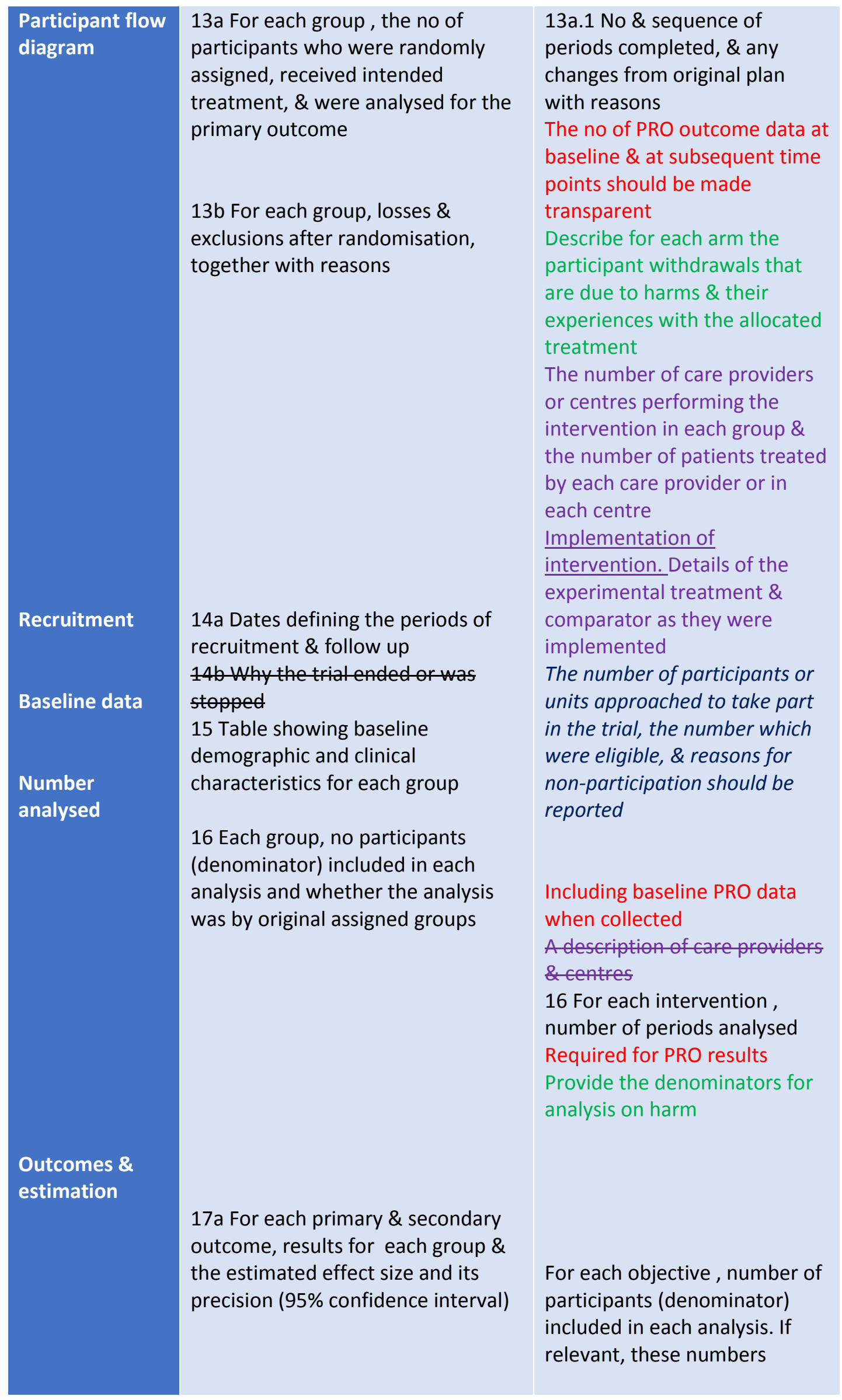




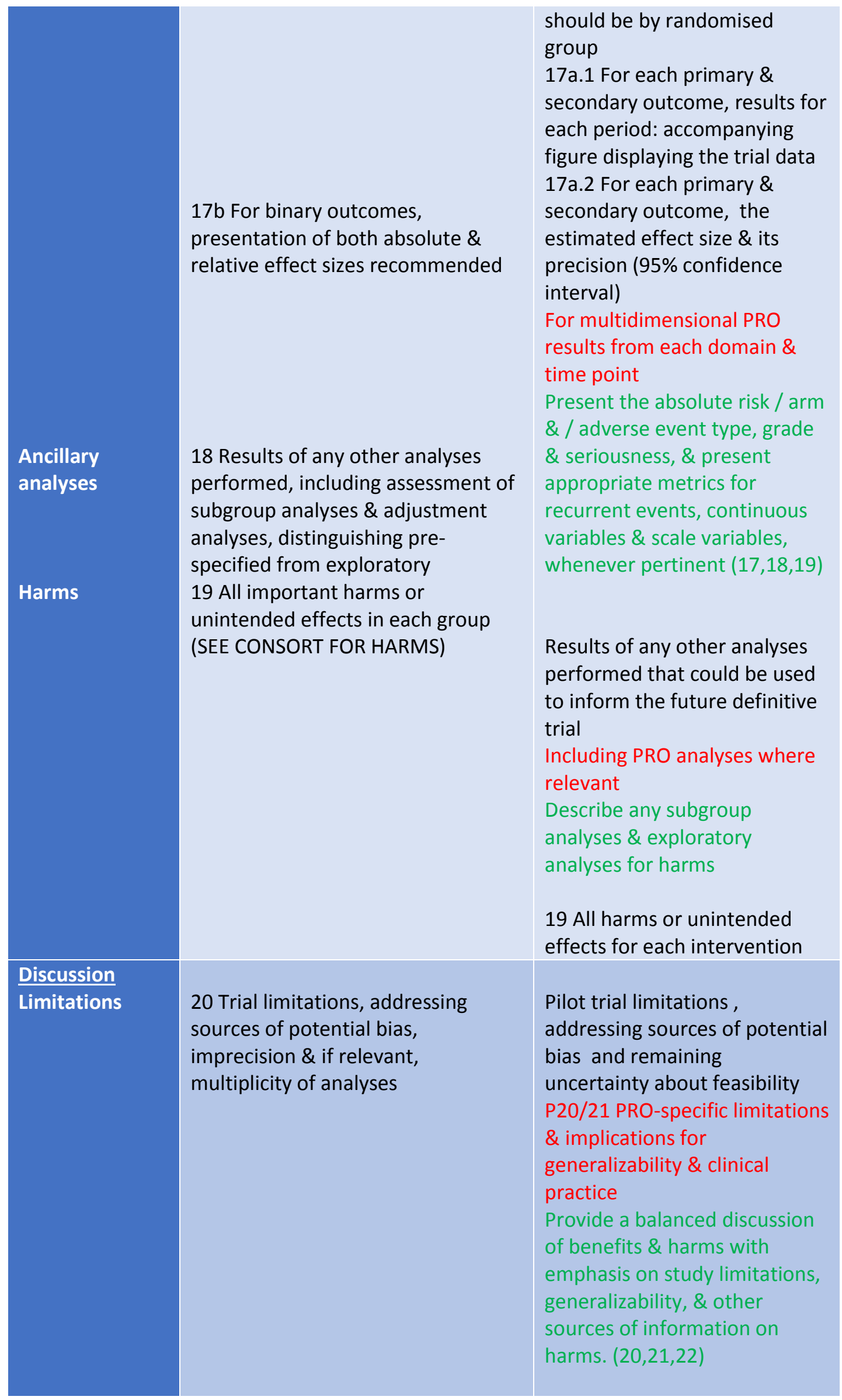




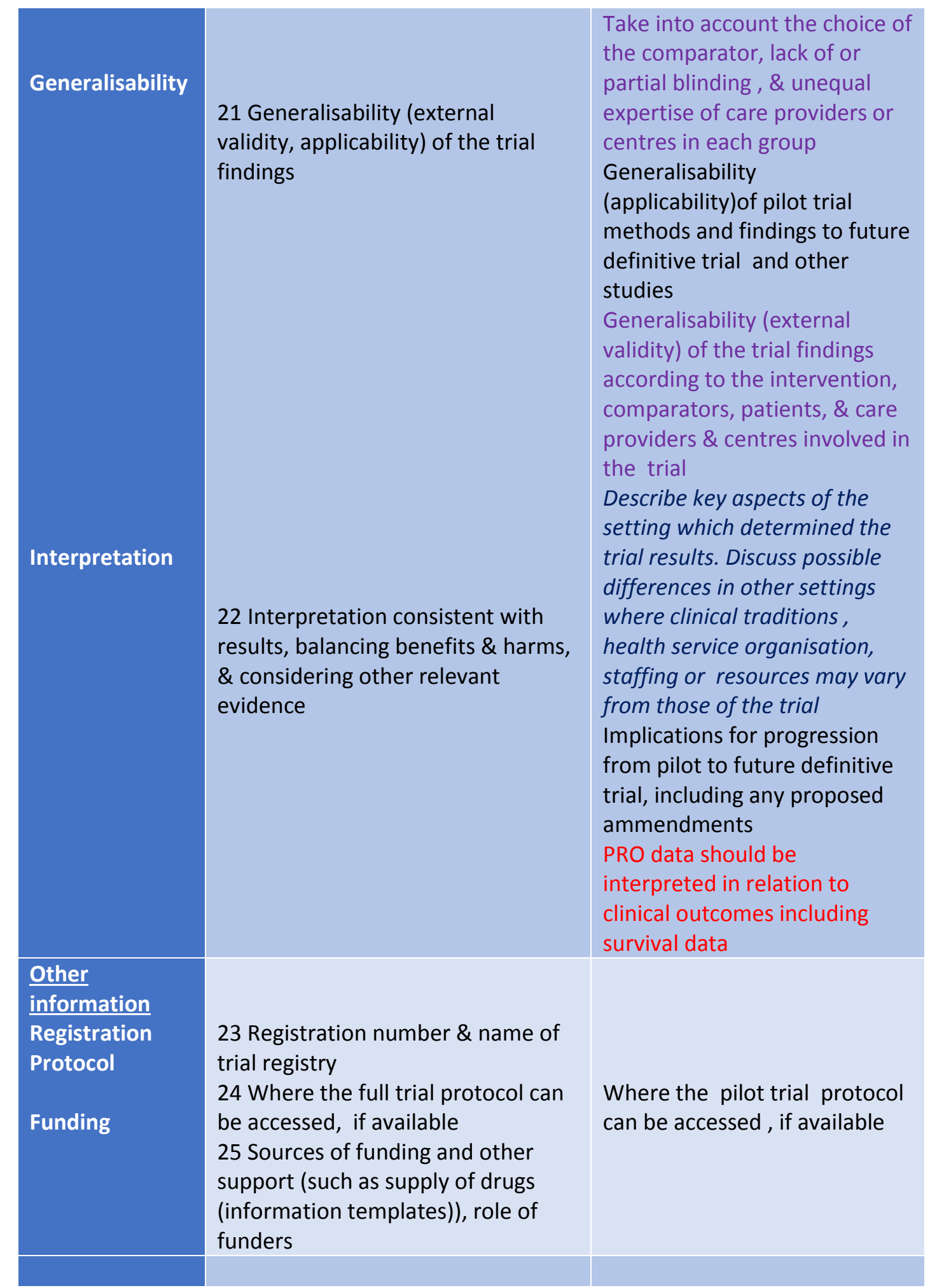

References:

Reporting of Patient-Reported outcomes in Randomised Trials: The CONSORT PRO Extension. JAMA. February 27, 2013_Vol309(8)

CONNSORT 2010 Statement: extension to randomised pilot and feasibility trials. BMJ. 2016; 355:i5239/doi:10.1136/bmj.i5239

CONSORT 2010 Statement: updated guidelines for reporting parallel group randomised trials. BMJ. 27March2010_Vol340(698-702) 
CONSORT 2010 Explanation \& Elaboration: updated guidelines for reporting parallel group randomised trials. BMJ. 2010; 340:c869

loannidis J.P.A. et al. 2004. Better reporting of harms in randomized trials: an extension of the CONSORT statement. Annals of Internal Medicine. Vol 141. No 10 pp781-788

Boutron I. et al, 2008. Methods \& processes of the CONSORT group: example of an extension for trials assessing nonpharmacological treatments. Annals of Internal Medicine. Vol 148, no 4, ppw60-w66

Zwarenstein M. et al (2008). Improving the reporting of pragmatic trials: an extension of the CONSORT statement. BMJ 2008;337 
Appendix 14. List of treatments and investigations, frequency and likely linked to IBD

\begin{tabular}{|c|c|c|}
\hline Treatment/ investigation & Frequency of treatment/ investigation & Likely linked to IBD \\
\hline Admitted for 1 day & 2 & Yes \\
\hline Admitted for 4 days & 1 & Yes \\
\hline Admitted for 7 days & 1 & Yes \\
\hline Ambulance transfer & 1 & \\
\hline Barium follow through & 1 & Yes \\
\hline Blood test & 176 & Yes \\
\hline C difficile cytotoxin & 2 & Yes \\
\hline C. difficile stool sample & 1 & Yes \\
\hline Catheterised & 1 & \\
\hline Chest X ray & 3 & \\
\hline Chlamydia PCR & 3 & \\
\hline Colonoscopy & 4 & Yes \\
\hline Colposcopy & 1 & \\
\hline Colposcopy histopathology & 1 & \\
\hline CT abdomen \& pelvis & 2 & Yes \\
\hline CT thorax & 1 & \\
\hline Cystoscopy & 1 & \\
\hline Cytology & 3 & \\
\hline Doppla scan lower limb arteries & 1 & \\
\hline ECG & 1 & \\
\hline Faeces test microbiology & 2 & Yes \\
\hline Flexible sigmoidoscopy & 4 & Yes \\
\hline Histopathology & 8 & Yes \\
\hline Hydrogen breath test & 2 & \\
\hline HVS culture & 2 & \\
\hline Infusion in day unit & 3 & Yes \\
\hline Microbiology wound culture & 1 & \\
\hline MRI & 1 & Yes \\
\hline MRSA screen & 2 & \\
\hline OGD & 1 & \\
\hline Random urine test & 1 & \\
\hline Right hemicolectomy & 1 & Yes \\
\hline Sputum culture & 1 & \\
\hline Stool sample microbiology & 2 & Yes \\
\hline Total colectomy \& ileostomy & 1 & Yes \\
\hline Urine microbiology & 9 & \\
\hline USS kidneys & 1 & \\
\hline Wound culture microbiology & 2 & \\
\hline $\mathrm{X}$ ray abdomen & 4 & Yes \\
\hline $\mathrm{X}$ ray ankle & 1 & \\
\hline $\mathrm{X}$ ray both hand, knee, ankle & 1 & \\
\hline $\mathrm{X}$ ray fingers & 1 & \\
\hline $\mathrm{X}$ ray foot & 2 & \\
\hline $\mathrm{X}$ ray foot, wrist, hand & 1 & \\
\hline $\mathrm{X}$ ray hand & 1 & \\
\hline $\mathrm{X}$ ray knee & 1 & \\
\hline $\mathrm{X}$ ray pelvis & 2 & Yes \\
\hline
\end{tabular}


Appendix 15. Primary and secondary care appointments and frequency

\begin{tabular}{|l|l|}
\hline & \\
Primary care appointments & Frequency of appointments \\
\hline Appointment with GP & 152 \\
\hline Appointment with GP minor surgery & 1 \\
\hline Telephone call with GP & 31 \\
\hline Home visit from GP & 7 \\
\hline Out of hours GP & 1 \\
\hline Appointment with nurse & 129 \\
\hline Telephone call with nurse & 9 \\
\hline Appointment with HCSW & 11 \\
\hline
\end{tabular}

\begin{tabular}{|l|l|}
\hline Secondary care appointments & Frequency of appointments \\
\hline Email with Nurse Practitioner (band 7) & 2 \\
\hline Outpatient with Consultant & 43 \\
\hline Outpatient with Nurse Practitioner (band 7) & 17 \\
\hline Telephone call with Nurse Practitioner (band 7) & 20 \\
\hline Postal review & 2 \\
\hline
\end{tabular}


Appendix 16. List of medication

\begin{tabular}{|c|c|c|c|c|c|c|}
\hline Medications & Strength & Dose & Frequency & 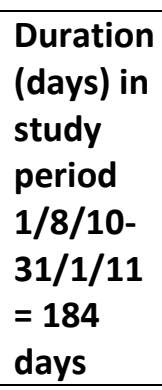 & $\begin{array}{l}\text { Number } \\
\text { of } \\
\text { patients }\end{array}$ & $\begin{array}{l}\text { Medication } \\
\text { used to } \\
\text { treat IBD } \\
\text { or effects } \\
\text { of IBD }\end{array}$ \\
\hline ACTOS & $45 \mathrm{mg}$ & 1 & OD & 184 & 1 & \\
\hline Adcal D3 & $1.5 \mathrm{~g}$ & 1 & $\mathrm{BD}$ & 184 & 1 & \\
\hline Adcal D3 & $1.5 \mathrm{~g}$ & 2 & & 78 & 1 & \\
\hline Alendronic acid & $70 \mathrm{mg}$ & 1 & 1/ week & 184 & 3 & \\
\hline Allopurinol & $100 \mathrm{mg}$ & 1 & OD & 184 & 1 & \\
\hline Amitryptiline & $10 \mathrm{mg}$ & 1 & OD & 184 & 1 & \\
\hline Amlodipine & $5 \mathrm{mg}$ & 1 & OD & 184 & 3 & \\
\hline Amlodipine & $10 \mathrm{mg}$ & 1 & OD & 184 & 1 & \\
\hline Asacol & $400 \mathrm{mg}$ & 1 & $\mathrm{BD}$ & 184 & 1 & \\
\hline Asacol & $400 \mathrm{mg}$ & 2 & TDS & 184 & 5 & \\
\hline Asacol & $400 \mathrm{mg}$ & 2 & $\mathrm{BD}$ & 184 & 3 & \\
\hline Asacol & $400 \mathrm{mg}$ & 2 & & 136 & 1 & \\
\hline Asacol & $400 \mathrm{mg}$ & 3 & & 48 & 1 & \\
\hline Asacol & $400 \mathrm{mg}$ & 2 & & 39 & 1 & \\
\hline Asacol & $400 \mathrm{mg}$ & 3 & $\mathrm{BD}$ & 184 & 1 & \\
\hline Asacol & $400 \mathrm{mg}$ & 2 & OD & 184 & 1 & \\
\hline Asacol & $400 \mathrm{mg}$ & 2 & & 184 & 1 & \\
\hline Aspirin & $75 \mathrm{mg}$ & 1 & OD & 184 & 12 & \\
\hline Atenolol & $50 \mathrm{mg}$ & 1 & OD & 184 & 1 & \\
\hline Atorvastatin & $10 \mathrm{mg}$ & 1 & OD & 184 & 2 & \\
\hline Atorvastatin & $40 \mathrm{mg}$ & 1 & OD & 184 & 1 & \\
\hline Azathioprine & $75 \mathrm{mg}$ & 1 & OD & 27 & 1 & \\
\hline Azathioprine & $50 \mathrm{mg}$ & 1 & OD & 4 & 1 & \\
\hline Azathioprine & $175 \mathrm{mg}$ & 1 & OD & 184 & 1 & \\
\hline Azathioprine & $50 \mathrm{mg}$ & 1 & $\mathrm{BD}$ & 184 & 1 & \\
\hline Azathioprine & $50 \mathrm{mg}$ & 2 & & 142 & 1 & \\
\hline Azathioprine & $50 \mathrm{mg}$ & 4 & OD & 184 & 1 & \\
\hline Azathioprine & $50 \mathrm{mg}$ & 2 & OD & 184 & 1 & \\
\hline
\end{tabular}




\begin{tabular}{|c|c|c|c|c|c|c|}
\hline Azathioprine & $50 \mathrm{mg}$ & 2 & & 39 & 1 & \\
\hline Azathioprine & $75 \mathrm{mg}$ & 1 & & 145 & 1 & \\
\hline Azathioprine & $125 \mathrm{mg}$ & 1 & OD & 184 & 1 & \\
\hline Azathioprine & $25 \mathrm{mg}$ & 1 & OD & 184 & 1 & \\
\hline Azathioprine & $50 \mathrm{mg}$ & 3 & OD & 184 & 1 & \\
\hline Azathioprine & & 3 & & 157 & 1 & \\
\hline Azathioprine & $50 \mathrm{mg}$ & 3 & & 184 & 1 & \\
\hline Balsalazide & $750 \mathrm{mg}$ & 3 & TDS & 184 & 1 & \\
\hline Beclometasone & $50 \mathrm{mcg}$ & 2 & $\mathrm{BD}$ & 184 & 1 & \\
\hline Bendroflumethazide & $2.5 \mathrm{mg}$ & 1 & OD & 184 & 6 & \\
\hline Betahistine & $8 \mathrm{mg}$ & 1 & TDS & 184 & 2 & \\
\hline Bisoprolol & $2.5 \mathrm{mg}$ & 1 & OD & 184 & 1 & \\
\hline Budesonide inhaler & $100 \mathrm{mcg}$ & 2 & $\mathrm{BD}$ & 184 & 1 & \\
\hline Buscopan & $10 \mathrm{mg}$ & 1 & & 1 & 1 & \\
\hline Buscopan & $20 \mathrm{mg}$ & 1 & OD & 184 & 1 & \\
\hline Calcichew D3 Forte & & 1 & $\mathrm{BD}$ & 184 & 2 & \\
\hline Calcichew D3 Forte & & 1 & OD & 184 & 6 & \\
\hline Calcichew D3 Forte & & 1 & $\mathrm{BD}$ & 78 & 1 & \\
\hline Calcichew D3 Forte & & 2 & $\mathrm{BD}$ & 184 & 1 & \\
\hline Calcichew D3 forte & & 2 & OD & 184 & 1 & \\
\hline Cefatazidime & & 1 & & 5 & 1 & \\
\hline Cefuroxime & $750 \mathrm{mg}$ & 3 & & 4 & 1 & \\
\hline Celluvisc $0.5 \%$ & & 1 & 6/day & 184 & 1 & \\
\hline Chlordiazepoxide & $30 \mathrm{mg}$ & 3 & & 1 & 1 & \\
\hline Cilostazol & $100 \mathrm{mg}$ & 1 & $\mathrm{BD}$ & 184 & 1 & \\
\hline Clexane & $40 \mathrm{mg}$ & 1 & & 10 & 1 & \\
\hline Clexane & $40 \mathrm{mg}$ & 1 & & 4 & 1 & \\
\hline Coamilofruse & & 1 & & 1 & & \\
\hline Coamoxiclav 500/125 & & 1 & & 1 & 1 & \\
\hline Cocodamol 500/30 & & 2 & QDS & 184 & 1 & \\
\hline Codydramol & & 2 & & 78 & 1 & \\
\hline Codyramol & $500 \mathrm{mg}$ & 2 & QDS & 184 & 1 & \\
\hline Colazide & $750 \mathrm{mg}$ & 2 & $\mathrm{BD}$ & 184 & 2 & \\
\hline Cyclizine & $50 \mathrm{mg}$ & 1 & & 1 & 1 & \\
\hline Cyclizine IV & $50 \mathrm{mg}$ & 1 & & 7 & 1 & \\
\hline Cyclizine IV & $50 \mathrm{mg}$ & 1 & & 1 & 1 & \\
\hline Diamorphine & $1.5 \mathrm{mg}$ & 1 & & 1 & 1 & \\
\hline Diamorphine & $1.25 \mathrm{mg}$ & 1 & & 1 & 1 & \\
\hline
\end{tabular}




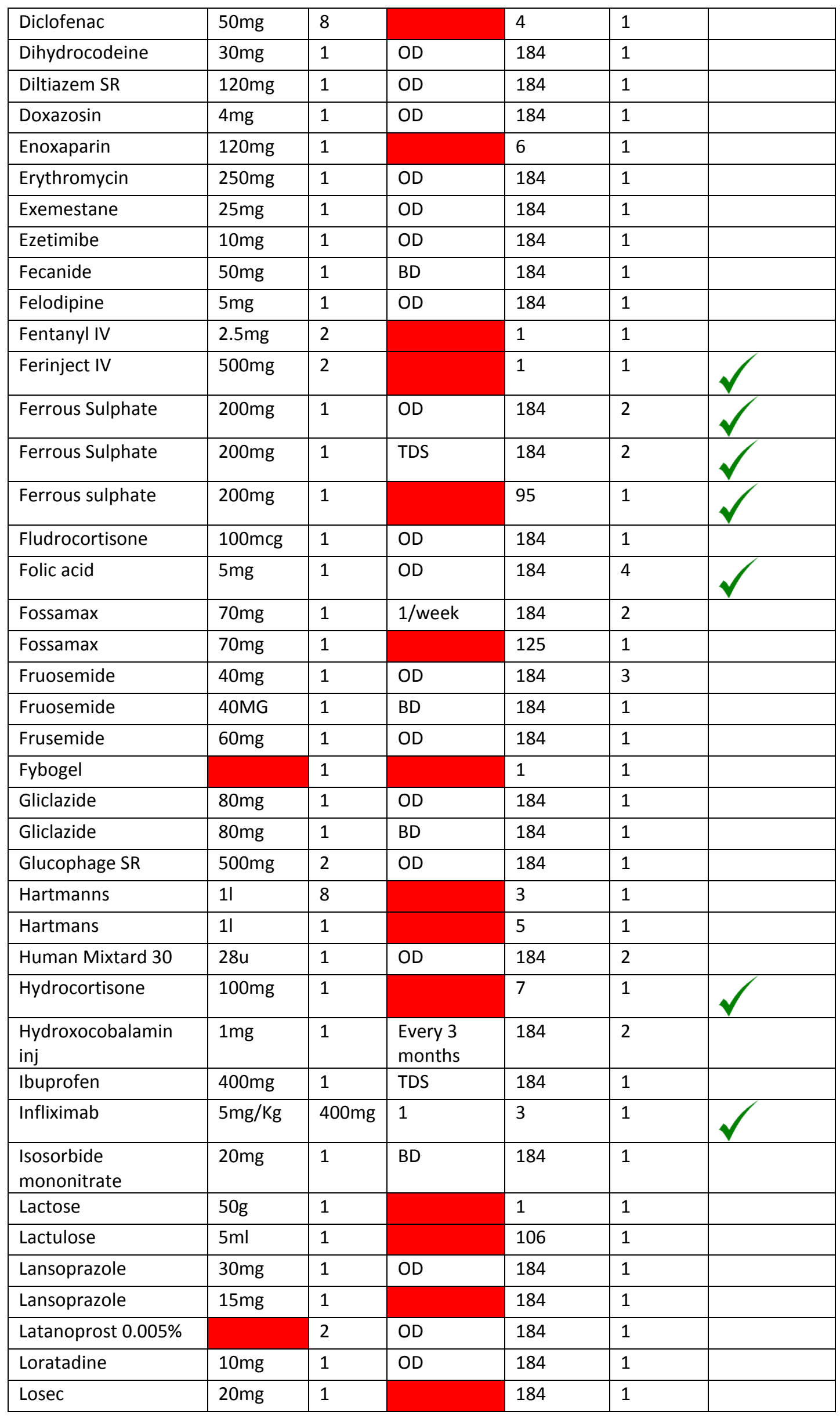




\begin{tabular}{|c|c|c|c|c|c|c|}
\hline Lymecycline & $408 \mathrm{mg}$ & 1 & OD & 184 & 1 & \\
\hline Mebeverine & $135 \mathrm{mg}$ & 1 & & 62 & 1 & \\
\hline Metformin & $500 \mathrm{mg}$ & 1 & QDS & 184 & 1 & \\
\hline Metformin & $500 \mathrm{mg}$ & 1 & TDS & 184 & 1 & \\
\hline Metformin & $500 \mathrm{mg}$ & 2 & $\mathrm{BD}$ & 184 & 2 & \\
\hline Metformin & $850 \mathrm{mg}$ & 1 & $\mathrm{BD}$ & 184 & 1 & \\
\hline Metoclopramide & $10 \mathrm{mg}$ & 1 & & 1 & 1 & \\
\hline Metoprolol & $50 \mathrm{mg}$ & 1 & $\mathrm{BD}$ & 184 & 1 & \\
\hline Metronidazole & $500 \mathrm{mg}$ IV & 1 & & 4 & 1 & \\
\hline Mezavant & $1200 \mathrm{mg}$ & 2 & OD & 184 & 1 & \\
\hline Mezavant & $1200 \mathrm{mg}$ & 3 & OD & 184 & 1 & \\
\hline Mezavant XL & $1200 \mathrm{mg}$ & 1 & & 184 & 1 & \\
\hline Mezavant XL & $1200 \mathrm{mg}$ & 1 & OD & 184 & 1 & \\
\hline Morphine & $100 \mathrm{mg}$ & 1 & & 1 & 1 & \\
\hline Movicol & & 1 & & 3 & 1 & \\
\hline Multivitamin & & 1 & & 78 & 1 & \\
\hline Mysolin & $250 \mathrm{mg}$ & 1 & $\mathrm{BD}$ & 184 & 1 & \\
\hline Naproxen & & 1 & & 92 & 1 & \\
\hline NONE & & & & & 12 & \\
\hline $\begin{array}{l}\text { Olmesartan } \\
\text { Medoxomil }\end{array}$ & $20 \mathrm{mg}$ & 1 & OD & 184 & 1 & \\
\hline Omeprazole & $20 \mathrm{mg}$ & 1 & OD & 184 & 4 & \\
\hline Ondansertron & $8 \mathrm{mg}$ & 2 & & 1 & 1 & \\
\hline Ondansetron & $4 \mathrm{mg}$ & 1 & & 1 & 1 & \\
\hline $\begin{array}{l}\text { Otrivine nasal drops } \\
0.1 \%\end{array}$ & $2-3$ drops & 1 & & 1 & 1 & \\
\hline Oxycontin & $10 \mathrm{mg}$ & 1 & OD & 184 & 1 & \\
\hline Paracetamol & $500 \mathrm{mg}$ & 2 & & 10 & 1 & \\
\hline $\begin{array}{l}\text { PCA: Heavy } \\
\text { Bupivcane }\end{array}$ & $0.50 \%$ & 1 & & 1 & 1 & \\
\hline Pentasa & $500 \mathrm{mg}$ & 2 & QDS & 184 & 4 & \\
\hline Pentasa & $500 \mathrm{mg}$ & 2 & $\mathrm{BD}$ & 184 & 7 & \\
\hline Pentasa & $500 \mathrm{mg}$ & 2 & TDS & 184 & 1 & \\
\hline Pentasa & $500 \mathrm{mg}$ & 2 & QDS & 64 & 1 & \\
\hline Pentasa & $500 \mathrm{mg}$ & 2 & & 120 & 1 & \\
\hline Pentasa & $500 \mathrm{mg}$ & 1 & TDS & 184 & 1 & \\
\hline Pentasa & $500 \mathrm{mg}$ & 2 & QDS & 140 & 1 & \\
\hline Pentasa & $500 \mathrm{mg}$ & 2 & & 83 & 1 & \\
\hline Pentasa & $500 \mathrm{mg}$ & 2 & & 101 & 1 & \\
\hline Pentasa & $500 \mathrm{mg}$ & 2 & & 37 & 1 & \\
\hline
\end{tabular}




\begin{tabular}{|c|c|c|c|c|c|c|}
\hline Pentasa & $500 \mathrm{mg}$ & 4 & & 146 & 1 & \\
\hline Pentasa enema & $1 \mathrm{~g}$ & 1 & & 1 & 1 & \\
\hline Pentasa enema & $1 g$ & 1 & OD & 184 & 2 & \\
\hline $\begin{array}{l}\text { Pentasa } \\
\text { suppositories }\end{array}$ & $1 \mathrm{~g}$ & 1 & & 28 & 1 & \\
\hline Perindopril & $4 \mathrm{mg}$ & 1 & $O D$ & 184 & 1 & \\
\hline Perindopril & $8 \mathrm{mg}$ & 1 & OD & 184 & 1 & \\
\hline Phenobarbitone & $30 \mathrm{mg}$ & 1 & $\mathrm{BD}$ & 184 & 1 & \\
\hline Pioglitazone & $45 \mathrm{mg}$ & 1 & OD & 184 & 1 & \\
\hline Polycal drink & & 1 & & 1 & 1 & \\
\hline Predfoam enema & $20 \mathrm{mg}$ & 1 & OD & 184 & 1 & \\
\hline Prednisolone & $5 \mathrm{mg}$ & 8 & OD & 8 & 1 & \\
\hline Prednisolone & $5 \mathrm{mg}$ & 12 & OD & 15 & 1 & \\
\hline Prednisolone & $5 \mathrm{mg}$ & 10 & OD & 16 & 1 & \\
\hline Prednisolone & $5 \mathrm{mg}$ & 8 & $O D$ & 30 & 1 & \\
\hline Prednisolone & $5 \mathrm{mg}$ & 6 & OD & 8 & 1 & \\
\hline Prednisolone & $5 \mathrm{mg}$ & 4 & OD & 10 & 1 & \\
\hline Prednisolone & $2.5 \mathrm{mg}$ & 6 & OD & 8 & 1 & \\
\hline Prednisolone & $2.5 \mathrm{mg}$ & 5 & OD & 8 & 1 & \\
\hline Prednisolone & $2.5 \mathrm{mg}$ & 4 & OD & 6 & 1 & \\
\hline Prednisolone & $5 \mathrm{mg}$ & 1 & OD & 75 & 1 & \\
\hline Prednisolone & $5 \mathrm{mg}$ & 1 & OD & 184 & 1 & \\
\hline Prednisolone & $5 \mathrm{mg}$ & 4 & & 4 & 1 & \\
\hline Prednisolone & $5 \mathrm{mg}$ & 8 & & 11 & 1 & \\
\hline Prednisolone & $5 \mathrm{mg}$ & 1 & & 39 & 1 & \\
\hline Prednisolone & $5 \mathrm{mg}$ & 8 & & 15 & 1 & \\
\hline Prednisolone & $5 \mathrm{mg}$ & 7 & & 7 & 1 & \\
\hline Prednisolone & $5 \mathrm{mg}$ & 6 & & 21 & 1 & \\
\hline Prednisolone & $5 \mathrm{mg}$ & 1 & OD & & 1 & \\
\hline Prednisolone & $5 \mathrm{mg}$ & 1 & & 172 & 1 & \\
\hline Prednisolone & $4 \mathrm{mg}$ & 1 & & 12 & 1 & \\
\hline Prednisolone & $2.5 \mathrm{mg}$ & 3 & & 184 & 1 & \\
\hline Prednisolone & $12.5 \mathrm{mg}$ & 1 & OD & 184 & 1 & \\
\hline Prednisolone & $2.5 \mathrm{mg}$ & 1 & & 184 & 1 & \\
\hline
\end{tabular}




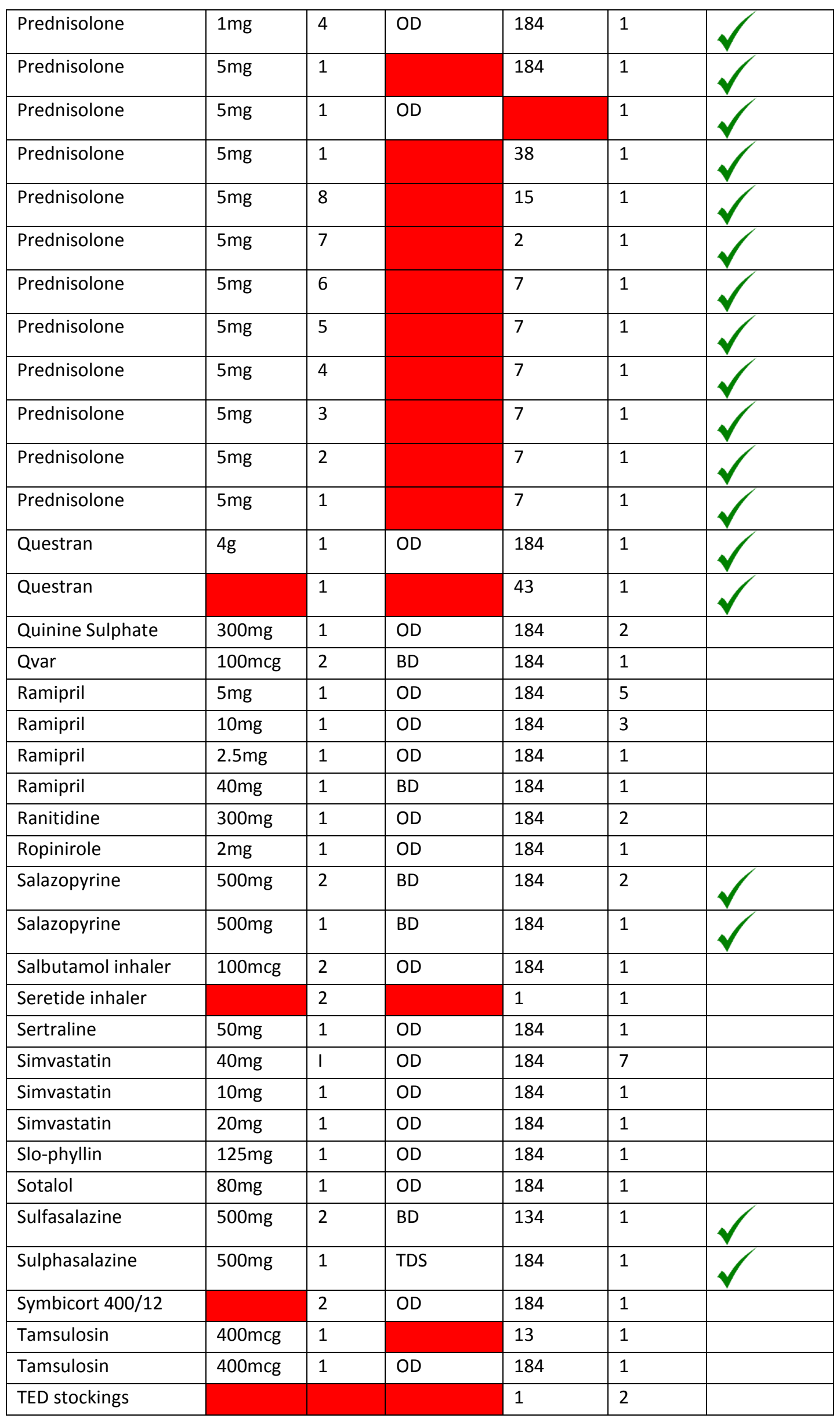




\begin{tabular}{|c|c|c|c|c|c|}
\hline Thyroxine & $125 \mathrm{mcg}$ & 1 & OD & 184 & 1 \\
\hline Thyroxine & $150 \mathrm{mcg}$ & 1 & OD & 184 & 1 \\
\hline Thyroxine & $100 \mathrm{mcg}$ & 1 & OD & 184 & 1 \\
\hline Tramadol & $100 \mathrm{mg}$ & 4 & & 28 & 1 \\
\hline Tramadol & $100 \mathrm{mg}$ & 3 & & 1 & 1 \\
\hline Tramadol IV & $100 \mathrm{mg}$ & 5 & & 4 & 1 \\
\hline Trimethoprim & $200 \mathrm{mg}$ & 1 & & 6 & 1 \\
\hline Vitamin B12 & & 1 & 3 monthly & 184 & 2 \\
\hline Warfarin & $10 \mathrm{mg}$ & 1 & & 2 & 1 \\
\hline Warfarin & $3 \mathrm{mg}$ & 1 & & 1 & 1 \\
\hline Warfarin & $1 \mathrm{mg}$ & 1 & & 1 & 1 \\
\hline Warfarin & $6 \mathrm{mg}$ & 2 & OD & 184 & 1 \\
\hline Zoton & $30 \mathrm{mg}$ & 1 & OD & 184 & 2 \\
\hline Zoton & $15 \mathrm{mg}$ & 1 & OD & 184 & 1 \\
\hline
\end{tabular}


Appendix 17. Time taken to produce the ELIJAH intervention

\begin{tabular}{|c|c|c|c|}
\hline & $\begin{array}{l}\text { Time taken in } \\
\text { minutes }\end{array}$ & Frequency & Total in minutes \\
\hline Requesting notes & $\begin{array}{l}1 \\
2 \\
3 \\
4 \\
5 \\
25 \\
30\end{array}$ & $\begin{array}{l}18 \\
11 \\
6 \\
2 \\
1 \\
1 \\
1\end{array}$ & 126 \\
\hline Reading notes & $\begin{array}{l}2 \\
3 \\
4 \\
5 \\
6 \\
7 \\
8 \\
9 \\
10 \\
11 \\
12 \\
13 \\
14 \\
15 \\
17 \\
19 \\
21 \\
24 \\
\end{array}$ & $\begin{array}{l}2 \\
4 \\
3 \\
5 \\
3 \\
2 \\
1 \\
2 \\
1 \\
2 \\
1 \\
1 \\
3 \\
3 \\
2 \\
1 \\
2 \\
2 \\
\end{array}$ & 398 \\
\hline $\begin{array}{l}\text { Accessing GeneCIS } \\
\text { information }\end{array}$ & $\begin{array}{l}1 \\
2 \\
3 \\
4 \\
6 \\
8 \\
11 \\
17 \\
\end{array}$ & $\begin{array}{l}11 \\
15 \\
9 \\
1 \\
1 \\
1 \\
1 \\
1 \\
\end{array}$ & 114 \\
\hline $\begin{array}{l}\text { Completing ELIJAH } \\
\text { questionnaire }\end{array}$ & $\begin{array}{l}2 \\
3 \\
4 \\
5 \\
6 \\
7 \\
8 \\
9 \\
10 \\
11 \\
12 \\
13 \\
14 \\
\end{array}$ & $\begin{array}{l}1 \\
4 \\
5 \\
3 \\
3 \\
1 \\
1 \\
2 \\
3 \\
1 \\
5 \\
2 \\
4 \\
\end{array}$ & 410 \\
\hline
\end{tabular}




\begin{tabular}{|l|l|l|l|}
\hline & 15 & 1 & \\
& 19 & 1 & \\
& 21 & 1 & \\
& 27 & 1 & \\
\hline Printing and sending & 45 & 1 & 146 \\
reports & 1 & 2 & \\
& 2 & 15 & \\
& 3 & 8 & \\
& 4 & 6 & \\
& 5 & 2 & \\
& 6 & 4 & \\
& 7 & 1 & \\
& 12 & 1 & \\
& 13 & 1 & \\
\hline
\end{tabular}


Appendix 18. List of ELIJAH Adverse Events

\begin{tabular}{|c|c|c|}
\hline Adverse Event & $\begin{array}{l}\text { Frequency AE } \\
\text { reported / identified }\end{array}$ & $\begin{array}{l}\text { Likely linked to } \\
\text { IBD }\end{array}$ \\
\hline ? Diagnosis & 1 & \\
\hline ? Sebaceous Keratosis & 1 & \\
\hline Abdominal pain & 1 & Yes \\
\hline Acne & 1 & \\
\hline Adhesive capsulitis & 1 & \\
\hline Admission postponed & 1 & \\
\hline Admitted unwell & 1 & \\
\hline $\mathrm{AF}$ & 1 & \\
\hline Angina & 1 & \\
\hline Ankle pain & 1 & \\
\hline Anxiety & 2 & \\
\hline AXR \& CT & 1 & \\
\hline Baf through & 1 & \\
\hline Backache & 1 & \\
\hline Banged head & 1 & \\
\hline Bheplorins & 1 & \\
\hline Blurry vision & 1 & \\
\hline Burning in feet & 1 & \\
\hline Burning on tongue & 1 & \\
\hline Campylobacter & 1 & \\
\hline Cataract extraction & 2 & \\
\hline Cataracts & 1 & \\
\hline Cervicalgia & 1 & \\
\hline Chest infection & 3 & \\
\hline Circumcision & 1 & \\
\hline Coccyx pain & 1 & \\
\hline Colectomy & 1 & \\
\hline Collapse & 2 & \\
\hline Colonoscopy & 4 & \\
\hline Conjunctivitis & 1 & \\
\hline constipation & 2 & Yes \\
\hline Cough & 10 & \\
\hline Cough with blood & 1 & \\
\hline CT brain & 1 & \\
\hline Declined lung transplant & 1 & \\
\hline degenerative hip & 1 & \\
\hline DeQuervaim & 1 & \\
\hline Diarrhoea \& constipation & 1 & Yes \\
\hline Dog bite & 1 & \\
\hline Dry mouth & 1 & \\
\hline DVT & 1 & \\
\hline Dyspepsia & 1 & \\
\hline Dysuria & 1 & \\
\hline Ear inflammation & 1 & \\
\hline ear pain & 1 & \\
\hline Ear syringing & 1 & \\
\hline Ear wax & 1 & \\
\hline Eczema & 1 & \\
\hline $\mathrm{F} / \mathrm{sig}$ & 5 & \\
\hline
\end{tabular}




\begin{tabular}{|c|c|c|}
\hline Fall & 2 & \\
\hline Fistula burst & 1 & Yes \\
\hline Foot injury & 1 & \\
\hline Gout & 1 & \\
\hline $\mathrm{H}$ breath test & 2 & \\
\hline Hands numb & 1 & \\
\hline High CRP & 1 & Yes \\
\hline Hypoglycaemia & 1 & \\
\hline Increased IBD & 11 & Yes \\
\hline Indigestion & 1 & \\
\hline Infection & 2 & \\
\hline Inflammation & 1 & Yes \\
\hline Injury L hand & 1 & \\
\hline Iritis & 2 & Yes \\
\hline Itchy eyes & 2 & Yes \\
\hline Joint aspiration & 1 & \\
\hline Joint pain & 1 & \\
\hline L shoulder pain & 1 & \\
\hline Laceration $\mathrm{R}$ elbow & 2 & \\
\hline Lack of taste & 1 & \\
\hline Light-headedness & 1 & \\
\hline LOC & 1 & \\
\hline Loose bowels & 1 & Yes \\
\hline Lower abdo pain & 1 & Yes \\
\hline Lumbago & 2 & \\
\hline Lump R groin & 1 & \\
\hline Macular degeneration & 1 & \\
\hline Medical escalation & 1 & Yes \\
\hline memory loss & 1 & \\
\hline Mouth ulcer & 2 & Yes \\
\hline Neuropathic pain & 1 & \\
\hline Nocturnal defaecation & 1 & \\
\hline Nose bleed & 1 & \\
\hline Oral thrush & 1 & \\
\hline Osteoarthritis & 1 & \\
\hline Otalgia & 1 & \\
\hline Pain & 1 & \\
\hline Pain neck \& arm & 1 & \\
\hline Palpitations & 2 & \\
\hline Pellety stool & 1 & Yes \\
\hline Penile discharge & 1 & \\
\hline Peripheral neuropathy & 1 & \\
\hline Plantar fascitis & 1 & \\
\hline Pleuritic pain & 1 & \\
\hline PR blood & 3 & Yes \\
\hline Pseudomonous & 1 & \\
\hline $\mathrm{R}$ abdo pain & 1 & \\
\hline $\mathrm{R}$ groin pain & 1 & \\
\hline $\mathrm{R}$ hand pain & 1 & \\
\hline $\mathrm{R}$ hemicolectomy & 2 & \\
\hline $\mathrm{R}$ hernia repair & 1 & \\
\hline Rash & 2 & \\
\hline
\end{tabular}




\begin{tabular}{|l|l|l|}
\hline Rectal inflammation & 1 & Yes \\
\hline redness of ear & 1 & \\
\hline Retention of urine & 1 & \\
\hline Rhinitis & 1 & \\
\hline sagittal sinus thrombosis & 1 & \\
\hline Shave excision & 1 & \\
\hline sinusitis & 1 & \\
\hline Skin deterioration & 1 & \\
\hline Skin tags & 1 & \\
\hline SOB & 4 & \\
\hline Sore throat & 1 & Yes \\
\hline Start infliximab & 1 & \\
\hline Steroids & 1 & \\
\hline Swollen eye & 1 & \\
\hline Swollen finger & 1 & \\
\hline Swollen legs & 1 & \\
\hline Syringing ear wax & 1 & \\
\hline Testicular pain & 1 & \\
\hline TIA & 1 & \\
\hline Tingling & 1 & \\
\hline Tinnitus & 1 & \\
\hline Transferred hospital & 1 & \\
\hline TWOC & 1 & \\
\hline Unwell & 1 & \\
\hline Upper respiratory infection & 1 & \\
\hline Urinary incontinence & 2 & \\
\hline Urticuria & 1 & \\
\hline UTI & 7 & \\
\hline Vaginal discomfort & 2 & \\
\hline Vaginitis & 1 & \\
\hline Watery eye & 1 & \\
\hline Weight loss & 1 & \\
\hline Wound discharge & 1 & \\
\hline Wound infection & 1 & \\
\hline Wound R foot & 1 & \\
\hline X-ray foot & 1 & \\
\hline X-ray hand & 1 & \\
\hline X-ray pelvis & 1 & \\
\hline X-ray spine & & \\
\hline & 1 & \\
\hline
\end{tabular}




\section{Appendix 19: List of ISSQ Patient free text comments}

\section{Intervention patients}

\begin{tabular}{|c|c|c|c|c|}
\hline $\begin{array}{l}\text { Participant } \\
\text { number }\end{array}$ & Trimester & Comment & $\begin{array}{l}\text { Positive } \\
\text { comment }\end{array}$ & $\begin{array}{l}\text { Negative } \\
\text { comment }\end{array}$ \\
\hline 006 & Baseline & Very pleased, takes tablets - salazapyrenes. V. Good. & & \\
\hline \multirow[t]{4}{*}{019} & Baseline & $\begin{array}{l}\text { Condition varys from day to day have lived with it for many years } \\
\text { so have come to accept it. }\end{array}$ & & \\
\hline & 1 & $\begin{array}{l}\text { Sister/ I am sorry I can not give a date when I was diagnosed, as } \\
\text { mentioned I had problems when I was in my Teens. Also I am not } \\
\text { sure what my condition is supposed to be. }\end{array}$ & & \\
\hline & 2 & $\begin{array}{l}\text { Sister: sorry for the delay in filling your form. Did have a fall which } \\
\text { meant I was feeling depressed. As you know I have never } \\
\text { contacted you concerning my colitis only seen you at clinic. I do } \\
\text { have bad days it seems when a bit stressed out. But seems to be } \\
\text { soon ok. I have had this complaint for so long I just take it in my } \\
\text { stride. Thank you. }\end{array}$ & & \\
\hline & 3 & $\begin{array}{l}\text { I have lived with my condition many years. I have my good days } \\
\text { and bad. I am happy that you are able to keep looking after me } \\
\text { which is very reassuring. }\end{array}$ & & \\
\hline 020 & 1 & $\begin{array}{l}\text { Some days I am fine but other days I am in pain and in discomfort } \\
\text { and feel very bloated. However I have not experienced the nausea } \\
\text { or sickness that I had a few months ago. I am awaiting result n a } \\
\text { food allergy test that my GP did andhope to see a dietician. }\end{array}$ & & \\
\hline 023 & 3 & $\begin{array}{l}\text { I have a follow up appointment to see Prof. j. G. Williams on } \\
\text { March 7th } 2011 .\end{array}$ & & \\
\hline \multirow[t]{3}{*}{024} & 1 & Sometimes I do get a little down but then I buck up & & \\
\hline & 2 & Since taking prebiotic low fat yoghurt drink seem to be a lot better & & \\
\hline & 3 & I am a little bit anxious when it flares up & & \\
\hline \multirow[t]{3}{*}{032} & 2 & $\begin{array}{l}\text { Moderately depressed because I have an ongoing eye infection } \\
\text { and I have a school inspection due in February which is making me } \\
\text { feel very stressed. }\end{array}$ & & \\
\hline & 2 & $\begin{array}{l}\text { Sorry for delay in returning information. I have a school inspection } \\
\text { due and paperwork coming out of everywhere! Happy new year. }\end{array}$ & & \\
\hline & 3 & $\begin{array}{l}\text { Very satisfied with the care I receive from the staff at the } \\
\text { Endoscopy Unit at Neath Port Talbot Hospital. }\end{array}$ & & \\
\hline 036 & Baseline & Stressful to start with a lot of examinations. & & \\
\hline 050 & 3 & $\begin{array}{l}\text { I suffer badly from constipation. If I take anything things become } \\
\text { extreme. I only go out once a week to shop as I cant hold my } \\
\text { water. The surgery are very helpful with necessary equipment. } \\
\text { Thank you. }\end{array}$ & & \\
\hline 059 & Baseline & I hope that if selected I would like electronic contact & & \\
\hline
\end{tabular}




\begin{tabular}{|c|c|c|c|c|}
\hline & 2 & As for the last question; I am occassionally anxious or depressed. & & \\
\hline 069 & Baseline & I am diabetic - type 2 & & \\
\hline \multirow[t]{2}{*}{070} & 1 & $\begin{array}{l}\text { Q26 the problems mentioned do not have anything to do with } \\
\text { chrones PS sorry for the delay }\end{array}$ & & \\
\hline & 2 & $\begin{array}{l}\text { Just finished a course of steroids after a flare up over Christmas. I } \\
\text { simply got a repeat prescription and its now back to normal. }\end{array}$ & & \\
\hline 075 & 1 & $\begin{array}{l}\text { Phedra! Its been a while since I've seen you which isnt a bad thing } \\
\text { and I mean that in terms of my colitis!! Imogen is growing and } \\
\text { changing every day - cant believe she is } 6 \text { months old - on solids, } \\
\text { sitting up on her own and has found her voice! Anyway just a } \\
\text { quick hello, hope all's well with you. Love }\end{array}$ & & \\
\hline \multirow[t]{2}{*}{076} & 1 & $\begin{array}{l}\text { The middle box under pain + discomfort has been ticked because } \\
\text { today I am experiencing mild constipation, I have received advice } \\
\text { on how to help when this happens, which is useful to me. There is } \\
\text { also a fatty lump present in the exact place of the pain (low, left } \\
\text { side of stomach) I feel that this may be contributing to my } \\
\text { discomfort and will ask this question in the future }\end{array}$ & & \\
\hline & 3 & $\begin{array}{l}\text { From time to time I experience problems at work, some tasks I do } \\
\text { are difficult to carry out if I am having what I call "flare ups" - I also } \\
\text { find it awkward to be able to communicate this information at } \\
\text { work and therefore experience anxiety at times. }\end{array}$ & & \\
\hline 078 & 2 & The discomfort is merely the excess flatulence. & & \\
\hline \multirow[t]{3}{*}{084} & Baseline & $\begin{array}{l}\text { I am not in any pain, on suffering with my mobility at present, } \\
\text { although I do have flare ups when my joints are quite painful. I } \\
\text { also get bouts of anxioutus from time to time especially if I have to } \\
\text { go on long trips I fear I will not be able to access a toilet. } \\
\text { with regard to questions (14) I put severe because the constant } \\
\text { need for the toilet and passing blood in my stools which lasted a } \\
\text { few weeks. (15) the pain I experienced was not to bad its the } \\
\text { bleeding and urgent need for the toilet that is the worst. (26) I do } \\
\text { have some problems with mobility when I get a flare up my joints } \\
\text { go really stiff and inflammed I do get anxious at certain times. I am } \\
\text { afraid I may not make it to the toilet on time in work or if I am in } \\
\text { the car. }\end{array}$ & & \\
\hline & 2 & $\begin{array}{l}\text { As in the last questionnaire I do experience some anxiety } \\
\text { especially when I am having a flare up, I worry that I will not be } \\
\text { able to make it to the toilet on time and I get some joint pain at } \\
\text { the time of flare up as well as quite a bit of bleeding from bowel. It } \\
\text { seems to come on quite severe in autumn I am having trouble } \\
\text { with it at the moment. }\end{array}$ & & \\
\hline & 3 & $\begin{array}{l}\text { The pain and discomfort is in the immediate area of the flare up. I } \\
\text { do feel rather anxious and depressed when the flare up occurs. I } \\
\text { am quite well otherwise. }\end{array}$ & & \\
\hline 096 & Baseline & $\begin{array}{l}\text { Excellent care last time in hospital \& good aftercare good } \\
\text { azopyroththese good when help needed call was returned within } \\
\text { the hour. }\end{array}$ & & \\
\hline 117 & Baseline & $\begin{array}{l}\text { My bowel condition is not too much of a problem most of the time } \\
\text { but my general health is made difficult by emphysema. }\end{array}$ & & \\
\hline
\end{tabular}




\begin{tabular}{|c|c|c|c|}
\hline & 1 & $\begin{array}{l}\text { My bowel condition is manageble most of the time but I have } \\
\text { emphysema / COPD and so am very limited in what I can } \\
\text { physically achieve }\end{array}$ & \\
\hline & 3 & $\begin{array}{l}\text { I have answered the "care" questions with the assumption 'care' } \\
\text { means that which I receive at the endoscopy unit when my } \\
\text { condition has worsened. I've been fortunate in not requiring much } \\
\text { attention and have no care at home - I'm able to look after myself. } \\
\text { I am still waiting for a bone scan as recommended at my last } \\
\text { appointment at the endoscopy clinic. }\end{array}$ & \\
\hline \multirow[t]{3}{*}{133} & 1 & $\begin{array}{l}\text { Recently I have had problems which tried to sort out myself; I } \\
\text { visited my GP to ask for some asacol suppositories which he } \\
\text { refused to give me saying that yourself recommended that I have } \\
\text { Predfoam I would it be possible to write to my GP to let me have } \\
\text { have the asacol suppositories if needed again please, as I had } \\
\text { some in the house that I found and it cleared it up within a couple } \\
\text { of days. I tried to explain that I knew what I needed but he refused } \\
\text { point blank to give me what I knew would clear it. Thank you }\end{array}$ & \\
\hline & 2 & $\begin{array}{l}\text { I dont know if you had my last questionnaire which I sent back } \\
\text { about } 3 \text { wks ago, I did ask if you could inform my GP that if I get } \\
\text { problems in future that he could give me Asacol suppositories, he } \\
\text { would only give me Predfoam last time, I find asacol suppositories } \\
\text { suite my needs better and clear any problems up within days. }\end{array}$ & \\
\hline & 3 & $\begin{array}{l}\text { I can usually keep my condition under controll if it comes on I take } \\
\text { Asacol supp. And at the moment it clears it up in the course of } 7 \\
\text { days if it doesent then I would get in touch with yourselfs but as } \\
\text { long as I take a fair amount of fruit and fibre based foods it keeps } \\
\text { it at bay. }\end{array}$ & \\
\hline \multirow[t]{3}{*}{134} & 1 & $\begin{array}{l}\text { My condition is good the last few years with no problems. I try not } \\
\text { to get stressed with anything anymore. Stress free and slowing } \\
\text { down my pace of life helps keep this condition at bay. }\end{array}$ & \\
\hline & 2 & No problems with my health recently. No symptoms at all. & \\
\hline & 3 & $\begin{array}{l}\text { Recently I have experienced "bloatyness" of my stomach and on a } \\
\text { few occassions extreme pain from trapped wind - much more than } \\
\text { over the past few years. Not sure if this is due to UC. }\end{array}$ & \\
\hline \multirow[t]{3}{*}{138} & Baseline & $\begin{array}{l}\text { Following a hernia operation, I have had very troublesome } \\
\text { diarrhoea, which I reported to the surgeon on my return visit to } \\
\text { the hospital he referred me to the endoscopy unit and on my } \\
\text { second visit I was given some tablets which have helped }\end{array}$ & \\
\hline & 2 & $\begin{array}{l}\text { Sister Phedra was very kind and patient. When i saw the doctor on } \\
\text { my last visit, he seemed to think I did not have Crohn's disease. } \\
\text { But a condition caused by my diabetes. I have another visit in } \\
\text { February to see Professor Williams. }\end{array}$ & \\
\hline & 3 & $\begin{array}{l}\text { I have had diarrhoea since August } 209 \text { following a hernia } \\
\text { operation. I also have diabetes and on insulin and metformin since } \\
\text { around } 1994 \text {. I did ? The metformin with my GP and he did not } \\
\text { think it was the tablets because I did not have any symptoms for } \\
\text { about } 4 \text { years before I had the operation. }\end{array}$ & \\
\hline \multirow[t]{2}{*}{154} & 2 & Been fine for several years now & \\
\hline & 3 & Fit as a fiddle! & \\
\hline
\end{tabular}




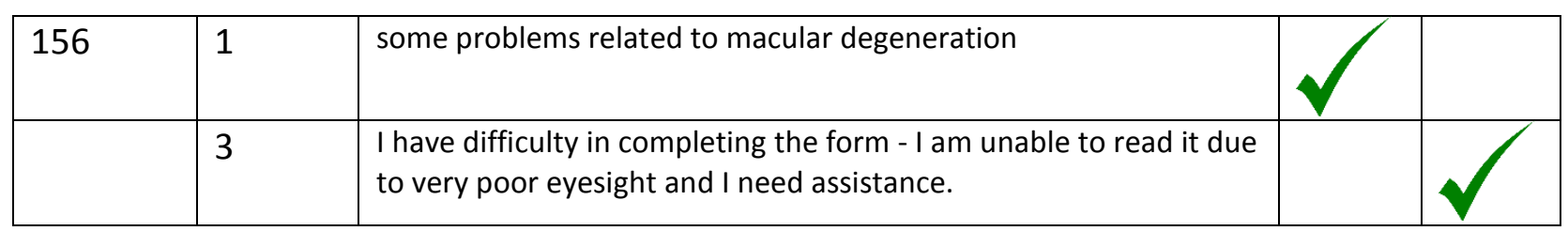

\section{Control patients}

\begin{tabular}{|c|c|c|c|c|}
\hline $\begin{array}{l}\text { Participant } \\
\text { Number }\end{array}$ & Trimester & Comment & $\begin{array}{l}\text { Positive } \\
\text { comment }\end{array}$ & $\begin{array}{l}\text { Negative } \\
\text { comment }\end{array}$ \\
\hline 004 & Baseline & $\begin{array}{l}\text { I was offered medication for my condition. I declined and visited a } \\
\text { homeopath instead. I noticed an improvement within hours and } \\
\text { that improvement continued. I have had no symptoms since } 2007 \text {. }\end{array}$ & & \\
\hline \multirow[t]{4}{*}{017} & Baseline & $\begin{array}{l}\text { On occasion I am moderately anxious + stressed - work related } \\
\text { triggers. I suffer from numerous allergies + sometimes find links } \\
\text { between flare up's + food/ chemicals (laxitives) }\end{array}$ & & \\
\hline & 1 & $\begin{array}{l}\text { After my appointment in July I was given the option of when to } \\
\text { receive a follow-up appointment, this being because I am trying to } \\
\text { conceive. I chose } 3 \text { months. I havent recieved an appointment and } \\
\text { its been over } 4 \text { months. I have had small flare-ups, but have self } \\
\text { managed the condition. I have been pro-active and com pleted an } \\
\text { 'expert patient programme', through my workplace. It would be } \\
\text { hugely beneficial if I were able to email regarding flare-ups, for } \\
\text { advice etc. Sorry this is late, I've been on holiday. Thank you. }\end{array}$ & & \\
\hline & 2 & $\begin{array}{l}\text { This is the third questionnaire I have filled out and sent back in } \\
\text { just over a month, either the mail isnt reaching the department or } \\
\text { getting to the hospital. } 2 \text {. I wish I could contact via email - as I can } \\
\text { only contact during the day/worktime and its an embarrasing } \\
\text { problem (I work in a male environment). 3. I was given the choice } \\
\text { of when to have a follow up appointment - as I was/am trying to } \\
\text { conceive I chose } 3 \text { months, back in June/july - its been more than } \\
3 \text { months and I haven't heard anything. When I do get treatment / } \\
\text { advice from my nurse practitioner its always fantastic, but its just } \\
\text { getting there/contact for advice/ appointments that dissapoint } \\
\text { me. }\end{array}$ & & \\
\hline & 3 & $\begin{array}{l}\text { I am very happy with the care I receive. I did however turn up to } \\
\text { an appointment that had been made for me to be told that it had } \\
\text { been rescheduled, however both letters I received hadnt } \\
\text { mentioned that at all, I received a very cold reception when I was } \\
\text { unhappy about making a wasted journey. In fact it was quite } \\
\text { accusational, but I let it go. Just thought it was worth mentioning } \\
\text { here - even if it is admin and not care. }\end{array}$ & & \\
\hline \multirow[t]{2}{*}{042} & 1 & $\begin{array}{l}\text { I have not had a problem for a long time if I should again I would } \\
\text { get in touch with Sr Phedra Dodds immediately. I concider myself } \\
\text { very lucky to have a son and daughter and grand children who } \\
\text { help my husband and I a lot such as helping with housework \& } \\
\text { shopping, my son in law is also a good helper. We are so lucky } \\
\text { they are true carers. I suffer from rhumatoid arthritis but } \\
\text { medication keeps it at bay. }\end{array}$ & & \\
\hline & 1 & $\begin{array}{l}\text { I have no pain at all, but if I eat too much chocolate or take gravy } \\
\text { made from juices of a meat joint then I am in trouble and spend a } \\
\text { lot of time in the toilet. I have learnt to avoid both. Hope this is of } \\
\text { help for you. }\end{array}$ & & \\
\hline 044 & Baseline & Note: spondulitis affects my ability more than the Chrones & & \\
\hline
\end{tabular}




\begin{tabular}{|c|c|c|c|c|}
\hline & 3 & $\begin{array}{l}\text { Please note: I also have spondulitis which is the main cause for } \\
\text { mobility and usual activities }\end{array}$ & & \\
\hline \multirow[t]{3}{*}{047} & 1 & $\begin{array}{l}\text { Mobility. I an very awry of going anywhere if I am not sure about } \\
\text { the provision of public toilets. }\end{array}$ & & \\
\hline & 2 & $\begin{array}{l}\text { Mobility. I would be happier if there were more public } \\
\text { conveniences open - as there were } 20 \text { years ago. }\end{array}$ & & \\
\hline & 3 & $\begin{array}{l}\text { Some problems - due to a flare up last week - I was concerned } \\
\text { about going out due to the } \\
\text { lack of public toilets. }\end{array}$ & & \\
\hline \multirow[t]{3}{*}{049} & 1 & $\begin{array}{l}\text { Since the last time I saw you (Phedra Dodds) believing it to be } \\
\text { wind and bloatedness. I am extremely tired and lifeless. Relating } \\
\text { to question } 3 \text { I feel I have not recieved enough information on my } \\
\text { condition and would like reading material to help me understand } \\
\text { and cope with the symptoms. }\end{array}$ & & \\
\hline & 2 & $\begin{array}{l}\text { Dear Phedra, Sorry about the delay in sending this form. I havn't } \\
\text { been up to standard. Everything seems to be ok at the moment, } \\
\text { still getting severe stomach cramps at time. Will explain during my } \\
\text { next appointment with you. Hope my answers are ok. Many } \\
\text { thanks. }\end{array}$ & & \\
\hline & 3 & $\begin{array}{l}\text { Everything is going well at the moment but I know that if needed I } \\
\text { can contact the department and get an appointment with any } \\
\text { worries or problems I may have. My usual appointment s are with } \\
\text { Phedra and my next one is not until July / August. Many thanks }\end{array}$ & & \\
\hline 090 & Baseline & I have multiple medical conditions & & \\
\hline \multirow[t]{3}{*}{091} & 1 & $\begin{array}{l}\text { Pain or discomfort I have only occasional discomfort which I am } \\
\text { well able to cope with. Many thanks for your continued help and } \\
\text { support. }\end{array}$ & & \\
\hline & 2 & $\begin{array}{l}\text { Apart fr om the occasional mild flare up I have been able to } \\
\text { manage my condition by various diet and eating habit changes. }\end{array}$ & & \\
\hline & 3 & $\begin{array}{l}\text { I am confident that the support is there if needed. Since my } \\
\text { condition was diagnosed in March } 07 \text { and the initial course of } \\
\text { medication completed I have experienced mild flare ups. Being of } \\
\text { a minor nature this has not induced me to seek care. My state of } \\
\text { health today is very good. }\end{array}$ & & \\
\hline \multirow[t]{2}{*}{104} & Baseline & Forgot glasses & & \\
\hline & 2 & $\begin{array}{l}\text { I can only say regarding when I was diagnosed with my condition } \\
\text { that it was in the "old neath hospital" by Professor Williams }\end{array}$ & & \\
\hline \multirow[t]{3}{*}{105} & 1 & Question 26 answers are for rheumatoid arthritis & & \\
\hline & 2 & The above answers are more to do with rheumatoid arthritis & & \\
\hline & 3 & $\begin{array}{l}\text { The discomfort and pain I experience is from rheumatoid arthritis } \\
\text { which I am now on treatment for. }\end{array}$ & & \\
\hline \multirow[t]{2}{*}{109} & Baseline & $\begin{array}{l}\text { My last coloscopy showed no sign of ulcerative colitis after } 45 \text { yrs. } \\
\text { I trust that God has healed me. }\end{array}$ & & \\
\hline & 1 & $\begin{array}{l}\text { I am totally satisfied with the care and treatment I have had in the } \\
\text { past }\end{array}$ & & \\
\hline
\end{tabular}




\begin{tabular}{|c|c|c|c|c|}
\hline & 3 & I appreciate very much the excellent care I have received. & & \\
\hline 127 & Baseline & $\begin{array}{l}\text { I have never queried Doctors remarks or made any extra queries } \\
\text { outside of surgery }\end{array}$ & & \\
\hline & 1 & I have to know where the nearest toilet location is. & & \\
\hline & 2 & $\begin{array}{l}\text { Started reducing medication of asathioprine from } 3 \text { - } 2 \text { on } 12 \text { Oct. } \\
\text { Then from } 2-1 \text { on } 30 \text { Nov. }\end{array}$ & & \\
\hline & 3 & I have never asked for help other than my regular appointment. & & \\
\hline
\end{tabular}




\section{Appendix 20. ELIJAH budget}

\begin{tabular}{|l|l|}
\hline Amount awarded & $£ 74,336.00$ \\
\hline
\end{tabular}

\begin{tabular}{|c|c|c|}
\hline Type of cost & Budgeted (total) $f$ & Spend (total) $f$ \\
\hline Project Manager 0.4 WTE & 18,336 & 18,153 \\
\hline Project Setup & 1,000 & 0 \\
\hline Health Economics & 5,000 & 5,000 \\
\hline Data Management & 5,000 & 6,055 \\
\hline Travelling & 1,000 & 1,120 \\
\hline Technical Support & 42,000 & 42000 \\
\hline User Costs & 2,000 & 1,680 \\
\hline Incidental & 0 & 328 \\
\hline Total & 74,336 & 74,336 \\
\hline
\end{tabular}


Appendix 21. PRISMA checklist 2009

\begin{tabular}{|c|c|}
\hline Section / & PRISMA 2009 \\
\hline topic & No. Item \\
\hline Title & 1 Identify the report as a systematic review, meta-analysis, or both \\
\hline Abstract & \\
\hline $\begin{array}{l}\text { Structured } \\
\text { summary }\end{array}$ & $\begin{array}{l}2 \text { Provide a structured summary including, as applicable: background; objectives; } \\
\text { data sources; study eligibility criteria, participants, and interventions, study } \\
\text { appraisal and synthesis methods; results; limitations; conclusions \& implications of } \\
\text { key findings; systematic review registration number }\end{array}$ \\
\hline Introduction & \\
\hline Rationale & 3 Describe the rationale for the review in the context of what is already known \\
\hline Objectives & $\begin{array}{l}4 \text { Provide an explicit statement of questions being addressed with reference to } \\
\text { participants, interventions, comparisons, outcomes, and study design (PICOS) }\end{array}$ \\
\hline Methods & \\
\hline $\begin{array}{l}\text { Protocol \& } \\
\text { registration }\end{array}$ & $\begin{array}{l}5 \text { Indicate if a review protocol exists, if } \& \text { where it can be accessed (e.g. Web } \\
\text { address), and, if available, provide registration information including registration } \\
\text { number }\end{array}$ \\
\hline $\begin{array}{l}\text { Eligibility } \\
\text { criteria }\end{array}$ & $\begin{array}{l}6 \text { Specify study characteristics (e.g. PICOS, length of follow up) \& report } \\
\text { characteristics (e.g. years considered, language, publication status) used as criteria } \\
\text { for eligibility, giving rationale }\end{array}$ \\
\hline $\begin{array}{l}\text { Information } \\
\text { sources }\end{array}$ & $\begin{array}{l}7 \text { Describe all information sources (e.g. databases with dates of coverage, contact } \\
\text { with study authors to identify additional studies) in the search and date last } \\
\text { searched }\end{array}$ \\
\hline Search & $\begin{array}{l}8 \text { Present full electronic search strategy for at least one database, including any } \\
\text { limits used, such that it could be repeated }\end{array}$ \\
\hline $\begin{array}{l}\text { Study } \\
\text { selection }\end{array}$ & $\begin{array}{l}9 \text { State the process for selecting studies (i.e. screening, eligibility, included in } \\
\text { systematic review, and, if applicable, included in the meta-analysis). }\end{array}$ \\
\hline Data & 10 Describe method of data extraction from reports (e.g. piloted forms, \\
\hline $\begin{array}{l}\text { collection } \\
\text { process }\end{array}$ & $\begin{array}{l}\text { independently, in duplicate) } \& \text { any processes for obtaining } \& \text { confirming data from } \\
\text { investigators }\end{array}$ \\
\hline Data items & $\begin{array}{l}11 \text { List \& define all variables for which data were sought (e.g. PICOS, funding } \\
\text { sources) \& any assumptions \& simplifications made }\end{array}$ \\
\hline $\begin{array}{l}\text { Risk of bias in } \\
\text { individual } \\
\text { studies }\end{array}$ & $\begin{array}{l}12 \text { Describe methods used for assessing risk of bias of individual studies ( including } \\
\text { specification of whether this was done at the study or outcome level), \& how this } \\
\text { information is to be used in any data synthesis }\end{array}$ \\
\hline $\begin{array}{l}\text { Summary } \\
\text { measures }\end{array}$ & 13 State the principle summary measures (e.g. risk ration, difference in terms) \\
\hline $\begin{array}{l}\text { Synthesis of } \\
\text { results }\end{array}$ & $\begin{array}{l}14 \text { Describe the methods of handling data and combining results of studies, if } \\
\left.\text { done, including measures of consistence (e.g. }\left.\right|^{2}\right) \text { for each meta analysis }\end{array}$ \\
\hline $\begin{array}{l}\text { Risk of bias } \\
\text { across studies }\end{array}$ & $\begin{array}{l}15 \text { Specify any assessment of risk of bias that may affect the cumulative evidence } \\
\text { (e.g. publication bias, selective reporting within studies) }\end{array}$ \\
\hline $\begin{array}{l}\text { Additional } \\
\text { analyses }\end{array}$ & $\begin{array}{l}16 \text { Describe methods of additional analyses (e.g. sensitivity or subgroup analyses, } \\
\text { meta-regression), if done, indicating which were pre-specified }\end{array}$ \\
\hline Results & \\
\hline $\begin{array}{l}\text { Study } \\
\text { selection }\end{array}$ & $\begin{array}{l}17 \text { Give numbers of studies screened, assessed for eligibility, \& included in the } \\
\text { review, with reasons for exclusions at each stage, ideally with a flow diagram }\end{array}$ \\
\hline
\end{tabular}




\section{Study}

characteristics

Risk of bias

within studies

Results of

individual

studies

Synthesis of

results

Risk of bias

across studies

Additional

analysis

Discussion

Summary of

evidence

Limitations

Conclusions

Funding

Funding
18 For each study, present characteristics for which data were extracted (e.g. study size, PICOS, follow up period) \& provide the citations

19 Present data on risk of bias of each study and, if available, any outcome level assessment

20 For all outcomes considered (benefits or harms), present, for each study: (a) simple summary data for each intervention group (b) effect estimates and confidence intervals, ideally with a forest plot

21 Present results of each meta-analysis done, including confidence intervals and measures of consistency

22 Present results of any assessment of risk of bias across studies

Give results of additional analysis, if done (e.g. sensitivity or subgroup analyses, meta regression)

24 Summarise the main findings including the strength of evidence for each main outcome; consider their relevance to key groups (e.g. healthcare providers, users \& policy makers)

25 Discuss limitations at study \& outcome level (e.g. risk of bias), \& at review-level (e.g. incomplete retrieval of identified research, reporting bias)

26 Provide a general interpretation of the results in the context of other evidence, \& implications for further research

27 Describe sources of funding for the systematic review \& other support (e.g. supply of data); role of funders for the systematic review

Ref: Moher D., Liberati A., Tetzlaff J., Altman D., The PRISMA Group. (2009). Preferred Reporting Items for Systematic Reviews and Meta-analyses: The PRISMA Statement. PLoS Med 6(7): e1000097. Doi:10.1371/journal.pmed.1000097 
Appendix 22: Search strategy and findings

\begin{tabular}{|l|l|l|}
\hline Electronic database & $\begin{array}{l}\text { Number of articles } \\
\text { identified and appraised }\end{array}$ & $\begin{array}{l}\text { Number of articles } \\
\text { included in the } \\
\text { systematic literature } \\
\text { review }\end{array}$ \\
\hline AMED & 69 & $\mathbf{0}$ \\
\hline BNI & 40 & $\mathbf{0}$ \\
\hline CINAHL & 35 & $\mathbf{0}$ \\
\hline Cochrane & 40 & $\mathbf{4}$ \\
\hline EMBASE & 76 & $\mathbf{0}$ \\
\hline EMCARE & 27 & $\mathbf{3}$ \\
\hline Google Scholar & 13 & $\mathbf{1 2}$ \\
\hline Medline & 559 & $\mathbf{1 9}$ \\
\hline Other & - & $\mathbf{5}$ \\
\hline Psychinfo & 44 & $\mathbf{2}$ \\
\hline TRIP & 13 & $\mathbf{0}$ \\
\hline Web of Science & 300 & $\mathbf{2 0}$ \\
\hline
\end{tabular}


Appendix 23. Quality scoring of articles

\begin{tabular}{|c|c|c|c|c|c|c|c|c|}
\hline $\begin{array}{l}\text { Article } \\
\text { number }\end{array}$ & Author & $\begin{array}{l}\text { Selection } \\
\text { bias }\end{array}$ & Design & Confounders & Blinding & $\begin{array}{l}\text { Data } \\
\text { collection }\end{array}$ & Withdrawals & \begin{tabular}{|l|} 
Total \\
score
\end{tabular} \\
\hline 1. & Al-Sahan A. & 0 & 0 & 0 & 0 & 2 & 0 & 2 \\
\hline 2. & $\begin{array}{l}\text { Archer J.S. } \\
\text { et al. }\end{array}$ & N/A & N/A & N/A & N/A & N/A & N/A & N/A \\
\hline 3. & $\begin{array}{l}\text { Bartlett C. } \\
\text { et al. }\end{array}$ & 0 & 0 & 0 & 0 & 0 & 0 & 0 \\
\hline 4. & $\begin{array}{l}\text { Bell S.K. et } \\
\text { al. }\end{array}$ & 0 & 0 & 0 & 0 & 0 & 0 & 0 \\
\hline 5. & $\begin{array}{l}\text { Bhavnani V. } \\
\text { et al. }\end{array}$ & 0 & 1 & 0 & 0 & 0 & 1 & 2 \\
\hline 6. & $\begin{array}{l}\text { Bidmead E. } \\
\text { et al. }\end{array}$ & 0 & 0 & 0 & 0 & 0 & 0 & 0 \\
\hline 7. & $\begin{array}{l}\text { Casey I. et } \\
\text { al }\end{array}$ & 0 & 0 & 0 & 0 & 1 & 0 & 1 \\
\hline 8. & $\begin{array}{l}\text { Chunchu J.J. } \\
\text { et al. }\end{array}$ & 0 & 1 & 0 & 0 & 1 & 2 & 4 \\
\hline 9. & $\begin{array}{l}\text { Cimino J.J. } \\
\text { et al. }\end{array}$ & 0 & 0 & 0 & 0 & 0 & 1 & 1 \\
\hline 10. & $\begin{array}{l}\text { Cimino J.J. } \\
\text { et al. }\end{array}$ & 0 & 0 & 0 & 0 & 1 & 0 & 1 \\
\hline 11. & $\begin{array}{l}\text { Cimino J.J. } \\
\text { et al. } \\
\end{array}$ & 0 & 0 & 0 & 0 & 0 & 1 & 1 \\
\hline 12. & $\begin{array}{l}\text { Cruickshank } \\
\text { J. et al }\end{array}$ & 0 & 0 & 0 & 0 & 0 & 0 & 0 \\
\hline 13. & $\begin{array}{l}\text { Di Marco C. } \\
\text { et al. }\end{array}$ & $\mathrm{N} / \mathrm{A}$ & N/A & N/A & N/A & N/A & N/A & N/A \\
\hline 14. & $\begin{array}{l}\text { Druss B.G. } \\
\text { et al. }\end{array}$ & 2 & 2 & 0 & 0 & 1 & 2 & 7 \\
\hline 15. & $\begin{array}{l}\text { Farrelly S. } \\
\text { et al. }\end{array}$ & N/A & N/A & N/A & N/A & N/A & $\mathrm{N} / \mathrm{A}$ & N/A \\
\hline 16. & $\begin{array}{l}\text { Ferreira A. } \\
\text { et al. }\end{array}$ & N/A & N/A & N/A & N/A & N/A & N/A & N/A \\
\hline 17. & $\begin{array}{l}\text { Fisher B. et } \\
\text { al. }\end{array}$ & 0 & 0 & 0 & 0 & 0 & 0 & 0 \\
\hline 18. & $\begin{array}{l}\text { Forbes M. } \\
\text { et al. }\end{array}$ & 1 & 2 & 0 & 0 & 1 & 2 & 6 \\
\hline 19. & $\begin{array}{l}\text { Garcia- } \\
\text { Lizana F. et } \\
\text { al. }\end{array}$ & N/A & N/A & N/A & N/A & N/A & N/A & N/A \\
\hline 20. & $\begin{array}{l}\text { Gee P.M. et } \\
\text { al. }\end{array}$ & N/A & N/A & N/A & N/A & N/A & N/A & N/A \\
\hline 21. & $\begin{array}{l}\text { Gerard M. } \\
\text { et al. }\end{array}$ & 0 & 0 & 0 & 0 & 1 & 0 & 1 \\
\hline 22. & $\begin{array}{l}\text { Giardina } \\
\text { T.D. et al. }\end{array}$ & N/A & N/A & N/A & N/A & N/A & N/A & N/A \\
\hline 23. & $\begin{array}{l}\text { Greenberg } \\
\text { A.J. et al. }\end{array}$ & 1 & 1 & 0 & 0 & 1 & 0 & 3 \\
\hline 24. & $\begin{array}{l}\text { Hassol A. et } \\
\text { al. }\end{array}$ & 0 & 1 & 0 & 0 & 1 & 0 & 2 \\
\hline 25. & $\begin{array}{l}\text { Hemsley B. } \\
\text { et al. }\end{array}$ & N/A & N/A & N/A & N/A & N/A & N/A & N/A \\
\hline 26. & $\begin{array}{l}\text { Honeyman } \\
\text { A. et al. }\end{array}$ & 1 & 1 & 0 & 0 & 1 & 0 & 3 \\
\hline
\end{tabular}




\begin{tabular}{|c|c|c|c|c|c|c|c|c|}
\hline 27. & $\begin{array}{l}\text { Jeong D.E. } \\
\text { et al. }\end{array}$ & 0 & 1 & 0 & 0 & 1 & 0 & 2 \\
\hline 28. & $\begin{array}{l}\text { Kerns J.W. } \\
\text { et al }\end{array}$ & 0 & 0 & 0 & 0 & 1 & 0 & 1 \\
\hline 29. & $\begin{array}{l}\text { Kelstrup } \\
\text { A.M. et al. }\end{array}$ & 2 & 1 & 0 & 0 & 1 & 2 & 6 \\
\hline 30. & $\begin{array}{l}\text { Khaneghan } \\
\text { P.A. et al. }\end{array}$ & 0 & 1 & 0 & 0 & 1 & 0 & 2 \\
\hline 31. & Ko H. et al. & $\mathrm{N} / \mathrm{A}$ & $\mathrm{N} / \mathrm{A}$ & $\mathrm{N} / \mathrm{A}$ & $\mathrm{N} / \mathrm{A}$ & $\mathrm{N} / \mathrm{A}$ & N/A & N/A \\
\hline 32. & $\begin{array}{l}\text { Laugesen J. } \\
\text { et al. }\end{array}$ & 1 & 2 & 0 & 1 & 2 & 1 & 7 \\
\hline 33. & $\begin{array}{l}\text { Masys D. et } \\
\text { al. }\end{array}$ & 0 & 0 & 0 & 0 & 1 & 1 & 2 \\
\hline 34. & $\begin{array}{l}\text { McKinstry } \\
\text { B. et al. }\end{array}$ & 0 & 2 & 1 & 1 & 2 & 2 & 8 \\
\hline 35. & $\begin{array}{l}\text { Mold F. et } \\
\text { al }\end{array}$ & N/A & N/A & $\mathrm{N} / \mathrm{A}$ & N/A & N/A & N/A & N/A \\
\hline 36. & $\begin{array}{l}\text { Muhamma } \\
\text { d R. et al. }\end{array}$ & N/A & N/A & $\mathrm{N} / \mathrm{A}$ & N/A & N/A & N/A & N/A \\
\hline 37. & $\begin{array}{l}\text { Nahm E-S. } \\
\text { et al. }\end{array}$ & 1 & 2 & 0 & 1 & 1 & 2 & 7 \\
\hline 38. & $\begin{array}{l}\text { Palen T.E. } \\
\text { et al. }\end{array}$ & 0 & 1 & 0 & 0 & 1 & 0 & 2 \\
\hline 39. & $\begin{array}{l}\text { Papoutsi C. } \\
\text { et al. }\end{array}$ & 0 & 0 & 0 & 0 & 0 & 0 & 0 \\
\hline 40. & $\begin{array}{l}\text { Pavlik V. et } \\
\text { al. }\end{array}$ & 2 & 2 & 1 & 0 & 1 & 2 & 8 \\
\hline 41. & $\begin{array}{l}\text { Phelps R.G. } \\
\text { et al. }\end{array}$ & 0 & 1 & 0 & 0 & 1 & 0 & 2 \\
\hline 42. & $\begin{array}{l}\text { Politi P. et } \\
\text { al. }\end{array}$ & 0 & 1 & 1 & 0 & 1 & 0 & 3 \\
\hline 43. & $\begin{array}{l}\text { Powell H. et } \\
\text { al. }\end{array}$ & $\mathrm{N} / \mathrm{A}$ & $\mathrm{N} / \mathrm{A}$ & $\mathrm{N} / \mathrm{A}$ & $\mathrm{N} / \mathrm{A}$ & $\mathrm{N} / \mathrm{A}$ & N/A & N/A \\
\hline 44. & $\begin{array}{l}\text { Price M. et } \\
\text { al. }\end{array}$ & 0 & 1 & 0 & 0 & 1 & 0 & 2 \\
\hline 45. & $\begin{array}{l}\text { Price M.M. } \\
\text { et al. }\end{array}$ & N/A & N/A & $\mathrm{N} / \mathrm{A}$ & $\mathrm{N} / \mathrm{A}$ & N/A & N/A & N/A \\
\hline 46. & $\begin{array}{l}\text { Riippa I. et } \\
\text { al. }\end{array}$ & 0 & 1 & 0 & 0 & 1 & 0 & 2 \\
\hline 47. & $\begin{array}{l}\text { Ross S.E. et } \\
\text { al. }\end{array}$ & N/A & $\mathrm{N} / \mathrm{A}$ & $\mathrm{N} / \mathrm{A}$ & $\mathrm{N} / \mathrm{A}$ & N/A & N/A & N/A \\
\hline 48. & $\begin{array}{l}\text { Ross S.E. et } \\
\text { al. }\end{array}$ & 1 & 1 & 0 & 0 & 1 & 1 & 4 \\
\hline 49. & $\begin{array}{l}\text { Royal } \\
\text { College of } \\
\text { Physicians }\end{array}$ & 0 & 0 & 0 & 0 & 1 & 2 & 3 \\
\hline 50. & $\begin{array}{l}\text { Royal } \\
\text { College of } \\
\text { Physicians }\end{array}$ & N/A & N/A & N/A & N/A & N/A & N/A & N/A \\
\hline 51. & $\begin{array}{l}\text { Royal } \\
\text { College of } \\
\text { Physicians }\end{array}$ & N/A & N/A & $\mathrm{N} / \mathrm{A}$ & $\mathrm{N} / \mathrm{A}$ & N/A & N/A & $\mathrm{N} / \mathrm{A}$ \\
\hline 52. & $\begin{array}{l}\text { Royal } \\
\text { College of } \\
\text { Physicians }\end{array}$ & N/A & N/A & $\mathrm{N} / \mathrm{A}$ & $\mathrm{N} / \mathrm{A}$ & N/A & N/A & N/A \\
\hline
\end{tabular}




\begin{tabular}{|c|c|c|c|c|c|c|c|c|}
\hline 53. & \begin{tabular}{|l} 
Royal \\
College of \\
Physicians
\end{tabular} & N/A & N/A & $\mathrm{N} / \mathrm{A}$ & N/A & $\mathrm{N} / \mathrm{A}$ & $\mathrm{N} / \mathrm{A}$ & N/A \\
\hline 54. & \begin{tabular}{|l|} 
Royal \\
College of \\
Physicians
\end{tabular} & N/A & N/A & N/A & N/A & N/A & N/A & N/A \\
\hline 55. & \begin{tabular}{|l|} 
Royal \\
College of \\
Physicians \\
\end{tabular} & 0 & 0 & 0 & 0 & 2 & 2 & 4 \\
\hline 56. & $\begin{array}{l}\text { Sartain S.A. } \\
\text { et al. }\end{array}$ & N/A & N/A & $\mathrm{N} / \mathrm{A}$ & N/A & N/A & $\mathrm{N} / \mathrm{A}$ & N/A \\
\hline 57. & Showell C. & N/A & N/A & $\mathrm{N} / \mathrm{A}$ & N/A & N/A & $\mathrm{N} / \mathrm{A}$ & N/A \\
\hline 58. & $\begin{array}{l}\text { Somner } \\
\text { J.E.A. et al. }\end{array}$ & 0 & 1 & 0 & 0 & 0 & 1 & 2 \\
\hline 59. & $\begin{array}{l}\text { Tenforde } \\
\text { M. et al. }\end{array}$ & N/A & N/A & $\mathrm{N} / \mathrm{A}$ & N/A & N/A & $\mathrm{N} / \mathrm{A}$ & N/A \\
\hline 60. & $\begin{array}{l}\text { Wagner P.J. } \\
\text { et al. }\end{array}$ & 0 & 2 & 0 & 0 & 2 & 1 & 5 \\
\hline 61. & $\begin{array}{l}\text { Wells S. et } \\
\text { al. }\end{array}$ & 0 & 1 & 0 & 0 & 0 & 0 & 1 \\
\hline 62. & $\begin{array}{l}\text { Wells S. et } \\
\text { al. }\end{array}$ & 0 & 1 & 0 & 0 & 0 & 0 & 1 \\
\hline 63. & $\begin{array}{l}\text { Williams } \\
\text { J.G. et al. }\end{array}$ & 0 & 2 & 0 & 0 & 2 & 1 & 5 \\
\hline 64. & $\begin{array}{l}\text { Winkleman } \\
\text { W.J. et al. }\end{array}$ & N/A & N/A & $\mathrm{N} / \mathrm{A}$ & N/A & N/A & $\mathrm{N} / \mathrm{A}$ & N/A \\
\hline 65. & $\begin{array}{l}\text { Zarcadoolas } \\
\text { C. et al. }\end{array}$ & 0 & 1 & 0 & 0 & 1 & 0 & 2 \\
\hline
\end{tabular}




\section{$\underline{\text { References }}$}

Al-Sahan A., Saddik B. (2016). Perceived challenges for adopting the Personal Health Record (PHR) at Ministry of National Guard Health Affairs (MNGHA) Riyadh. Online Journal of Public Health Informatics. http://ojphi.org 8(3):e205

Arain M., Campbell M.J., Cooper C.L., Lancaster G.A. (2010). What is a pilot or feasibility study? A review of current practice and editorial policy. BMC Medical Research Methodology 2010, 10:67. P1

Archer N., Keshavjee K., Demers C., Lee R. (2014). Online self-management interventions for chronically ill patients: Cognitive impairment and technology issues. International Journal of Medical Informatics. 83 (2014) 264-272

Bartlett C., Simpson K., Turner A.N. (2012). Patient access to complex chronic disease records on the internet. BMC Medical Informatics \& Decision Making. 12:87

Beard E., Lewis J.J., Copas A., Davey C., Osrin D., Baio G., Thompson J.A., Fielding K.L., Omar R.Z., Ononge S., Hargreaves J., Prost A. (2015). Stepped wedge randomised controlled trials: systematic review of studies published between 2010 and 2014. Trials. 16:353

Bell S.K., Mejilla R., Anselmo M., Darer J.D., Elmore J.G., Leveille S., Ngo L., Ralston J.D., Delbanco T., Walker J. (2015). When doctors share visit notes with patients: a study of patient and doctor perceptions of documentation errors, safety opportunities and the patient-doctor relationship. BMJ Quality and Safety. 0: 1-9

Bench S., Day T., Metcalfe A. (2013) Randomised controlled trials: an introduction for nurse researchers. Nurse Researcher. 20, 5. p 43

Bhavnani V.,Fisher B., Winfield M., Seed P. (2010). How patients use access to their electronic GP record - a quantitative study. Family Practice. 0: 1-7

Bidmead E., Marshall A. (2016). A case study of stakeholder perceptions of patient held records: the Patients Know Best (PKB) solution. Digital Health. Volume 2: 1-15

Bowling A. (2004). Research methods in health. Investigating health and health services. Second edition. Open University Press. Berkshire. p 227

Bradbury-Jones C., Hughes S.M., Murphy W., Parry L., Sutton J. (2009). A new way of reflecting in nursing: the Peshkin Approach. Journal of Advanced nursing. 65(11) p. 2485

British Society of Gastroenterology. (2006). Care of patients with GastroIntestinal Disorders in the United Kingdom. A strategy for the future. British Society of Gastroenterology. March 2006 www.bsg.org.uk

Brooker C., Peters J., McCabe C., Short N. (1999). The views of nurses to the conduct of a randomised controlled trial of problem drinkers in an accident and emergency department. International Journal of Nursing Studies. 36 p.33

Brown C.A., Lilford R.J. (2006). The stepped wedge trial design: a systematic review. BMC Medical Research Methodology. 6:54 doi:10.1186/1471-2288-6-54 
Carter M.J., Lobo A.J., Travis S.P.L. (2004). Guidelines for the management of inflammatory bowel disease in adults. Gut. 53(Supplement V):v1

Casey I. (2016). The effect of education on portal personal health record use. Online Journal of Nursing Informatics. July 2016 www.himss.org/ojni

Cheung W-Y, Alrubaiy L, Durai D, Russell IT, Williams JG.

Chi C., Street W.N., Robinson J.G., Crawford M.A. (2012). Individualized patientcentred lifestyle recommendations: An expert system for communicating patient specific cardiovascular risk information and prioritizing lifestyle options. Journal of Biomedical Informatics. 45 (2012) 1164-1174

Chunchu K., Mauksch L. (2012). A patient centered care plan in the EHR: improving collaboration and engagement. Families, Systems and Health. Vol.30, No. 3, 199-209

Cimino J.J., Li J., Mendonca E.A., Sengupta S., Patel V.L., Kushniruk A.W. (2000). An evaluation of patient access to their electronic medical records via the world wide web. AIMA. 1067-5027

Cimino J.J., Li J., Patel V.L., Kushniruk A.W. (2002). The patient clinical information system (PatCIS): technical solutions for and experience with giving patient access to their electronic medical records. International Journal of Medical Informatics. Vol. 68. Iss. 1-3. 18 December 2002. P 113-127

Cimino J.J., Patel V.L., Kushniruk A.W. (2001). What do patients do with access to their medical records? Chapter 17: Consumer Health Informatics. MEDINFO

Coates V., (2004). Randomised controlled trials - almost the best available evidence for practice. Journal of Diabetes Nursing. Vol 8, no 5, 167-172

Cruickshank J., Packman C., Paxman J. (2012). Personal Health Records Putting patients in control? 2020health.org

Culotta E. (1993). Teamwork is key to solving complex research problems. The Scientist. March 1993

Curtis, L. (2011). PSSRU Unit Costs of Health and Social Care. Personal Social Services Research Unit. www.pssru.ac.uk

Cutting K.F. (2008). Should evidence dictate clinical practice or support it? Journal of Wound Care. 17:5 May2008 p. 216

Department of Health. (2010) Equity and excellence: Liberating the NHS.

Department of Health. P 1, 8, 11, 13

Department of Health. (2011). National Schedule of reference costs 2010 - 2011 for NHS Trusts and PCT's combined. www.dh.gov.uk

Development and validation of the Gastrointestinal Endoscopy Satisfaction

Questionnaire (GESQ). Endoscopy, 2015.. Doi: 10.1055/s-0034-1392547

Di Marco C., Bray P., Covvey H.D., Cowan D.D., Di Ciccio V., Hovy E., Lipa J., Yang C. (2006). Authoring and generation of individualized patient education materials. AIMA 2006 Symposium Proceedings. Page 195-199 
Dieppe P. (2004). Complex interventions. Musculoskeletal Care p. 180, 182

Druss B.G., Ji X., Glick G., von Esenwein S.A. (2014). Randomized trial of an electronic personal health record for patients with serious mental illness. Am J Psychiatry. 171:3, March 2014 p360-368

Dumville J.C., Hahn S., Miles J.N.V., Torgerson D.J. (2006). The use of unequal randomisation ratios in clinical trials. A review. Contemporary Clinical Trials. 27 (2006) $1-12$

Duncan F., Haigh C. (2007). The realities of a nurse-led Randomised Controlled Trial (RCT). Nurse Education in Practice. 7 p. 1

Eldridge S.M., Chan C.L., Campbell M.J., Bond C.M., Hopewell S., Thabane L., Lancaster G.A. (2016). CONSORT 2010 statement: extension to randomised pilot and feasibility trials. The BMJ. 2016;355:i5239Idoi:10.1136/bmj.i5239

Farrelly S., Brown G.E., Barley E., Laugharne R., Henderson C. (2013). User-held personalised information for routine care of people with severe mental illness

(Review). Cochrane Database of Systematic Reviews 2013. Iss. 10. Art. No.:CD001711

Ferreira A., Correia A., Silva A., Corte A., Pinto A., Saavedra A., Pereira A.L., Pereira A.F., Cruz-Correia R., Antunes L.F. (2007). Why facilitate patient access to medical records. Stud Health Technol Inform. 2007;127:77-90

Fisher B., Bhavnani V., Winfield M. (2009). How patients use access to their full health records: a qualitative study of patients in general practice. Journal of the Royal Society of Medicine. 102: 538-544

Forbes M., Fairlamb H., Jonker L. (2017). Impact of patient-held record on knowledge at 1-year follow-up for glaucoma patients: single-center randomized controlled trial. Eur J Opthalmol. 27 (5): 542-547

Fridlund B., Jönsson A.C., Andersson E.K., Bala S.-V., Dahlman G.-B., Forsberg A., Glasdam S., Hommel A., Kristensson A., Lindberg C., Sivberg B., Sjöström-Strand A., Wihlborg J., Samuelson K. (2014). Essentials of Nursing Care in Randomized Controlled Trials of Nurse-Led Interventions in Somatic Care: A Systematic Review. Open Journal of Nursing. 4, 181-197

Garcia-Lizana F., Sarria-Santamera A. (2007). New technologies for chronic disease management and control: a systematic review. Journal of Telemedicine and Telecare. 13: $62-68$

Gee P.M., Paterniti D.A., Ward D., Soederberg L.M. (2015). e-patients perceptions of using health reciords for self-management support of chronic illness. $\underline{\text { CIN: }}$ Computers, Informatics, Nursing. Vol.33, No. 6, 229-237

Gerard M., Fossa A., Folcarelli P.H,, Walker J., Bell S.K. (2017). What patients value about reading visit notes: A qualitative inquiry of patient experiences with their health information. J Med Internet Res. 19 (7) 
Giardina T.D., Menon S., Parrish D.E., Sittig D.F., Singh H. (2013). Patient access to medical records and healthcare outcomes: a systematic review. J. Am Med Inform Assoc. 21:737-741

Greenberg A.J., Falisi A.L., Finney Rutten L.J., Chou W.S., Patel V., Moser R.P., Hesse B.W. (2017). Access to electronic personal health records among patients with multiple chronic conditions: a secondary data analysis. Journal of Medical Internet

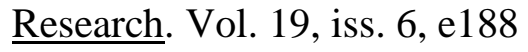

Hall A. (2007). Self-management in the care of patients with inflammatory bowel disease. Gastrointestinal Nursing. 5:5 p 34-38

Harris P. (2018). Research Electronic Data Capture (REDCap). Journal of the Medical Library Association. DOI:dx.doi.org/10.5195/jmla.2018.319

Hassol A., Walker J.M., Kidder D., Rokita K., Young D., Pierdon S., Deitz D., Kuck S., Ortiz E. (2004). Patients experiences and attitudes about access to a patient electronic health care record and linked web messaging. Journal of the American Medical Informatics Association. Vol. 11. No. 6. Nov / Dec

Hemsley B., Rollo M., Georgiou A., Balandin S., Hill S. (2018). The health literacy demands of electronic personal health records (e-PHRs): An integrative review to inform future inclusive research. Patient Education and Counseling. 101 (2018) 2-15

Hicks C. (1998). The randomised controlled trial: a critique. Nurse Researcher. 6, 1, autumn 1998

Hoffmann T.C., Glasziou P.P., Boutron I., Milne R., Perera R., Moher D., Altman D.G., Barbour V., Mcdonald H., Johnston M., Lamb S.E., Dixon-Woods M., McCulloch P., Wyatt J.C., Chan A-W, Michie S. (2014). Better reporting of interventions: template for intervention description and replication (TIDieR) checklist and guide. BMJ. 348:g1687 doi: 10.1136/bmj.g1687

Honeyman A., Cox B., Fisher B. (2005). Potential impacts of patient access to their electronic care records. Informatics in primary care. 13:55-60

https://euroqol.org/

Jeong D.E., Kim K.O., Jang B.I., Kim E.Y., Jung J.T., Jeon S.W., Lee H.S., Kim E.S., Park K.S., Cho K.B. (2015). The clinical usefulness of a web-based messaging system between patients with Crohn disease and their physicians. Medicine. 95:26

Johns C. (2009). Becoming a Reflective Practitioner. Wiley-Blackwell. West Sussex.

Kelstrup A.M., Juillerat P., Korzenik J. (2014). The accuracy of self-reported medical history: a preliminary analysis of the promise of internet-based research in inflammatory bowel diseases. Journal of Crohn's and Colitis. 8, 349-356

Kerns J.W., Krist A.H., Longo D.R., Kuzel A.J., Woolf S.H. (2013). How patients want to engage with their personal health record: a qualitative study. BMJ Open 3:e002931 
Khaneghan P.A., Miguel-Cruz A., Bentley P., Liu L., Stroulia E., Ferguson-Pell M. (2016). Users' attitudes towards personal health records. Applied Clinical Informatics. 7:573-586

Kitzinger J. (1995). Qualitative research: introducing focus groups. BMJ. 311:299302

Ko H., Turner T., Jones C., Hill C. (2010). Patient-held medical records for patients with chronic disease: a systematic review. Quality Safety Health Care. 19:e41

Lancaster G.A. (2015). Pilot and feasibility studies come of age! Pilot and Feasibility Studies. 1:1. BioMed Central. P 2

Laugesen J., Hassanein K. (2016). Adoption of personal health records by chronic disease patients: A research model and an empirical study. Computers in Human Behavior. 66(2017)256-272

Litvin C. (2007). In the dark - the case for electronic health records. New England Journal of Medicine. 356 (24): p. 2454

Lomas G., Massey S., Pantrini S., Ritchie N. (2002). Taking part in the MRC CRASH Trial. Emergency Nurse. 10:6 p.35

Mantzoukas S. (2007). A review of evidence-based practice, nursing research and reflection: levelling the hierarchy. Journal of Clinical Nursing. P. 214

Masys D., Baker D., Butros A., Cowles K.E. (2002). Giving patients access to their medical records via the internet: the PICASSO experience. Journal of the American Medical Informatics Association. Vol. 9. No. 2. Mar/Apr 2002

McKinstry B., Hanley J., Heaney D., McCloughan L., Elton R., Webb D.J. (2006). Impact on hypertension control of a patient-held guideline: a randomised controlled trial. British Journal of General Practice. 56:842-847

Mclaughlin J., Stansfield C., Lal S., Bodger K., Robinson A. (2018). My-IBD Portal: progress and impact update. GUT.67(Suppl 1): A223

Medical Research Council. (2000). A framework for development and evaluation of RCTs for complex interventions to improve health.

Medical Research Council. (2007). Developing and evaluating complex interventions: new guidance.

Mold F., de Lusignan S., Sheikh A., Majeed A., Wyatt J.C., Quinn T., Cavill M., Franco C., Chauhan U., Blakey H., Kataria N., Arvanitis T.N., Ellis B. (2015).

Patients' online access to their electronic health records and linked online services: a systematic review in primary care. British Journal of General Practice. March 2015 e141-e151

Mowat C., Cole A., Windsor A., Ahmad T., Arnott I., Driscoll R., Mitton s., Orchard T., Rutter M., Younge L., Lees C., Ho G., Satsangi J., Bloom S. (2011). Guidelines for the management of inflammatory bowel disease in adults. GUT. 60:571-607 
Muhammad R., Law T., Limdi J. (2012) The IBD Passport-bridging another gap in quality of care? Journal of Crohn's and Colitis. 6, 261-262

Nahm E-S., Diblasi C., Gonzales E., Silver K., Zhu S., Sagherian K., Kongs K. (2017). Patient-centered personal health record and portal implementation toolkit for ambulatory clinics. CIN: Computers, Informatics, Nursing. Vol.35, No. 4, 176-185

Newall N., Miller C., Lewin G., Kapp S., Gliddon T., Carville K., Santamaria N. (2009). Nurses' experience of participating in a randomised controlled trial (RCT) in the community. Wound Practice and Research. 17, 1, February 2009

NHS National Institute for Health Research. (2017). NIHR Research for Patient Benefit (RfPB) Programme Guidance on Applying for Feasibility Studies. P 2

Palen T.E., Ross C., Powers J.D., Xu S. (2012). Association of online patient access to clinicians and medical records with use of clinical services. JAMA. November 21, 2012-vol 308, No. 19

Papoutsi C., Reed J.E., Marston C., Lewis R., Majeed A., Bell D. (2015). Patient and public views about the security and privacy of electronic health records (EHR's) in the UK: results from a mixed methods study. BMC Medical Informatics \& Decision Making. 15:86

Pavlik V., Brown A.E., Nash S., Gossey J.T. (2014). Association of patient recall, satisfaction, and adherence to content of an electronic health record (EHR)-generated after visit summary: a randomized clinical trial. JABFM. March-April 2014 vol.27 No.2 p209-218

Phelps R.G., Taylor J., Simpson K., Samuel J., Turner N. (2014). Patients' continuing use of an online health record: A quantitative evaluation of 14,000 patient years of access data. Journal of Medical Internet Research. 16(10):e241

Pierson W. (1998). Reflection and nursing education. Journal of Advanced Nursing

Politi P., Bodini P., Mortilla M.G., Beltrami M., Fornaciari G., Formisano D., Munkholm P., Riis L., Wolters F., Hoie O., Katsanos K., O’Morain C., Shuhaibar M., Lalli P., De Falco M., Pereira S., Freitas J., Odes S., Stockbrugger R.W. (2008). Communication of information to patients with inflammatory bowel disease: a European Collaborative Study in a multinational prospective inception cohort. Journal of Crohn's and Colitis. 2, 226-232

Powell H. Gibson P.G. (2002). Options for self-management education for adults with asthma (Review). Cochrane Database of Systematic Reviews 2002. Iss. 3. Art. No.:CD004107

Price M., Bellwood P., Kitson N., Davies I., Weber J., Lau F. (2015). Conditions potentially sensitive to a personal health record (PHR) intervention, a systematic review. BMC Medical Informatics and Decision Making. 15:32

Price M.M., Pak R., Muller H., Stronge A. (2012). Older adults' perceptions of usefulness of personal health records. Univ Access Inf Soc. DOI 10.1007/s 10209012-0275-y 
Rapport F. (2010). Summative analysis: A qualitative method for social science and health research. International Journal of Qualitative Methods. 9(3) p 270-290

Riippa I., Linna M., Ronkko I., Kroger V. (2014). Use of an electronic patient portal among the chronically ill: an observational study. Journal of Medical Internet

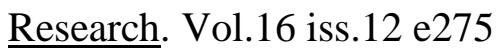

Robinson A., Thompson D.G., Wilkin D., Roberts C. (2001). Guided selfmanagement and patient-directed follow-up of ulcerative colitis: a randomised trial. The Lancet. 358 September 22 p. 976

Robinson N. (1999). The use of focus group methodology - with selected examples from sexual health research. Journal of advanced Nursing. 29(4) 905-913

Robson C. (2002). Real World Research. Second Edition. Blackwell Publishing. Oxford. p 114, 116

Rogers A., Kennedy A., Nelson E., Robinson A. (2004). Patients' experiences of an open access follow up arrangement in managing inflammatory bowel disease. Quality and Safety in Health Care. 13:374-378

Rolfe G. Freshwater D., Jasper M. (2001). Critical reflection for nursing and the helping professions. Palgrave. Wales. p. 34, 35

Ross S.E., Lin C. (2003). The effects of promoting patient access to medical records: a review. Journal of the American Medical Informatics Association. Vol. 10, No. 2, Mar/Apr 2003

Ross S.E., Todd J., Moore L.A., Beaty B.L., Wittevrongel L., Lin C-T. (2005). Expectations of patients and physicians regarding patient-accessible records. Journal of Medical Internet Research. Apr-Jun; 7(2): e13

Royal College of Physicians. (2016). Personal health record (PHR) landscape review. Final report. RCP

Royal College of Physicians. (2016). Personal health record (PHR) landscape review. Final report. London: RCP P 2

Royal College of Physicians. 2017. Personal health record (PHR) case study. Multimedia advocacy in Nottinghamshire. Royal College of Physicians

Royal College of Physicians. 2017. Personal health record (PHR) case study. Myhealth@QEHB. Royal College of Physicians

Royal College of Physicians. 2017. Personal health record (PHR) case study. Patient access. Royal College of Physicians

Royal College of Physicians. 2017. Personal health record (PHR) case study. PatientView. Royal College of Physicians

Royal College of Physicians. 2017. Personal health record (PHR) case study. St Mark's Hospital. Royal College of Physicians 
Royal College of Physicians. 2017. Personal health record (PHR). User insights Sugra's journey. Royal College of Physicians

Royal College of Physicians. 2017. Personal health record (PHR). User insights. Final report. Royal College of Physicians

Russell I.T. (2010). Responsibilities of Sponsor, WWORTH \& participating sites: Electronic Linkage of Information for Joint Access to Health records (ELIJAH). Unpublished

Sartain S.A., Stressing S., Prieto J. (2014). Patients' views on the effectiveness of patient-held records: a systematic review and thematic synthesis of qualitative studies. Health Expectations. Vol. 18. Iss. 6 (Medline)

Schön D.A. (1983 / 2003). The Reflective Practitioner. Ashgate. Hampshire. p. 345

Seers K. (1997). Randomised controlled trials in nursing. Quality in Health Care. 6:1 $\mathrm{p} 1$

Shneiderman B. (2016). How to do team research.

www.insiderhighered.com/advantage-doing-research-teams-essay

Showell C. (2017). Barriers to the use of personal health records by patients: a structured review. PeerJ. 5:e3268;DOI10.7717/peerj.3268

Somner J.E.A., Sii F., Bourne R., Cross V., Shah P. (2013). What do patients with glaucoma think about personal health records? Opthalmic \& Physiological Optics. 33 627-633

Stange E.F., Travis S.P.L., Vermeire S., Reinisch W., Geboes K., Barakauskiene A., Feakins R., Fléjou J.F., Herfarth H., Hommes D.W., Kapcinskas L., Lakatos P.L., Mantzaris G.J., Schreiber S., Villanacci V., Warren B.F. (2008). European evidencebased Consensus on the management of ulcerative colitis: Definitions and diagnosis. Journal of Crohn's and Colitis. 2,

T. Wang Vedelø, K. Lomborg (2010). Reported challenges in nurse-led randomised controlled trials: an integrative review of the literature. Scandinavian Journal of Caring Sciences. 25 p. 199

Taylor B.J. (2006). Reflective Practice. A guide for Nurses and Midwives. Second Edition. Open University Press. Berkshire

Tenforde M., Jain A., Hickner J. (2011). The value of personal health records for chronic disease management: what do we know? Family Medicine. Vol. 43, No. 5 p351-354

Thabane L., Ma J., Chu R., Cheng J., Ismaila A., Rios L.P., Robson R., Thabane M., Giangregorio L., Goldsmith C.H. (2010). A tutorial on pilot studies: the what, why and how. BMC Medical Research Methodology. BioMed Central. P 5

The IBD Standards Group. (2009). Quality Care. Service standards for the healthcare of people who have Inflammatory Bowel Disease (IBD). www.ibdstandards.org.uk p.6, 19 
The IBD Standards Group. 2013. IBD Standards 2013 Update. Standards for the Healthcare of People who have IBD Inflammatory Bowel Disease. Oyster Healthcare communications ltd

Tickle-Degnen L. (2013). Nuts and Bolts of Conducting Feasibility Studies. The American Journal of Occupational Therapy. March/April 2013, Vol 67, No 2, p 172

Tong A. , Sainsbury P., Craig J. (2007) Consolidated criteria for reporting qualitative research (COREQ): a 32 - item checklist for interviews \& focus groups

Travis S.P.L., Stange E.F., Lémann M., Øresland T., Bemelman W.A., Chowers Y., Colombel J.F., D’Haens G., Ghosh S., Marteau P., Kruis W., Mortensen N.J.McC., Penninckx F., Gassull M. (2008). European evidence-based Consensus on the management of ulcerative colitis: Current management. Journal of Crohn's and Colitis. 2,

Wagner P.J., Dias J., Howard S., Kintziger K.W., Hudson M.F., Seol Y., Sodomka P. (2012). Personal health records and hypertension control: a randomized trial. J AM Med inform Assoc. 19:626-634

Wells S., Rozenblum R., Park A., Dunn M., Bates D.W. (2014). Organizational strategies for promoting patient and provider uptake of personal health records. Journal of the American Medical Informatics Association. 0:1-7

Wells S., Rozenblum R., Park A., Dunn M., Bates D.W. (2014). Personal health records for patients with chronic disease. Applied Clinical Informatics. 5:416-429

Williams J.G. (1999). The use of clinical information to help develop new services in a district general hospital. International Journal of Medical Informatics. 56:151-159

Williams J.G., Cheung W., Russell I., Cohen D., Lervy B. (2000). Open access follow-up for inflammatory bowel disease - a pragmatic randomised trial and cost effectiveness study. British Medical Journal. 320 p. 544 - 547

Williams J.G., Cheung W-Y., Chetwynd N., Cohen D.R., El-Sharkawi S., Finlay I., Lervy B., Longo M., Malinovszky K. (2001). Pragmatic randomised trial to evaluate the use of patient held records for the continuing care of patients with cancer. Quality in Health Care. 10:159-165

Williams J.G., Roberts S.E., Ali M.F., Cheung W.Y., Cohen D.R., Demery G., Edwards A., Greer M., Hellier M.D., Hutchings H.A., Ip B., Longo M.F., Russell I.T., Snooks H.A., Williams J.C. (2007). Gastroenterology services in the UK. The burden of disease, and the organisation and delivery of services for gastrointestinal and liver disorders: a review of the evidence. GUT. Gut 2007;0:1-113. doi:

10.1136/gut.2006.117598

Winkleman W.J., Leonard K.J., Rossos P.G. (2005). Patient-perceived usefulness of online electronic medical records: employing grounded theory in the development of information and communication technologies for use by patients living with chronic illness. J AM Med Inform Assoc. 12:306-314

Wright Oliver J., Kravitz R.L., Kaplan S.H., Meyers F.J. (2001). Journal of Clinical Oncology 19.8.2206. https://doi.org/10.1200/JCO.2001.19.8.2206 
Zarcadoolas C., Vaughon W.L., Czaja S.J., Levy J., Rockoff M.L. (2013).

Consumers' perceptions of patient-accessible electronic medical records. Journal of Medical Internet Research. 15(8):e168 